\title{
WestVirginiaUniversity
}

THE RESEARCH REPOSITORY @ WVU

Graduate Theses, Dissertations, and Problem Reports

1999

\section{Econometric analysis of household expenditures}

\author{
Samuel Berhanu \\ West Virginia University
}

Follow this and additional works at: https://researchrepository.wvu.edu/etd

\section{Recommended Citation}

Berhanu, Samuel, "Econometric analysis of household expenditures" (1999). Graduate Theses,

Dissertations, and Problem Reports. 3124.

https://researchrepository.wvu.edu/etd/3124

This Dissertation is protected by copyright and/or related rights. It has been brought to you by the The Research Repository @ WVU with permission from the rights-holder(s). You are free to use this Dissertation in any way that is permitted by the copyright and related rights legislation that applies to your use. For other uses you must obtain permission from the rights-holder(s) directly, unless additional rights are indicated by a Creative Commons license in the record and/ or on the work itself. This Dissertation has been accepted for inclusion in WVU Graduate Theses, Dissertations, and Problem Reports collection by an authorized administrator of The Research Repository @ WVU.

For more information, please contact researchrepository@mail.wvu.edu. 


\title{
ECONOMETRIC ANALYSIS OF HOUSEHOLD EXPENDITURES
}

\author{
Samuel Berhanu \\ Dissertation Submitted to the \\ College of Agriculture, Forestry and Consumer Sciences \\ at West Virginia University \\ in partial fulfilment of the requirements \\ for the degree of \\ Doctor of Philosophy \\ in \\ Natural Resource Economics \\ Dale K. Colyer, Ph.D., Chair \\ Timothy T. Phipps, Ph.D. \\ Stratford M. Douglas, Ph.D. \\ Gerard D'Souza, Ph.D. \\ Laura Blanciforti, Ph.D. \\ Department of Agricultural and Resource Economics
}

Morgantown, West Virginia

1999

Keywords: Household Expenditures, Budget Share, Expenditure Inequality

Copyright 1999 Samuel Berhanu 


\section{ABSTRACT \\ An Econometric Analysis of Household Expenditures}

Samuel Berhanu

While the traditional methods of measuring income inequality reveals interesting and important features of labor markets, estimates of income inequality do not provide complete summary statistics of the distribution of well-being. Interpreting the Gini coefficient of family earnings as a measure of disparity in welfare implicitly assumes that households with the same level of before tax income are equally well-off. Utility is derived from the consumption of goods and services and there is ample empirical evidence which indicate that the distribution of total expenditure is likely to be different from the distribution of income. As Friedman indicated households with low income levels are disproportionately represented by with those temporary reductions in current income and will typically have high ratios of consumption to income. Households with high income levels are over represented by those with transitory increases in income and will exhibit low ratios of consumption to income. The implication is that, all other things equal, one would expect less dispersion in the distribution of total expenditure relative to the income distribution. The problems of using family income as a measure of well-being go beyond the differences in the expenditure and income distributions. Treating heterogeneous households symmetrically, as is common in income inequality studies, indirectly assumes that two households with the same level of income but different sizes are equally well-off. If household characteristics influences household expenditure patterns, consumption needs and welfare, such effects are likely to have an important effect on both the level and trend of inequality in the distribution of welfare. Consumption rather than income may be a better measure of the actual economic welfare of a household than its current income.

The main objectives of this study are to: 1. Measure the impact of demographic characteristics on the distribution of individual expenditures on the consumption of goods and services. 2. Examine the inequality in the distribution of household consumption expenditures using the Gini coefficient.

The data are drawn from the 1980 through 1994 interview surveys conducted and gathered by the U.S. Labor Statistics. An econometric method using the translog model is specified for seven commodity groups. We estimated six equations using Seemingly Unrelated Regression procedure.

The parameters estimated to measure the impacts of demographic characteristics on the consumption of goods and services indicated that the allocation of budget shares for different consumer goods is affected by the composition and characteristics of households.

The decomposition of the Gini provides specific information concerning the concentration of consumption expenditures by budget components, and information about how the marginal changes in particular expenditures affect overall inequality. Unlike in income distribution, the Gini estimates in expenditure distribution appear to be closer. It is possible to conclude that expenditure on goods and services does depend not only on current income, but also on income earned through the years. This substantiates the permanent income hypothesis theory articulated by Friedman (1957). Being able to measure these impacts can be useful for policy makers interested in the effect that certain programs may have on the spending patterns of households. Results obtained in this study substantiate the importance of evaluating the differential impacts of proposed and enacted policies 
on subgroups of the population and differences in inequality which can result when expenditures for budget components change. Without adequate evaluation, policies and programs intended to decrease inequality may lead to the opposite outcome in the distribution of material well-being across household units in the population. 


\section{ACKNOWLEDGMENT.}

The task of conducting this research has been on of the most challenging and satisfying experiences of my life. The completion of this work would have been impossible without the generous advice, support and encouragement of many people.

The guidance and support of my committee members are greatly appreciated. Dr. Dale Colyer, my committee chair provided practical and valuable knowledge of the subject, theoretical and conceptual expertise. His professional advice and continuous encouragement, not only as the chair of this committee, but also as a chair of my committee for my masters thesis will always be valued. I also wish to acknowledge the contributions of the other members of my committee: Dr. Gerard D’Souza, Dr. Tim Phipps, Dr. Strat Douglas, and Dr. Laura Blanciforti. Dr. Blanciforti provided me with the opportunity to work on a project where I was privileged to obtain the data used in this study. I have enormously profited from her expertise in the area of household budget and the theory of demand systems. I am always grateful for her professional help and friendship.

I thank Lisa Lewis, Ellen Hartley, Gloria Nestor for their friendship and help. During my doctoral program at WVU, I received funding from the Division of Resource Management and the Regional Research Institute. I thank Dr. Luc Anselin, Dr. Scott Loveridge, Dr. Virgil Norton and Dr. Peter Schaeffer for providing me with employment and financial assistance. Especially, Dr. Schaeffer has played important roles in making the environment in the department more pleasant and enjoyable. I am immensely grateful for his help and outstanding leadership.

Many other individuals have played various roles in making this difficult process more pleasant. I am especially thankful for the friendship and unfailing support of Teferra Dinberu, Elias Zewde and their families. Most importantly and with immense gratitude, I thank my good friends 
Meselu Teferra and Zakarias Gebeyehu. They have practically demonstrated the true meaning of friendship by standing with me during the bad and good times.

Finally, last but by no means least, a grateful kiss goes to my wife, Seble Hailu and my two daughters, Rebecca and Leah for their unwavering love and support. Their devotion, patience and understanding were indispensable.

I gratefully dedicate this piece of work to my late mother and father, Gete Mekonen and Berhanu W. Mariam who instilled in me at an early age the importance of education and the value of hard work. I only wish you could have been here to see me finish the journey I started with your efforts and initiatives. I know you would have been so proud. 


\section{TABLE OF CONTENTS}

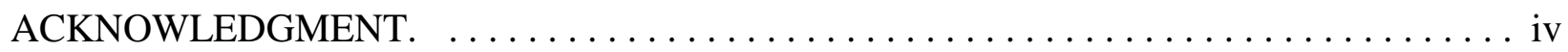

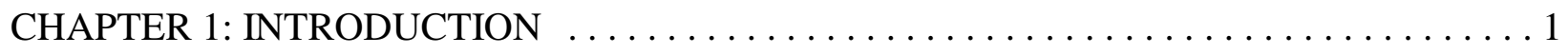

1.1 Background and Statement of the Problem $\ldots \ldots \ldots \ldots \ldots \ldots \ldots \ldots \ldots \ldots \ldots$

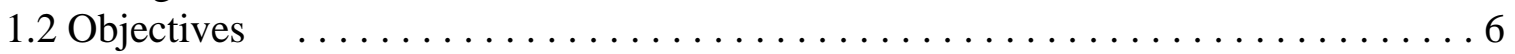

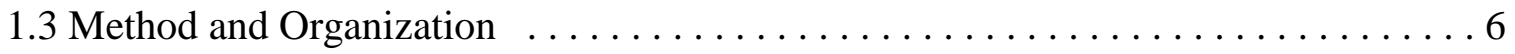



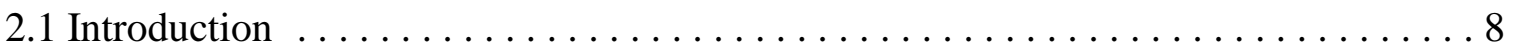

2.2 The History and Development of Welfare Economics $\ldots \ldots \ldots \ldots \ldots \ldots \ldots$

2.3 Conventional Ways of Measuring Income Distribution $\ldots \ldots \ldots \ldots \ldots \ldots . \ldots 26$

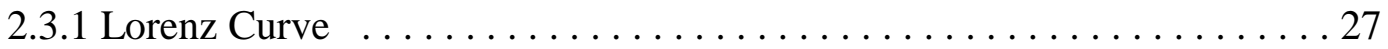

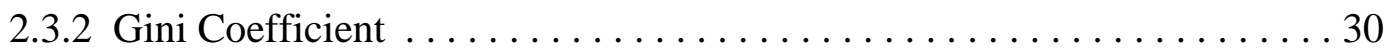

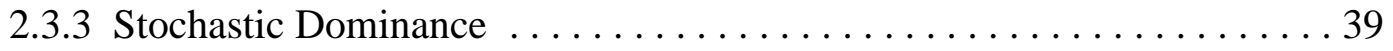

2.3.4 An Income-Net Worth Approach . . . . . . . . . . . . . . . . . . 45

2.4 The Contributions of this Research .......................... 47

CHAPTER 3: THEORETICAL FRAMEWORK $\ldots \ldots \ldots \ldots \ldots \ldots \ldots \ldots \ldots \ldots \ldots$

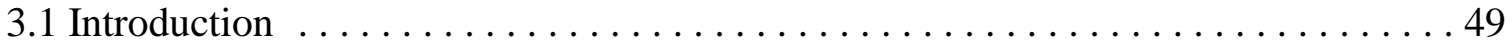

3.2 Aggregate Consumer Behavior $\ldots \ldots \ldots \ldots \ldots \ldots \ldots \ldots \ldots \ldots \ldots \ldots \ldots$



3.4 Inequality in the Distribution of Household consumption Expenditure . . . . . . 64

CHAPTER 4: DATA AND DATA ORGANIZATION $\ldots \ldots \ldots \ldots \ldots \ldots \ldots \ldots \ldots \ldots$

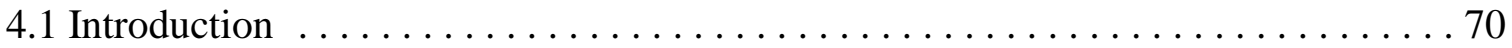

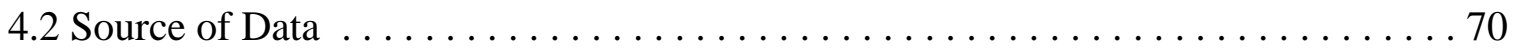

4.3 Data Organization and Manipulation . . . . . . . . . . . . . . . . . 71

4.4 The Transformation of Time-Series-Cross Section Data to Panel Data $\ldots \ldots \ldots 72$

Chapter 5: Econometric Model and Estimation Results $\ldots \ldots \ldots \ldots \ldots \ldots \ldots \ldots \ldots \ldots$



5.2 Econometric Model ................................ 74

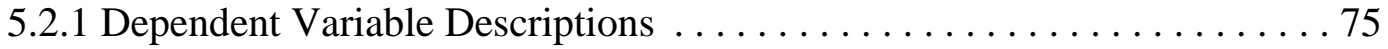

5.2 .2 Independent Variables ............................ 75

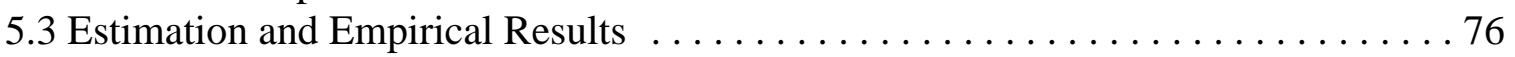

5.3.1 Food and Beverages ........................... 78

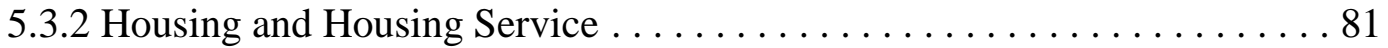

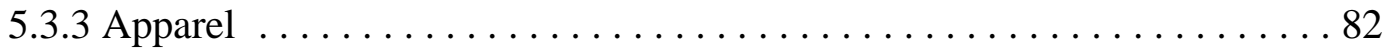

5.3.4 Entertainment ................................ 84

5.3.5 Heath Care and Health Related Services $\ldots \ldots \ldots \ldots \ldots \ldots . \ldots . \ldots 6$

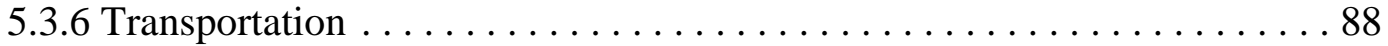






5.4 Summary and Conclusions . . . . . . . . . . . . . . . . . . . . . 91

5.4.1 The Impacts of the Age of the Head of the Household . . . . . . . . . 94

5.4.2 The Impact of the Size of Household ..................... 94

5.4.3 The Impacts of Geographic Location ..................... 96

5.4.4 The Impacts of Race . . . . . . . . . . . . . . . . . . . . 97

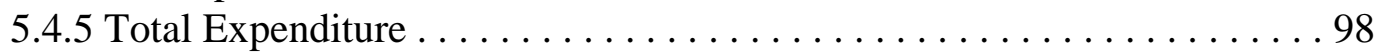

CHAPTER 6: INEQUALITY IN HOUSEHOLD CONSUMPTION EXPENDITURES . . . . . 99

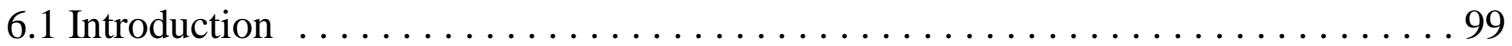

6.2 The Gini Coefficient and Its Decomposition $\ldots \ldots \ldots \ldots \ldots \ldots \ldots \ldots \ldots$

6.3 Results and Discussions . . . . . . . . . . . . . . . . . . . . . . 102



CHAPTER 7. SUMMARY AND CONCLUSION $\ldots \ldots \ldots \ldots \ldots \ldots \ldots \ldots \ldots \ldots \ldots \ldots \ldots \ldots$

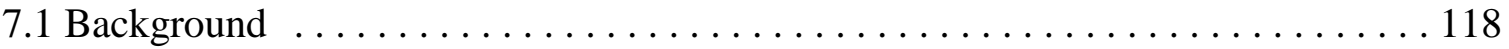

7.2 Empirical Analysis . ................................. 120

7.2.1 The Impact of Demographic Characteristics . . . . . . . . . . . . 121

7.2.2 Inequality in the Distribution of Consumption Expenditures ........ 123

7.3 Conclusions and Policy Implications . . . . . . . . . . . . . . . . . . 125

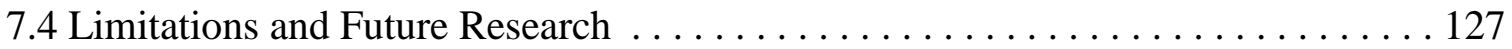

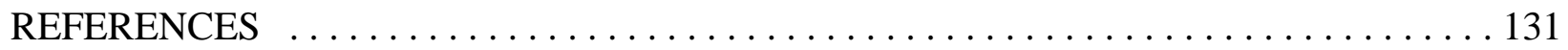

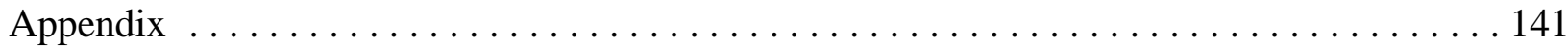

Appendix P-1: Program to Download Data and Create Data Set . . . . . . . . . 142

Appendix P-2: Program to Compute Expenditures by Month and Year . . . . . . . . . 174

Appendix P-3: Rearrange the Month with the Year ................... 177

Appendix P-4: Program to Merge the Price File With the Expenditure Master File . . . 179

Appendix P-5: Program to Display the Content of the Data Set .............. 180

Appendix P-6: Program to Copy File $\ldots . \ldots \ldots \ldots \ldots \ldots \ldots \ldots \ldots \ldots \ldots \ldots . \ldots \ldots 1$

Appendix P-7: Program to Sort the Data Set ....................... 182

Appendix P-8: Program to Compute Mean and Frequency ................. 183

Appendix P-9: Program to Display Frequency Table ..................... 184 


\section{LIST OF TABLES}

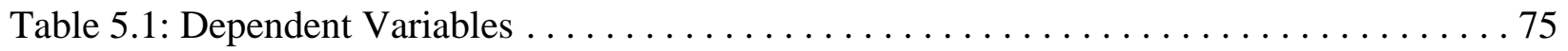

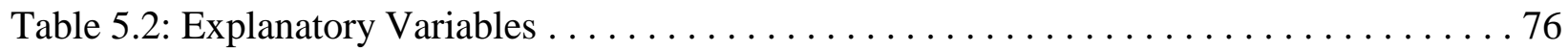

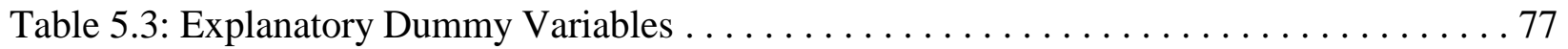

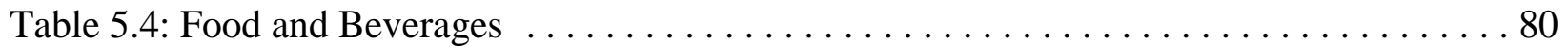

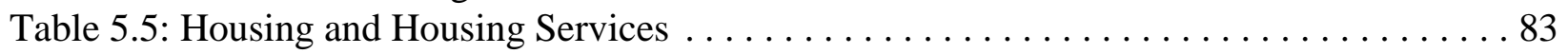

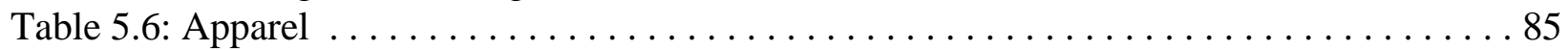

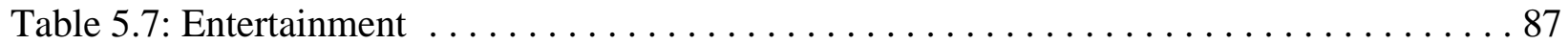

Table 5.8: Health and Health Related Services . . . . . . . . . . . . . . . . . . . . 89

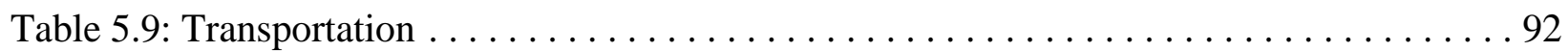

Table 5.10: Utilities . . . . . . . . . . . . . . . . . . . . . . . . 93

Table 5.11: The Impact of Age of the Household (Compared to age 16-24 household . . . . . 95

Table 5.12: The Impact of Size of the Household (Compared to single member household) . . 95

Table 5.13: Impacts of Geographic Location of a Household (Compared to the Northeast) . . . 96

Table 5.14: The Impact of Race (Compared to white) . . . . . . . . . . . . . . . . 97

Table 5.15: The Impact of Total Expenditure on Share of Expenditures $\ldots \ldots \ldots \ldots \ldots$

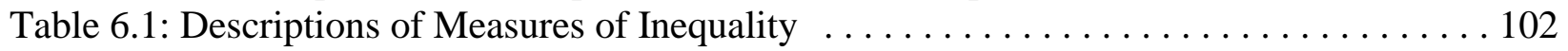



Table 6.3: Expenditure Inequality Effects by Expenditure Component for Year 1980 . . . . . 107

Table 6.4: Expenditure Inequality Effects by Expenditure Component for Year 1981 . . . . . 108

Table 6.5: Expenditure Inequality Effects by Expenditure Component for Year 1982 . . . . . 108

Table 6.6: Expenditure Inequality Effects by Expenditure Component for year 1983 . . . . . 109

Table 6.7: Expenditure Inequality Effects by Expenditure Component for Year 1984 . . . . . 109

Table 6.8: Expenditure Inequality Effects by Expenditure Component for Year 1985 . . . . . 110

Table 6.9: Expenditure Inequality Effects by Expenditure Component for Year 1986 . . . . . 110

Table 6.10: Expenditure Inequality Effects by Expenditure Component for Year 1987 . . . . 111

Table 6.11: Expenditure Inequality Effects by Expenditure Component for Year 1988 . . . . 111

Table 6.12: Expenditure Inequality Effects by Expenditure Component for Year 1989 . . . . 112

Table 6.13: Expenditure Inequality Effects by Expenditure Component for Year 1990 . . . . 112

Table 6.14: Expenditure Inequality Effects by Expenditure Component for Year 1991 . . . . 113

Table 6.15: Expenditure Inequality Effects by Expenditure Component for Year 1992 . . . . 113

Table 6.16: Expenditure Inequality Effects by Expenditure Component for Year 1993 . . . . 114

Table 6.17: Expenditure Inequality Effects by Expenditure Component for Year 1994 . . . . 114

Table 6.18: Expenditure Inequality by Age Using the Gini Coefficient . . . . . . . . . . . 115

Table 6.19: Expenditure Inequality Effects by Race Using the Gini Coefficient $\ldots \ldots \ldots \ldots 116$

Table 6.20: Income Inequality $\ldots \ldots \ldots \ldots \ldots \ldots \ldots \ldots \ldots \ldots \ldots \ldots \ldots \ldots \ldots \ldots \ldots$ 


\section{LIST OF FIGURES}

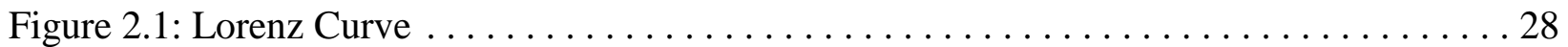

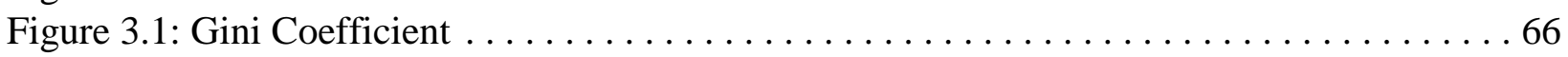

Figure 6.1: Gini Coefficient for Total Expenditure, 1980-1994 . . . . . . . . . . . . . . 107 


\section{CHAPTER 1: INTRODUCTION}

\subsection{Background and Statement of the Problem}

The measurement of individual and household welfare stands out in applied welfare economics for its ability to usefully combine economic theory with empirical practice. It is an area where empirical study clearly relies on theoretical insight. There are important issues to be addressed in identifying who lost and who gained as a result of complex policy implementations. Potential Pareto improvements to societal welfare may not be known until the sizes of the gains and losses are specifically measured or evaluated in some kind of quantitative unit.

In welfare economics, different considerations arise between the theoretical formulation of a problem and the actual measurement of the effect of initiating a particular policy. Some theoretical variables are not observable in the real world. For example, how does one measure a change in conditions and how does one determine if the change is generally good or not. Measures showing changes in income, wealth or expenditures are often used. However, these indicators are far from precise and difficult to interpret for different circumstances. Alternative measures must be designed.

One observable alternative for measuring the intensity of individual preferences for a situation is the amount of money the individual would pay or accept to move from one situation to another (Just, Hueth and Schmitz, p.10, 1982). This principle has become the basis of modern applied welfare economics. The two most important willingness-to-pay measures are compensating (CV) and equivalent variations (EV). Based on the definition by Just, Hueth and Schmitz (p. 10-11, 1982) compensating variation (CV) is the amount of money, which when taken away from an individual after a price and/or income change, will restore the individual's original welfare level. Similarly, equivalent variation is the amount of money given to an individual which if an economic 
change does not happen leaves the individual as well off as if the change had taken place. In this case the individual can be a consumer or producer. Thus, compensating and equivalent variations are defined and perceived as mechanisms used to adjust the consumer's income in order to maintain his or her level of welfare. The compensating variation deals with the initial level of welfare, that which the consumer held prior to price and/or income changes; and equivalent variation deals with the subsequent level of welfare, that which the consumer would obtain with potential price and/or income changes.

In most real world cases, public policies are enacted on a large number of people in a uniform fashion. However, the determination of the policy effects on each individual decision unit is impractical, both computationally and from the stand point of the availability of relevant data. Generally, to perform a good welfare analysis of alternative policies, some aggregation is needed. The welfare change measures discussed above are constructed on the assumption that all consumers could be aggregated into a single representative consumer for welfare measurement purposes. The conditions under which this can be done are very stringent. For one, it assumes that the marginal social utility of income is identical for all persons, whether this results from a process of continually redistributing income to maintain this equality, or whether this is a created assumption such as marginal utility of income is the same for all households. The latter situation is straightforward in the case where household indifference curve maps coincide. Failing either of these means that the entire demand side of the economy could not be aggregated into a single individual from the social point of view.

Nonetheless, most empirical studies using applied welfare economics proceed to measure welfare change by simply aggregating CVs or consumer's surplus over individuals. The question 
naturally arises as to what interpretation can be given to the results of such exercises. The usual argument is that the use of aggregated CVs to measure welfare change should not be interpreted as measuring social welfare in any direct sense but, rather, it should be interpreted as indicating whether or not there has been a potential improvement in social welfare. A potential improvement means that the gainers from the change could hypothetically compensate the losers from the change while remaining at least as well off after the change as before.

To obtain a measure of social change many consumer-economists rank all alternatives. The ranking of social states involves making value judgements regarding measurability and comparability which are not required when using the Pareto criterion or the compensation test. Although a social welfare function is a desirable concept in theory, it does not exist in reality. As Just et al. (1982) suggested, one should keep the concept of welfare economics in the background; but this does not mean that one should totally forget the study of welfare economics just because the welfare function cannot be specified in terms of any practical meaning. Even those who are critical of welfare economics for the lack of defining a welfare function, must come to a consensus that it is often possible to conclude who loses and who gains at least in monetary terms, as well as the magnitude of these losses and gains, from specific policies, and that this information is crucial for policymakers. Due to the problem of welfare aggregation and the non-existence of the social welfare function, we are forced to rely on imperfect measures of welfare such as income distribution, wealth distribution and expenditure functions.

There are a number of ways of characterizing income distributions. These are often used as summary statistics for evaluating inequality in the distribution of income or for evaluating the distributive impact of, say, tax policy changes. They include the Gini coefficient, or its graphical 
counterpart the Lorenz curve, the variance of income, the relative mean deviation, the standard deviation of logarithms of incomes, and the like.

Similarly, a money metric of utility, such as an expenditure function, has a role in measuring social welfare. The utility of an individual may be written as a function of a money metric representing the expenditure function. Indifference curves can uniquely define utility associated with the expenditure function. Utility can be written or defined as a function of expenditures given the reference price vector. Based on this definition, the value of the indirect utility of the consumer at the reference prices, given that utility is, fully measurable. Social welfare may be written as a function of the individual expenditure function at a given set of reference prices. The measurement of social welfare can proceed by using the appropriate aggregation of the money metric measures of utilities rather than the utilities themselves. There are also a variety of other imperfect methods to measure welfare changes, in addition to the ones discussed above.

While the investigation of inequality using the imperfect methods observed above reveals interesting and important features of the market, estimates of inequality are not particularly informative summary statistics of the distribution of well-being in the United States. For example, interpretation of the Gini coefficient of family income as a measure of dispersion in welfare implicitly assumes that families with the same level of before tax income are equally well-off. However, utility is derived from the consumption of goods and services and there is ample evidence, emanating from Friedman's (1957) permanent income hypothesis, which suggests that the distribution of total expenditures is likely to be quite different from the distribution of incomes. According to Friedman, households with low income levels are disproportionately represented by those with temporary reductions in current income and will typically have high ratios of consumption 
to income. Households with high income levels are over represented by those with transitory increases in income and will exhibit low ratios of consumption to income. The implication is that, all other things equal, one would expect less dispersion in the distribution of total expenditures relative to the income distribution.

The problems created as a result of using family income as a measure of well-being go beyond the differences in income and expenditure distributions. Households have different characteristics. Treating heterogeneous households symmetrically, as is common in income inequality examination, indirectly assumes that two households with the same level of income but different sizes and demographic characteristics are equally well-off. If household composition influences household expenditure patterns, needs and welfare, such effects are likely to have an important impact on both the levels and trends of expenditures and inequality in the distribution of welfare.

Using family income as a measure of household welfare also ignores the potential impact of prices on the distribution of well-being. Increases in the prices of basic necessities relative to luxuries will hurt the poor relatively more than the rich and increase the disparity in welfare. The large increase in the relative prices of energy goods in the 1970s could have had a substantial impact on the relative welfare levels. Looking at the distribution of family income alone would obviously ignore the above effect.

One of the goals of this study is to use a different methodology for measuring inequality in the distribution of welfare, one which is operationally feasible and broader in scope than the traditional money income measure. This approach to inequality measurement is based on the theory of exact aggregation developed by Lau (1977). One of the important implication's of Lau's theory 
of exact aggregation is that systems of demand functions for individuals with common demographic characteristics can be recovered uniquely from the system of aggregate demand functions. By requiring that the individual demand functions be integrable, it is possible to recover the indirect utility functions for all consumers. Finally, measures of individual welfare can be defined in terms of these indirect utilities. The model used in this study incorporates pseudo-panel micro data on the allocation of consumer expenditures due to different demographic consumer characteristics.

\subsection{Objectives}

The overall of goals of this study are to provide information on inequality in the distribution of household consumption expenditures and to measure the impact of demographic attributes of a household on consumption expenditures. The specific objectives are to:

1. Measure the impact of demographic characteristics on the distribution of individual expenditures on the consumption of goods and services in the United States between 1980 and 1994.

2. Evaluate the changes in individual household expenditures across demographic subgroups.

3. Examine the inequality in the distribution of household consumption expenditures using the Gini coefficient. Gini coefficients will be calculated for commodity components and demographic subgroups of the population defined in terms of household composition, the race, age of the reference person, and region of residence.

\subsection{Method and Organization}

Chapter 2 presents a review of related literature and is divided into 4 sections. An introduction is given in section 2.1 followed by section 2.2 addressing the history and development of welfare economics. The conventional ways of measuring income distribution are presented in 
section 2.3. A discussion on the expected contribution of this study is given in section 2.4. The theoretical framework to address the development of empirical models for this topic is addressed in sections 3.2 and 3.4 of chapter 3 . The data set used in this study is discussed in chapter 4 . This data set is developed from a BLS consumer expenditure survey. In section 5.2 of chapter 5 , the econometric methodology for developing a model to measure the impact of demographic characteristics on household consumption expenditures is outlined. In section 5.3 of the same chapter, the implementation of the econometric model, its results, and detailed discussions are presented. In chapter 6 , section 6.2 the method for measuring the inequality of household consumption expenditures is presented. The estimates are presented and broad discussions of the results are reported in section 6.3 .

Finally, a summary, conclusions, limitations of the study, and a discussions of future research needs are presented in chapter 7. 


\section{CHAPTER 2 LITERATURE REVIEW}

\subsection{Introduction}

The measurement of inequality has long concerned writers in the field of personal income distribution. Interest in measurement of income inequality and level of poverty can be traced to as early as 1890, when the development of a poverty line was discussed by Charles Booth. Economists are well aware that money income is not a completely accurate indication of relative standard of living. But most people interested in the issue of inequality base their perception of the degree of economic inequality on the Census Bureau's data on the distribution of money income. The underlaying issues of measuring the economic status of families and defining the poor remain to be settled. The effects of these problems are detrimental if the intention is to provide uniform treatment to families of equivalent economic status. For example, government programs directed at poor families often intend to include all those who are poor and to totally exclude those who are not. When receipt or denial of very much needed benefits is decided by a single empirical index, it is obviously important for that index to conform to a generally shared view of both horizontal and vertical equity. Hugh Dalton, in the preface to The Inequality of Income (September 1920), referred to the ambiguity of the conception of inequality and the need to give it a more precise definition and a logical measure (Atkinson, 1983). Dalton, in this pioneering article on the measurement of inequality, took issue with earlier researchers who had suggested that the position of an economist choosing a measure of inequality was identical to that of a biologist in determining the distribution of a physical characteristic (Atkinson, 1983). Dalton (1920, p. 348) argued that:

This is clearly wrong. For the economist is primarily interested, not in the distribution of income as such, but in the effect of the distribution of income upon the distribution and total amount of economic welfare, which may be derived from 
income.

The above statement of Dalton did not receive the attention which it deserved for many years (Atkinson, 1983). Empirical work on income and wealth inequality continued to use summary indicators of inequality, such as the mean deviation of the Gini coefficient, which were statistical in origin rather than derived from considerations of social welfare. It was, indeed, nearly fifty years later that Serge Kolm (1969) independently raised Dalton's approach and argued for a reconsideration of the measurement of inequality. These contributions led in turn to a very substantial literature on the underlying and basic conceptual issues.

Cash income is the most commonly used indicator of economic status, but it is widely recognized that this measure is inadequate. Comparisons using a cash income measure may not assure horizontal equity since other consumable resources may be missing. For some families current cash receipts constitute only a small portion of the available sources of economic welfare. Differing amounts of in kind transfers and physical and human capital can substantially change the economic status of families with similar cash incomes, causing them to no longer be as equals. For this reason, other sources of resources are often included to create alternative indices of family status. Moreover, vertical equity considerations--the ranking of the families and the equality of the distribution are more likely to be affected. Wealth, family size, location of residence, disability, income variability, and age are often introduced to alter the rankings that result from using either cash income alone or some expanded definition of economic welfare.

The need for a more expansive and accurate measure of economic status for descriptive, analytic, and policy purposes is obvious if standards are to be identified. The place to start, perhaps, is the theory of welfare economics, since measurement of inequality falls in the study of welfare 
economics. Welfare economics is a branch of economics developed to help society make better choices (Just et al., 1982). The measurement of individual and household welfare stands out in applied welfare economics for its capability to usefully blend economic theory with empirical practice (Blundell et al., 1994). It is an area where empirical investigation clearly benefits from theoretical insight and where theoretical concepts are brought alive and appropriately focused by the discipline of empirical relevance and policy design (Blundell et al., 1994). Yet there are many unanswered questions in identifying who gains and who loses from complex policy initiatives. This is exactly the problem to which this study is directed. A good measure of well-beingness is required for successful policy implementation.

This chapter has three more sections. The summary of the history of welfare economics and related theoretical and empirical developments is presented in section 2.2. Section 2.3 addresses the traditional methods of the measurement of income inequality and gives a summary of literature in this area. The third section, 2.4, discusses the potential contributions this research will make in field of income and welfare distribution.

\subsection{The History and Development of Welfare Economics}

An answer to the question of the method and content of normative economics, and more precisely welfare economics, can be made to turn on historic analysis. What for instance, did Marshal (1920), Pigou (1946), Little (1957), Graaf (1957), and many others, mean when they wrote about welfare economics? There is much conflict between what the better known writers have meant by welfare economics and its understanding among the profession today. Differences between the conclusions reached by the older tradition associated with Marshal, Pigou, Robertson, and to some extent Lerner (1946), as distinguished proponents of the Cambridge or Neoclassical School--which 
is built on a foundation of diminishing marginal utility and a belief in a basic similarity of human beings and a more modern approach, associated with the names of Vilfredo Pareto (1896), Hicks (1939), Samuelson (1950), and many others, turn out to be significant only with respect to distributional propositions. With respect to the purely allocative analysis, there is a general agreement, although with the passage of time there is a greater appreciation today of its limitations. We adopt what is today the more popular approach to the subject, building on the foundation laid by Bergson (1938), Kaldor (1939), and Hicks (1939) from whence sprang modern welfare economics; there will be little difficulty in pointing out, from time to time, certain differences in premises and conclusions between the older neoclassicist treatment and the more modern treatment.

Often, a distinction is made between the old welfare economics of Marshal et al. and what has come to be called the new welfare economics. The old welfare economics accepts the principle that social gains are maximized by competitive markets and, therefore, where noncompetitive interferences exist, the economist is justified in recommending policy measures that eliminate those distortions (Just et al., 1982). Also, the old welfare economics employs the technique of partialequilibrium analysis in developing recommendations. Partial-equilibrium or piecemeal analysis considers the welfare effects of a change in one market, assuming the effects in other markets are negligible (Just et al., 1982). From an empirical stand point, the old welfare economics holds that the triangle like area to the left of the demand curve and above price (often called consumer surplus) is a serviceable money measure of utility to the consumer in a market and that a triangle like area to the left of the supply curve and below price (producer's surplus) is similarly an adequate money measure of welfare for producers in a market (Just et al., 1982). Changes in these areas can be used to measure welfare changes to society. 
The principles of the old welfare economics have been attacked on several grounds by those economists associated with the new welfare economics. For example, beginning in 1942, economists such as Paul A. Samuelson demonstrated that the basic welfare measure of the old welfare economics--consumer surplus--is not well defined (Just et al., 1982). That is, consumer surplus is not generally a unique money measure of utility; uniqueness can imply contradictions depending on the use of empirical data. This criticism of the use of consumer surplus put applied welfare economics on somewhat shaky grounds until Willig's work appeared in the mid 1970's (Just et al., 1982).

Another criticism of welfare economics is based on an argument advanced as early as 1896 by Pareto. He argued that any policy that makes any person worse off cannot be supported on objective grounds. As further elaborated by Hicks and Kaldor, the welfare weight attached to each individual need not be the same and, hence, simply summing changes in consumer or producer surpluses across individuals is not a sufficient basis for evaluating change. Pareto argued that the only objective basis under which one can say society is better off is when some people are made better off and no one is made worse off. This criterion has come to be known as the Pareto principle.

In an attempt to extend the class of questions that can be addressed objectively by welfare economics, Hicks and Kaldor introduced the compensation principle in 1939 by which a change should be made if potential gain exists so all could be made better off by some redistribution of goods or income following the change (Just et al., 1982). The associated measurement problem was addressed by Hicks who suggested that alternative money measures of welfare, while not directly related to utility gains and losses, can be given willingness to pay interpretations (Just et al., 1982). These measures, known as compensating and equivalent variations, are unique measures in any 
situation and are hence not subject to the Samuelson criticism of consumer surplus (Just et al., 1982). The notion of compensating and equivalent variations and the associated compensating criteria are key concepts and form the foundation of applied welfare economics.

But even the compensating principles did not escape criticism. Scitovsky, in what has become known as the reversal paradox, illustrated how inconsistencies can arise in using this principle in policy analysis. Later, Gorman extended this analysis to illustrated the intransivity problem associated with inconsistent rankings of three or more situations (Just et al., 1982).

Applied welfare economics have been used extensively in recent years as though (if not actually) innocent of the controversy. Applied welfare economists continued to use partial equilibrium models for policy recommendations; and some recommendations have been legislatively mandated. The Flood Control Act of 1936 required that the benefits from water resource development projects must exceed the costs regardless of to whomever either may accrue (Just et al., 1982). To measure these benefits and costs in project evaluation work, economists continue to use the areas behind supply and demand curves. Policy makers demand economic analysis of policy decisions and applied welfare economists have used the only tools they have had available to provide information (Just et al., 1982).

Fortunately, however, some theoretical justification for feasible empirical work practices have followed. For example, the piecemeal approach has been shown to be appropriate when some markets or sectors have little economic impact on others. Where market interdependence exists, welfare economists now have better guidance as to how far they need to look to obtain the total welfare effects of a policy change. Similar advances have been made in other areas and under other assumptions. A number of important issues have characterized the recent literature on the 
measurement of welfare: how to incorporate differences in household characteristics into welfare evaluation; how to evaluate the welfare of individuals when they live in households; the potential for using subjective survey data for measuring welfare; and how to measure social welfare, inequality and poverty from individual welfare measures (Blundell et al., 1994).

One of the key concepts in economics is utility or welfare. The first thorough introductions of the concept were those by Gossen (1854) and Jevons (1871) and Edgeworth (1881). They assumed, using modern jargon, that a commodity bundle $\mathbf{x}$ in the commodity space $\left(\Re^{+}\right)$contains the intrinsic utility value (Ux). The consumer problem could then be described as looking for the bundle with the highest utility value that could be bought at prices p and income y (Van Praag, 1994). Such a model is capable of describing and predicting the purchasing behavior of an individual. Actually, this is the behavioral aspect of the model. According to Van Praag the model can also be used for normative purposes, where we compare utility differences between bundles $\mathrm{x}_{1}, \mathrm{x}_{2}, \mathrm{x}_{3}$ for a specific individual. The utility of income levels $\mathrm{y}_{1}, \mathrm{y}_{2}, \mathrm{y}_{3}$ may be calculated by means of the indirect utility function $\mathbf{V}(\mathrm{y}, \mathbf{p})$ which is defined as the maximum utility to be derived from income $y$ at given prices p. It also would be possible to define a social welfare function, $\mathrm{W}\left(\mathrm{U}_{1}, \ldots \ldots . ., \mathrm{Un}\right)$, where social welfare is a function of individual utilities. The most common application of that concept is to compare distributions of social wealth and design policies which may lead to a better distribution.

Pareto (1909) gave a fierce blow to the utility concept by showing that demand behavior was completely determined by the contour lines, defined by the equation $\mathrm{U}(\mathrm{x})=$ constant (Van Praag, 1994; Just et al., 1982). The result is that demand behavior does not define the utility function uniquely, but rather that there is a whole equivalence class of utility functions which yields the same demand behavior. Those utility functions have a property that $\hat{v}=\phi(\mathrm{U})$ where $\phi($.$) is any$ 
monothonically increasing function (Van Praag, 1994). This eroded utility concept is called the ordinal concept. The original one of, for example, Edgeworth is called the cardinal utility concept. Pareto (1909) did not state that cardinal utility was a nonsensical concept but only that it was not necessary to know the utility function to explain demand behavior, as knowledge of the contour lines of the utility surface on the commodity space is all that is needed (Kirman, 1987).

Robbins (1932) made a fierce attack on cardinal utility and stated that it was an unmeasurable concept altogether. Hicks and Allen (1934) and later Houthakker (1950) gave rigorous explanations of demand behavior without applying the utility concept at all. Deaton and Muellbauer (1982) made similar observations. So, the utility concept degenerated to a handsome tool to describe choice behavior. However, during the last thirty years the number of economists disagreeing with Pareto has been increasing. Several attempts at measurement or developing methods of possible measurement of utility have been made. The procedure can be described by the assumption that utility is the same function of a number of determinants or components for all individuals or households but with parameters characterized by the individual being considered which differ among individuals (Jorgenson and Slesnick, 1984). Thus, in recent years, major empirical measurements were made by three different groups of economists American, Dutch, and French groups.

The American group, which is made up of Christensen, Jorgenson, Slesnick, and Stocker, use a translog utility function, that is, one where the log utility is a quadratic function of the log of determinants and the latter are three or five consumption goods or services. The number of parameters to characterize the groups of consumers is also five: family size, age of head, region of residence, race, and type of residence. They introduce restrictions on preferences not used by ordinalists which may be considered the price they pay to justify being cardinalists. The restrictions 
used are exact aggregation of individual demand to total demand and the integrability of demand functions rather than formal criteria.

The Dutch economists are led by Van Praag and Kapteyn. They use one determinant, income and test a large number of utility functions, although they prefer the cumulated lognormal function, for reason of convenience in a number of applications (Van Praag, 1971; Kapteyn, 1977; Van Herwaarden and Kapteyn, 1981). The function they prefer is linear in the logs of determinants $\mathrm{x}_{\mathrm{i}}$, plus unity:

$$
w=\sum_{i} \alpha_{i} \ln \left(x_{i}+1\right)
$$

The advantage of this relationship is that it shows falling marginal utilities, namely:

$$
\frac{\partial w}{\partial x_{i}}=\frac{\alpha_{i}}{\left(x_{i}+1\right)}
$$

The general restriction implies that the qualifications used to carry out the measurement procedure of the satisfaction experienced have the same meaning to the person compared. This restriction can be accepted since, in discussion on the policy resulting from the use of welfare measurement, the same words are also used either to accept or reject the policy. The restriction can be applicable only on a local or national level, rather than on international level, because the concept of a good income means something different to, say, an American and a Chinese metal worker.

The French economist who engaged in measuring welfare is Maurice Allias. He uses one component, psychological assets, and prefers the functional shape of linearity in its log (Allias, 1984). He only claims this shape for the main interval of the variable and admits that deviations 
occur at the extremes. At the upper extreme he finds the phenomenon of satiety (an asymptote).

Measuring welfare or utility has become a respectable activity among many economists, and is considered to be comparable to similar processes and developments in other sciences. Clear examples can be found in physics where initially qualitative characteristics were followed by very satisfactory quantitative measurements. In the theory of heat qualification, qualitative values such as hot, warm, luckwarm, and cold were later replaced by specific temperature. In the theory of light, qualitative characteristics such as red, orange, yellow, green, blue, and purple were replaced by wave length. In the theory of sound and music, wave lengths also became characteristics of low and high sounds.

One way to measure economic status as suggested by Peter Hammond (1976) is to do interpersonal comparisons. Interpersonal comparisons can be of utility levels and/or utility differences. Comparisons of levels can be used to define equity in the distribution of income. Sen (1973) gives a particular example by a thorough and interesting discussion of the welfare economics of income distribution in his book, On Economic Inequality. At the beginning of this book, utilitarianism is criticized on the grounds that it may lead to choices of income distribution which conflict with the notion of equity (Sen, 1973). He emphasized how one can make interpersonal comparisons of utility differences.

Hammond (1976), instead, set out to find an equity-regarding additive Bergson social welfare function, taking account of both types of comparisons. He further explains (p. 70):

It may not exist unless the interpersonal comparisons satisfy certain restrictions. The precise nature of these restrictions depends upon the precise nature of the dual interpersonal comparison. The most restrictive case is the one which Sen considered, 
where both levels and differences of a single list of consumers' utility functions are being compared. In the least restrictive case, the level of one list of utility functions and the differences of a quite separable list of utility functions are compared. There is a third, intermediate case, where one compares the levels of a list of utility functions and the differences of a cardinally related but different list of utility functions.

If the price vector is considered along with the distribution of income, then dual interpersonal comparability may restrict the form of the consumers' indirect utility functions (Hammond, 1976). Hammond goes on to say (p.70):

In the most restrictive case, the restrictions imply that any one consumer's Engle curves can be obtained from any other consumer's Engle curves by way of simple lateral shift. The property needed for consistent aggregation, the Engle curves are parallel straight lines, emerges as special case. The intermediate kind of dual comparability gives somewhat weaker restrictions; the least restrictive kind of dual comparability puts no restriction at all on consumers' indirect utility functions, or on their demand functions.

Hammond (1976) points out that market data helps to determine the precise form of the welfare function.

Muellbauer (1974a) analyzed household composition, Engle curves and welfare comparisons between households using a duality approach. The household composition effects in consumer theory are important for the specification and estimation of Engel curves and demand functions. The models examined by Muellbauer (1974a) have important applications in the areas of measurement 
of cost of living indices, the study of poverty and equality and in certain aspects of social policy. These models are based on the approach of Barten (1964). In his study, test differences between households are parameterized in a way which has been called simple good augmenting or simple repackaging in the literature on equality change--see Fisher and Shell (1967) and Muellbauer (1973a). In this theory, changes in household composition play an analogous role to price changes. Barten (1964) suggests that price elasticities might be estimated from cross-section data alone.

The indices introduced are of considerable importance in analyzing poverty and inequality (Muellbauer,1974a). Unless household composition is taken into account in this way, it makes virtually no sense to compare the money incomes of different households. Recently Atkinson (1970) and Sen (1973), among others, have discussed measures of inequality. As far as operational measures are concerned, this always boils down to measures of money inequality and it is always assumed that the individual utility functions are identical (Muellbauer, 1974a). Clearly, this is inadequate for households. However, with the above theory, the approach of Atkinson and Sen can be extended to measure economic inequality between households. Muellbauer states that the Engel method is painfully devoid of any micro-economic theoretical basis and continues in use only because recent advances in the basic theory of consumption economics have not been applied to the estimation of equivalence scale.

Still on the subject of welfare comparison, Pollak and Wales (1979) addressed the distinction between the equivalence scale required for welfare comparisons and the equivalence scale which arises in demand analysis. Of course, equivalence scales are used in both demand and welfare analyses. In demand analysis they permit us to pool data from households of different sizes, or more generally, with different demographic profiles. In welfare analysis, they enable comparison of the 
well-being of such households, since they purport to answer questions of the form: what expenditure level would make a family with three children as well off as it would be with two children and $\$ 12,000$ ? According to Pollak and Wales (1979) such welfare comparisons are generally thought to provide the rationale for different treatments of different family types in income tax or family allowance schedules, or in an income maintenance program (Pollak and Wales,1979).

The authors also explicitly pointed out the types of equivalence scale appropriate for demand analysis or welfare comparisons. Conditional equivalence scales are used in demand analysis while unconditional equivalence scales are used for welfare comparisons. Conditional equivalence scales can be estimated from observed differences in the consumption patterns of households with different demographic profiles, but construction of unconditional equivalence scales requires more information than is contained in household consumption data (Pollak and Wales, 1979).

Pollak and Wales (1979) explicitly stated the implications of their analysis of welfare comparisons and equivalence scales as:

1. Even if all families have identical unconditional preferences, conditional equivalence scales estimated from observed differences in the consumption patterns of families with different demographic profiles cannot be used to make welfare comparisons; for example, we cannot use such data to determine the amount needed to make families with three children as well off as those with two children and $\$ 12,000$. Unconditional equivalence scales are required to make welfare comparisons.

2. If tastes vary systematically with demographic characteristics, then the construction of unconditional equivalence scales requires the selection of an 
appropriate base unconditional preference ordering; theory offers little guidance in making this selection, but there is no selection which permits us to compare the welfare of a family with a strong desire for children with that of one with a weak desire for children. Such comparisons require interpersonal or inter family comparisons of welfare levels.

Slesnick (1994) empirically demonstrated that the distribution of expenditures is different from the distribution of income. The paper also assesses the robustness of the widely accepted conclusion that inequality in the United States has reversed course and attained unprecedented (high) levels. The author avoided the problems associated with money income inequality studies by using a measure of welfare that is based on consumption level and incorporates the needs of households, as well as the influence of prices. It came out that the distribution of a consumption based welfare measure is different from the family income distribution, which is used to demonstrate rising inequality in the United States (Slesnick, 1994). The result points out that income performs poorly as a proxy for household welfare in measuring inequality (Slesnick, 1994). Further, Slesnick found that income inequality overstates consumption based on inequality measures by a substantial amount. The trends and consumption based on inequality indexes also diverge, with income measures indicating rising inequality over the postwar United States and the consumption measure showing the reverse.

What accounts for the difference between the distribution of before tax income and the distribution of real per equivalent expenditure? The answer given by Slesnick is that the distribution of total expenditure is less dispersed than the distribution of income which, in turn, appears to be the result of consumption smoothing across the population. The inclusion of household needs in the 
evaluation of welfare is also an important component in accounting for the differences in the levels and trends of inequality in the United States.

The focus of attention of policy makers and researchers has been the U-turn in income inequality in the United States. But Slesnick's findings indicate that when household welfare is measured using real per equivalent expenditures, the level of inequality fell until the early 1970s and has remained essentially constant thereafter. However, in 1991 the level of inequality remains high so that substantial gains in social welfare can be had through further equalization of the distribution of welfare. The suggestion given on policy issues is that it is perhaps more useful to focus attention on the forces that induced the reduction in inequality rather than try to explain the illusory U-turn in inequality that occurred in the 1970's and 1980's.

On a related topic Blundell, Browning and Meghir (1994) estimated the parameters of household preferences that determine the allocation of goods within the period and over the lifecycle, using micro data. In doing so, they were able to identify important effects of demographic, labor market status and other household characteristics on the intertemporal allocation of expenditures. The distinctive feature of their approach is that it integrates traditional demand analysis with an intertemporal substitution model in a coherent way.

Based on the author's suggestions, the findings of this type of research is open to a variety of interpretations which cannot be distinguished convincingly within this framework. First, it is quite possible that the importance of labor market variables in the intertemporal model does in fact reflect a shift in tastes as a function of labor market status; since labor market status and the growth rate of income are obviously correlated ignoring the former makes the later spuriously significant (Blundell, Browning and Meghir, 1994). Further, they point out that for the same reason labor 
market status is a good predictor of income growth and, thus, labor market status may just capture excess sensitivity. In a recent empirical finding, Jorgenson and Slesnick (1984) were able to measure welfare inequality based on an econometric model of aggregate consumer behavior. This model allows them to uniquely recover systems of individual demand functions from the systems of aggregate demand functions. By requiring that individual demand functions be integrable, they recovered indirect utility functions for all consumers (Jorgenson and Slesnick, 1984). As a result, they were able to define measures of individual welfare in terms indirect utility functions.

To represent preferences for all individuals in a form suitable for measuring individual welfare, households are taken as consuming units. It is also assumed that expenditures on individual commodities are allocated so as to maximize welfare functions. As a result, the household behaves in the same way as an individual maximizing a utility function, as demonstrated by Samuelson (1956) and Pollak (1981). By assuming that each household maximizes a household welfare function, the focus can be on the distribution of welfare among households (Jorgenson and Slesnick, 1984). An econometric model based on exact aggregation can be defined through representing individual preferences by means of an indirect utility function for each consuming unit (Jorgenson and Slesnick, 1984). They also assume the kth consuming unit allocates expenditures in accordance with the translog indirect utility function. By applying Roy's identity, the system of individual shares is obtained. Aggregate expenditure patterns depend on the distribution of expenditures over all consuming units through summary statistics of the joint distribution of expenditures and attributes (Jorgenson and Slesnick, 1984). The first step in analyzing inequality in the distribution of individual welfare is to select a representation of the individual welfare function. The assumption is that the individual welfare of the kth consuming unit is equal to the logarithm of the indirect utility 
function. The indirect utility function provides a cardinal measure of utility. If a system of individual expenditure shares can be generated as an indirect utility function, we can say that the system is integrable. A complete set of conditions for integrability is given by Jorgenson and Slesnick (1984):

Homogeneity The individual expenditure shares are homogeneous of degree zero in prices and total expenditure.

Summability: The sum of the individual expenditure shares over all commodity groups is equal to unity.

Symmetry: The matrix of compensated own- and cross-price substitution effects must be symmetric Nonnegativity: The individual expenditure shares must be nonnegative.

Monotonicity: The matrix of compensated own-and cross-price substitution effects must be nonpositive definite.

To provide a basis for evaluating the impact of transfers among households on social welfare, it is useful to represent household preferences by means of utility functions that are the same for all consuming units. Consumer equilibrium implies the existence of an indirect utility function that is the same for all consuming units. The level of utility for the kth consuming unit depends on the price s of individual commodities, the household equivalence scale, and the level of total expenditures (Jorgenson and Slesnick, 1984). The first step in analyzing inequality in the distribution of welfare is to select a representation of the individual welfare function. Jorgenson and Slesnick (1984) assume that the individual welfare for the kth consuming unit is equal to the logarithm of the translog utility function. The next step is to generate a social welfare function that has the properties of an unrestricted domain, independence of irrelevant alternatives, positive 
association, nonimpostion, and cardinal full comparability (Jorgenson and Slesnick, 1984). They impose the additional assumption that the degree of aversion to inequality is constant and require the social welfare function to satisfy requirements of horizontal and vertical equity.

To develop indexes of inequality in the distribution of individual welfare, Jorgenson and Slesnick (1984) decompose the measure of social welfare into measures of efficiency and measures of equity. Efficiency can be defined as the maximum level of welfare that is potentially available through redistribution of aggregate expenditures. The absolute level of inequality is defined as the difference between the measure of efficiency and the actual level of social welfare. Also, a relative measure of inequality is defined as the ratio between the absolute index of inequality and the measure of efficiency. The decomposition of social welfare into measures of efficiency and equity takes place through the maximization of social welfare for a fixed level of aggregate expenditure. The average level of individual welfare for a given level of aggregate expenditures can be maximized by means of the Langrangian.

If aggregate expenditure is distributed so as to equalize total expenditures per household equivalent member, the level of individual welfare is the same for all consuming units. Equivalent member is a member of a household for which expenditure is allocated based on an index called equivalent scale. Equivalent scale is an index which deflates family income or expenditure by a score that may be less than one for each extra member. This is the maximum level of welfare that is potentially available and can be taken as a measure of efficiency. We can refer to this measure as the translog index of efficiency. The translog index is equal to the translog indirect utility function, evaluated at aggregate expenditure per household equivalent member for society as a whole (Jorgenson and Slesnick, 1984). 
Given the translog index of efficiency defined in terms of the social welfare function, we can define a measure of inequality as the difference between the translog index of efficiency and the actual value of the social welfare function (Jorgenson and Slesnick, 1984). We can refer to this measure as the translog index of inequality. Likewise, it is possible to develop a measure of inequality within subgroups of the U.S. population. For this purpose, a group welfare functions are introduced that are precisely analogous to the social welfare function discussed earlier. A group welfare function can be defined as a mapping from the set of individual welfare functions to the set of group orderings(Jorgenson and Slesnick, 1984). A group ordering can be described in terms of properties of a social welfare function. The same steps can be taken to decompose a group welfare function into measures of efficiency and equity. As a result, measures of inequality within groups are obtained.

\subsection{Conventional Ways of Measuring Income Distribution}

The distribution of income is one of the main features of any social system. David Ricardo, the classical economist par excellence, regarded the determination of income distribution as the most important task facing economics. This view is no longer widely held in the face of today's problems (unemployment, inflation). Nevertheless, stagnation in economic growth in virtually all modern industrialized societies, which has became the subject of public debate recently, has meant increasing pressure for more attention to be paid to the distribution of the national pie.

Theoretical success in the study of personal income distribution is still modest. None of the existing theories are entirely satisfactory. Money income is what we observe and tax. But it is not completely satisfactory indicator of well-being. Throughout the last fifty years numerous measurement methods have been employed to measure the distribution of income. This section 
reviews and discusses some of the methods used and some of the articles and books published on this particular topic.

\subsubsection{Lorenz Curve}

The Lorenz curve is a powerful tool in the analysis of the size distribution of income and wealth. The curve is defined as the relationship between the commutative portion of income and the commutative portion of income receiving units. Let $\pi(\mathrm{x})$ represent the proportion of the units that receive income up to $\mathrm{x}$ and $\eta(\mathrm{x})$ represent the proportion of total income received by the same units. The Lorenz curve is then the graphical representation of the parametric relationship between $\eta$ and $\pi$. The graph of the curve is represented in a unit square. The straight line is joining the points $(0,0)$ and $(1,1)$ is called the egalitarian line, because along the line $\eta=\pi$, which means that each unit receives the same income. The Lorenz curve falls below the egalitarian line. Figure 2.1 illustrates the Lorenz curve.

To derive the Lorenz curve, let $\mathrm{x}$ be the income of the unit and $\mathrm{g}(\mathrm{x})$ be the probability density function of $x . G(x) d x$ will then represent the probability that a unit selected at random will have income less that or equal to $\mathrm{x}$ is:

$$
\pi(x)=\int_{0}^{x} g(r) d r
$$

and the average income earned by these units is:

$$
Q(x)=\int_{0}^{x} r g(r) d r
$$


Figure 2.1: Lorenz Curve

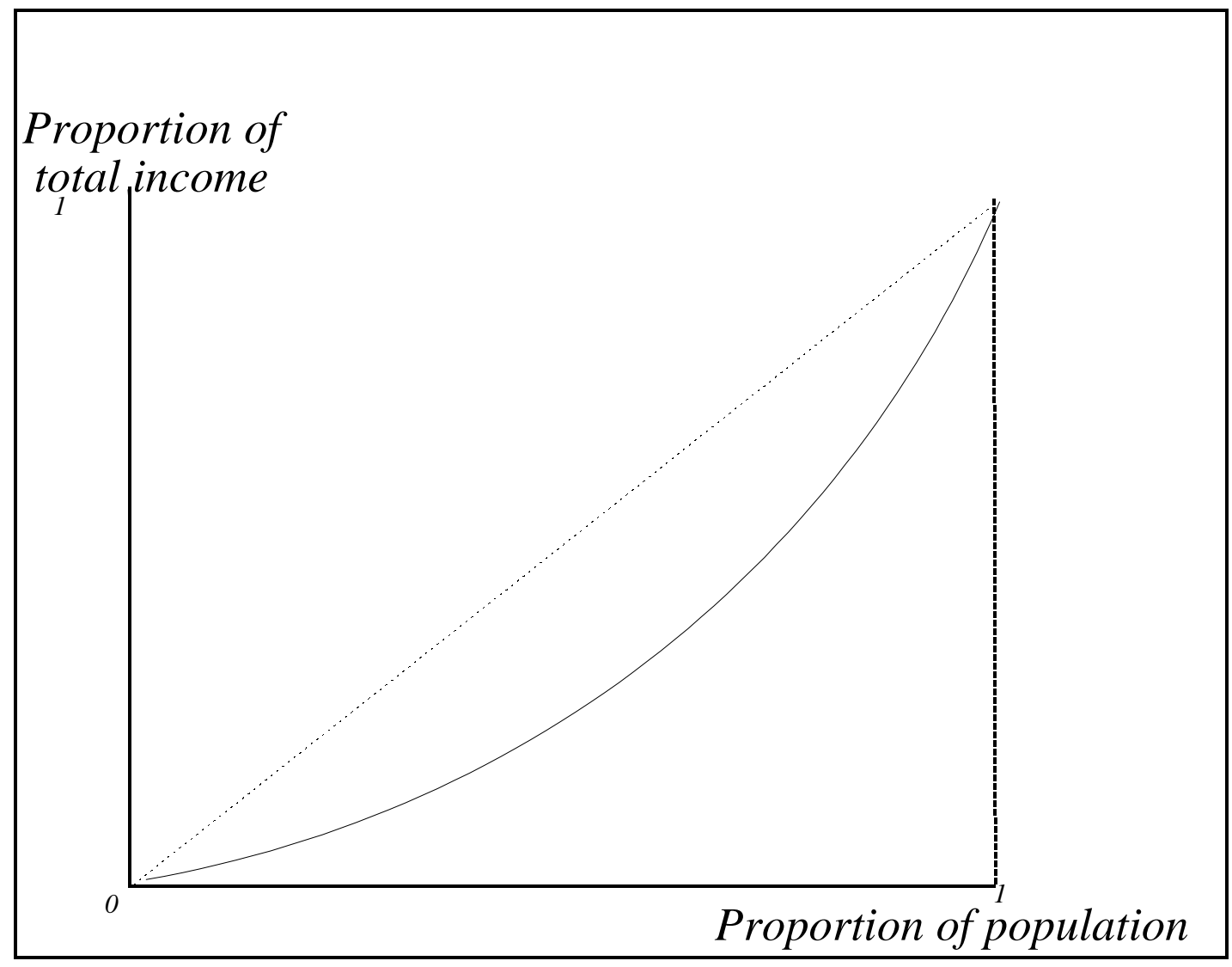

Then the proportion of income earned by units whose incomes are less than or equal to $\mathrm{x}$ will be:

$$
\eta(x)=\frac{Q(x)}{Q}
$$

where $\mathrm{Q}$ is the average income of all the units. The Lorenz curve can be obtained by inverting the functions (2.3) and (2.5) and eliminating $\mathrm{x}$ if the functions are conveniently invertible. Alternatively, the curve can be plotted by generating the values of $\pi(x)$ and $\eta(x)$ from (2.3) and (2.5) by giving some arbitrary values of $\mathrm{x}$. If the distribution of income follows Pareto's, the equation of the Lorenz curve will be:

$$
(1-\eta)=(1-\pi)^{\delta}
$$


where $0<\delta<1, \delta$ being the parameter. This Lorenz curve is not symmetric about the $45^{0}$ line perpendicular to the egalitarian line. Generally, the Lorenz curve must satisfy the following conditions (Kakwani and Podder, 1973):

1. If $\pi=0, \eta=0$

2. If $\pi=1, \eta=1$

3. $\eta<\pi$

4. The slope of the curve increases monotonically.

Condition 1 rules out the possibility of a unit earning zero or negative income. Condition 4 implies that the curve lies below the egalitarian line. It should be recognized that the concept of Lorenz curve has been extended and generalized to deal with consumer behavior patterns with respect to different commodities. According to Kakwani and Podder (1973), generalized Lorenz curves, which describe the consumption pattern for commodities, are called concentration curves and the Lorenz curve is only a special case of such curves, namely, the concentration curve for income. Kakwani and Podder (1973) pointed out that the more general form of the Lorenz curve which satisfies the condition may be:

$$
\eta=\pi^{\alpha} e^{-\beta(1-\pi)}
$$

Where $\alpha$ and $\beta$ are parameters. Kakwani and Podder (1973) estimated the concentrated ratio for Australia on the basis of data collected in a survey of consumer expenditures during 1967-68. The general formula (2.8) gives a marginally better fit than the simple formula. Kakwani and Podder (1973) expressed the simple formula as:

$$
\eta=\pi e^{-\beta(1-\pi)}
$$


The standard error of the concentration ratio based on the general formula is higher than that of the simple one. This may be because the concentration ratio is a function of a coefficient which could not be estimated precisely in the general formula due to the high correlation between the independent variables .

\subsubsection{Gini Coefficient}

The Gini coefficient is a well-known summary measure of inequality. It is derived from the Lorenz curve. A variety of empirical studies on income distribution have used the Gini and extended Gini to measure income distribution. Garner (1993) used the Lerman and Yitzhaki covariance method to analyze inequality in the distribution of household consumption expenditures, and to examine relationships between various expenditure budget components and total expenditures using United States data. This method had been applied previously to the study income inequality by income source in the U.S. (e.g., Ahearn, Johnson, and Strickland, 1985; Lerman and Yitzhaki, 1985), to assess the progressivity of taxation in Israel (Yitzhaki, 1990), and to determine the welfare dominance of excise taxation for the Cote d'Ivoire (Yitzhaki and Thrisk, 1990).

Other researchers (e.g. Iyengar, 1960; Kakwani, 1978; Blaylock and Smallwood, 1982; Yitzhaki, 1990; Yitzhaki and Thrisk, 1990) have used the Gini coefficient and concentration curves to produce income or expenditure elasticities. In each of these previous studies, with the exception of Kakwani (1978), elasticities were produced for a selected few commodities and commodity groups.

Gartner's (1993) study disaggregated total expenditures into nine exhaustive categories: food, shelter, household fuels and utilities, household operations, apparel and services, transportation, medical care and services, entertainment, and other expenditures. Expenditures allocated to savings, 
such as personal insurance and pensions, were excluded. Micro level data from the U.S. Consumer Expenditure Interview Survey (CEX) were analyzed with expenditures referring to those of the consumer unit (United States Department of Labor, 1978).

On another front, Silber (1989) presented the use of a new linear operator, called the Gmatrix, which greatly simplifies not only the computation of the Gini Index but also the decomposition by factor components or population subgroups. The proposed approach also allows one to give a clear interpretation of the interaction term which is obtained when the Gini Index is broken down by population subgroups.

Following the work of Sen (1973) and Donaldson and Weymark (1980), it has been shown that the Gini index of inequality $\mathrm{I}_{\mathrm{G}}$ could be written as (Berrebi and Silber, 1985; Silber, 1989):

$$
I_{G}=\sum_{j=1}^{n} s_{j}\left[\frac{(n-j)}{n}-\frac{(j-1)}{n}\right]
$$

Where $s_{\mathrm{j}}$ is the proportion of total income earned by the individual whose income has the $\mathrm{j}^{\text {th }}$ rank in the income distribution, assuming that

$$
\mathrm{s}_{1} \geq \mathrm{s}_{2} \geq \ldots \quad \geq \mathrm{s}_{\mathrm{j}} \geq \ldots \quad \geq \mathrm{s}_{\mathrm{n}}
$$

Expression (2.15) may be written as (Silber, 1989):

$$
I_{G}=\sum_{i=1}^{n} s_{i}\left[\sum_{j \geq i}\left(\frac{1}{n}\right)-\sum_{j \leq i}\left(\frac{1}{n}\right)\right]
$$

According to Berrebi and Silber (1987) equation (2.16) can be written as:

$$
I_{G}=\left(e^{\prime} G s\right)
$$


Where $\mathrm{e}$ is a column vector of $\mathrm{n}$ elements which are equal to $1 / \mathrm{n}$ ( $\mathrm{e}^{\prime}$ being the corresponding row vector), $\mathrm{s}$ is a column vector of $\mathrm{n}$ elements being, respectively, equal to $\mathrm{s}_{1}, \mathrm{~s} 2, \ldots, \mathrm{s}_{\mathrm{n}}$ and $\mathrm{G}$ (which could be called the G-matrix) is an $\mathrm{nX} n$ matrix whose elements $\mathrm{g}_{\mathrm{ij}}$ are equal to -1 when $\mathrm{j}>\mathrm{I}$, to +1 when $\mathrm{I}>\mathrm{j}$ and 0 when $\mathrm{I}=\mathrm{j}$. This approach may be used to estimate an upper bound to the Gini Index when only group observation are available (Silber, 1989).

To show factor of components and the Gini Index, let $\mathrm{X}_{\mathrm{j}}$ denote an individual $\mathrm{j}$ 's total income and $\mathrm{X}_{\mathrm{ij}}$ the income the individual receives by providing productive factor I component of individual $\mathrm{j}$ 's income. The share of individual $\mathrm{j}$ in total income will now be denoted by $\mathrm{s}_{\mathrm{j}}$ and is written as (Silber, 1989):

$$
s_{j}=\left(\frac{X_{j}}{X_{T}}\right)
$$

Where $X_{T}=\sum_{j=1}^{n} X_{j}$, and where the share of component I in society's total income will be denoted by $\mathrm{s}_{\mathrm{i}}$ defined by

$$
s_{i}=\frac{\left(\sum_{j=1}^{n} X_{j i}\right)}{X_{T}}
$$

Let us call $\mathrm{s}_{\mathrm{ji}}$ the share of the component I of individual $\mathrm{j}$ in total income $\mathrm{X}_{\mathrm{T}}$, that is,

$$
s_{j i}=\frac{X_{j i}}{X_{T}}
$$

and define an $n$ by $(k+1)$ matrix $S$, whose first column is the vector $s$ of the shares of $s_{j}$, whose 
second column is the vector $s_{.1}$ of the shares $s_{j 1}$ and whose $(I+1)^{\text {th }}$ column in the vector $s_{. i}$ of the shares $\mathrm{s}_{\mathrm{ji}}$. The product

$$
e^{\prime} G S=z
$$

is a row vector of $(\mathrm{k}+1)$ elements whose first element, as indicated by equation (2.12), is the Gini Index of total income inequality. The next $\mathrm{k}$ element of $\mathrm{z}$ may be written as:

$$
z_{i+1}=e^{\prime} G s_{. i} \quad(i=1 \ldots k)
$$

so that

$$
\begin{aligned}
\sum_{i=1}^{k} z_{i+1} & =e^{\prime} G\left(s_{.1}+\ldots .+s_{. i}+s_{. k}\right) \\
& =e^{\prime} G s=z_{1}
\end{aligned}
$$

Let us call $v_{. i}$ the vector of the ratios $\left(s_{\mathrm{ji}} / \mathrm{s}_{\mathrm{i}}\right)(\mathrm{j}=1 \ldots \mathrm{n})$ so that the element $\mathrm{v}_{\mathrm{ji}}$ of $\mathrm{v}_{\mathrm{.i}}$ is the share of individual $\mathrm{j}$ in the total income derived from component I. Expression (2.17) may then be written as:

$$
z_{i+1}=e^{\prime} G\left[\begin{array}{c}
\left(\frac{s_{1 i}}{s_{. i}}\right) s_{. i} \\
\cdot \\
\cdot \\
\cdot \\
\left(\frac{s_{n i}}{s_{. i}}\right) s_{. i}
\end{array}\right]=\left(s_{. i}\right) e^{\prime} G v_{. i}
$$


The scalar e' $\mathrm{Gv}_{\mathrm{i}}$ is generally not the Gini Inequality Index $\mathrm{G}_{\mathrm{i}}$ of the $\mathrm{i}^{\text {th }}$ component of income since the elements $v_{\mathrm{ji}}$ and $\mathrm{v}_{. \mathrm{i}}(\mathrm{j}=1 \ldots . \mathrm{n})$ may not necessarily be ranked by decreasing value as are the elements $s_{\mathrm{j}}$ of $\mathrm{s}$. To obtain the Gini Inequality index of $\mathrm{G}_{\mathrm{i}}$ of component $\mathrm{I}$, one has to construct a new vector $y_{. i}$ whose elements $y_{j i}(j=1 \ldots . . n)$ are the shares $\left(s_{j i} / s_{. i}\right)$ previously defined, but they are not ordered according to the order of the shares $s_{j}$ of vector $s$ but according to their own rank in the vector $\mathrm{y}_{\mathrm{i}}$. The Gini Index $\mathrm{G}_{\mathrm{i}}$ for component $\mathrm{I}$ is therefore defined as:

$$
G_{i}=e^{\prime} G y_{. i}
$$

The scalar $\mathrm{C}_{\mathrm{i}}=\mathrm{e}^{\prime} \mathrm{Gv}_{\mathrm{.}}$, on the other hand, has been called the pseudo Gini of component I by Fei, Ranis and Kuo (1978) or the concentration ratio of component I by Rao (1969), Kakwani (1980), Pyatt, Chen and Fei (1980) and Shalit (1985).

The above procedure to decompose the Gini Inequality Index among all factors that contribute to income is, therefore, relatively uncomplicated. It requires construction of a matrix $\mathrm{S}$ whose first column refers to the shares of each individual's total income in society's total income whereas the next column refers to the shares of each individual's income from specific component in society's total income (Silber, 1989). All vectors are ranked according to the (decreasing) rank of the individuals in total income. The product e'GS is then a vector $\mathrm{z}$ whose first element is the Gini Inequality Index $\mathrm{I}_{\mathrm{G}}$, whereas the other elements are the contributions of each component to the overall inequality $\mathrm{I}_{\mathrm{G}}$. Both techniques presented above were tested with real data. The outcome is very consistent with the other measures of inequality.

Another study, by Husted (1991), examines the change in state-level income inequality from 1981 to 1987 . Inequality is measured by the state's Gini coefficient, as calculated from each state's 
Lorenz curve. The study uses techniques developed in Kakwani and Podder $(1973,1976)$ and described in Slottje (1989) to estimate state-leve Lorenz curves. The parameter estimates then are used to calculate the associated Gini coefficients and their asymptotic standard errors.

Following Kakwani and Podder (1976), family income $\mathrm{Y}$ is a random variable with probability density function $\mathrm{f}(\mathrm{Y})$, so that

$$
P(Y)=\int_{0}^{y} f(Y) d Y
$$

is the proportion of families with income less than or equal to $\mathrm{y}$ and

$$
Q(Y)=\frac{1}{\mu} \int_{0}^{y} Y f(Y) d Y
$$

is the proportion of income earned by the families who have income less than or equal to $y$, where $\mu$ represents the mean income of all families in the population.

Given these definitions, any point of a Lorenz curve can be described by two line segments,

$$
\pi=\frac{1}{\sqrt{2}}[P(Y)+Q(Y)], \sigma=\frac{1}{\sqrt{2}}[P(Y)-Q(Y)]
$$

The first line segment $\pi$ is the ordinate from the point on the Lorenz curve to the diagonal egalitarian line. The second segment $(\sigma)$ extends from the origin to this ordinate along the diagonal egalitarian line. It follows this definition that

$$
\frac{d \pi}{d \pi}=\frac{(\mu-y)}{(\mu+y)}
$$

The proposed Lorenz curve for this study is (Husted, 1991): 


$$
\sigma=a \pi \alpha(\sqrt{2}-\pi)^{\beta}, 0<\pi<\sqrt{2},-: a, \alpha, \beta>0
$$

Taking the log of both sides, equation (2.25) becomes

$$
\log (\sigma)=\log (a)+\alpha \log (\pi)+\beta \log (\sqrt{2}-\pi)
$$

This specification satisfies the necessary properties for a Lorenz curve (Husted, 1991). In particular, $\sigma>0$ when $a>0$ and the Lorenz curve lies below the egalitarian line. The parameters $\alpha$ and $\beta$ are restricted to be greater than zero, so that $\sigma=0$ when $\pi=0$ or $\pi=\sqrt{ } 2$. Additional restrictions are imposed by equation (2.24) and the negative second derivative. The additional restrictions contain $0<\sigma \leq 1$ and $0<\beta \leq 1$ and indicate, for the Lorenz curve defined in equation (2.25), that

$$
\sigma(\sqrt{2}-\pi)-\beta \pi=\frac{(\mu-y)}{(\mu+)} \pi \frac{(\sqrt{2}-\pi)}{\sigma}
$$

To calculate the Gini coefficient, the parameters of the Lorenz curve in equation (2.25) and the restriction on the curve in equation (2.26) must be jointly estimated. However, since the available income data for the analysis by Husted (1991) are grouped by income class, $\pi$ and $\sigma$ are not observed (Husted, 1991). In the data used for this study, there are $\mathrm{N}$ families grouped into $\mathrm{K}+1$ income classes for each time series $t(1=1, \ldots \ldots ., \mathrm{T})$ and within each cross section. If $_{\mathrm{t}, \mathrm{c}}{ }^{\mathrm{k}}$ is the number of families earning income between $\mathrm{y}_{\mathrm{k}-1}$ and $\mathrm{y}_{\mathrm{k}}$ in time period $\mathrm{t}$ and cross section $\mathrm{c}$, then $\mathrm{f}_{\mathrm{t}, \mathrm{c}}{ }^{\mathrm{k}}=\mathrm{n}_{\mathrm{t}, \mathrm{c}}{ }^{\mathrm{k}} / \mathrm{N}$ is a consistent estimator of the probability that a family belongs to this particular income group in cross section $\mathrm{c}$ and time $\mathrm{t}$ (Husted, 1991). Therefore the estimators of $\mathrm{P}(\mathrm{Y})$ and $\mathrm{Q}(\mathrm{Y})$ are (Husted, 1991): 


$$
\begin{aligned}
p_{t, c}^{k} & =\sum_{f_{\sigma=1 \sigma}}^{k} \quad t=1, \ldots . . C \\
q_{t, c}^{k} & =\frac{1}{\mu_{t, c}} \sum_{\sigma \approx 1}^{k} m_{\sigma} f_{\sigma} \quad t=1, \ldots \ldots \ldots . T . \quad c=1, \ldots \ldots \ldots . C .
\end{aligned}
$$

where $\mathrm{m}_{\sigma}$ is the mean income group $\sigma$, and $\mu_{\mathrm{t}, \mathrm{c}}$ is the mean income for all families in cross section $\mathrm{c}$ and in year t. By substituting $\mathrm{p}_{\mathrm{t}, \mathrm{c}}{ }^{\mathrm{k}}$ and $\mathrm{q}_{\mathrm{t}, \mathrm{c}}{ }^{\mathrm{k}}$ into the expressions in equation (2.23), consistent estimators of $\pi$ and $\sigma$ are (Husted, 1991):

$$
I_{t, c}^{k}=\frac{\left[p_{t, c}^{k}+q_{t, c}^{k}\right]}{\sqrt{2}}, \quad n_{t, c}^{k}=\frac{\left[p_{t, c}^{k}+q_{t, c}^{k}\right]}{\sqrt{2}}
$$

Since the estimators differ from the true $\pi$ and $\sigma$ by a random disturbance, equation (2.26) is expressed as:

$$
\log \left(n_{t, c}^{k}=a^{\prime}+\alpha \log \left(I_{t, c}^{k}\right)+\beta \log \left(\sqrt{2}-I_{t, c}^{k}\right)+\varepsilon_{1}\right.
$$

Finally, after substituting $\mathrm{p}_{\mathrm{t}, \mathrm{c}}{ }^{\mathrm{k}}$ and $\mathrm{q}_{\mathrm{t}, \mathrm{c}}{ }^{\mathrm{k}}$ for $\pi$ and $\sigma$, equation (2.27) becomes

$$
\frac{\left(\mu_{t, c}-y_{k}\right)}{\left(\mu_{t, c}-y_{k}\right)} \frac{\left(\sqrt{2} I_{t, c}^{k}\right)}{n_{t, c}^{k}}=\alpha\left(\sqrt{2}-I_{t, c}^{k}\right)-\beta\left(I_{t, c}^{k}\right)+\varepsilon 1
$$

A joint generalized least square (GLS) estimation of the proposed Lorenz curve in the equation (2.30) and its restrictions in equation (2.31) is carried out for state level grouped pre-tax family income data (Husted, 1991). This estimation is more efficient than ordinary least squares estimation 
of the Lorenz curve parameters in equation (2.29). With the estimated coefficients from the GLS estimation - a, $\alpha$, and $\beta$, the Gini coefficient can be calculated. The Gini coefficient for each state derived from the Lorenz curve in equation (2.29) is (Husted, 1991):

$$
G=2 a(\sqrt{2})^{1+\alpha+\beta} \beta(1+\alpha, 1+\beta)
$$

where $\beta(1+\alpha, 1+\beta)$ is the beta function, with $1+\alpha$ and $1+\beta$ degrees of freedom.

The calculated state level Gini coefficients for family income from 1981 to 1987 reflect the increasing inequality observed in the United States during the 1980s (Husted, 1991). This measure also indicates significant differences in the growth of family income inequality across states. Although the paper did not explore the exact cause of these differences, they reflect, in part, the uneven incidence of the state level economic restructuring, from high and middle wage manufacturing, construction, and mining sectors to the low wage service and trade sectors (Husted, 1991).

To explain the drawbacks to Gini measurements, Braun (1988) re-examined the direct relationship between income inequality (as measured by a variety of indices, including the Gini ratio) and development or economic improvement (as measured by several independent variables, including mean income). A corollary hypothesis suggested by Braun is that the original relationships may not be present when other measurements of income inequality are employed, both because of their differing sensitivities and because these alternate techniques are measuring substantively different types of income inequality. Growing evidence shows that the Gini ratio has serious weaknesses (Braun, 1988). The simple aging of a population will increase inequality (Morgan, 1962). Although Paglin (1975) introduced a modification to correct for this bias, it has 
not been widely adopted in subsequent research. A popular method of computing Gini scores utilizes census income categories, frequently with the adjustment using a Pareto curve for the openended interval at the top (Knott, 1970). Employing the Pareto curve is not always done, however, which can lead to inconsistent comparisons. It has been shown that the Gini coefficient will be reduced to the degree that the number of income intervals also declines (Sale, 1974). Income intervals differ from one census to another, with 14 in 1950, 13 in 1960, 15 in 1970, and 9 in 1980.

The Gini coefficient is also insensitive to non-money income components and differential price indices between states, which exaggerate income inequalities in rural area (Jonish and Kau, 1973). Bud (1973) finds a tendency toward error for researchers making comparisons between various dates. Additionally, the Gini coefficient is more responsive to changes in income of the middle class than to changes among the rich or the poor (Osberg, 1984; Allison, 1978). This is perhaps why Gini scores show such stability over long periods of time in the United States (Braun, 1987). One study of Wisconsin income data (Soltow, 1971) shows no great change in Gini scores over 100 years. Reynolds and Smolensky (1977) find that despite major changes in taxation and welfare in the 1950-1970 period, inequality is virtually unchanged as measured by Gini ratios. A serious problem also results when Lorenz curves intersect as countries are compared (Allison, 1978). Schwarz and Winship's (1979) re-examination of Kuznets' data concludes that of 66 possible pairs of comparisons between countries, in only 16 comparisons is it possible to use Lorenz-based Gini scores to discover which country unequivocally has the most unequal distribution of income (Braun, 1988).

\subsubsection{Stochastic Dominance}

Until relatively recently, the conventional view in economics was that the size distribution 
of income does not change very much across time (Bishop and Formby, 1994). Dominance techniques for ranking entire distributions stand at the forefront of these developments. If two income distributions differ, which one is better? If two growth processes distribute the benefits of economic growth differently, which is better? The dominance method can be used to address both of this questions. If we are interested in comparing two multi-variance distributions, represented by the (continuous) cumulative distribution functions $\mathrm{F}(\mathrm{x})$ and $\mathrm{F}^{*}(\mathrm{x})$, where $\mathrm{x}$ is a vector of random variables. It is assumed that the comparison is based on the difference in expected utility (Atkinson, 1983):

$$
\Delta W=\int U(x) d F-\int U(x) d F^{*}
$$

Where expected utility is assumed to be well-defined. One distribution, F, is said to stochastically dominate the other, $\mathrm{F}^{*}$, for a specific class of utility functions when $\Delta \mathrm{W}$ is non-negative for all $\mathrm{U} \in U$ and is strictly positive for some $\mathrm{U}$ (Atkinson, 1983). The condition for $\mathrm{F}$ to dominate $\mathrm{F}^{*}$ becomes progressively weaker as one strengthens the conditions on the class $U$.

The dominance method of evaluating income distributions is very general and can be applied to investigate income inequality, economic efficiency, and changes in the overall status of welfare in an economic system. It can also be applied to evaluate the distribution of the benefits of economic growth across time. Recent empirical studies based on the dominance principle are indicative of the applicability of the methodology to the study of statistical distributions in general. Examples where dominance methodology is used to evaluate a variety of issues are changes in the U.S. income distribution across time (Bishop, Formby and Smith, 1991a; Bishop, Chow and Formby, 1991a); the convergence and divergence of U.S. regional income distribution in the 1970s (Bishop, Formby and 
Thistle, 1992a,b); the effects of growth and recessions on poverty (Bishop, Chow and Formby, 1991a); international differences in income distribution (Bishop, Formby and Smith, 1991b, 1993; Bishop, Formby and Sakano, 1992a); the effects of tax evasion on the distribution of income and tax burdens (Bishop ,Chow and Formby, 1991b; Bishop, Chow, Formby, and Ho, 1993); the effects of the U.S. Food Stamp program on under nutrition (Bishop, Formby and Zeager, 1992b); and differences in mortality distributions and the problem of "missing women" in major regions of the LDC world (Bishop, Formby and Zeager, 1992a).

According to Bishop and Formby (1994), the appeal of the dominance approach is traceable to three distinct but related features of the methodology. First, it rests upon explicit welfare criteria that are widely acceptable and which rank the distributions of interest using a series of steps, or stages, that are referred to as first, second, and third degree dominance. If two distributions can be ranked, any two researchers or policy makers are likely to be in general agreement concerning which of the distributions is best. Second, new statistical inference procedures developed over the last decade have substantially expanded the capacity of the dominance method to rank income distributions and evaluate comparative levels of welfare. As a consequence, studies of income distribution need no longer rely on descriptive statistics, but can make use of explicit tests of hypothesis. The dominance method relies on ordinal measures of entire distributions and levels of welfare, while avoiding the use of index numbers that rest on a dubious assumption of cardinality. If two income distributions differ, which is "better"? If two growth processes distribute the benefits of economic growth differently, which is better? The dominance method can be used to answer both of these questions. Important theoretical contributions by Atkinson (1970), Shorrocks (1983), and Saposnick (1981, 1983) establish a powerful relationship between the dominance of one 
income distribution over another and ordinal level of welfare. Foster and Skorrocks (1988) extend the theory to show an equally powerful relation between dominance of income distribution and poverty. New statistical inference procedures pioneered by Beach and Davidson (1983) complement the theoretical developments by permitting the dominance relationship between income distributions to be subjected to rigorous hypothesis testing.

Atkinson (1970) demonstrates that, for distributions with equal means, strong inferences can be made about comparative states of economic welfare when one Lorenz curve dominates another. As emphasized by Sen (1973), when the mean of the distributions of interest are unequal, the Lorenz dominance principle is devoid of welfare content. In related but distinct ways, Shorrocks (1983) and Saposnik $(1981,1983)$ extended the dominance approach to consider distributions with unequal means. Shorrocks demonstrates that Lorenz curves can be re-scaled by the mean of the distribution and dominance comparison can be made in the same fashion as with ordinary Lorenz curves. Shorrocks refers to this re-scaled Lorenz curve as the Generalized Lorenz curve. Like dominance in terms of ordinary Lorenz, GL dominance incorporates a preference for equality; but unlike the Lorenz curve, the GL curve also incorporates an efficiency preference (Bishop and Formby, 1994). Saposnik $(1981,1983)$ adopts a more straightforward approach and applies first order dominance techniques directly to income distributions. The criterion compares absolute income in ranked positions in the income distribution and is referred as "rank dominance" (Bishop and Formby, 1994). It is well established that first order dominance implies second order dominance; as a result rank dominance implies GL dominance. Further, a first order dominance is a pure efficiency criterion and, unlike second order dominance, does not contain a preference for equity (Bishop, Formby and Smith, 1991a) 
Several sources of micro data have been analyzed and some of the findings from the analysis of CPS, Public Use Samples of the decennial Census of Populations are summarized below. The Internal Revenue Service's Tax payer Compliance Measurement Program (TCMP) and the Luxembourg Income Study are two such studies. Perhaps the most dramatic change uncovered using inferences based dominance analysis is the rise in U.S. income inequality in the period following 1978. Bishop, Formby and Smith (1991a) analyze the period 1967-1986 and present statistics that identify the sub-periods: 1967-1977, 1978-1982 and 1983-1986. Their results reveal a significant rise in inequality between 1978 and 1982 which they describe as "massive". Before 1978, there were several statistically significant changes in U.S. Lorenz curves, which were associated with cyclical swings in the economy (Bishop and Formby, 1994). Consistent with earlier findings of Beach (1977) and Blinder and Esaki (1978), inequality rose in recession years and declined in years of recovery. But beginning 1978, the shifts in Lorenz curves were different; inequality began to rise well before any recession, the changes were quite large by historical standards, and there were no reverse movements toward equality during the period of recovery (Bishop, Formby and Smith, 1991a). In fact, inequality rose slightly between 1982 and 1986. Further, a more recent study (Bishop, Chiou and Formby, 1992) extends the Lorenz dominance analysis to 1989 and finds that inequality continued to rise in the late 1980s.

The second dramatic change in U.S. income distributions revealed by inference-based dominance analysis involves convergence of regional income distributions in the 1970s (Bishop, Formby and Thistle, 1992a,b). The U.S. south historically had both lower absolute incomes and greater inequality than the Non-South. Bishop, Formby and Thistle (1992a) apply the dominance methodology to Public Use Samples from the 1970 and 1980 decennial censuses and show that, as 
expected, the South was unambiguously dominated in 1969. However, the evidence reveals extraordinary changes in the 1970s. Lorenz curves, first order dominance and second order dominance all indicate that the south's income distribution either converged or almost converged to that of the Non-South (Bishop and Formby, 1994).

The third dramatic result from inference-based dominance analysis comes from a follow-up study of U.S. regional income distribution. Bishop, Formby and Thistle (1992b) disaggregate the Non-South into its major sub-regions consisting of the West, Midwest, and Northeast and apply the same methodology used to show the convergence of the South to Non-South. Income distributions in the major regions of the Non-South were equivalent in 1969 and the South was uniformly dominated by all other regions. Bishop and Formby (1994) further point out that fundamental changes in the 1970s resulted in the West's rank dominating the Midwest, which dominated the South, which in turn dominated the Northeast. Thus, while the South's income distribution was converging to the Non-South, the West, Northeast and Midwest income distributions were significantly diverging from one another (Bishop, Formby and Thistle, 1992a,b).

The fourth dramatic result uncovered using inference-based dominance analysis relates to the effects of tax evasion on the U.S. distribution of income and tax burdens. Bishop, Chow and Formby (1991b) and Bishop, Chow, Formby, and Ho (1993) use the internal revenue service TCMP micro data to analyze the effects of tax evasion on the Lorenz and associated concentration curves of income and tax burdens. Confidential TCMP data consisting of weighted samples of approximately 50,000 tax payers were analyzed for 1979, 1982, and 1985 Bishop, Chow and Formby,1991b; Bishop, Chow, Formby, and Ho, 1993). According to Bishop, Chow and Formby (1991b); Bishop, Chow, Formby and HO (1993) the results reveal a surprising but consistent 
pattern; lower income tax-paying units under report a larger percentage of their incomes than higher income tax-paying units and pay proportionally less tax than required under the Internal Revenue Code (IRC). Stated differently, higher income receiving units have smaller shares of after-tax income and pay larger shares of the income tax burden before the TCMP audits than they do after random audits and compulsory compliance with the IRS (Bishop, Chow and Formby,1991b; Bishop, Chow, Formby, and Ho, 1993).

The dominance technique is a general method that can be applied to evaluate income inequality, economic efficiency, and changes in the overall level of welfare in an economic system. This methodology has been used by many economists to address a variety of issues related to income, welfare and economics in general. The dominance technique remains one of the widely used methodologies.

\subsubsection{An Income-Net Worth Approach}

The income - net worth measure is based on the assumption that current income and current net worth are both important determinants, although not the sole determinants, of the economic position of a consumer. An individual's economic well-being should be thought of as a function of the flow of services over which he or she has command. This flow depends importantly on the consumer's current income and also on the services received from his or her assets, net of liabilities (Moon, 1977; Weisbrod and Hansen, 1977).

Weisbrod and Hansen used data from the Survey of Financial Characteristics of Consumers (SFCC) and the Current Population Survey (CPS) for 1962 to measure well-being or economic inequality in the United States. The SFCC provides data on families by age of head, income, and net worth; the CPS provides data on family income by age of head, broken down into finer income 
classes. As Weisbrod and Hansen pointed out, the income-net worth approach while incomplete as a measure of economic welfare, has a number of useful attributes, the major one being that of merging two separate but obviously related measures of economic status into a unified measure. The most striking result is its impact on the economic position of the aged, who by this measure appear to be considerably better-off than is shown by the current income measure (Weisbrod and Hansen, 1977). This results from the interaction of income, net worth holdings, and life expectancy. The authors suggest that the income-net worth measure may be useful as a basis for redefining tax progressivity, and as explanatory variable in consumption behavior theory.

An empirical study by Moon (1977) also used the income-net worth approach to measure the economic well-being of the aged poor. To derive an empirical approximation of the potential consumption measure, she makes several adjustments to the annual money income indicator of economic status. These adjustments include an imputation for net worth including home equity, the addition of an estimate of the cash value of three in-kind transfers -- medicare, medicaid, and public housing -- the subtraction of an estimate of income and payroll taxes paid and the addition of an estimate of intra-family transfers. Moon then examines how the rankings of several groups of the aged vary with the definition of economic status that she employs. She discovers, for example, that relative to the annual money income measure, her more comprehensive measure of economic status places an even larger proportion of families headed by nonwhites in the bottom part of the distribution of economic well-being. An unexpected finding is that more aged families with workers fall into the bottom part of the distribution when the more comprehensive measure of economic status is used.

Finally, Moon employs her more comprehensive definition of economic well-being to 
examine the impact of government programs on the well-being of the aged. Five cash transfer programs are examined: social security, public assistance, government pensions, veterans' benefits, unemployment insurance, and workmen's compensation; also included are three in-kind transfer programs (medicare, medicaid, and public housing) and three income tax provisions (the double personal exemption, exclusion of transfer income, and the retirement tax credit). Moon discovered that government pensions, workmen's compensation, and unemployment benefits do provide substantial benefits to some aged families. Social security and medicare provide almost universal coverage for the aged but are a very inefficient way of helping those at the lower end of both distributions. The study also revealed that the income-conditioned transfers which provide the greatest share of benefits to aged families with the lowest resource level are none-the-less of limited help to this group. On the tax expenditure Moon writes that it is the most inefficient means for directing resources towards the aged poor.

In addition to the above methods of measuring income distribution, there are numerous other ways of measuring inequality. A large number of books and articles have articulated this issue to the point of saturation. What is being questioned is the level of precision of these studies and their methodological approach. The need for the development of a better approach to measure the wellbeingness of families has become a hot topic in welfare economics.

\subsection{The Contributions of this Research}

The empirical results from this research will be used as indicators of economic well-being and will provide a better understanding for formulating public policy. The results are also expected to shed light on the impacts of relative price changes and the impacts of household composition on the patterns of distribution of household consumption expenditures. An examination of inequality 
at a desegregated level will reveal that most of the level and trends of the consumption-based measure can be explained by within group movements rather than inequality between groups. This is true for households expenditures classified by commodity components, age, and race. A greater effort will be devoted in summarizing the results and rationalizing the implications.

The theoretical and empirical background included in this study will definitely consolidate and expand the dimension of the literature (knowledge) concerning this topic and the issue of welfare measurement in general. The use of combined time series and cross sectional data may reveal some interesting results in the measurement of the impact of demographic attributes on the distribution of consumption expenditures. This is a major contribution expected from of this research. The empirical results of this study should also enable comparison of the inequality in the distribution of consumption expenditure among the years between 1980 and 1994. 


\section{CHAPTER 3: THEORETICAL FRAMEWORK}

\subsection{Introduction}

This chapter addresses the conceptual and methodological framework based on a remarkable convergence that has occurred between economic theory and econometrics over the past decade (Jorgensen et al., 1982). This convergence has taken place between the theory of social choice and econometric modeling of aggregate consumer behavior. The result of this phenomenon has produced a new approach to normative economics. This new approach has been implemented to test and evaluate economic policies, measure poverty and inequality, and assess the standard of living and its cost.

The following sections will be presented in this chapter: In section 3.2 aggregate consumer behavior is derived based on the theory of exact aggregation, following Jorgensen $(1980,1981,1982$, 1984); conclusions and a summary of the theoretical framework are given in section 3.3; section 3.4 presents methods for examining inequality in the distribution of consumption expenditures.

\subsection{Aggregate Consumer Behavior}

According to Jorgensen et al. (1982), a common problem in modeling consumer behavior and social choice is the representation of individual preferences. Simplification of the aggregate demand function is necessary for econometric modeling of aggregate consumer behavior. The simplest and most familiar approach to this problem is the technique of a representative consumer (Jorgensen et al., 1982). This model is required to justify applications of the theory of individual consumer behavior to aggregate data on prices and quantities consumed. The model is based on the assumption of identical homothetic preferences for all individuals.

Under identical homothetic preferences, aggregate quantities consumed are functions of 
aggregate expenditure and prices. The functions exhibit the same properties as demand functions in the theory of individual consumer behavior. The conditions for identical homothetic preferences was weakened by Gorman (1953) to permit displacements from the origin. Gorman showed that a necessary and sufficient condition for aggregate demand functions to depend on aggregate expenditure is that all individuals must have parallel linear Engle curves. This condition has been used many times in modeling aggregate consumer behavior.

In 1975, Muelbauer significantly broadened Gorman's definition of the concept of a representative consumer and constructed a model of a representative consumer where individual preferences are assumed to be identical, but not necessarily homothetic. Aggregate expenditure shares depend on prices and a function of the distribution of individual expenditures that is not restricted to aggregate expenditures. A model developed by Lau (1977b), however, does not require the concept of a representative consumer. Aggregate demand functions are obtained by exact aggregation over individual demand functions. The model incorporates differences in individual preferences into demand functions through attributes of individuals such as demographic characteristics. Aggregate demand functions depend on the joint distribution of attributes and total expenditure over all consuming units through summary statistics of the distribution. Jorgensen et al., (1982) point out that within the framework provided by Lau (1977b) and Muellbauer (1975), the assumption of identical homothetic preferences for all individuals appears as a highly oversimplified approach to modeling aggregate consumer behavior. Homethetic preferences are inconsistent with well established empirical regularities in the behavior of individual consumers (Jorgensen and Slesnick, 1984). Besides, identical preferences are inconsistent with empirical findings that expenditure patterns depend on the demographic characteristics of consumers, among 
other factors.

This framework to the measurement of welfare inequality is based on the an econometric model of aggregate consumer behavior. The advantage of this approach is that systems of individual demand functions can be obtained from the system of aggregate demand functions. Based on that demand function being integrable, one can recover the indirect utility functions for all consumers. Measures of individual welfare can be defined in terms of these utility functions.

To represent preferences for all individuals in a form suitable for measuring individual welfare, households are taken as a consuming unit. It is assumed that expenditures on individual commodities are allocated so as to maximize a household's welfare function. As a consequence, the household behaves in the same way as an individual maximizing a utility function, as demonstrated by Samuelson (1956) and Pollak (1981). By assuming that each household maximizes a household welfare function, the focus can be on the distribution of welfare among households rather than the distribution among individuals within households.

To construct an econometric model based on exact aggregation, individual preferences are represented by means of an indirect utility function for each consuming unit, using the following notation (Jorgenson and Slesnick, 1984):

$\mathrm{p}_{\mathrm{n}}$ is the price of the $\mathrm{n}^{\text {th }}$ commodity, assumed to be the same for all consuming units. $\mathrm{p}=\left(\mathrm{p}_{1}, \mathrm{p}_{2}, \ldots . ., \mathrm{p}_{\mathrm{N}}\right)$ is the vector of prices of all commodities, $\mathrm{x}_{\mathrm{nk}}$ is the quantity of the $\mathrm{n}^{\text {th }}$ commodity group consumed by the $\mathrm{k}^{\text {th }}$ consuming unit $(\mathrm{n}=1,2, \ldots \ldots ., \mathrm{N} ; \mathrm{k}=1,2, \ldots \ldots ., \mathrm{K})$, $\mathrm{M}_{\mathrm{k}}=\sum_{\mathrm{n}=1} \mathrm{~N}_{\mathrm{n}} \mathrm{p}_{\mathrm{nk}}$ to the total expenditure of the $\mathrm{k}^{\text {th }}$ consuming unit $\quad(\mathrm{k}=1,2, \ldots \ldots, \mathrm{K})$, $\mathrm{w}_{\mathrm{nk}}=\mathrm{p}_{\mathrm{n}} \mathrm{x}_{\mathrm{nk}} / \mathrm{M}_{\mathrm{k}}$ is the expenditure share of the $\mathrm{n}^{\text {th }}$ commodity group in the budget of the $\mathrm{k}^{\text {th }}$ 
consuming unit $(\mathrm{n}=1,2, \ldots \ldots ., \mathrm{N} ; \mathrm{k}=1,2, \ldots \ldots \ldots, \mathrm{K})$,

$\mathrm{w}_{\mathrm{k}}=\left(\mathrm{w}_{1 \mathrm{k}}, \mathrm{w}_{2 \mathrm{k}}, \ldots \ldots . ., \mathrm{w}_{\mathrm{Nk}}\right)$ is the vector of expenditure shares for the $\mathrm{k}^{\text {th }}$ consuming unit, $(\mathrm{k}=1,2, \ldots \ldots, \mathrm{K})$,

$$
\ln \frac{p}{M_{k}}=\left(\ln \frac{p_{1}}{M_{k}}, \ln \frac{p_{2}}{M_{k}}, \ldots \ldots . ., \ln \frac{p_{N}}{M_{k}}\right),
$$

is the vector of logarithms of ratios of prices to expenditure by the $\mathrm{k}^{\text {th }}$ consuming unit $(\mathrm{k}=$ $1,2, \ldots . ., \mathrm{K})$

$\ln \mathrm{p}=\left(\ln \mathrm{p}_{1}, \ln \mathrm{p}_{2}, \ldots \ldots, \ln \mathrm{p}_{\mathrm{N}}\right)$ is the vector of logarithms of prices, and

$A_{k}$ is the vector of attributes of the $k^{\text {th }}$ unit $(k=1,2, \ldots ., K)$.

It is assumed that the $\mathrm{k}^{\text {th }}$ consuming unit allocates expenditures in accord with the transcendental logarithmic or translog indirect utility function, say $\mathrm{V}_{\mathrm{k}}$, where:

$$
\begin{gathered}
\ln V_{k}=G\left(\ln \frac{p^{\prime}}{M_{k}} \alpha_{p}+\frac{1}{2} \ln \frac{p^{\prime}}{M_{k}} \beta_{p p} \ln \frac{p^{\prime}}{M_{k}} \beta_{p a} A_{k}, A_{k}\right) \\
(k=1,2, \ldots, K)
\end{gathered}
$$

In this representation, the function $\mathrm{G}$ is a monotone increasing function of the variable:

$$
\ln \frac{p^{\prime}}{M_{k}} \alpha_{p}+\frac{1}{2} \ln \frac{p^{\prime}}{M_{k}} \beta_{p p} \ln \frac{p}{M_{k}}+\ln \frac{p^{\prime}}{M_{k}} \beta_{p A} A_{k}
$$

In addition, the function $G$ depends directly on the attribute vector $A_{k}$. The vector $\alpha_{p}$ and the matrices $\beta_{\mathrm{pp}}$ and $\beta_{\mathrm{pA}}$ are constant parameters that are the same for all consuming units.

The expenditure shares of the $\mathrm{k}^{\text {th }}$ consuming unit can be derived by the logarithmic form of 
Roy's (1943) identity:

$$
\begin{aligned}
w_{n k}= & \frac{\partial \ln V_{k}}{\partial \ln \left(p_{n} / M_{k}\right)} / \sum_{n=1}^{N} \frac{\partial \ln V_{k}}{\partial \ln \left(p_{n} / M_{k}\right)} \\
(n=1,2, \ldots \ldots, N ; \quad k=1,2, \ldots \ldots ., K) &
\end{aligned}
$$

Applying this identity to translog indirect utility function (3.1), the system of individual expenditure shares is obtained:

$$
w_{k}=\frac{1}{D_{k}(p)}\left(\alpha_{p}+\beta_{p p} \ln \frac{p}{M_{k}}+\beta_{p A} A_{k}\right), \quad(k=1,2, \ldots \ldots, K)
$$

Where the denominators $\left\{D_{k}\right\}$ take the form:

$$
D_{k}=i^{\prime} \alpha_{p}+i^{\prime} \beta_{p p} \ln \frac{p}{M_{k}}+i^{\prime} \beta_{p A} A_{k}, \quad(k=1,2, \ldots . ., K) .
$$

The individual expenditure shares are homogeneous of degree zero in the unknown parameters $\alpha_{\mathrm{p}}, \beta_{\mathrm{pp}}, \beta_{\mathrm{pA}}$. By multiplying a given set of these parameters by a constant, another set of parameters that generates the same system of individual budget shares is obtained. Accordingly, we can choose a normalization for the parameters without affecting observed patterns of individual expenditure allocation. The normalization is applied as:

$$
\text { i' } \alpha_{\mathrm{p}}=-1
$$

Under this restriction any change in the set of unknown parameters will be reflected in changes in individual expenditure patterns. 
The conditions for exact aggregation are that the individual expenditure shares are linear in functions of the attributes $\left\{A_{k}\right\}$ and total expenditures $\left\{M_{k}\right\}$ for all consuming units. These conditions will be satisfied if and only if the terms involving the attributes and expenditures do not appear in the denominators of the expressions given above for the individual expenditure shares, so that:

$$
\begin{aligned}
& i^{\prime} \beta_{p p} i=0 \\
& i^{\prime} \beta_{p A}=0
\end{aligned}
$$

The exact aggregation restrictions imply that the denominators $\left\{D_{k}\right\}$ reduce to:

$$
D=-1+i^{\prime} \beta_{p p} \ln p
$$

Where the subscript $\mathrm{k}$ is no longer required, since the denominator is the same for all consuming units. Under these restrictions the individual expenditure shares can be written as:

$$
\begin{gathered}
w_{k}=\frac{1}{D(p)}\left(\alpha_{p}+\beta_{p p} \ln p-\beta_{p p} i \cdot \ln M_{k}+\beta_{p A} A_{k}\right), \\
(k=1,2, \ldots \ldots \ldots, K) .
\end{gathered}
$$

The individual expenditure shares are linear in the logarithms of expenditures $\left\{\ln \mathrm{M}_{\mathrm{k}}\right\}$ and in the attributes $\left\{A_{k}\right\}$, as required for exact aggregation.

Under exact aggregation the indirect utility function for each consuming unit can be represented by the form: 


$$
\begin{gathered}
\ln V_{k}=F\left(A_{k}\right)+\ln p^{\prime}\left(\alpha_{p}+\frac{1}{2} \beta_{p p} \ln p+\beta_{p A} A_{k}\right)-D(p) \ln M_{k} \\
(k=1,2, \ldots \ldots \ldots \ldots \ldots \ldots \ldots ., K)
\end{gathered}
$$

In this representation the indirect utility function is linear in the logarithm of total expenditures (ln $\mathrm{M}_{\mathrm{k}}$ ) with a coefficient that depends on the prices $\mathrm{p}(\mathrm{k}=1,2, \ldots \ldots ., \mathrm{K})$. This property is invariant with respect to positive affine transformations, but is not preserved by arbitrary monotone increasing transformations. It is concluded that the indirect utility function (3.10) provides a cardinal measure of utility for each consuming unit.

To provide a basis for evaluating the impact of transfers among households on social welfare, it is useful to represent household preferences by means of a utility function that is the same for all accounting units. For this purpose, it is assumed that the $\mathrm{k}^{\text {th }}$ consuming unit maximizes its utility, say $\mathrm{U}_{\mathrm{k}}$, where:

$$
\begin{gathered}
U_{k}=U\left[\frac{x_{1 k}}{m_{1}\left(A_{k}\right)}, \frac{x_{2 k}}{m_{2}\left(A_{k}\right)}, \ldots \ldots, \frac{x_{N k}}{m_{N}\left(A_{k}\right)}\right], \\
(k=1,2, \ldots \ldots \ldots \ldots, K),
\end{gathered}
$$

subject to the budget constraint

$$
M_{k}=\sum_{n=1}^{N} p_{n} x_{n k}, \quad(k=1,2, \ldots \ldots, K)
$$

In this representation of consumer preferences, the quantities $\left\{\mathrm{x}_{\mathrm{nk}} / \mathrm{m}_{\mathrm{n}}\left(\mathrm{A}_{\mathrm{k}}\right)\right\}$ can be regarded as effective quantities consumed, as proposed by Barten (1964). The crucial assumption embodied in this representation is that differences in preferences among consumers enter the utility function $\mathrm{U}$ 
only through differences in the commodity specific household equivalence scales $\left\{m_{k}\left(A_{k}\right)\right\}$.

Consumer equilibrium implies the existence of an indirect utility function, say $\mathrm{V}$, that is the same for all consuming units. The level of utility for the $\mathrm{k}^{\text {th }}$ consuming unit, say $\mathrm{V}_{\mathrm{k}}$, depends on the prices of individual commodities, the household equivalence scales, and the level of total expenditure:

$$
\begin{gathered}
V_{k}=V\left[\frac{p_{1} m_{1}\left(A_{k}\right)}{M_{k}}, \frac{p_{2} m_{2}\left(A_{k}\right)}{M_{k}}, \ldots \ldots \ldots, \frac{p_{N} m_{N}\left(A_{k}\right)}{M_{k}}\right], \\
(k=1,2, \ldots \ldots \ldots \ldots \ldots ., K) .
\end{gathered}
$$

In this representation the prices $\left\{\mathrm{p}_{\mathrm{n}} \mathrm{m}_{\mathrm{n}}\left(\mathrm{A}_{\mathrm{k}}\right)\right\}$ can be regarded as effective prices. Differences in preferences among consuming units enter this indirect utility function only through the household equivalence scales $\left\{\mathrm{m}_{\mathrm{n}}\left(\mathrm{A}_{\mathrm{k}}\right)\right\}(\mathrm{k}=1,2, \ldots \ldots \ldots .$,$) .$

To represent the translog indirect utility function (3.2) in terms of household equivalence scales, Jorgenson and Slesnick (1984) used some additional notations:

$\ln \operatorname{pm}\left(A_{k}\right) / M_{k}$ is the vector of logarithms of ratios of effective prices $\left\{p_{n} m_{n}\left(A_{k}\right)\right\}$ to total expenditure $\mathrm{M}_{\mathrm{k}}$ of the $\mathrm{k}^{\text {th }}$ consuming unit $(\mathrm{k}=1,2, \ldots \ldots, \mathrm{K})$, and

$\ln m\left(A_{k}\right)=\left(\ln m_{1}\left(A_{k}\right), \ln m_{2}\left(A_{k}\right), \ldots \ldots \ldots ., \ln m_{N}\left(A_{k}\right)\right.$ is the vector of logarithms of the household equivalence scales of the $\mathrm{k}^{\text {th }}$ consuming unit $(\mathrm{k}=1,2, \ldots \ldots \ldots, \mathrm{K})$.

It is assumed, as before, that the $\mathrm{k}^{\text {th }}$ consuming unit allocates its expenditures in accord with the translog indirect utility function (3.2). However, it is assumed that this function, expressed in terms of the effective prices $\left\{p_{n} m_{n}\left(A_{k}\right)\right\}$ and total expenditures $M_{k}$, is the same for all consuming units. The indirect utility function takes the form: 


$$
\begin{gathered}
\ln V_{k}=\left[\ln \frac{p m\left(A_{k}\right)^{\prime}}{M_{k}} \alpha_{p}+\frac{1}{2} \ln \frac{p m\left(A_{k}\right)^{\prime}}{M_{k}} \beta_{p p} \ln \frac{p m\left(A_{k}\right)}{m_{k}}\right], \\
(k=1,2, \ldots \ldots \ldots \ldots ., K) .
\end{gathered}
$$

Taking logarithms of the effective prices $\left\{\mathrm{p}_{\mathrm{n}} \mathrm{m}_{\mathrm{n}}\left(\mathrm{A}_{\mathrm{k}}\right)\right\}$, the indirect utility function (3.14) can be rewritten in the form:

$$
\begin{gathered}
\ln V_{k}=\ln m\left(A_{k}\right)^{\prime} \alpha_{p}+\frac{1}{2} \ln m\left(A_{k}\right)^{\prime} \beta_{p p} \ln m\left(A_{k}\right)+\ln \frac{p^{\prime}}{M_{k}} \alpha_{p} \\
+\frac{1}{2} \ln \frac{p^{\prime}}{m_{k}} \beta_{p p} \ln \frac{p}{M_{k}}+\ln \frac{p^{\prime}}{M_{k}} \beta_{p p} \ln m\left(A_{k}\right), \\
(k=1,2, \ldots \ldots \ldots \ldots ., K) .
\end{gathered}
$$

Comparing the representation (3.10) with the representation (3.15), we can see that the term involving only the household equivalent scales must take the form:

$$
\begin{gathered}
F\left(A_{k}\right)=\ln m\left(A_{k}\right)^{\prime} \alpha_{p}+\frac{1}{2} \ln m\left(A_{k}\right)^{\prime} \beta_{p p} \ln m\left(A_{k}\right), \\
(k=1,2, \ldots \ldots \ldots \ldots \ldots, K)
\end{gathered}
$$

Second, the term involving ratios of prices to total expenditure and the household equivalence scales must satisfy:

$$
\begin{array}{r}
\ln \frac{p^{\prime}}{M_{k}} \beta_{p p} A_{k}=\ln \frac{p^{\prime}}{M_{k}} \beta_{p p} \ln m\left(A_{k}\right), \\
(k=1,2, \ldots \ldots \ldots \ldots \ldots \ldots, K),
\end{array}
$$

for all prices and total expenditure.

The household equivalence scales $\left\{m_{n}\left(A_{k}\right)\right\}$ defined by (3.17) must satisfy the equation:

$$
\beta_{p A} A_{k}=\beta_{p p} \ln m\left(A_{k}\right), \quad(k=1,2, \ldots \ldots ., K)
$$


Under monotonicity of the individual expenditures shares the matrix $\beta_{\mathrm{pp}}$ has an inverse, so that we can express the household equivalence scales in terms of the parameters of the translog indirect utility function, $\beta_{\mathrm{pp}}, \beta_{\mathrm{pA}}$, and the attributes $\left\{\mathrm{A}_{\mathrm{k}}\right\}$ :

$$
\ln m\left(A_{k}\right)=\beta_{p p}^{-1} \beta_{p A} A_{k}, \quad(k=1,2, \ldots \ldots \ldots ., K) .
$$

These scales are referred to as the commodity specific translog household equivalence scales.

Substituting the commodity specific equivalence scales (3.18) into the indirect utility function (3.15) a representation of the indirect utility function can be obtained in terms of the attributes $\left\{A_{k}\right\}$ :

$$
\begin{gathered}
\ln V_{k}=A_{k}^{\prime} \beta_{p A}^{\prime} \beta_{p p}^{-1} \alpha_{p}+\frac{1}{2} A_{k}^{\prime} \beta_{p A} \beta_{p p}^{-1} \beta_{p A} A_{k}+\ln p^{\prime}\left(\alpha_{p}\right. \\
\left.+\frac{1}{2} \beta_{p p} \ln p+\beta_{p A} A_{k}\right)-D(p) \ln M_{k}, \\
(k=1,2, \ldots \ldots \ldots \ldots \ldots \ldots \ldots \ldots ., K) .
\end{gathered}
$$

This form of the translog indirect utility function is equivalent to the form (3.2) in that both generate the same system of individual demand functions. By requiring that the attributes $A_{k}$ enter only through the commodity specific household equivalence scales, the Jorgenson and Slesnick (1984) provided a specific form for the function $\mathrm{F}\left(\mathrm{A}_{\mathrm{k}}\right)$ in (3.10).

Given the indirect utility function (3.20) for each consuming unit, total expenditures can be expressed as a function of prices, consumer attributes, and the level of utility:

$$
\begin{gathered}
\ln M_{k}=\frac{1}{D(p)}\left[A_{k}^{\prime} \beta_{p A}^{\prime} \beta_{p p}^{-1} \alpha_{p}+\frac{1}{2} A_{k}^{\prime} \beta p A^{\prime} \beta p p^{-1} \beta_{p A} A_{k}\right. \\
\left.+\ln p^{\prime}\left(\alpha_{p}+\frac{1}{2} \beta_{p p} \ln p+\beta_{p A} A_{k}\right)-\ln V_{k}\right], \\
(k=1,2, \ldots \ldots \ldots \ldots \ldots \ldots \ldots . ., K) .
\end{gathered}
$$


We can refer to this function as the translog expenditure function. The translog expenditure function gives the minimum expenditures required for the $\mathrm{k}^{\text {th }}$ consuming unit to achieve the utility level $\mathrm{V}_{\mathrm{k}}$, given prices $\mathrm{p}(\mathrm{k}=1,2, \ldots \ldots \ldots, \mathrm{K})$.

Jorgenson and Slesnick (1984) also introduced household equivalence scales that are not specific to a given commodity. Equivalent scale is an index which deflates family income by a score that may be less than one for each extra member. Equivalent income for household equals observed income divided by the equivalence scale value for household of its type. Following Muellbauer (1974a), they defined a general household equivalence scale, say $\mathrm{m}_{0}$, as follows:

$$
m_{0}=\frac{M_{k}\left[p m\left(A_{k}\right), V_{k}^{0}\right]}{M_{0}\left(p, V_{k}^{0}\right)}, \quad(k=1,2, \ldots \ldots \ldots \ldots, K)
$$

Where $M_{k}$ is the expenditure function for the $\mathrm{k}^{\text {th }}$ household, $\mathrm{M}_{0}$ is the expenditure function for a reference household with commodity specific equivalence scales equal to unity for all commodities, and $\operatorname{pm}\left(\mathrm{A}_{\mathrm{k}}\right)$ is a vector of effective prices $\left\{\mathrm{p}_{\mathrm{n}} \mathrm{m}_{\mathrm{n}}\left(\mathrm{A}_{\mathrm{k}}\right)\right\}$.

The general household equivalence scale $\mathrm{m}_{0}$ is the ratio between total expenditures required by the $\mathrm{k}^{\text {th }}$ household and by the reference household for the same level of utility, $\mathrm{V}_{\mathrm{k}}{ }^{0}$ $(\mathrm{k}=1,2, \ldots \ldots \ldots \ldots \ldots \ldots \ldots \ldots, \mathrm{K})$. This scale can be interpreted as the number of household equivalence members. The number of members depends on the attributes $A_{k}$ of the consuming unit and on the prices $\mathrm{p}$.

If each household has a translog indirect utility function, then the general household equivalence scale for the $\mathrm{k}^{\text {th }}$ household takes the form: 


$$
\begin{aligned}
& \ln m_{0}=\ln M_{k}-M_{0} \\
& \frac{1}{D(p)}\left[\ln m\left(A_{k}\right)^{\prime} \alpha_{p}+\frac{1}{2} \ln m\left(A_{k}\right)^{\prime} \beta_{p p} \ln m\left(A_{k}\right)+\ln m\left(A_{k}\right)^{\prime}\right. \\
& \quad \\
& (k=1,2, \ldots \ldots \ldots \ldots . ., K) .
\end{aligned}
$$

We can refer to this scale as the general translog household equivalence scale. Given this general translog equivalence scale, the indirect utility function can be rewritten as:

$$
\begin{aligned}
\ln V_{k}=\ln p^{\prime}\left(\alpha_{p}+\right. & \frac{1}{2} \beta_{p p} \ln p-D(p) \ln \left[M_{k} / m_{0}\left(p, A_{k}\right)\right], \\
& (k=1,2, \ldots \ldots \ldots \ldots ., K) .
\end{aligned}
$$

The level of utility for the $\mathrm{k}^{\text {th }}$ consuming unit depends on prices $\mathrm{p}$ and total expenditure per household equivalent member $\mathrm{M}_{\mathrm{k}} / \mathrm{m}_{0}\left(\mathrm{p}, \mathrm{A}_{\mathrm{k}}\right)$. Also, the expenditure function can be rewritten as:

$$
\begin{aligned}
& \ln M_{k}=\frac{1}{D(p)}\left[\ln p^{\prime}\left(\alpha_{p}+\frac{1}{2} \beta_{p p} \ln p\right)-\ln V_{k}\right] \\
& +\ln m_{0}\left(p, A_{k}\right) \text {, } \\
& (k=1,2, \ldots \ldots \ldots \ldots . .,=K) \text {. }
\end{aligned}
$$

To construct an econometric model of aggregate consumer behavior based on exact aggregation, we obtain aggregate expenditure shares, say w, by multiplying individual expenditure shares (3.9) by expenditures for each consuming unit, adding over all consuming units, and dividing by aggregate expenditure, $\mathrm{M}=\sum_{\mathrm{k}=1}{ }^{\mathrm{K}} \mathrm{M}_{\mathrm{k}}$ :

$$
w=\frac{\sum M_{k} w_{k}}{M}
$$


The aggregate expenditure shares can be expressed as:

$$
w=\frac{1}{D(p)}\left(\alpha_{p}+\beta_{p p} \ln p-\beta_{p p} i \frac{\sum M_{k} \ln M_{k}}{M}+\beta_{p A} \frac{\sum M_{k} A_{k}}{M}\right)
$$

The aggregate expenditure patterns depend on the distribution of expenditures over all consumer units through summary statistics of the joint distribution of expenditures and attributes. Systems of individual expenditure shares (3.9) for consuming units with identical demographic characteristics can be recovered in one only one way from the system of aggregate expenditure share (3.23).

In estimating systems of demand equations many models have been proposed, but perhaps the most important apart from the translog model, are the linear expenditure system, the Rotterdam model and the Almost Ideal Demand System (AIDS). The AIDS is comparable to the Rotterdam and translog models and it has considerable advantages over both. The AIDS gives an arbitrary first-order approximation to any demand system; it satisfies the axiom of choice exactly; it aggregates perfectly over consumers without invoking parallel linear Engel curves; it has a functional form which is consistent with known household budget data; it is simple to estimate, largely avoiding the need for non-linear estimation; and it can be used to test the restrictions of homogeneity and symmetry through linear restrictions on fixed parameters (Deaton and Muellbauer, 1980). Many of these properties are possessed by one or other of the Rotterdam or translog models, neither possesses all of them simultaneously

\subsection{Summary of Theoretical Considerations}

In this section a model of aggregate consumer behavior based on transcendental logarithmic indirect utility functions for all consuming units is presented. These indirect utility functions 
incorporate restrictions on individual behavior that result from maximization of utility functions subject to budget constraints. Each individual consuming unit has an indirect utility function that is homogeneous of degree zero in prices and expenditures, non-increasing in prices and non-decreasing in expenditures. To include differences in individual preferences in the model of aggregate consumer behavior, we allow the indirect utility functions for all consuming units to depend on attributes, such as demographic characteristics, that vary among individual households.

Given a translog indirect utility function for each consuming unit, we derive the expenditure shares for that unit by using Roy's identity. This results in expenditure shares that can be expressed as ratios of two functions that are linear in the logarithms of ratios of prices for all commodities to total expenditure and attributes. The denominators of these ratios are functions that are the same for all commodity groups. Under exact aggregation the individual expenditure shares are linear in functions of attributes and total expenditures, so that the denominators are independent of total expenditures and attributes and are the same for all individuals.

Under the exact aggregation condition, the translog indirect utility function is additive in functions of the attributes and the total expenditures of the individual consuming unit and provides a cardinal measure of individual welfare as well as an ordinal measure. Based on the indirect utility function for each unit, we can explicitly solve for the expenditure function, giving the minimum expenditures required to achieve the stipulated level of the individual welfare for given prices.

The expenditure function and indirect utility function can be employed in examining the impacts of alternative economic policies on the welfare of the individual consuming unit. In fact, the concept of equivalent and compensating variations in expenditures can be empirically tested. The equivalent variation gives the additional or reduction in expenditures required to achieve the level of utility after 
the change in policy. The compensating variation gives the additional or reduction in expenditures to achieve required to achieve the level of utility before the change in policy, i.e., that which would exist if the change actually taken place.

To derive aggregate expenditure shares, we multiply the individual expenditure shares by total expenditures for each consuming unit, sum over all consuming units, and divide by aggregate expenditure. The aggregate expenditure shares, can be expressed as ratios of two functions. The denominators are the same as for individual expenditure shares. The numerators are linear in the logarithms of prices, in a statistic of the distribution of expenditures over all consuming units $\sum \mathrm{M}_{\mathrm{k}} \ln$ $\mathrm{M}_{\mathrm{k}} / \sum \mathrm{M}_{\mathrm{k}}$, and in the shares of all demographic groups in aggregate expenditures.

The individual expenditure shares are homogeneous of degree zero in prices and expenditures. Given the restrictions implied by exact aggregation, this implies an additional $\mathrm{N}$ - 1 restrictions on the parameters of the trans indirect utility functions, where $\mathrm{N}$ is the number of commodities. Second, the sum of individual expenditure shares over all commodity groups is equal to unity. Given the exact aggregation restrictions, there are $\mathrm{N}$ additional restrictions implied by summability. Third, the matrix of compensated own -- and cross - - price effects must be symmetric. The implication of this is that there are $1 / 2(\mathrm{~N}-1)$ restrictions on the parameters of the translog indirect utility functions.

Monotonicity of the indirect utility functions implies that the individual expenditure shares must be non-negative. The indirect utility function is quasi convex, which implies that the individual expenditure shares must be monotonic, or equivalently, that the matrix of compensated own -- and cross - price substitution effects must be non-positive definite. It is always possible to choose prices so that monotonicity of the indirect utility functions or non-negativity of the individual expenditure shares is violated. Accordingly, we consider restrictions that imply monotonicity of the expenditure 
shares wherever they are non-negative.

3.4 Inequality in the Distribution of Household Consumption Expenditure

Economic well-being can be defined in terms of the capability individuals or households have for potential consumption. Official income statistics are produced to reflect the consumption ability of individuals and families, with money income used to proxy this consumption potential most frequently. Garner (1993) pointed out that consumption may be a better measure of the actual economic welfare of a household than its current income. The value of consumption sometimes can be greater than annually reported income to the extent that households have accumulated savings or accounting losses from a business (Sawhill, 1988; Garner, 1993), or that they are able to borrow against future income. Thus, it may be safe to assume that consumption reflects material well-being in terms of past, current, and expected future income, not just current income. How a household budgets its income across different consumption groups can reflect the overall economic well-being of households differently. Measuring the impact of marginal changes in different expenditures on the inequality of total expenditures can provide important information, particularly for policy makers.

The inequality in the distribution of household consumption can be measured using the Gini Coefficient. One of the most commonly calculated inequality statistics is the Gini Coefficient, which is illustrated in figure 3.1. It is equal to the ratio of the area enclosed by the Lorenz curve and the diagonal line of perfect equality to the total area below the diagonal.

$$
G=\frac{X}{X+Y}
$$

Although the standard Gini lacks the flexibility to yield estimates that vary with individual' aversion 
to inequality (Atkinson, 1970), several authors including Kakwani (1980), Yitzhaki (1983), and Donaldson and Weymark (1983) have developed versions of the extended Gini, a family of Ginis that depend on social welfare functions in a manner resembling the Atkinson index. More recently, Lerman and Yitzhaki (1984) derived a method for decomposing the Gini by income source and for calculating the marginal effects on inequality from alternative sources.

In spite of the advantages of the Gini index and the existence of many derivations of the Gini, calculating the Gini has remained a cumbersome process (Lerman and Yitzhaki, 1984). On this same subject Deaton (1982) noted that it is considerably easier to calculate the Theil information index than the Gini index. Lerman and Yitzhaki (1984) pointed out that this inconvenience in calculation along with the ease in working with such variance measures as the coefficient of variation and the log of the variance, have probably contributed to the frequent substitution of other measures for the Gini.

One formula for the absolute Gini as derived by Lerman and Yitzhaki (1983), is

$$
A=\int_{a}^{b} F(y)[1-F(y)] d y
$$

where A is half of Gini's expected mean difference, a is the lowest and b is the highest value of the variable $\mathrm{y}$, and $\mathrm{F}(\mathrm{y})$ is the commutative distribution of $\mathrm{y}$. Using integration by part, with $\mathrm{u}=\mathrm{F}(\mathrm{y})[1$ $\mathrm{F}(\mathrm{y})]$ and $\mathrm{v}=\mathrm{y}$, we obtain

$$
A=2 \int_{a}^{b} y\left[F(y)-\frac{1}{2}\right] f(y) d y
$$


Figure 3.1: Gini Coefficient



By transformation of variables, defining $y(F)$ as the inverse function of $F(y)$, we obtain

$$
A=2 \int_{0}^{1} y(F)\left(F-\frac{1}{2}\right) d F
$$

Note that $\mathrm{F}$ is uniformly distributed between $[0,1]$ so that its mean is $1 / 2$. This means that equation (3.31) can be written as: 


$$
A=2 \operatorname{cov}[y, F(y)]
$$

Dividing by the mean of y yields the relative Gini. Stuart (1954) recognized the relationship between the absolute Gini and the covariance, but his interest was in the correlation coefficient.

Given equation (3.32), it becomes relatively simple to calculate the Gini. First, obtain the rank (R) for each observation i, Next, calculate the covariance between R and y. Since R/n terms are the empirical representation of $\mathrm{F}(\mathrm{y})$, one must divide the covariance by $\mathrm{n}$. Divide the covariance by mean $y$, multiply by 2 and voila, we have the Gini of y. Note that unlike standard approaches for calculating the Gini, this method requires no grouping of individual data to economize on computations. Thus, the method is not only easier, but also more accurate than standard methods.

A simple transformation of equation (3.32) shows the relationship between the Gini and the standard regression coefficients. This relationship is convenient for the purpose of interpretation as well as calculation. A regression of $\mathrm{y}$ on $\mathrm{R} / \mathrm{n}$ yields the slope coefficient,

$$
B=\frac{\operatorname{cov}\left(y, \frac{R}{n}\right)}{\operatorname{var}\left(\frac{R}{n}\right)}
$$

The variance of $R / n$ is a constant equal to $(1 / 12)(n+1) / n$, which for large samples of converges to $1 / 12$. Thus, the absolute Gini is essentially a constant times the regression coefficient. Using the regression coefficient yields a general graphical interpretation of the Gini.

In another step, Yitzhaki (1983) showed how to extend the Gini to resemble the sensitive property of the Atkinson index. Atkinson developed an index of income inequality that is sensitive to 
judgements about how much one values reducing income inequality. As Lerman and Yitzhaki (1984) put it, the formula for the extended Gini is:

$$
G(v)=1-v(v-1) \int_{0}^{1}(1-F)^{v-2} \varphi(F) d F, \quad v>1
$$

Where $\mathrm{G}(\mathrm{v})$ is the relative extended Gini, $\phi(\mathrm{F})$ is the Lorenz curve, and $\mathrm{v}$ is a parameter that reflects a preference for inequality. Aversion to inequality rises as $\mathrm{v}$ goes from zero to infinity. From 0 to 1 , the index represents a preference for inequality. The index becomes the standard Gini at $v=2$, and implies indifference to inequality at $\mathrm{v}=1$.

As in the case of the conventional Gini, the extended Gini also turns out to be a function of the covariance. Specifically, the Gini at a value v may be written as:

$$
G(v)=\frac{-v \operatorname{cov}\left[y,(1-F)^{v-1}\right]}{m_{y}}
$$

where $\mathrm{m}$ is the mean of $\mathrm{y}$. In addition, Lerman and Yitzhaki (1984) proposed a way of calculating marginal contributions to inequality from the various elements.

Let $\mathrm{y}=\mathrm{x}, \mathrm{k}=1,2, \ldots ., \mathrm{K}, \mathrm{m}_{\mathrm{k}}$ and $\mathrm{F}_{\mathrm{k}}()$ be equal to the mean and the cumulative distribution of $\mathrm{x}_{\mathrm{k}}$, and $\mathrm{m}_{\mathrm{y}}$ and $\mathrm{F}_{\mathrm{y}}$ be the mean and cumulative distribution of $\mathrm{y}$, then the overall Gini can be expressed as Lerman and Yitzhaki, (1983):

$$
G(v)=\sum_{k=1}^{K} \frac{\operatorname{cov}\left[x_{k},\left(1-F_{k}\right)^{v-1}\right]}{\operatorname{cov}\left[x_{k},\left(1-F_{y}\right)^{v-1}\right]} \frac{-v) \operatorname{cov}\left[x_{k},\left(1-F_{k}\right)^{v-1}\right]}{m_{k}} \frac{m_{k}}{m_{y}}
$$




$$
=\sum_{k=1}^{K} C_{k} G_{k} S_{k}
$$

Where $C_{k}$ is the Gini correlation between element $k$ and the rank of total $y, G_{k}$ is the Gini element $k$, and $S_{k}$ is the mean of $x$ divided by the mean of $y$ (or x's share of $y$ ). The Gini correlation has properties that are similar to Pearson's and the rank correlation. Lerman and Yitzhaki (1983) pointed out that Pearson correlation and Gini correlation between component $\mathrm{x}$ and the rank of $\mathrm{y}$ have the same numerators, but the Pearson numerator correlation deflates the $\operatorname{cov}\left(\mathrm{x}_{\mathrm{k}}, \mathrm{R}_{\mathrm{k}}\right)$ by a constant (equal to the standard deviation of the rank of $\mathrm{x}_{\mathrm{k}}$ ) while the Gini correlation uses the Gini of $\mathrm{x}_{\mathrm{k}}$ as denominator. The result yields a convenient interpretation in the case of the standard Gini $(v=2)$, where $G_{k}$ may be represented by the ratio of the slope coefficient from the regression of $x_{k}$ and $R_{y}$ the slope coefficient from the regression of $\mathrm{x}_{\mathrm{k}}$ and $\mathrm{R}_{\mathrm{k}}$, according to Lerman and Yitzhaki.

The key rationale for studying decomposition by source is to learn how changes in particular income sources will affect overall income inequality. The theoretical framework explained in this section extends derivations reported by Kakwani (1977) and Shorrocks (1982) in which a given source's contribution is the product of the share of total income and a term called the pseudo-Gini. The pseudo-Gini appears as the product of the source itself and the correlation between the source and the rank of total income (Lerman and Yitzhaki, 1984). It also has been shown that a similar result holds for the extended Gini, a measure that is like the Atkinson (1970) index in permitting alternative weights in different parts of income distributions (Lerman and Yitzhaki, 1984) . 


\section{CHAPTER 4: DATA AND DATA ORGANIZATION}

\subsection{Introduction}

This chapter discusses the source, organization and transformation of data. It is divided into three additional sections. The source of the data and the method in which the data are collected are presented in section 4.2. Section 4.3 discusses how the data are downloaded from one form of storage to another form of storage using the Job Control (JCL) and Statistical Analysis System Languages (SAS), including the creation of the SAS data set. The transformation of the cross sectional data downloaded from the external medium of storage to panel data is presented in section 4.4.

\subsection{Source of Data}

The key ingredient to the evaluation of consumption-based inequality is a disaggregated data set on consumer expenditures. In the United States, the only source of such data is the consumer expenditure surveys. The Census Bureau conducts this survey on behalf of the Bureau of Labor Statistics. The consumer expenditure data are collected from a national probability sample of households designed to represent the total civilian noninstitutional population and a portion of institutional population living in selected types of group quarters. Housing units occupied by students are also surveyed. The interview sample, selected on a rotating panel basis, is targeted at 5000 consumer units per quarter. Each quarter one-fifth of the sample is new to the survey. After being interviewed for five consecutive quarters, a panel is dropped from the survey. The fifth quarter overlaps with the first quarter of the next year.

The rotating sample design of the interview survey has an effect on the structure of the data files and the use of the data itself. This is described by the Bureau as a distinction between calendar period and collection period. Respondents are asked to report expenditures made since the first of the month 
three months prior to the interview month. For example, if the Consumer Unit is interviewed in January of 1991, they are reporting expenditures for October, November, and December of 1990. The period between October 1 and December 31 is referred as the reference period for the interview. Files on the public use tapes are organized and identified by collection period, and the actual period of expenditure is not reflected.

The data upon which this study is based are drawn from the 1980 through 1994 Interview Surveys which include consumer characteristics and expenditures. The consumer characteristics or family characteristics data pertain to age, sex, race, martial status, education, and consumer unit relationship for each member. The expenditure file, which is referred as 'Detailed Expenditure', provides expenditure data at the most detailed level available. The mechanics of downloading the above two files and the creation of the SAS data set are presented in the next section.

\subsection{Data Organization and Manipulation}

Two files, consumer characteristics and expenditure files, were downloaded from a reel tape obtained from the BLS, to cartridge tapes by quarter using job control computer language (JCL). A permanent SAS data set was created by merging the two files, the consumer characteristics and expenditures by the unique consumer identification number assigned to each household. Appendix P-1 illustrates the JCL and SAS programs used to download and merge files, including that for creating a permanent SAS data set.

As stated in section 4.2, one problem with the structure is that the reference and collection periods of the data are different. The collection period is not consistent with the true price of the commodity for which the expenditure is made. The questions are written in such a way to ask the respondent how much she/he spent on a particular commodity in the last three months. Since this study 
uses prices and price data are collected by month, it is important to make the date in which the expenditure was made consistent with price on the actual date of purchase. To do that we divided each quarter by three and back dated to the month of purchase. Once the data is disaggregated by month, the next task is to merge the data set with the data set for prices. Data for the prices of the commodities used in this study are obtained from BLS database using the internet access. All prices are reported as indexes. Appendix P-1 through appendix P9 show the SAS programs used to accomplish the above computing

\subsection{The Transformation of Time-Series-Cross Section Data to Panel Data}

The transformation of cross section data to panel data is based on the theoretical framework described in chapter 3. The Consumer Expenditure Survey is not a panel; the same individual households are not followed through long period of time. Participation of a household is limited to only

five quarters after adjustments. However, the survey is a continuous operation so that it provides a random sample of the population each quarter (subject to the exclusion and inclusion of certain households every quarter). Our data represents the period between 1980 and 1994. Hence, although we cannot track individual households, we can track groups of households. In particular, if we take age as age of the household head, we can look at the average behavior of, say, those 25 years old in 1980 , 26 years old in 1981, etc. Given the linear in parameter functional forms, mean cohort behavior reproduces the form of individual behavior and the cohorts can thus effectively be treated as individuals. If the price of lifetime utility is constant for all members of the cohort from one year to the next, then its mean is constant for the cohort as a whole. Hence, the sample mean from the survey will be a consistent estimator of the same quantity from year to year, with a precision determined by the sample design (Deaton, 1985). Based on the conclusion made by Deaton (1985), the cohorts means can 
be treated as panel data. Table 4.1 illustrates the number of households in each cohort in each year. Table 4.1: Number of Households in Each Cohort in Each Year

\begin{tabular}{lllllll}
\hline Year & Age & Age & Age & Age & Age & Age \\
\cline { 2 - 7 } & $16-25$ & $25-34$ & $35-44$ & $45-54$ & $55-64$ & $>64$ \\
\hline 1980 & 187 & 187 & 187 & 187 & 187 & 187 \\
1981 & 187 & 187 & 187 & 187 & 187 & 187 \\
1982 & 187 & 187 & 187 & 187 & 187 & 187 \\
1983 & 187 & 187 & 187 & 187 & 187 & 187 \\
1984 & 187 & 187 & 187 & 187 & 187 & 187 \\
1985 & 187 & 187 & 187 & 187 & 187 & 187 \\
1986 & 187 & 187 & 187 & 187 & 187 & 187 \\
1987 & 187 & 187 & 187 & 187 & 187 & 187 \\
1988 & 187 & 187 & 187 & 187 & 187 & 187 \\
1989 & 187 & 187 & 187 & 187 & 187 & 187 \\
1990 & 187 & 187 & 187 & 187 & 187 & 187 \\
1991 & 187 & 187 & 187 & 187 & 187 & 187 \\
1992 & 187 & 187 & 187 & 187 & 187 & 187 \\
1993 & 187 & 187 & 187 & 187 & 187 & 187 \\
1994 & 187 & 187 & 187 & 187 & 187 & 187 \\
\hline
\end{tabular}

In practice, one year cohorts yield samples that are too small to give accurate estimates of the sample mean. Consequently, we use a ten-year age band. Deaton (1985) pointed out that in constructing cohort samples there is a trade off between cohort size and the number of cohort means. Smaller cohort size implies less precise sample means so the essential trade off is between the number of observations and the accuracy of each. 


\section{CHAPTER 5: Econometric Model and Estimation Results}

\subsection{Introduction}

This chapter has three sections. Section 5.2 presents the econometric model and its implementation to estimate the impact of demographic characteristics on individual household expenditure patterns. The results of the empirical estimations are illustrated and discussed in section 5.3. Section 5.4 presents the summary and conclusions.

\subsection{Econometric Model}

The general econometric model to measure the impact of prices and demographic characteristics on the expenditure pattern of household units is specified as:

$$
Y_{i t}=\alpha+\beta X_{i t}+\epsilon_{i t}
$$

Where $\mathrm{Y}$ is the a vector of expenditure shares used as dependent variables. The expenditures are divided among eight commodity groups. X represents a vector of independent variables, a nonrandom function of prices, expenditure and demographic characteristics. $\epsilon$ is an unobserved random disturbance that is functionally independent of the explanatory variables. The disturbance may result from errors in implementation, random elements in the determination of consumer preferences not reflected in the list of attributes of consuming units, errors in measurements of individual expenditure shares, specification error, or errors in the design and collection of data. We assume that the individual disturbances have an expected value equal to zero. Since the individual expenditure shares for all commodities sum to unity for each consuming unit in each time period, the unobservable random disturbances for all commodities sum to zero. These disturbances are distributed normally with mean zero and covariance matrix $\Omega_{\epsilon}$. We also assume that the covariance matrix of the individual 
disturbances has the rank equal to $\mathrm{N}-1$, where $\mathrm{N}$ is the number of commodities. Finally, we assume that disturbances corresponding to distinct observations are uncorrelated. The above model is specified for eight commodity groups in which eight equations are specified and only seven equations are required for a complete model. Since the equations for the budget shares are generated from the indirect translog utility function, the parameters satisfy equality and symmetry restrictions that are strictly analogous to the corresponding restrictions the direct translog utility function..

\subsubsection{Dependent Variable Descriptions}

There are seven dependent variables one for each equation. As stated in chapter three, these expenditure shares are derived by the logarithmic form of Roy's identity. Table 5.1 gives descriptions of the dependent variables which are the budget shares.

Table 5.1: Dependent Variables

\begin{tabular}{ll}
\hline VARIABLE & \multicolumn{1}{c}{ DESCRIPTION } \\
\hline FOOD_SHARE & SHARE OF EXPENDITURE ON FOOD AND BEVERAGES. \\
HOUSING_SHARE & AGGREGATED EXPENDITURE SHARE ON HOUSING. \\
APPAREL_SHARE & EXPENDITURE SHARE ON APPAREL. \\
ENTER_SHARE & EXPENDITURE SHARE ON ALL FORMS OF ENTERTAINMENT. \\
HEALTH_SHARE & EXPENDITURE SHARE ON HEALTH. \\
TRANS_SHARE & EXPENDITURE SHARE ON TRANSPORTATION. \\
UTILITY_SHARE & EXPENDITURE SHARE ON UTILITY \\
\hline
\end{tabular}

\subsubsection{Independent Variables}

There are twenty five independent variables of which 17 are dummy variables. We have four categories of demographic characteristics: age of head of the household, family size, geographic region of residence, and race. The logarithms of price indexes for each commodity group along with the logarithms of total expenditure for each commodity group are also defined as explanatory variables. 
Tables 5.2 and 5.3 illustrate the description of the independent variables used in the econometric model. Table 5.2: Explanatory Variables

\begin{tabular}{ll}
\hline VARIABLE & \multicolumn{1}{c}{ VARIABLE DESCRIPTION } \\
\hline ENTER_PRICE & PRICE INDEX FOR ENTERTAINMENT \\
UTILITY_PRICE & PRICE INDEX FOR ENERGY. \\
FOOD_PRICE & PRICE INDEX FOR FOOD AND BEVERAGES. \\
HOUSING_PRICE & PRICE INDEX FOR HOUSING. \\
HEALTH_PRICE & PRICE INDEX FOR HEALTH. \\
TRANS_PRICE & PRICE INDEX FOR TRANSPORTATION. \\
APPAREL_PRICE & PRICE INDEX FOR APPAREL \\
TOTAL_EXPENSE & TOTAL EXPENDITURE OF A HOUSEHOLD UNIT. \\
\hline
\end{tabular}

5.3 Estimation and Empirical Results

The translog model of individual expenditures described in chapter 3 can be presented in the form:

$$
w_{i t}=\alpha_{P}+\beta_{P P} \ln p_{i t}-\beta_{P P} \ln M_{i t}+B_{P A} A_{i t}+\epsilon_{i t}
$$

Where $\mathrm{w}_{\mathrm{it}}$ is the observed budget share at time $\mathrm{t}, \mathrm{M}_{\mathrm{it}}$ is the observed expenditure for the $\mathrm{i}^{\text {th }}$ consuming unit at time $t, \ln p_{i t}$ is the vector of logarithms of prices at time $t$, and $A_{i t}$ is the vector of attributes of the $i^{\text {th }}$ consuming unit at time t. We have seven commodity groups and we estimate six equations because of the symmetry restrictions we imposed on the system of equations. We employ time series cross sectional data on household expenditure patterns for the years 1980 through 1994. By imposing the symmetry restriction, the system of equations defined above were estimated using the seemingly unrelated regression method (SUR). Seemingly unrelated regression may improve the efficiency of parameter estimates when there is contemporaneous correlation of errors across equations. In practice, 
a contemporaneous correlation matrix is estimated using OLS residuals and the final parameter estimates take this information into account. Under two sets of circumstances, SUR parameter estimates are the same as those produced by OLS: when there is no contemporaneous correlation of errors across equations where $\Omega$ is diagonal, or where independent variables are the same across equations. Theoretically, SUR parameters will always be at least as efficient as OLS in large samples, provided that the equations are correctly specified. The consequences of specification error are more serious with SUR than with OLS.

Table 5.3: Explanatory Dummy Variables

\begin{tabular}{|c|c|}
\hline VARIABLE & DUMMY VARIABLE DESCRIPTION \\
\hline A1 & A1 = 1 IF AGE IS 16 - 24, OTHERWISE A1 = 0. (Omitted) \\
\hline A 2 & $\mathrm{~A} 2=1 \mathrm{IF}$ AGE IS $25-34$, OTHERWISE A2 = 0 \\
\hline A3 & $\mathrm{A} 3=1 \mathrm{IF}$ AGE IS $35-44$, OTHERWISE A3 = 0. \\
\hline A4 & A4 = 1 IF AGE IS $45-54$, OTHERWISE A4 = 0. \\
\hline A5 & A5 = 1 IF AGE IS $55-64$, OTHERWISE A5 = 0. \\
\hline A6 & A6 = 1 IF AGE IS GREATER OR EQUAL TO 65, OTHERWISE A6 = 0 \\
\hline F1 & F1 = 1 IF FAMILY SIZE EQUALS 1, ELSE F1 = 0. (Omitted) \\
\hline $\mathrm{F} 2$ & $\mathrm{~F} 2=1$ IF FAMILY SIZE EQUALS 2, ELSE F2 = 0. \\
\hline $\mathrm{F} 3$ & $\mathrm{~F} 3=1 \mathrm{IF}$ FAMILY SIZE EQUALS 3, ELSE F3 = 0. \\
\hline F4 & F4 = 1 IF FAMILY SIZE EQUALS 4, ELSE F4 = 0. \\
\hline F5 & F5 = 1 IF FAMILY SIZE EQUALS OR GREATER THAN 5, ELSE F5 = 0. \\
\hline NE & NE = 1 IF RESIDENCE IS IN NORTHEAST, ELSE NE = 0. (Omitted) \\
\hline WE & $\mathrm{WE}=1 \mathrm{IF}$ RESIDENCE IS IN THE WEST, ELSE WE $=0$. \\
\hline MW & MW = 1 IF RESIDENCE IS IN THE MIDWEST, ELSE MW = 0. \\
\hline $\mathrm{SO}$ & $\mathrm{SO}=1$ IF RESIDENCE IS IN THE SOUTH, ELSE SO =0. \\
\hline $\mathrm{W}$ & $\mathrm{W}=1$ IF RACE IS WHITE, OTHERWISE W = $0 .($ Omitted $)$ \\
\hline $\mathrm{B}$ & $\mathrm{B}=1$ IF RACE IS BLACK, OTHERWISE B =0. \\
\hline
\end{tabular}


Economic theory requires that the individual expenditure shares be homogeneous of degree zero in prices and total expenditures, the sum of the individual expenditure shares over all commodity groups, be equal to unity, the matrix of compensated own and cross-price substitution effects be symmetric, and the individual expenditure shares be non-negative. The translog model with the above conditions imposed is estimated using the Zellner Regression Method and the results are illustrated in tables 5.5 - 5.11. To avoid the problem of perfect multicollinearity, one dummy variable from each category is omitted. The significant variables are shaded in the tables and the degree of significance is indicated by asterisks in the last column of each table.

\subsubsection{Food and Beverages}

Prices play an important role in the allocation of budget share for the consumption of food and beverages. The coefficient for FOOD_PRICE, price for food and beverages indicates that as price increases by one unit, the level of expenditure share for food and beverages increases by 0.075 (see table 5.4) indicating inelastic demand. Other prices such as the prices of health care and housing have negative effect indicating substitutability in the distribution of share of expenditures. The coefficient for apparel is $99 \%$ significant with a positive sign. Households tend to allocate less for food as the amount of their total expenditure rises. The coefficient for the prices of entertainment, utility, and transportation are not statistically significant.

As indicated by the coefficient for A2, the food expenditure share for the head of the household age 25-35 is less by 0.005597 compared with the expenditure share for a household headed by an individual aged 16-24 (Table 5.4). This difference may be attributed to the difference in life styles between these two age groups. The individual aged 16-24 may be spending more money on food and beverages away from home in outlets such as restaurants and hotels which are more expensive or it 
could be that the income for age group 16-24 is smaller and, typically, people with smaller incomes spend a greater proportion of that income on food. Households headed by individuals aged 35-44, 4554, and 55-64 have relatively larger shares of expenditures on food and beverages than the 16-24 age group. Estimates representing family size show that families with 2, 3, 4, and 5 family members have larger expenditure shares for food and beverages than households with a single person. The more the members the more the expenditure share on food and beverages. In terms of residence, households living in the west, south and mid-west allocate relatively less to food than do households residing in the northeast geographical region. This may be related to differences in prices, income, life style or culture.

The dummy variable representing race shows that the expenditure share decreases when the head of the household is black instead of white. Actually, the result should have been the other way around because of that blacks earn less than whites and lower income people tend to spend more of their incomes on food. One possible explanation for this phenomenon is that since many low income families receive subsidies in the form of food stamps they do not need to allocate more cash for food and this study does not include expenditures in other forms other than cash. However, lower income people may allocate more of their income on food items such as potatoes, chicken, and others which are priced low. Since higher income people are more educated and health conscious their share of expenditure could be higher because the type of food they consume may be more expensive. These data include food at home, food away from home, beverages, and other expenditures related to food, so that consumption patterns could also affect the results. 
Table 5.4: Food and Beverages

\begin{tabular}{|c|c|c|c|c|}
\hline PARAMETR & ESTIMATE & STANDARD ERROR & T_VALUE & SIGNIFICANT \\
\hline INTERCEPT & 0.847938 & 0.061826 & 13.715 & $* * *$ \\
\hline ENTER_PRICE & 0.077517 & 0.116390 & 0.666 & \\
\hline UTILITY_PRICE & -0.008486 & 0.030860 & -0.275 & \\
\hline FOOD_PRICE & 0.074533 & 0.029649 & 2.514 & $* *$ \\
\hline HOUSING_PRICE & -0.341018 & 0.057025 & -5.980 & $* * *$ \\
\hline HEALTH_PRICE & -0.007435 & 0.004518 & -1.646 & $*$ \\
\hline TRANS_PRICE & -0.088516 & 0.067397 & -1.313 & \\
\hline APPAREL_PRICE & 0.179230 & 0.055576 & 3.225 & $* * *$ \\
\hline TOTAL_EXPENSE & -0.065926 & 0.002371 & -27.808 & $* * *$ \\
\hline A2 & -0.005597 & 0.002251 & -2.486 & $* *$ \\
\hline A3 & 0.005981 & 0.002415 & 2.477 & $* *$ \\
\hline A4 & 0.011470 & 0.002437 & 4.706 & $* * *$ \\
\hline A5 & 0.009822 & 0.002313 & 4.246 & $* * *$ \\
\hline A6 & 0.000924 & 0.002263 & 0.408 & \\
\hline $\mathrm{F} 2$ & 0.021300 & 0.002055 & 10.365 & $* * *$ \\
\hline F3 & 0.033982 & 0.002170 & 15.658 & $* * *$ \\
\hline $\mathrm{F} 4$ & 0.054142 & 0.002308 & 23.454 & $* * *$ \\
\hline F5 & 0.065719 & 0.002377 & 27.650 & $* * *$ \\
\hline WE & -0.022193 & 0.001700 & -13.053 & $* * *$ \\
\hline SO & -0.032529 & 0.001704 & -19.087 & $* * *$ \\
\hline MW & -0.016303 & 0.001775 & -9.186 & $* * *$ \\
\hline B & -0.018472 & 0.001488 & -12.413 & $* * *$ \\
\hline $\begin{array}{ll}k * * & \text { Significant at } 0 \\
k * & \text { Significant at } 0 \\
& \text { Significant at } a\end{array}$ & $\begin{array}{l}=.01 \\
=.05 \\
=.10\end{array}$ & & & \\
\hline
\end{tabular}




\subsubsection{Housing and Housing Service}

The price variable for housing, HOUSING_PRICE has a positive relation with the expenditure share for housing. As the price increases by one unit the expenditure share increases by 0.050 (Table 5.5). Expenditure on housing is a long term planned commitment and one cannot react to changes in prices right away. If the prices of maintenance goes up, the owner has little choice, except to pay for it in order to protect his or her investment and/or life style. On the other hand, the effect of data aggregation might have resulted in positive estimate than a negative one, since expenditure share for housing includes the mortgage/rent, expenditure on furniture and related items, housing maintenance, and domestic serves. While prices for utilities, health care, and total expenditures have negative coefficient estimates, prices for transportation and apparel have positive coefficients. The coefficients of the other price variables are not statistically significant.

Dummy variables representing the age category indicate that expenditure share for housing and housing related services is relatively higher for households headed by individuals aged 25-34 and 35-44 when compared with the head os a household age 16-24. In most cases people between 25-55 maintain a larger family and make investments in housing and real estate. So, increases in the age of the head of the household, at least until 50, may be one possible factor for the increase in expenditure share for housing and housing related services such as rent, mortgage, maintenance, and other services. Also, the two age groups mentioned were buying homes in an era when costs increasing. The fact that 16-24 age group is a typical low income group, may be one more reason for having less expenditure share than the next two age groups. Estimates for the variables representing ages 45-54, 55-64 and 65 or over are not statistically significant.

Increases in the family size have negative effects on expenditure share for housing. From the 
simple inspection of this expenditure data we observe that housing takes a high share of the household's budget. Households with more family members may be forced to allocate their resources for other basic necessities rather than to bigger or more expensive homes and services. Also, the more people in the family the greater the possibility that some of the services could be rendered by the family members, which may help reduce the cost of housing.

Expenditure share for housing and housing related services is less in the West and South geographic regions than the Northeast. This phenomenon could be attributed to the difference in the climatic conditions of the regions, especially during winter. Also, the differences in prices of housing and the wages rate may be a factor, as well as differences in land values. Households living in the midwest geographical region have a higher expenditure share than those living in the northeast region.

The relative expenditure share on housing and housing related services by a household headed by a black person is less than the household headed by a white individual. This can be directly attributed to the low proportion of income distribution for blacks. According to Charles Nelson (1994) in 1967 the Black-White household income ratio was 0.58. In 1990, 23 years later, this ratio was only slightly higher (0.62). This fact directly supports the our findings regarding expenditure inequality between blacks and whites on housing and housing related investments with its root cause being inequality in earnings. Since blacks earn less and spend a smaller share of that on housing, probably means that they 1. live in inferior housing, and 2. a greater proportion live in government subsidized housing.

\subsubsection{Apparel}

The own price for apparel is not statistically significant (Table 5.6). While estimates for the prices of entertainment, and housing are positive, estimate for the price of health care is negative. As 
Table 5.5: Housing and Housing Services

\begin{tabular}{|c|c|c|c|c|}
\hline PARAMETR & ESTIMATE & STANDARD ERROR & T_VALUE & SIGNIFICANCE \\
\hline INTERCEPT & 0.294487 & 0.104539 & 2.817 & $* * *$ \\
\hline ENTER_PRICE & -0.008486 & 0.030860 & -0.275 & \\
\hline UTILITY_PRICE & -0.113629 & 0.031441 & -3.614 & $* * *$ \\
\hline FOOD_PRICE & -0.028550 & 0.018834 & -1.516 & \\
\hline HOUSING_PRICE & 0.050135 & 0.023511 & 2.132 & $* *$ \\
\hline HEALTH_PRICE & -0.015791 & 0.004999 & -3.159 & $* * *$ \\
\hline TRANS_PRICE & 0.145934 & 0.054527 & 2.676 & $* * *$ \\
\hline APPAREL_PRICE & 0.048422 & 0.028591 & 1.694 & $*$ \\
\hline TOTAL_EXPENSE & -0.031175 & 0.004430 & -7.037 & $* * *$ \\
\hline A2 & 0.044804 & 0.004111 & 10.900 & $* * *$ \\
\hline A3 & 0.040076 & 0.004408 & 9.092 & $* * *$ \\
\hline A4 & 0.004809 & 0.004418 & 1.089 & \\
\hline A5 & -0.006514 & 0.004214 & -1.546 & \\
\hline A6 & -0.006008 & 0.004175 & -1.439 & \\
\hline $\mathrm{F} 2$ & -0.009668 & 0.003829 & -2.525 & $* *$ \\
\hline F3 & -0.009329 & 0.004032 & -2.314 & $* *$ \\
\hline F4 & -0.010969 & 0.004291 & -2.557 & $* *$ \\
\hline F5 & -0.026052 & 0.004435 & -5.875 & $* * *$ \\
\hline WE & -0.023951 & 0.003256 & -7.355 & $* * *$ \\
\hline SO & -0.035285 & 0.003253 & -10.484 & $* * *$ \\
\hline MW & 0.016101 & 0.003381 & 4.762 & $* * *$ \\
\hline B & -0.005210 & 0.002844 & -1.832 & $*$ \\
\hline $\begin{array}{ll}* * * & \text { Significant at } 0 \\
& \text { Significant at } 0 \\
& \text { Significant at }\end{array}$ & $\begin{array}{l}=.01 \\
=.05 \\
=.10\end{array}$ & & & \\
\hline
\end{tabular}


expenditure increases the share of budget for apparel decreases. The estimates for the other variables are statistically insignificant.

Expenditure shares on apparel tend to decrease as the age of the head of the household increases except for the 55-64 age group. Since apparel is an expendable and non-basic item, people may shift their resource to something more important or to something which has a return. Also, the life styles of people in different age groups are different. It appears households between age 55-64 spend more and those age 65 or over spend relatively less than the household between age 16-24. Households with two or three family members spend a smaller share of their income on apparel than household with a single individual, which is contrary to expectations in that families with more members would seem to need more clothing, but they also need more food, medical services, etc. Households living in the Western geographical region allocate relatively more and those living in the south have relatively less expenditure shares than those living in the Northeastern geographical region. This phenomenon may be attributed to differences in life style of people living in different regions and also differences in climate of the geographical regions. In the case of race, blacks tend to have relatively larger expenditure shares on apparel than whites.

\subsubsection{Entertainment}

Table 5.7 illustrates the estimates for entertainment. Entertainment is a fast growing industry, both in terms demand and supply. As the price of entertainment increases by a unit the expenditure share for entertainment decreases by 0.341 and its significant level is over $99 \%$. Coefficients for prices of food and beverages, housing, and apparel indicate that they are complements for entertainment, i.e., they have positive coefficients. When the entertainment activity takes place at home, more is allocated to pay for domestic services or for furniture or electronic appliances. Differences in the age of the head of a 
Table 5.6: Apparel

\begin{tabular}{|c|c|c|c|c|}
\hline PARAMETR & ESTIMATE & STANDARD ERROR & T_VALUE & SIGNIFICANCE \\
\hline INTERCEPT & -0.233550 & 0.048494 & -4.816 & $* * *$ \\
\hline ENTER_PRICE & 0.075533 & 0.029649 & 2.514 & $* *$ \\
\hline UTILITY_PRICE & -0.028550 & 0.018834 & -1.516 & \\
\hline FOOD_PRICE & 0.000767 & 0.023324 & 0.033 & \\
\hline HOUSING_PRICE & 0.035884 & 0.021538 & 1.666 & $*$ \\
\hline HEALTH_PRICE & -0.008108 & 0.003502 & -2.315 & $* *$ \\
\hline TRANS_PRICE & 0.028252 & 0.037279 & 0.758 & \\
\hline APPAREL_PRICE & 0.029201 & 0.022511 & 1.297 & \\
\hline TOTAL_EXPENSE & 0.004590 & 0.001917 & 2.395 & $* *$ \\
\hline A2 & -0.007387 & 0.001802 & -4.099 & $* * *$ \\
\hline A3 & -0.004782 & 0.001932 & -2.475 & $* *$ \\
\hline A4 & -0.008805 & 0.001954 & -4.505 & $* * *$ \\
\hline A5 & 0.011277 & 0.001850 & -6.094 & $* * *$ \\
\hline A6 & -0.017957 & 0.001816 & -9.889 & $* * *$ \\
\hline $\mathrm{F} 2$ & -0.004003 & 0.001657 & -2.417 & $* *$ \\
\hline F3 & -0.001072 & 0.001749 & -0.612 & \\
\hline $\mathrm{F} 4$ & -0.004443 & 0.001861 & -2.387 & $* *$ \\
\hline F5 & -0.002320 & 0.001918 & -1.210 & \\
\hline WE & 0.000540 & 0.001383 & 0.390 & \\
\hline SO & -0.005847 & 0.001384 & -4.224 & $* * *$ \\
\hline MW & -0.005205 & 0.001441 & -3.613 & $* * *$ \\
\hline B & 0.009396 & 0.001210 & 7.765 & $* * *$ \\
\hline $\begin{array}{ll}k * * & \text { Significant at } 0 \\
k * & \text { Significant at } \\
& \text { Significant at } 0\end{array}$ & $\begin{array}{l}=.01 \\
=.05 \\
=.10\end{array}$ & & & \\
\hline
\end{tabular}


household is a factor in the allocation of resources for entertainment purpose. People in the age groups 25-34 and 35-44 tend to have relatively more expenditure shares for entertainment than people between the age 16-24. It is not uncommon for people between $25-45$ to have a family and choose a form of entertainment like traveling, out door entertainment and others which are more expensive. The coefficients for households aged 45 to 64 are not significant, whereas the coefficient for those households aged 65 or older is negative. Households residing in the west and mid-west tend to allocate relatively more money for entertainment than those living in northeast and the south. The environments which these households live under could be a factor in the difference. Again, blacks allocate relatively less resources for entertainment than whites. On one hand, differences in income could be a factor but, on the other hand, preference and tastes may determine the kind of entertainment blacks tend consume.

\subsubsection{Heath Care and Health Related Services}

We can easily observe from the data set used in this study that in the last fifteen years alone the prices for health care and health care related services have doubled. Government expenditures on medicare and medicaid, and health insurance rates also have increased. Table 5.8 shows that almost all estimates except one for personal care and education have negative coefficients, which indicates that their expenditure shares can be substituted for the expenditure share of health care. The coefficient for price of health care is not significant, a surprising finding since rising health care costs have been blamed for increasing expenditures. However, insurance, medicare, and medicaid pay for a large share of health care.

The coefficients for age variables between 25-45 are not statistically significant, however ages 45 and over spend relatively more on health care as their age increases. Naturally, as a person gets older the chance of having a health problem also increases. By almost any measure, the elderly comprise the 
Table 5.7: Entertainment

\begin{tabular}{|c|c|c|c|c|}
\hline PARAMETR & ESTIMATE & STANDARD ERROR & T_VALUE & SIGNIFICANCE \\
\hline INTERCEPT & -0.101563 & 0.049748 & -2.042 & $* *$ \\
\hline ENTER_PRICE & -0.341018 & 0.057025 & -5.980 & $* * *$ \\
\hline UTILITY_PRICE & 0.050135 & 0.023511 & 2.132 & $* *$ \\
\hline FOOD_PRICE & 0.035884 & 0.021538 & 1.666 & $*$ \\
\hline HOUSING_PRICE & 0.301138 & 0.045866 & 6.566 & $* * *$ \\
\hline HEALTH_PRICE & -0.006835 & 0.003609 & -1.894 & $*$ \\
\hline TRANS_PRICE & -0.160623 & 0.051228 & -3.135 & $* * *$ \\
\hline APPAREL_PRICE & 0.123587 & 0.031179 & 3.964 & $* * *$ \\
\hline TOTAL_EXPENSE & -0.000649 & 0.001881 & -0.345 & \\
\hline A2 & 0.003056 & 0.001792 & 1.705 & $*$ \\
\hline A3 & 0.003654 & 0.001921 & 1.902 & $*$ \\
\hline A4 & 0.001013 & 0.001942 & 0.522 & \\
\hline A5 & -0.001395 & 0.001841 & -0.758 & \\
\hline A6 & -0.007458 & 0.001796 & -4.152 & $* * *$ \\
\hline $\mathrm{F} 2$ & -0.005380 & 0.001631 & -3.297 & $* * *$ \\
\hline F3 & -0.007160 & 0.001722 & -4.158 & $* * *$ \\
\hline $\mathrm{F} 4$ & -0.005998 & 0.001832 & -3.273 & $* * *$ \\
\hline F5 & -0.006589 & 0.001885 & -3.496 & $* * *$ \\
\hline WE & 0.000220 & 0.001344 & 0.164 & \\
\hline $\mathrm{SO}$ & -0.003246 & 0.001346 & -2.408 & $* *$ \\
\hline MW & 0.006426 & 0.0001405 & 4.574 & $* * *$ \\
\hline B & -0.012547 & 0.001176 & -10.669 & $* * *$ \\
\hline $\begin{array}{ll}* * * & \text { Significant at } 0 \\
* * & \text { Significant at } 0 \\
& \text { Significant at } 0\end{array}$ & $\begin{array}{l}=.01 \\
=.05 \\
=.10\end{array}$ & & & \\
\hline
\end{tabular}


age group most affected by problems of ill health. According to Viscusi (1979) only $20 \%$ of those aged 65 to 75 are free of chronic illness and less than $13 \%$ of those aged 75 and older are classified healthy. In terms of limitations on their normal activities, far fewer elderly are affected. Less than one fourth of those aged 75 and over are not physically able to carry out their daily activities. These assertions directly and indirectly support the findings concerning the increase in share of expenditures on health as the individual gets older. The results also show that as the number of people in the family increases the amount of expenditure shares also increases. For family size two and three the estimated coefficients are statistically significant, but not for larger family size. Health care expenditure shares for households living in the western and mid-western geographical regions are relatively less than the ones living in the northeastern geographical region. This difference can be attributed at least in part to the higher price index for medical services in the northeastern geographical region. The race variable indicates that blacks allocate less on health care services than whites. Households earning below certain amount of income get free health benefits from the government and other public programs. A good proportion of the black population may rely on these programs for their health care services.

\subsubsection{Transportation}

The need of transportation has become a basic necessity in the life styles of industrialized societies. The information age might be able to reverse this phenomenon in the future. As indicated in table 5.9, as the price of transportation goes up the expenditure shares for transportation also increase. This is probably due to transportation being vital to the household's livelihood, making the the response inelastic. The prices of food and personal care and education are negatively related to the share of expenditures on transportation, while the remainder of the price variables, and the total expenditures are positively related. 
Table 5.8: Health and Health Related Services

\begin{tabular}{|c|c|c|c|c|}
\hline PARAMETR & ESTIMATE & STANDARD ERROR & T_VALUE & SIGNIFICANCE \\
\hline INTERCEPT & 0.167811 & 0.026545 & 6.322 & $* * *$ \\
\hline ENTER_PRICE & -0.007435 & 0.004518 & -1.646 & $*$ \\
\hline UTILITY_PRICE & -0.015791 & 0.004999 & -3.159 & $* * *$ \\
\hline FOOD_PRICE & -0.008108 & 0.003502 & -2.315 & $* *$ \\
\hline HOUSING_PRICE & -0.006835 & 0.003609 & -1.894 & $*$ \\
\hline HEALTH_PRICE & 0.001078 & 0.002239 & 0.482 & \\
\hline TRANS_PRICE & -0.007954 & 0.007149 & -1.113 & \\
\hline APPAREL_PRICE & -0.013534 & 0.006420 & -2.108 & $* *$ \\
\hline TOTAL_EXPENSE & -0.006755 & 0.001110 & -6.086 & $* * *$ \\
\hline A2 & 0.000783 & 0.001034 & 0.757 & \\
\hline $\mathrm{A} 3$ & 0.000100 & 0.001108 & 0.090 & \\
\hline A4 & 0.001836 & 0.001114 & 1.648 & $*$ \\
\hline A5 & 0.006805 & 0.001060 & 6.420 & $* * *$ \\
\hline A6 & 0.021404 & 0.001048 & 20.416 & $* * *$ \\
\hline $\mathrm{F} 2$ & 0.001666 & 0.000959 & 1.738 & $*$ \\
\hline F3 & 0.001833 & 0.001011 & 1.813 & $*$ \\
\hline $\mathrm{F} 4$ & 0.000761 & 0.001076 & 0.707 & \\
\hline F5 & -0.000054 & 0.001111 & -0.049 & \\
\hline WE & -0.001439 & 0.000814 & -1.767 & $*$ \\
\hline SO & 0.000812 & 0.000814 & 0.998 & \\
\hline MW & -0.003168 & 0.000846 & -3.744 & $* * *$ \\
\hline B & -0.001769 & 0.000711 & -2.489 & $* *$ \\
\hline $\begin{array}{ll}k * * & \text { Significant at } 0 \\
k * & \text { Significant at } 0 \\
& \text { Significant at } 0\end{array}$ & $\begin{array}{l}=.01 \\
=.05 \\
=.10\end{array}$ & & & \\
\hline
\end{tabular}


Expenditure shares on transportation decrease as both the age and the number of people in the household increase. As both age and family size increase, people may find ways to reduce the transportation costs such as trading vehicle less frequently and by doing more things at home. Households residing in the west and south have a higher expenditure shares on transportation than people living in the northeast. This could be attributed to a difference in public transportation where the west and the south may be lagging behind the northeast. Distances also tend to be higher since the Northeast is a relatively compact region compared to the others. In terms of race, blacks have relatively higher expenditure shares on transportation than whites, which may be related to social and cultural differences between blacks and whites.

\subsubsection{Utilities}

Utilities are another important category of commodity which is essential for life and Americans tend to spend a large amounts of money for the consumption of energy and energy related items. As table 5.10 illustrates, the expenditure shares for utilities increase as the price increases. Energy is a vital ingredient of a household system. The prices for housing, transportation, and apparel have a negative relations with the utility expenditure share. The economic rationale is that when prices increase people tend to select smaller and more energy efficient homes, use cheaper forms of transportation, drive less, and buy less or cheaper clothes.

Households headed by people over the age of 35 spend more on utilities than those below the age of 25. Usually people older than 30 live in larger houses that require more energy during the summer and winter seasons. Also, households with three or five family members allocate relatively more expenditure shares on utilities than families with a single individual, since large numbers of people require more heat, light and water. Blacks tend to have relatively larger expenditure shares 
on utilities than whites, since with lower income they must spend a higher proportion towards the consumption of energy for the purpose of heating, cooling, and cooking. It requires a good understanding in the efficient use of energy and utility related items. Even though blacks earn less than whites, a higher proportion of their income may be allocated towards the consumption of energy for the purpose of heating, cooling, and cooking. These could be some of the factors for the difference between the expenditure shares of blacks and whites on the consumption of energy items.

\subsection{Summary and Conclusions}

We have implemented an econometric model by combining time-series and cross-section data for the years between 1980 and 1994. The model allocates personal consumption expenditures among eight commodity groups: food and beverages, housing, apparel, entertainment, health, transportation, utility, and personal items and education. Households are classified by four sets of demographic characteristics: age of the head of the household, family size, region of residence, and race. The impacts of changes in total expenditures as related to demographic characteristics of the individual household are estimated very precisely.

The results of the estimation clearly show that prices and demographic characteristics of households have an effect on the expenditure patterns of households. There is a clear difference and pattern in the allocation of resources for the consumption of food and beverages based on the age of the head of the family, the size of the household, the race of the head of the family, and the geographical location of the residence of the household. We summarize the effect of each household characteristic on expenditure by category. 
Table 5.9: Transportation

\begin{tabular}{|c|c|c|c|c|}
\hline PARAMETR & ESTIMATE & STANDARD ERROR & T_VALUE & SIGNIFICANCE \\
\hline INTERCEPT & -1.217490 & 0.122682 & -9.924 & $* * *$ \\
\hline ENTER_PRICE & 0.071854 & 0.026769 & 2.684 & $* * *$ \\
\hline UTILITY_PRICE & -0.019666 & 0.020023 & -0.982 & \\
\hline FOOD_PRICE & -0.073406 & 0.013188 & -5.566 & $* * *$ \\
\hline HOUSING_PRICE & 0.033784 & 0.017109 & 1.975 & $*$ \\
\hline HEALTH_PRICE & 0.0035765 & 0.004502 & 7.944 & $* * *$ \\
\hline TRANS_PRICE & 0.291606 & 0.030345 & 9.610 & $* * *$ \\
\hline APPAREL_PRICE & 0.072412 & 0.027554 & 2.628 & $* * *$ \\
\hline TOTAL_EXPENSE & 0.107508 & 0.005031 & 21.369 & $* * *$ \\
\hline A2 & -0.026898 & 0.004666 & -5.764 & $* * *$ \\
\hline A3 & -0.050782 & 0.005022 & -10.113 & $* * *$ \\
\hline A4 & -0.039980 & 0.005043 & -7.928 & $* * *$ \\
\hline A5 & -0.028099 & 0.004786 & -5.870 & $* * *$ \\
\hline A6 & -0.035686 & 0.004716 & -7.567 & $* * *$ \\
\hline $\mathrm{F} 2$ & -0.006821 & 0.004331 & -1.575 & \\
\hline F3 & -0.029488 & 0.004570 & -6.453 & $* * *$ \\
\hline $\mathrm{F} 4$ & -0.043290 & 0.004866 & -8.896 & $* * *$ \\
\hline F5 & -0.046758 & 0.005021 & -9.312 & $* * *$ \\
\hline WE & 0.027316 & 0.003641 & 7.502 & $* * *$ \\
\hline $\mathrm{SO}$ & 0.013297 & 0.003642 & 3.652 & $* * *$ \\
\hline MW & 0.003628 & 0.003789 & 0.957 & \\
\hline $\mathrm{B}$ & 0.006372 & 0.003190 & 1.997 & $* *$ \\
\hline $\begin{array}{ll}* * * & \text { Significant at } \\
* * & \text { Significant at } \\
& \text { Significant at }\end{array}$ & $\begin{array}{l}=.01 \\
=.05 \\
=.10\end{array}$ & & & \\
\hline
\end{tabular}


Table 5.10: Utilities

\begin{tabular}{|c|c|c|c|c|}
\hline PARAMETR & ESTIMATE & STANDARD ERROR & T_VALUE & SIGNIFICANCE \\
\hline INTERCEPT & 1.242367 & 0.096984 & 12.810 & $* * *$ \\
\hline ENTER_PRICE & -0.088516 & 0.067397 & -1.313 & \\
\hline UTILTIY_PRICE & 0.145934 & 0.054527 & 2.676 & $* * *$ \\
\hline FOOD_PRICE & 0.028252 & 0.037279 & 0.758 & \\
\hline HOUSING_PRICE & -0.160623 & 0.051228 & -3.135 & $* * *$ \\
\hline HEALTH_PRICE & -0.007954 & 0.007129 & -1.113 & \\
\hline TRANS_PRICE & -0.202295 & 0.117370 & -1.724 & $*$ \\
\hline APPAREL_PRICE & -0.267671 & 0.046258 & -5.787 & $* * *$ \\
\hline TOTAL_EXPENSE & 0.002691 & 0.003794 & 0.709 & \\
\hline A2 & 0.000153 & 0.003574 & 0.043 & \\
\hline A3 & 0.011376 & 0.003834 & 2.967 & $* * *$ \\
\hline A4 & 0.024628 & 0.003470 & 6.364 & $* * *$ \\
\hline A5 & 0.036780 & 0.003671 & 10.020 & $* * *$ \\
\hline A6 & 0.057905 & 0.003597 & 16.099 & $* * *$ \\
\hline $\mathrm{F} 2$ & 0.003027 & 0.003282 & 0.922 & \\
\hline F3 & 0.009527 & 0.003471 & 2.745 & $* * *$ \\
\hline $\mathrm{F} 4$ & 0.003702 & 0.003688 & 1.004 & \\
\hline F5 & 0.010809 & 0.003800 & 2.844 & $* * *$ \\
\hline WE & 0.017589 & 0.002729 & 6.446 & $* * *$ \\
\hline SO & 0.064373 & 0.002734 & 23.550 & $* * *$ \\
\hline MW & -0.001499 & 0.002845 & -0.527 & \\
\hline B & 0.020208 & 0.002390 & 8.455 & $* * *$ \\
\hline $\begin{array}{ll}* * & \text { Significant at } \alpha \\
& \text { Significant at } \alpha \\
& \text { Significant at } \alpha\end{array}$ & $\begin{array}{l}=.01 \\
=.05 \\
=.10\end{array}$ & & & \\
\hline
\end{tabular}




\subsubsection{The Impacts of the Age of the Head of the Household}

There is a clear difference and pattern in the allocation of resources for the consumption of food and beverages based on the age of the head of the family. It appears that as the age increases the expenditure share for food also increases. Expenditure on housing increases at the earlier ages of the head of the household. One reason for the increase on the share of expenditure on housing might be that expenditure on housing is considered as a long term investment. People tend to make major investment decisions in their earlier age. The budget share for apparel generally decreases as age increases and it is significant at $99 \%$. It is reasonable to say that people allocate more for entertainment and leisure services during their prime age. The results indicate that the older the head of the household the less the budget share for entertainment. As people get older their health the state of their health deteriorates and more is allocated towards health care and health related expenditures. This fact is supported by this result at $99 \%$ level of confidence. While the share of budget for transportation decreases as age increases, on the contrary the expenditure on utilities increases. The summary of the effects of the age of the head of the household on the share of expenditure for food is illustrated in Table 5.11.

\subsubsection{The Impact of the Size of Household}

It appears that as age and family size increase the expenditure shares for food and beverages also increases. The more the number of people in a household the more food consumed causing an increase in the share of expenditure for food. The effect of the size of household has a positive effect on goods and services which are considered basic necessities; goods such as food, health and utilities. The margin of expenditure decreases for housing, apparel, entertainment, and transportation and the size of the household increases. The priorities of household consumption are reflected in the amount of resources allocated for certain commodities and services as the size of the household grows. Table 5.12 just 
reflects this notion of priorities.

Table 5.11: The Impact of Age of the Household (Compared to age 16-24 household)

\begin{tabular}{|c|c|c|c|c|c|}
\hline \multirow[b]{2}{*}{ Dependent Variable } & \multicolumn{5}{|c|}{ Age } \\
\hline & $25-34$ & $35-44$ & $45-54$ & $55-64$ & $65 \&$ Over \\
\hline Food_Share & $-0.0056 * *$ & $0.0060 * *$ & $0.0115^{* * *}$ & $0.0098 * * *$ & 0.0009 \\
\hline Housing_Share & $0.0448 * * *$ & $0.0400 * * *$ & 0.0048 & -0.0065 & -0.0060 \\
\hline Apparel_Share & $-0.0074 * * *$ & $-0.0048 * *$ & $-0.0088 * * *$ & $0.0113 * * *$ & $-0.0180 * * *$ \\
\hline Enter_Share & $0.0031 *$ & $0.0037^{*}$ & 0.0010 & -0.0014 & $-0.0075 * * *$ \\
\hline Health_Share & 0.0008 & 0.0001 & $0.0018 *$ & $0.0068 * * *$ & $0.0214 * * *$ \\
\hline Trans_Share & $-0.0269 * * *$ & $-0.0508 * * *$ & $-0.0400 * * *$ & $-0.0281 * * *$ & $-0.0357 * * *$ \\
\hline Utiltiy_Share & 0.0002 & $0.0114 * * *$ & $0.0246 * * *$ & $0.0368 * * *$ & $0.0579 * * *$ \\
\hline $\begin{array}{ll}\text { k** } & \text { Significant a } \\
\text { ** } & \text { Significant a } \\
\text { Significant a }\end{array}$ & & & & & \\
\hline
\end{tabular}

Table 5.12: The Impact of Size of the Household (Compared to single member household)






\subsubsection{The Impacts of Geographic Location}

Geographic location of residence of a household has an effect on the share of expenditure allocated for the consumption of goods and services. Households living in the east tend to allocate more for food and beverages than those living in the west, south, and midwest. Households residing in the southern geographic regions of the country allocate relatively less resources to those living in the northeast. The Western region residents allocate marginally more on apparel, entertainment, transportation and utilities while the south spends more on health, transportation, utilities, and less on apparel, entertainment. Households in the midwestern geographic region spend relatively less on food, apparel, health and utilities while more is allocated for housing, entertainment, and transportation. Table 5.13 illustrates the relationship and the level of significance.

Table 5.13: Impacts of Geographic Location of a Household (Compared to the Northeast)

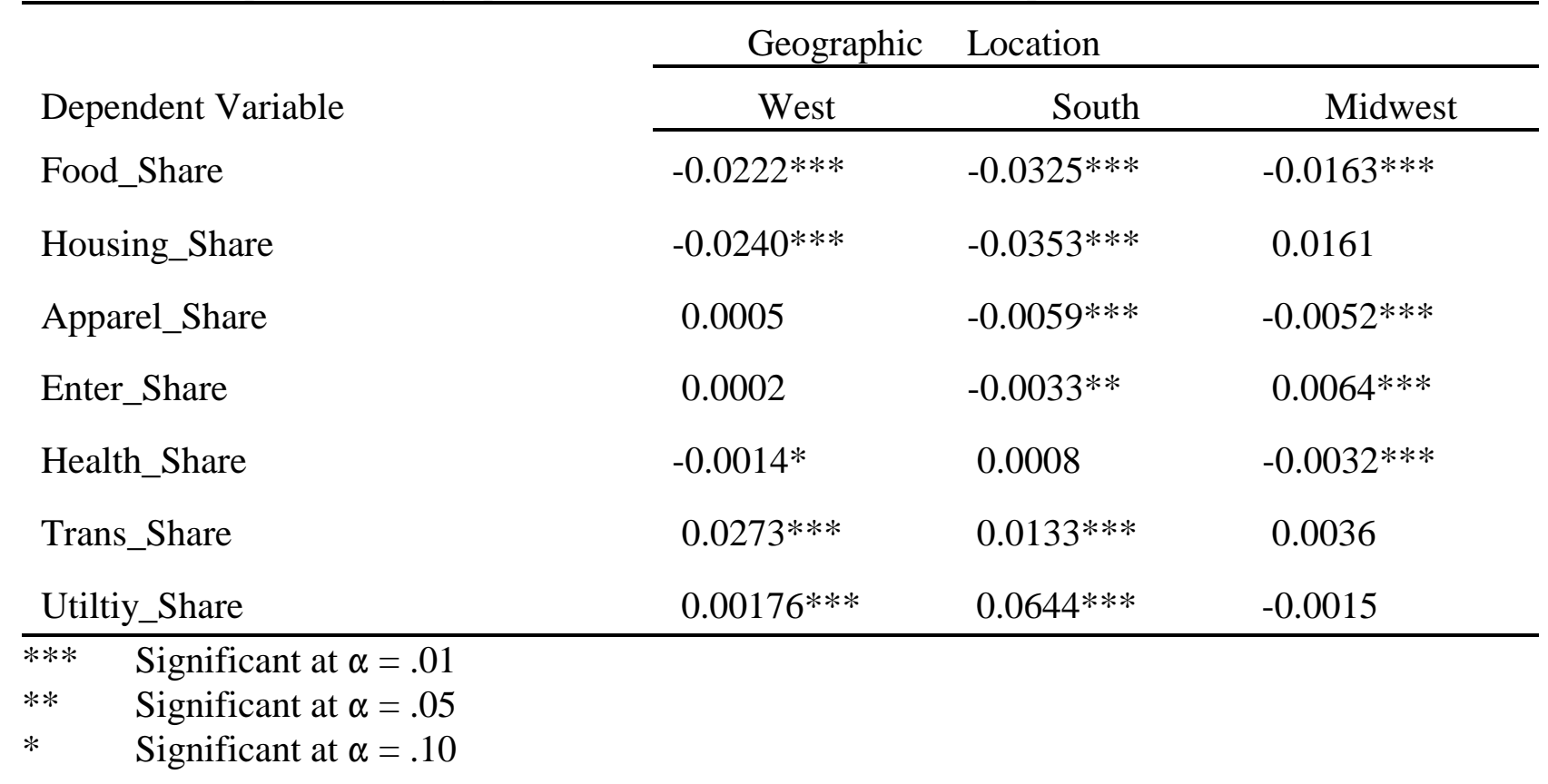




\subsubsection{The Impacts of Race}

The regression coefficients for the dummy variable race are all statistically significant, indicating that share of income spent on the different categories vary significantly between white and black households. Households with a black head of household spend smallest shares of their incomes on food, housing, health and entertainment, but larger shares on clothing, transportation and utilities. People whose income is critically small usually receive government assistance in the form of food stamps, housing rent subsidies and health care services. If blacks allocate less on food, housing and health care it could be possible that substantial part of their expenditure is covered by public assistance programs. The assistance received from the public program would free some of these resources, enabling them to increase the budget shares for apparel, transportation and utilities. Table 5.14 illustrates this relationship with the degree of statistical significance level.

Table 5.14: The Impact of Race (Compared to white)

\begin{tabular}{ll}
\hline Dependent Variable & \multicolumn{1}{c}{ Black } \\
\cline { 2 - 2 } Food_Share & $-0.0185^{* * *}$ \\
Housing_Share & $-0.0005^{*}$ \\
Apparel_Share & $0.0094 * * *$ \\
Enter_Share & $-0.0126 * * *$ \\
Health_Share & $-0.0018^{* * *}$ \\
Trans_Share & $0.0064 * *$ \\
Utiltiy_Share & $0.0202 * * *$ \\
\hline$* * *$ Significant at $\alpha=.01$ & \\
$* * \quad$ Significant at $\alpha=.05$ & \\
$* \quad$ Significant at $\alpha=.10$ &
\end{tabular}




\subsubsection{Total Expenditure}

Table 5.15 shows the relation between expenditure and budget shares for varius types of goods and services. The interpretation has to be handled with greater care, because expenditures in this case does not replace income. To some degree expenditures may indicate whether the good or service is normal or superior. Most goods and services classified as basic necessity goods are normal goods. Such goods and services are indicated by negative signs, where as the budget shares for transportation, utilities and apparel increase as expenditures increase. This is a very interesting finding for understanding the consumption patterns of households.

The impact of demographic characteristics has a wide range of implications for both private organizations, which have a business interest in understanding the distribution of expenditure patterns of households, and government agencies which help determine the economic well-being of the nation and make long term and short term planning to improve the welfare of especially the less fortunate.

Table 5.15: The Impact of Total Expenditure on Share of Expenditures

\begin{tabular}{ll} 
Dependent Variable & Total Expenditure \\
\cline { 2 - 2 } Food_Share & $-0.0659^{* * *}$ \\
Housing_Share & $-0.0312^{* * *}$ \\
Apparel_Share & $0.0046^{* *}$ \\
Enter_Share & -0.0007 \\
Health_Share & $-0.0068^{* * *}$ \\
Trans_Share & $0.1075^{* * *}$ \\
Utiltiy_Share & 0.0027 \\
\hline$* * * \quad$ Significant at $\alpha=.01$ & \\
$* * \quad$ Significant at $\alpha=.05$ & \\
$* \quad$ Significant at $\alpha=.10$ &
\end{tabular}




\section{CHAPTER 6: INEQUALITY IN HOUSEHOLD CONSUMPTION EXPENDITURES}

\subsection{Introduction}

Following the methodology and formulas laid out in section 3.3 of chapter 3 , this chapter is an analysis of inequality in the household consumption expenditures, where relationships are examined between various expenditure budget components using the consumer expenditure data from 1980 to 1994. Identifying the impact of marginal changes in expenditures for specific commodities on the inequality of total expenditures can provide useful information concerning the effect that certain policies, such as the introduction of percentage commodity taxes and subsidies, may have on the spending patterns of consumers. Section 6.2 addresses the use of the Gini coefficient and its decomposition. Then, the results are presented and discussed in section 6.3. Conclusions are presented in section 6.4.

\subsection{The Gini Coefficient and Its Decomposition}

The overall Gini coefficient is applied to produce an estimate of the inequality in the distribution of total household consumption expenditure over the population. Following the derivation by Lerman and Yitzhaki (1984), we can express the formula for the Gini coefficient as:

$$
G=\frac{2 \operatorname{cov}(X, F)}{m}
$$

This formula is expressed in terms of the covariance between total expenditures (X) and the commutative distribution of $X(F)$, and the mean of $X(m)$. The lower the value of the Gini, the lower the inequality in the distribution of expenditures; zero represents absolute equality. The overall Gini is decomposed by expenditure budget components as: Let $\mathrm{x}_{1}, \ldots ., \mathrm{x}_{\mathrm{k}}$ represent the level of expenditure for budget components. The Gini coefficient for component $\mathrm{k}$ is: 


$$
G_{k}=\frac{2 \operatorname{cov}\left(X_{k}, F_{k}\right)}{m_{k}}
$$

Following the derivation by Lerman and Yitzhaki (1985) It can be shown that the overall Gini coefficient of the total expenditures based upon the budget components is expressed as:

$$
G=\frac{2 \sum_{k=1}^{K} \operatorname{cov}\left(x_{k}, F\right)}{m}
$$

Where $\operatorname{cov}\left(\mathrm{x}_{\mathrm{k}}, \mathrm{F}\right)$ is the concentration index of expenditures for budget component $\mathrm{k}$ with respect to the commutative distributions of the total expenditures, $\mathrm{X}$. Multiplying and dividing each component $\mathrm{k}$ in equation (6.3) by $\operatorname{cov}\left(\mathrm{x}_{\mathrm{k}}, \mathrm{F}_{\mathrm{k}}\right)$ and by $\mathrm{m}_{\mathrm{k}}$ yields the sum of the budget components decomposed as:

$$
\begin{aligned}
G & =\sum_{k=1}^{K}\left[\frac{\operatorname{cov}\left(x_{k}, F\right)}{\operatorname{cov}\left(x_{k}, F_{k}\right)} \cdot \frac{2 \operatorname{cov}\left(x_{k}, F_{k}\right)}{m_{k}} \cdot \frac{m_{k}}{m}\right. \\
& =\sum_{k=1}^{K} R_{k} G_{k} S_{k}
\end{aligned}
$$

Where $\mathrm{R}_{\mathrm{k}}$ is defined as the Gini correlation between the expenditure component $\mathrm{k}$ and the rank of total consumption expenditure, $\mathrm{G}_{\mathrm{k}}$ is the relative Gini of component $\mathrm{k}$ (the index of concentration for component k), and $\mathrm{S}_{\mathrm{k}}$ is component k's share of total expenditures (Lerman and Yitzhaki, 1984). One good reason for using the decomposition approach is its usefulness in examining how marginal changes in expenditures for particular components can affect overall inequality. Let us assume that there is a change in each household's expenditure for a particular component $\mathrm{k}$ equal to $\mathrm{ex}_{\mathrm{k}}$. If e represents a percentage change in expenditures for component $\mathrm{k}$ that is identical for all households, the component's 
marginal effect relative to the overall Gini coefficient can be represented as (Garner, 1989):

$$
\frac{\frac{\partial G}{\partial e_{k}}}{G}=\frac{R_{k} G_{S} k_{k}}{G}-S_{k}
$$

The interpretation of the above equation is that the percentage change in the overall Gini, caused by a small change in a commodity expenditure is equal to the commodity's contribution to overall inequality (named as $\mathrm{I}_{\mathrm{k}}$ in the results column). The overall Gini would remain unchanged if all components are multiplied by e (Lerman and Yitzhaki, 1985). The result from equation (8.5) may help to determine the distributional effect of imposing a commodity percentage tax or raising the tax rate, where the tax leads to a small change in commodity expenditures. When the relative marginal effect is positive, taxing a commodity would decrease overall inequality (Garner, 1993). Such a tax would be progressive since it affects the rich more than it affects the poor at the margin. When the relative marginal effect is negative, taxing the commodity would increase inequality, as would be expected from a tax which is regressive (Garner, 1993).

The above method and approach is implemented using total expenditures which are disaggregated into eight categories: food and beverages, housing, apparel, entertainment, health care, transportation, utilities, and personal care and education. Also, inequality in the distribution of expenditures is measured within each of the age categories of 16-24, 25-34, 35-44, 45-54, 55-64, and 65 and above, as well as within each of the two racial subgroups.

As described in chapter 6, microlevel data from the U.S. Consumer Expenditure Interview Survey for the years 1980-1994 are analyzed. Table 6.1 gives descriptions of the measures of inequality. 
Table 6.1: Descriptions of Measures of Inequality

\begin{tabular}{ll}
\hline NAME & DESCRIPTION \\
\hline $\mathrm{C}_{\mathrm{k}}$ & CONTRIBUTION TO TOTAL INEQUALITY FOR COMPONENT K \\
$\mathrm{R}_{\mathrm{k}}$ & CORRELATION TO RANK OF TOTAL EXPENDITURE \\
$\mathrm{G}$ & OVERALL Gini COEFFICIENT FOR THE WHOLE POPULATION \\
$\mathrm{G}_{\mathrm{k}}$ & Gini OF COMPONENT $\mathrm{k}$ \\
$\mathrm{S}_{\mathrm{k}}$ & EXPENDITURE SHARE FOR COMPONENT K \\
$\mathrm{I}_{\mathrm{k}}$ & SHARE EXPENDITURE INEQUALITY FOR COMPONENT K \\
$\mathrm{I}_{\mathrm{k} / \mathrm{S}}$ & RELATIVE EXPENDITURE INEQUALITY FOR COMPONENT K \\
$\mathrm{I}_{\mathrm{k}}-\mathrm{S}_{\mathrm{k}}$ & RELATIVE MARGINAL EFFECT FOR COMPONENT K \\
\hline
\end{tabular}

\subsection{Results and Discussions}

The expenditure inequality effects by budget component are presented in tables $6.3-6.17$ for the years 1980 - 1994. In the discussion of the results, the focus is mainly on the result for the year 1980. There are two reasons for doing this: first, the differences in the Gini inequality in consumption expenditures, among the years from 1980 to 1994 is small. There are no clear patterns or trends of inequality from year to year. Second, by showing how to interpret the results for one year, the reader can make his/her interpretations for the rest, using the same approach.

The first column in the table 6.3 presents the contribution of each budget component to total inequality as identified by $\mathrm{C}_{\mathrm{k}}$. This measure is the product of three terms: the Gini correlation between the budget component and the rank of total expenditures $\left(\mathrm{R}_{\mathrm{k}}\right)$, the component's Gini $\left(\mathrm{G}_{\mathrm{k}}\right)$, and its share of total expenditures $\left(\mathrm{S}_{\mathrm{k}}\right)$. The higher the value of each factor, the greater is the contribution of the budget component to total inequality. The proportion of inequality to total expenditures attributable to each commodity is given in column five as $\mathrm{I}_{\mathrm{k}}$, and is defined as $\mathrm{C}_{\mathrm{k}}$ divided by G. Relative effects are presented in columns six and seven. 
The overall Gini based on the total annual consumption expenditure for the last 15 year is between 0.195 the lowest and 0.281 the highest. The overall Gini ratio (from the total row Table 6.3) of household expenditure inequality for the year 1980 calculated as 0.214 . The Gini coefficient for total expenditure inequality is graphically illustrated in figure 6.1. These numbers indicate a relatively low household inequality in expenditures. Nelson (1994) calculated the Gini for family income inequality as 0.365 (see table 6.19) and a study by Garner (1993) calculated the Gini for income and expenditure inequalities for the 1987 as 0.435 and 0.330 respectively. In both cases the differences between expenditure and income inequalities is around 0.100. The smaller expenditure inequality can be attributed to the consumption and expenditure patterns based on the permanent income theory. Expenditures in one year do not depend only on the income of that year. People with reduced incomes tend to spend from their savings or they may borrow and spend against their expected future income. Also, there are numerous government and community based programs which provide food, energy, medical even cash assistance to millions who are in the lower income brackets. Above all, the major factor for the difference in inequality between consumption and expenditure is that in normal years people usually do not consume everything they earn, some of it goes to savings and investment. As a result of the inequality in consumption is smaller than inequality in income. In general, the overall Gini for expenditure inequality has not changed much through the years from 1980 to 1994.

Expenditures shares for food and beverages, housing, and transportation account for over $50 \%$ of the inequality in total expenditures. Their share of total expenditures is about the same as their share of inequality. Housing and transportation have the highest shares of expenditure inequality as represented by $\mathrm{I}_{\mathrm{k},}, 0.229$ and 0.234 , respectively for 1980 .

A high Gini correlation indicates higher total expenditures with greater spending on the 
individual commodity. Expenditures for food, housing, and transportation are more highly correlated with the rank of total expenditures. High $\mathrm{G}_{\mathrm{k}}$ 's are an indication that there are differences in consumption expenditures. The results in general imply that there are relatively large differences in spending for health care, entertainment, utilities, transportation, and personal care and education. Expenditures for food and beverages, apparel, and housing are fairly equally distributed, relative to expenditures for other commodities.

Relative expenditure inequality $\left(\mathrm{I}_{\mathrm{k} /} \mathrm{S}_{\mathrm{k}}\right)$ measures the inequality for components as a percentage of expenditure shares. These estimates are calculated as the ratio of the proportional contribution to the share of total expenditures. Expenditures for food, housing, entertainment, transportation, and personal care and education contribute more to the inequality in total expenditures than they contribute to total expenditures in terms of their shares.

Changes in expenditures which would lead to reductions in inequality are associated with expenditures categories for which the expenditure shares are greater than the shares of inequality. The direction of the relative marginal relationship indicates the effect at the margin of an increase in expenditures for a component for overall inequality $\left(I_{k}-S_{k}\right)$. These results reveal that increases in expenditures in 1980 for food and beverages, housing, apparel, entertainment, health care, utilities, and personal care and education would have decreased overall inequality in total expenditures, holding all else constant. Table 6.2 illustrates the signs for the overall inequality $\left(I_{k}-S_{k}\right)$ for all commodities for the year between 1980-1994. Food, apparel. And housing expenditures had negative signs in all fifteen years, while transportation had a positive sign in 13 of the 15 years, entertainment was positive about half the time. The other categories all had 13 to 14 years with negative signs. From a policy perspective, increases in overall inequality could be achieved by reducing taxes on these goods and services or by 
exempting them from the tax base. Of the 45 states that levy a general retail sales tax, many exemptions from the tax base apply, serving as a mechanism for providing relief through tax base modification. Food for home consumption, utilities for heating and cooling, and prescription drugs and medical services are exempt from taxation in over half of the states (Case and Ebel, 1989; ACIR, 1990; Garner, 1993). Reductions in overall inequality could also result from introducing or increasing a percentage tax on a commodity for which the relative marginal effect is positive, i.e., on transportation and, possibly, entertainment. These results Thus, taxes could be increased or implemented on specific commodities not only to reduce the degree of inequality, but the improve the welfare households.

Table 6.2: Signs for $\mathrm{I}_{\mathrm{k}}-\mathrm{S}_{\mathrm{k}}$

\begin{tabular}{|l|l|l|l|l|l|l|l|l|}
\hline & FB & HSNG & APP & ENT & HLTH & TRAN & UTIL & TPE \\
\hline 1980 & - & - & - & - & - & ${ }^{\prime}$ & - & 0 \\
\hline 1981 & - & - & - & - & + & + & - & - \\
\hline 1982 & - & - & - & + & - & + & - & - \\
\hline 1983 & - & - & - & - & - & + & + & - \\
\hline 1984 & - & - & - & 0 & - & + & - & + \\
\hline 1985 & - & - & - & - & - & + & - & - \\
\hline 1986 & - & - & - & - & - & + & - & - \\
\hline 1987 & - & - & - & 0 & - & - & - & - \\
\hline 1988 & - & - & - & - & - & - & - & - \\
\hline 1989 & - & - & - & - & - & + & - & - \\
\hline 1990 & - & - & - & - & + & - & - & - \\
\hline 1991 & - & - & - & + & - & + & - & - \\
\hline 1992 & - & - & - & + & - & + & - & - \\
\hline 1993 & - & - & - & + & - & + & - & - \\
\hline 1994 & - & - & - & + & - & + & - & - \\
\hline Total & All (-) & All (-) & All (-) & $8(-) / 5(+)$ & $13(-) / 2(1)$ & $2(-) / 13(+)$ & $14(-) / 1(+)$ & $13(-) / 1(+)$ \\
\hline
\end{tabular}


Inequality in expenditures by age is computed and presented in table 6.18 . The categories are made up of ages 16-24, 25-34, 35-44, 45-54, 55-64, and 65 and over. The overall Gin is within each group are extremely low (all under 0.08) implying that expenditures are fairly equal within each group. Table 6.19 illustrates expenditure inequality based on race: black and white. Again, the overall Gini is for both races are relatively low, and are similar to those for all consumers. The highest Gini for whites is 0.284 in 1988 and the lowest 0.176 in 1981. For blacks the highest Gini is 0.244 in 1984 and the lowest 0.166 in 1991 . These results do not, however, indicate that expenditures are equal between the races; this was not measured. Table 6.20 is included to show the difference between the income and expenditure inequalities.

\subsection{Conclusion}

The focus of this chapter has been to measure inequality in the distribution of consumption expenditures across consumer units in general, consumers grouped based on age, and consumers categorized by race. The overall Gini coefficient and other forms of inequality measures were produced as estimates to shed light on the state of consumer expenditures for the years 1980-1994. These results reveal very important information which can be used in the formulation of policy initiatives. The inequality of household consumption expenditures in particular commodity categories suggests possible targets for additional consumption taxation introduced to reduce the social impact created by other economic inequalities. 
Figure 6.1: Gini Coefficient for Total Expenditure, 1980-1994

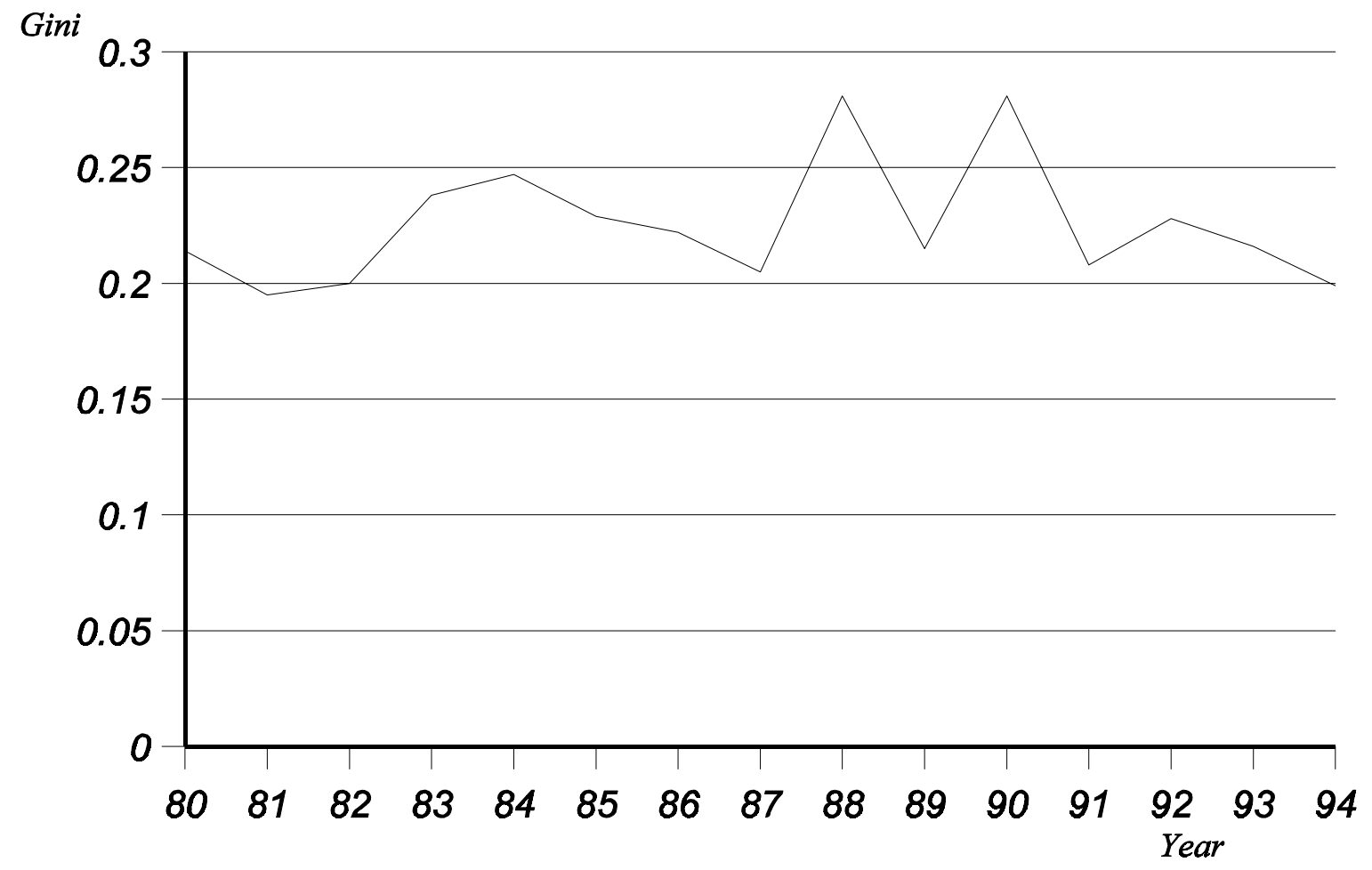

Table 6.3: Expenditure Inequality Effects by Expenditure Component for Year 1980

\begin{tabular}{llllllll}
\hline Component & $\mathrm{C}_{\mathrm{k}}$ & $\mathrm{R}_{\mathrm{k}}$ & $\mathrm{G}_{\mathrm{k}}$ & $\mathrm{S}_{\mathrm{k}}$ & $\mathrm{I}_{\mathrm{k}}$ & $\mathrm{I}_{\mathrm{k}} / \mathrm{S}_{\mathrm{k}}$ & $\mathrm{I}_{\mathrm{k}}-\mathrm{S}_{\mathrm{k}}$ \\
\hline FB & 0.039 & 0.839 & 0.209 & 0.224 & 0.182 & 0.813 & -0.042 \\
HSNG & 0.049 & 0.810 & 0.192 & 0.316 & 0.229 & 0.725 & -0.087 \\
APP & 0.006 & 0.203 & 0.447 & 0.062 & 0.028 & 0.452 & -0.034 \\
ENT & 0.008 & 0.508 & 0.319 & 0.049 & 0.037 & 0.755 & -0.012 \\
HLTH & 0.001 & 0.192 & 0.370 & 0.016 & 0.005 & 0.313 & -0.011 \\
TRAN & 0.050 & 0.814 & 0.298 & 0.205 & 0.234 & 1.142 & 0.029 \\
UTIL & 0.011 & 0.326 & 0.330 & 0.101 & 0.051 & 0.505 & -0.050 \\
TPE & 0.006 & 0.519 & 0.416 & 0.208 & 0.028 & 1.000 & 0.000 \\
TOTAL & 0.214 & 1.000 & 0.214 & 1.000 & 1.00 & 1.000 & 0.000 \\
\hline
\end{tabular}


Table 6.4: Expenditure Inequality Effects by Expenditure Component for Year 1981

\begin{tabular}{llllllll}
\hline Component & $\mathrm{C}_{\mathrm{k}}$ & $\mathrm{R}_{\mathrm{k}}$ & $\mathrm{G}_{\mathrm{k}}$ & $\mathrm{S}_{\mathrm{k}}$ & $\mathrm{I}_{\mathrm{k}}$ & $\mathrm{I}_{\mathrm{k}} / \mathrm{S}_{\mathrm{k}}$ & $\mathrm{I}_{\mathrm{k}}-\mathrm{S}_{\mathrm{k}}$ \\
\hline FB & 0.038 & 0.813 & 0.222 & 0.211 & 0.195 & 0.924 & -0.016 \\
HSNG & 0.053 & 0.770 & 0.211 & 0.323 & 0.272 & 0.842 & -0.051 \\
APP & 0.012 & 0.740 & 0.277 & 0.063 & 0.062 & 0.984 & -0.001 \\
ENT & 0.009 & 0.563 & 0.328 & 0.048 & 0.046 & 0.958 & -0.002 \\
HLTH & 0.010 & 0.218 & 0.371 & 0.017 & 0.051 & 3.000 & 0.034 \\
TRAN & 0.047 & 0.784 & 0.293 & 0.204 & 0.241 & 1.181 & 0.037 \\
UTIL & 0.017 & 0.620 & 0.254 & 0.106 & 0.088 & 0.830 & -0.018 \\
TPE & 0.005 & 0.434 & 0.420 & 0.028 & 0.026 & 0.929 & -0.002 \\
TOTAL & 0.195 & 1.000 & 0.195 & 1.000 & 1.000 & 1.000 & 0.000 \\
\hline
\end{tabular}

Table 6.5: Expenditure Inequality Effects by Expenditure Component for Year 1982

\begin{tabular}{llllllll}
\hline Component & $\mathrm{C}_{\mathrm{k}}$ & $\mathrm{R}_{\mathrm{k}}$ & $\mathrm{G}_{\mathrm{k}}$ & $\mathrm{S}_{\mathrm{k}}$ & $\mathrm{I}_{\mathrm{k}}$ & $\mathrm{I}_{\mathrm{k}} / \mathrm{S}_{\mathrm{k}}$ & $\mathrm{I}_{\mathrm{k}}-\mathrm{S}_{\mathrm{k}}$ \\
\hline FB & 0.036 & 0.860 & 0.220 & 0.192 & 0.180 & 0.938 & -0.012 \\
HSNG & 0.058 & 0.858 & 0.205 & 0.333 & 0.290 & 0.871 & -0.043 \\
APP & 0.012 & 0.788 & 0.248 & 0.061 & 0.060 & 0.984 & -0.001 \\
ENT & 0.011 & 0.722 & 0.297 & 0.049 & 0.055 & 1.120 & 0.006 \\
HLTH & 0.001 & 0.097 & 0.303 & 0.017 & 0.005 & 0.294 & -0.012 \\
TRAN & 0.046 & 0.776 & 0.295 & 0.201 & 0.230 & 1.144 & 0.029 \\
UTIL & 0.016 & 0.534 & 0.264 & 0.114 & 0.080 & 0.702 & -0.034 \\
TPE & 0.006 & 0.385 & 0.432 & 0.034 & 0.030 & 0.882 & -0.004 \\
TOTAL & 0.200 & 1.000 & 0.200 & 1.000 & 1.000 & 1.000 & 0.000 \\
\hline
\end{tabular}


Table 6.6: Expenditure Inequality Effects by Expenditure Component for year 1983

\begin{tabular}{llllllll}
\hline Component & $\mathrm{C}_{\mathrm{k}}$ & $\mathrm{R}_{\mathrm{k}}$ & $\mathrm{G}_{\mathrm{k}}$ & $\mathrm{S}_{\mathrm{k}}$ & $\mathrm{I}_{\mathrm{k}}$ & $\mathrm{I}_{\mathrm{k}} / \mathrm{S}_{\mathrm{k}}$ & $\mathrm{I}_{\mathrm{k}}-\mathrm{S}_{\mathrm{k}}$ \\
\hline FB & 0.037 & 0.881 & 0.227 & 0.186 & 0.155 & 0.833 & -0.031 \\
HSNG & 0.039 & 0.447 & 0.262 & 0.336 & 0.164 & 0.488 & -0.172 \\
APP & 0.008 & 0.434 & 0.296 & 0.060 & 0.034 & 0.567 & -0.026 \\
ENT & 0.008 & 0.437 & 0.356 & 0.050 & 0.034 & 0.680 & -0.016 \\
HLTH & 0.001 & 0.195 & 0.362 & 0.014 & 0.004 & 0.286 & -0.010 \\
TRAN & 0.053 & 0.805 & 0.323 & 0.204 & 0.223 & 1.100 & 0.019 \\
UTIL & 0.053 & 0.453 & 0.311 & 0.116 & 0.223 & 1.900 & 0.107 \\
TPE & 0.006 & 0.373 & 0.426 & 0.035 & 0.025 & 0.714 & -0.010 \\
TOTAL & 0.238 & 1.000 & 0.238 & 1.000 & 1.000 & 1.000 & 0.000 \\
\hline
\end{tabular}

Table 6.7: Expenditure Inequality Effects by Expenditure Component for Year 1984

\begin{tabular}{llllllll}
\hline Component & $\mathrm{C}_{\mathrm{k}}$ & $\mathrm{R}_{\mathrm{k}}$ & $\mathrm{G}_{\mathrm{k}}$ & $\mathrm{S}_{\mathrm{k}}$ & $\mathrm{I}_{\mathrm{k}}$ & $\mathrm{I}_{\mathrm{k}} / \mathrm{S}_{\mathrm{k}}$ & $\mathrm{I}_{\mathrm{k}}-\mathrm{S}_{\mathrm{k}}$ \\
\hline FB & 0.036 & 0.793 & 0.248 & 0.181 & 0.146 & 0.807 & -0.035 \\
HSNG & 0.037 & 0.380 & 0.289 & 0.338 & 0.150 & 0.444 & -0.188 \\
APP & 0.011 & 0.686 & 0.277 & 0.055 & 0.045 & 0.818 & -0.010 \\
ENT & 0.012 & 0.689 & 0.348 & 0.049 & 0.049 & 1.000 & 0.000 \\
HLTH & 0.002 & 0.251 & 0.398 & 0.024 & 0.008 & 0.333 & -0.016 \\
TRAN & 0.053 & 0.722 & 0.348 & 0.210 & 0.215 & 1.020 & 0.005 \\
UTIL & 0.017 & 0.543 & 0.278 & 0.115 & 0.069 & 0.600 & -0.046 \\
TPE & 0.012 & 0.496 & 0.805 & 0.030 & 0.049 & 1.630 & 0.019 \\
TOTAL & 0.247 & 1.000 & 0.247 & 1.000 & 1.000 & 1.000 & 0.000 \\
\hline
\end{tabular}


Table 6.8: Expenditure Inequality Effects by Expenditure Component for Year 1985

\begin{tabular}{llllllll}
\hline Component & $\mathrm{C}_{\mathrm{k}}$ & $\mathrm{R}_{\mathrm{k}}$ & $\mathrm{G}_{\mathrm{k}}$ & $\mathrm{S}_{\mathrm{k}}$ & $\mathrm{I}_{\mathrm{k}}$ & $\mathrm{I}_{\mathrm{k}} / \mathrm{S}_{\mathrm{k}}$ & $\mathrm{I}_{\mathrm{k}}-\mathrm{S}_{\mathrm{k}}$ \\
\hline FB & 0.036 & 0.873 & 0.230 & 0.180 & 0.157 & 0.872 & -0.023 \\
HSNG & 0.069 & 0.865 & 0.238 & 0.335 & 0.301 & 0.899 & -0.034 \\
APP & 0.012 & 0.734 & 0.275 & 0.061 & 0.052 & 0.852 & -0.009 \\
ENT & 0.010 & 0.575 & 0.369 & 0.051 & 0.044 & 0.863 & -0.047 \\
HLTH & 0.002 & 0.189 & 0.452 & 0.024 & 0.009 & 0.375 & -0.015 \\
TRAN & 0.058 & 0.813 & 0.350 & 0.202 & 0.253 & 1.252 & 0.051 \\
UTIL & 0.018 & 0.549 & 0.290 & 0.112 & 0.079 & 0.705 & -0.033 \\
TPE & 0.007 & 0.357 & 0.463 & 0.034 & 0.020 & 0.588 & -0.014 \\
TOTAL & 0.229 & 1.000 & 0.229 & 1.000 & 1.000 & 1.000 & 0.000 \\
\hline
\end{tabular}

Table 6.9: Expenditure Inequality Effects by Expenditure Component for Year 1986

\begin{tabular}{llllllll}
\hline Component & $\mathrm{C}_{\mathrm{k}}$ & $\mathrm{R}_{\mathrm{k}}$ & $\mathrm{G}_{\mathrm{k}}$ & $\mathrm{S}_{\mathrm{k}}$ & $\mathrm{I}_{\mathrm{k}}$ & $\mathrm{I}_{\mathrm{k}} / \mathrm{S}_{\mathrm{k}}$ & $\mathrm{I}_{\mathrm{k}}-\mathrm{S}_{\mathrm{k}}$ \\
\hline FB & 0.033 & 0.841 & 0.223 & 0.176 & 0.149 & 0.847 & -0.027 \\
HSNG & 0.065 & 0.861 & 0.227 & 0.333 & 0.293 & 0.880 & -0.040 \\
APP & 0.010 & 0.757 & 0.251 & 0.059 & 0.045 & 0.763 & -0.014 \\
ENT & 0.009 & 0.473 & 0.347 & 0.053 & 0.041 & 0.774 & -0.012 \\
HLTH & 0.002 & 0.268 & 0.338 & 0.021 & 0.006 & 0.286 & -0.015 \\
TRAN & 0.058 & 0.838 & 0.332 & 0.208 & 0.261 & 1.260 & 0.053 \\
UTIL & 0.020 & 0.556 & 0.297 & 0.121 & 0.090 & 0.744 & -0.031 \\
TPE & 0.006 & 0.462 & 0.427 & 0.030 & 0.027 & 0.223 & -0.003 \\
TOTAL & 0.222 & 1.000 & 0.222 & 1.000 & 1.000 & 1.000 & 0.000 \\
\hline
\end{tabular}


Table 6.10: Expenditure Inequality Effects by Expenditure Component for Year 1987

\begin{tabular}{llllllll}
\hline Component & $\mathrm{C}_{\mathrm{k}}$ & $\mathrm{R}_{\mathrm{k}}$ & $\mathrm{G}_{\mathrm{k}}$ & $\mathrm{S}_{\mathrm{k}}$ & $\mathrm{I}_{\mathrm{k}}$ & $\mathrm{I}_{\mathrm{k}} / \mathrm{S}_{\mathrm{k}}$ & $\mathrm{I}_{\mathrm{k}}-\mathrm{S}_{\mathrm{k}}$ \\
\hline FB & 0.032 & 0858 & 0212 & 0.175 & 0.156 & 0.891 & -0.019 \\
HSNG & 0.049 & 0.618 & 0.235 & 0.335 & 0.239 & 0.713 & -0.096 \\
APP & 0.010 & 0.620 & 0.246 & 0.063 & 0.049 & 0.778 & -0.014 \\
ENT & 0.011 & 0.665 & 0.295 & 0.054 & 0.054 & 1.000 & 0.000 \\
HLTH & 0.002 & 0.267 & 0.313 & 0.021 & 0.010 & 0.476 & -0.011 \\
TRAN & 0.048 & 0.789 & 0.298 & 0.205 & 0.234 & 1.142 & -0.029 \\
UTIL & 0.020 & 0.659 & 0.259 & 0.114 & 0.098 & 0.860 & -0.016 \\
TPE & 0.005 & 0.421 & 0.385 & 0.032 & 0.024 & 0.750 & -0.008 \\
TOTAL & 0.205 & 1.000 & 0.205 & 1.000 & 1.000 & 1.000 & 0.000 \\
\hline
\end{tabular}

Table 6.11: Expenditure Inequality Effects by Expenditure Component for Year 1988

\begin{tabular}{llllllll}
\hline Component & $\mathrm{C}_{\mathrm{k}}$ & $\mathrm{R}_{\mathrm{k}}$ & $\mathrm{G}_{\mathrm{k}}$ & $\mathrm{S}_{\mathrm{k}}$ & $\mathrm{I}_{\mathrm{k}}$ & $\mathrm{I}_{\mathrm{k}} / \mathrm{S}_{\mathrm{k}}$ & $\mathrm{I}_{\mathrm{k}}-\mathrm{S}_{\mathrm{k}}$ \\
\hline FB & 0.031 & 0.782 & 0.224 & 0.179 & 0.110 & 0.615 & -0.069 \\
HSNG & 0.014 & 0.390 & 0.307 & 0.339 & 0.146 & 0431 & -0.193 \\
APP & 0.010 & 0.677 & 0.268 & 0.057 & 0.036 & 0.632 & -0.021 \\
ENT & 0.011 & 0.609 & 0.349 & 0.052 & 0.039 & 0.750 & -0.013 \\
HLTH & 0.002 & 0.225 & 0.338 & 0.023 & 0.007 & 0.304 & -0.016 \\
TRAN & 0.023 & 0.245 & 0.464 & 0.205 & 0.082 & 0.400 & -0.123 \\
UTIL & 0.017 & 0.432 & 0.332 & 0.117 & 0.061 & 0.521 & -0.560 \\
TPE & 0.005 & 0.475 & 0.392 & 0.028 & 0.018 & 0.643 & -0.010 \\
TOTAL & 0.281 & 1.000 & 0.281 & 1.000 & 1.000 & 1.000 & 0.0000 \\
\hline
\end{tabular}


Table 6.12: Expenditure Inequality Effects by Expenditure Component for Year 1989

\begin{tabular}{llllllll}
\hline Component & $\mathrm{C}_{\mathrm{k}}$ & $\mathrm{R}_{\mathrm{k}}$ & $\mathrm{G}_{\mathrm{k}}$ & $\mathrm{S}_{\mathrm{k}}$ & $\mathrm{I}_{\mathrm{k}}$ & $\mathrm{I}_{\mathrm{k}} / \mathrm{S}_{\mathrm{k}}$ & $\mathrm{I}_{\mathrm{k}}-\mathrm{S}_{\mathrm{k}}$ \\
\hline FB & 0.032 & 0.812 & 0.209 & 0.189 & 0.149 & 0.788 & -0.040 \\
HSNG & 0.063 & 0.839 & 0.221 & 0.341 & 0.293 & 0.859 & -0.048 \\
APP & 0.010 & 0.597 & 0.282 & 0.060 & 0.017 & 0.283 & -0.043 \\
ENT & 0.010 & 0.562 & 0.378 & 0.049 & 0.047 & 0.959 & -0.002 \\
HLTH & 0.002 & 0.277 & 0.350 & 0.025 & 0.009 & 0.360 & -0.016 \\
TRAN & 0.049 & 0.778 & 0.333 & 0.187 & 0.228 & 1.22 & 0.041 \\
UTIL & 0.017 & 0.441 & 0.322 & 0.117 & 0.079 & 0.675 & -0.038 \\
TPE & 0.005 & 0.366 & 0.433 & 0.034 & 0.023 & 0.677 & -0.011 \\
TOTAL & 0.215 & 1.0000 & 0.215 & 1.000 & 1.000 & 1.000 & 0.000 \\
\hline
\end{tabular}

Table 6.13: Expenditure Inequality Effects by Expenditure Component for Year 1990

\begin{tabular}{llllllll}
\hline Component & $\mathrm{C}_{\mathrm{k}}$ & $\mathrm{R}_{\mathrm{k}}$ & $\mathrm{G}_{\mathrm{k}}$ & $\mathrm{S}_{\mathrm{k}}$ & $\mathrm{I}_{\mathrm{k}}$ & $\mathrm{I}_{\mathrm{k}} / \mathrm{S}_{\mathrm{k}}$ & $\mathrm{I}_{\mathrm{k}}-\mathrm{S}_{\mathrm{k}}$ \\
\hline FB & 0.030 & 0.784 & 0.211 & 0.183 & 0.107 & 0.585 & -0.076 \\
HSNG & 0.055 & 0.782 & 0.217 & 0.324 & 0.196 & 0.605 & -0.128 \\
APP & 0.011 & 0.693 & 0.259 & 0.060 & 0.039 & 0.650 & -0.021 \\
ENT & 0.011 & 0.615 & 0.338 & 0.051 & 0.039 & 0.765 & -0.012 \\
HLTH & 0.003 & 0.298 & 0.357 & 0.026 & 0.001 & 0.039 & 0.025 \\
TRAN & 0.021 & 0.213 & 0.522 & 0.185 & 0.075 & 0.405 & -0.110 \\
UTIL & 0.020 & 0.345 & 0.442 & 0.130 & 0.071 & 0.546 & -0.059 \\
TPE & 0.006 & 0.496 & 0.395 & 0.032 & 0.021 & 0.656 & -0.011 \\
TOTAL & 0.281 & 1.000 & 0.281 & 1.000 & 1.000 & 1.000 & 0.0000 \\
\hline
\end{tabular}


Table 6.14: Expenditure Inequality Effects by Expenditure Component for Year 1991

\begin{tabular}{llllllll}
\hline Component & $\mathrm{C}_{\mathrm{k}}$ & $\mathrm{R}_{\mathrm{k}}$ & $\mathrm{G}_{\mathrm{k}}$ & $\mathrm{S}_{\mathrm{k}}$ & $\mathrm{I}_{\mathrm{k}}$ & $\mathrm{I}_{\mathrm{k}} / \mathrm{S}_{\mathrm{k}}$ & $\mathrm{I}_{\mathrm{k}}-\mathrm{S}_{\mathrm{k}}$ \\
\hline FB & 0.033 & 0.844 & 0.216 & 0.181 & 0.159 & 0.879 & -0.022 \\
HSNG & 0.064 & 0.861 & 0.218 & 0.339 & 0.308 & 0.909 & -0.031 \\
APP & 0.011 & 0.701 & 0.249 & 0.060 & 0.053 & 0.883 & -0.007 \\
ENT & 0.011 & 0.626 & 0.324 & 0.053 & 0.018 & 0.340 & -0.035 \\
HLTH & 0.003 & 0.324 & 0.322 & 0.030 & 0.014 & 0.467 & -0.016 \\
TRAN & 0.042 & 0.783 & 0.291 & 0.183 & 0.202 & 1.104 & 0.019 \\
UTIL & 0.012 & 0.274 & 0.353 & 0.119 & 0.058 & 0.487 & -0.061 \\
TPE & 0.006 & 0.506 & 0.365 & 0.034 & 0.012 & 0.353 & -0.022 \\
TOTAL & 0.208 & 1.000 & 0.208 & 1.000 & 1.000 & 1.000 & 0.000 \\
\hline
\end{tabular}

Table 6.15: Expenditure Inequality Effects by Expenditure Component for Year 1992

\begin{tabular}{llllllll}
\hline Component & $\mathrm{C}_{\mathrm{k}}$ & $\mathrm{R}_{\mathrm{k}}$ & $\mathrm{G}_{\mathrm{k}}$ & $\mathrm{S}_{\mathrm{k}}$ & $\mathrm{I}_{\mathrm{k}}$ & $\mathrm{I}_{\mathrm{k}} / \mathrm{S}_{\mathrm{k}}$ & $\mathrm{I}_{\mathrm{k}}-\mathrm{S}_{\mathrm{k}}$ \\
\hline FB & 0.030 & 0.804 & 0.210 & 0.176 & 0.132 & 0.750 & -0.044 \\
HSNG & 0.060 & 0.807 & 0.222 & 0.336 & 0.263 & 0.783 & -0.073 \\
APP & 0.008 & 0.465 & 0.283 & 0.059 & 0.035 & 0.593 & -0.024 \\
ENT & 0.012 & 0.676 & 0.331 & 0.052 & 0.053 & 1.020 & 0.001 \\
HLTH & 0.005 & 0.483 & 0.350 & 0.028 & 0.022 & 0.786 & -0.006 \\
TRAN & 0.049 & 0.705 & 0.356 & 0.193 & 0.215 & 1.114 & 0.022 \\
UTIL & 0.020 & 0.361 & 0.436 & 0.126 & 0.088 & 0.698 & -0.038 \\
TPE & 0.004 & 0.330 & 0.411 & 0.030 & 0.018 & 0.600 & -0.012 \\
TOTAL & 0.228 & 1.000 & 0.228 & 1.000 & 1.000 & 1.000 & 0.000 \\
\hline
\end{tabular}


Table 6.16: Expenditure Inequality Effects by Expenditure Component for Year 1993

\begin{tabular}{llllllll}
\hline Component & $\mathrm{C}_{\mathrm{k}}$ & $\mathrm{R}_{\mathrm{k}}$ & $\mathrm{G}_{\mathrm{k}}$ & $\mathrm{S}_{\mathrm{k}}$ & $\mathrm{I}_{\mathrm{k}}$ & $\mathrm{I}_{\mathrm{k}} / \mathrm{S}_{\mathrm{k}}$ & $\mathrm{I}_{\mathrm{k}}-\mathrm{S}_{\mathrm{k}}$ \\
\hline FB & 0.031 & 0.814 & 0.216 & 0.173 & 0.144 & 0.832 & -0.029 \\
HSNG & 0.067 & 0.835 & 0.234 & 0.344 & 0.310 & 0.901 & -0.034 \\
APP & 0.009 & 0.552 & 0.273 & 0.059 & 0.042 & 0.712 & -0.017 \\
ENT & 0.012 & 0.094 & 0.335 & 0.052 & 0.056 & 1.08 & 0.004 \\
HLTH & 0.005 & 0.509 & 0.324 & 0.030 & 0.023 & 0.767 & -0.007 \\
TRAN & 0.050 & 0.773 & 0.356 & 0.181 & 0.232 & 1.282 & 0.051 \\
UTIL & 0.019 & 0.474 & 0.306 & 0.130 & 0.088 & 0.677 & -0.042 \\
TPE & 0.006 & 0.483 & 0.399 & 0.030 & 0.028 & 0.933 & -0.002 \\
TOTAL & 0.216 & 1.000 & 0.216 & 1.000 & 1.000 & 1.000 & 0.000 \\
\hline
\end{tabular}

Table 6.17: Expenditure Inequality Effects by Expenditure Component for Year 1994

\begin{tabular}{llllllll}
\hline Component & $\mathrm{C}_{\mathrm{k}}$ & $\mathrm{R}_{\mathrm{k}}$ & $\mathrm{G}_{\mathrm{k}}$ & $\mathrm{S}_{\mathrm{k}}$ & $\mathrm{I}_{\mathrm{k}}$ & $\mathrm{I}_{\mathrm{k}} / \mathrm{S}_{\mathrm{k}}$ & $\mathrm{I}_{\mathrm{k}}-\mathrm{S}_{\mathrm{k}}$ \\
\hline FB & 0.029 & 0.809 & 0.216 & 0.168 & 0.146 & 0.869 & -0.022 \\
HSNG & 0.059 & 0.811 & 0.213 & 0.343 & 0.297 & 0.866 & -0.046 \\
APP & 0.008 & 0.604 & 0.246 & 0.054 & 0.040 & 0.741 & -0.014 \\
ENT & 0.010 & 0.732 & 0.295 & 0.048 & 0.050 & 1.042 & 0.002 \\
HLTH & 0.005 & 0.547 & 0.336 & 0.029 & 0.025 & 0.862 & -0.004 \\
TRAN & 0.043 & 0.656 & 0.328 & 0.201 & 0.216 & 1.075 & 0.015 \\
UTIL & 0.021 & 0.537 & 0.315 & 0.125 & 0.106 & 0.848 & -0.019 \\
TPE & 0.005 & 0.436 & 0.369 & 0.033 & 0.025 & 0.758 & -0.008 \\
TOTAL & 0.199 & 1.000 & 0.199 & 1.000 & 1.000 & 1.000 & 0.000 \\
\hline
\end{tabular}


Table 6.18: Expenditure Inequality by Age Using the Gini Coefficient.

\begin{tabular}{lllllll}
\hline YEAR & $16-24$ & $25-34$ & $35-44$ & $45-54$ & $55-64$ & $>=65$ \\
\hline 1980 & 0.035 & 0.020 & 0.028 & 0.041 & 0.037 & 0.032 \\
1981 & 0.022 & 0.025 & 0.028 & 0.034 & 0.030 & 0.036 \\
1982 & 0.022 & 0.026 & 0.030 & 0.033 & 0.040 & 0.030 \\
1983 & 0.025 & 0.030 & 0.035 & 0.036 & 0.054 & 0.041 \\
1984 & 0.033 & 0.035 & 0.052 & 0.036 & 0.035 & 0.045 \\
1985 & 0.032 & 0.034 & 0.033 & 0.032 & 0.044 & 0.038 \\
1986 & 0.025 & 0.031 & 0.036 & 0.036 & 0.039 & 0.038 \\
1987 & 0.023 & 0.029 & 0.028 & 0.033 & 0.038 & 0.035 \\
1988 & 0.026 & 0.028 & 0.044 & 0.052 & 0.032 & 0.078 \\
1989 & 0.023 & 0.029 & 0.033 & 0.037 & 0.042 & 0.029 \\
1990 & 0.026 & 0.076 & 0.034 & 0.033 & 0.051 & 0.037 \\
1991 & 0.020 & 0.027 & 0.040 & 0.034 & 0.029 & 0.040 \\
1992 & 0.025 & 0.033 & 0.035 & 0.043 & 0.035 & 0.038 \\
1993 & 0.021 & 0.027 & 0.034 & 0.038 & 0.042 & 0.026 \\
1994 & 0.021 & 0.029 & 0.031 & 0.034 & 0.034 & 0.036 \\
\hline
\end{tabular}


Table 6.19: Expenditure Inequality Effects by Race Using the Gini Coefficient

\begin{tabular}{lll}
\hline YEAR & WHITE & BLACK \\
\hline 1980 & 0.204 & 0.197 \\
1981 & 0.176 & 0.207 \\
1982 & 0.177 & 0.196 \\
1983 & 0.212 & 0.196 \\
1984 & 0.212 & 0.244 \\
1985 & 0.180 & 0.207 \\
1986 & 0.183 & 0.197 \\
1987 & 0.179 & 0.182 \\
1988 & 0.284 & 0.214 \\
1989 & 0.181 & 0.211 \\
1990 & 0.281 & 0.203 \\
1991 & 0.234 & 0.166 \\
1992 & 0.200 & 0.206 \\
1993 & 0.187 & 0.172 \\
\hline 994 & & \\
\hline
\end{tabular}


Table 6.20: Income Inequality

\begin{tabular}{ll}
\hline YEAR & GINI RATIO \\
\hline 1980 & 0.365 \\
1981 & 0.369 \\
1982 & 0.380 \\
1983 & 0.382 \\
1984 & 0.383 \\
1985 & 0.389 \\
1986 & 0.392 \\
1987 & 0.393 \\
1988 & 0.395 \\
1989 & 0.401 \\
1990 & 0.396 \\
\hline Sourc Nen & $(1994)$ \\
\hline
\end{tabular}

Source: Nelson (1994) 


\section{CHAPTER 7. SUMMARY AND CONCLUSION}

\subsection{Background}

The measurement of inequality has long concerned writers in the field of personal income distribution. A casual examination the menu of government programs reveals that distributional considerations play an important role in the formulation of public policy in the United States. There are many different expenditures on social insurance and transfer programs that are designed both to provide a minimal standard of living for the poor as well as reduce the level of inequality, however, there also are some tax and other policies that increase inequality. There are traditional methods of measuring income inequality that help to shed light on the situation in the labor market. However, many issues in the distribution of well-being have remained unanswered.

Using family income as a measure of well-being without taking into account prices and other characteristics may lead to erroneous conclusions about the general welfare of households. Each household has its own characteristics in which its consumption and expenditure patterns are a function of its composition and other demographic factors. A household with five members differs from a household with two members in its expenditure and consumption patterns, given the same amount of resources. Using earnings alone to measure welfare ignores the effects of prices and the impacts of demographic characteristics and may not be a good indicator of welfare disparity.

Economic well-being can be defined in terms of the command individuals or households have over potential consumption. Official income statistics are produced to reflect the consumption potential of individuals or families with money income used most frequently to proxy this consumption potential. However, consumption, rather than income, may be a better indicator of the actual economic welfare of a household. The value of consumption may be much greater than annually reported income to the extent 
that households have accumulated savings or accounting losses from businesses, or because they are able to borrow against future income (Garner, 1993). Thus, one could argue that consumption reflects material well-being in terms of past, current, and expected future income. How a household allocates its income across different consumption categories can affect the overall economic well-being of households differently. Identifying the effects of demographic characteristics of a household, the impact of marginal changes in different expenditures on the inequality of total expenditures can provide useful information, especially for policy makers.

This study addresses two important issues related to measures of economic well-being. The first part analyzes the impacts of demographic characteristics on the expenditure patterns of households using an econometric approach. In this model a system of individual demand functions depend of the prices faced by all households, total expenditures, and attributes such as demographic characteristics that vary among households. There are four categories of demographic characteristics included in the model. These characteristics are represented with a dummy variable valued 1 if true or 0 if false. Consumer expenditures are divided among eight commodity groups and with the share of expenditures of each used as the dependent variable.

1. Food and Beverages: Expenditures on food and beverages at home and away from home.

2. Housing: Expenditures on housing and housing services.

3.Apparel: Expenditures on clothing

4. Entertainment: Expenditures on all forms entertainment.

5. Heath: Expenditures on health and health services.

6. Transportation: Expenditures on transportation.

7. Utilities: Expenditures on utilities. 
8. Personal care and education: Expenditures on personal care and education.

The following demographic characteristics are employed as attributes of individual households; to avoid perfect collinearity the first dummy variable from each group is omitted.

1. Family size: $1,2,3,4,5$ persons.

2.Age of the head of the family: $16-24,25-34,35-44,45-54,55-64,65$ or greater.

3. Region of residence: Northeast, West, Midwest, South.

4. Race: White, black.

The logarithmic indirect translog functional form is used in the application of the model. Aggregate demand functions are obtained by summing over individual functions. Yearly consumer expenditure data for the years 1980-1994 are used in this analysis and combined cross section-time series are used in the econometric estimation..

The second part of this study evaluates inequality in consumption expenditures across consumer units including inequality within time, age and race categories. Gini coefficients are calculated for the total population sample and for demographic subgroups for the years 1980-1994. In addition, the Gini coefficients are decomposed by budget components, using the Lerman-Yitzhaki covariance method, to examine the effects of changes in expenditures on overall inequality. The same data set, the consumer expenditure survey, used in the econometric analysis is also used in estimating inequality in expenditures.

\subsection{Empirical Analysis}

The next two sections summarize the analyses conducted in this study. Section 7.2.1 addresses the econometric model and estimations to measure the impact of demographic characteristics of households on expenditures. Section 7.2.2 presents the summary of the measurement of inequality in the distribution of expenditures. 


\subsubsection{The Impact of Demographic Characteristics}

Based on the conceptual framework discussed in chapter three and the econometric model specified in chapter five, seven equations with eight expenditure shares as endogenous variables, eight explanatory variables representing commodity prices and total expenditures, and fifteen dummy variables for demographic characteristics were estimated using the seemingly unrelated regression method. To avoid perfect multicollinearity, one dummy variable from each category of the demographic attributes is necessarily omitted. All required conditions such as homogeneity, symmetry, and non-negativity conditions were imposed on the system of equations.

In general there is statistically conclusive evidence that demographic characteristics affect the expenditures of households on goods and services. In this section, we discusses the results for three commodities. For detailed discussion of the results please see chapter five. As the age of the head a household and the size of the household increases the rate of expenditure on food and beverages also increases. People living in the western, midwestern, and southern geographical regions spend relatively less money on food and beverages when compared with households living in the northeastern geographical region. The variables representing the race attribute show that blacks spend relatively less on food and beverages than whites which, since, they also have lower incomes indicate lower expenditures too.

The estimates on expenditures on housing and housing related services indicate that a head of a household aged between 25 and 45 spends relatively more than the head of a household aged 16-24. While families living in the west and south spends relatively less money on housing than those in northeast, the variable representing the midwest shows that typical families living in that region have higher relative expenditures than households in the northeast. A household headed by a black relatively 
spends less than a household headed by a white person.

Another interesting result obtained from this analysis is the impact of demographic attributes on health care expenditures. Heads of households who are 45 years old or older spend more money on heath care services than younger heads of households. Also families with two or three members have relatively larger health expenditures than families with a single member. Households residing in the western and midwestern regions allocate relatively more resources for health care services than families living in the northeastern geographical region. At a $95 \%$ level of statistical significance, the analysis confirms that the expenditures for the consumption of health care services by households headed by blacks are relatively less than the expenditures by households headed by whites, and by implication also absolutely lower.

These results confirm that demographic characteristics are important factors in the decision of households to allocate resources for the consumption of goods and services. One may not reach the right conclusions about well being without the inclusion of prices and demographic attributes in the process of measuring inequality. The impact of geographic location of residence has clearly an impact on the patterns of household expenditures. This is directly attributed to differences in the cost of living, but may also be affected by other factors.

All these household attributes have very significant implications not only on the well-being of individuals, but also on the design and implementation of public policy measures to improve the quality of life. For example, low income people spend a major portion of their income on the consumption of food and other basic necessity and the elderly might allocate substantial portion of their income on health care and other health related items. Programs such as the ones financed by the government must identify the expenditure patterns of each subgroup in order to provide right assistance and services. 


\subsubsection{Inequality in the Distribution of Consumption Expenditures}

The overall Gini coefficient is used to produce an estimate of the inequality in the distribution of total household consumption expenditures for the U.S. population based on the consumer expenditure survey ; Gini coefficients are also calculated for age and racial subgroups, and by expenditure budget components. The following parameters are used to measure the inequality:

G : Overall Gini Coefficient.

$\mathrm{G}_{\mathrm{k}}$ : Gini coefficient for component k, age k or race k..

$\mathrm{C}_{\mathrm{k}}$ : Contribution to total inequality of component $\mathrm{k}$.

$\mathrm{R}_{\mathrm{k}}$ : Correlation with rank of total expenditures of component $\mathrm{k}$.

$\mathrm{S}_{\mathrm{k}}$ : Expenditure share of component $\mathrm{k}$.

$\mathrm{I}_{\mathrm{k}}$ : Share expenditure inequality of component $\mathrm{k}$.

$\mathrm{I}_{\mathrm{k}} / \mathrm{S}_{\mathrm{k}}$ : Relative expenditure inequality of component $\mathrm{k}$.

$I_{k}-S_{k}:$ Relative marginal effect of component $k$.

All of these parameters are calculated for the years 1980 through 1994. The expenditure categories are the same as the ones in the econometric analysis and the same data are used to measure inequality. The results only for the year 1980 are discussed in this section, for a more detailed discussion see chapter 6 .

The overall Gini coefficient of the whole population for 1980 is 0.214 , with 0 being the lowest (no inequality) and 1 the highest. The disparity in consumption expenditures appears to be high for the following goods and services: apparel $=0.447$, entertainment $=0.319$, heath care $=0.370$, utility $=0.330$, and personal care and education $=0.416$. Four commodities: food $=0.224$, housing $=0.316$, transportation $=0.205$, and personal care and education make up over $65 \%$ of the total share of expenditures and contribute over $50 \%$ of the inequality in the total expenditures. 
To determine the contribution of each budget component to the overall Gini, the column under $I_{k}$ (in tables 6.3-6.17) presents the proportion of inequality of total expenditures attributable to the component. This proportion is given by the ratio of each component's contribution to total inequality to the overall Gini $\left(\mathrm{C}_{\mathrm{k}}\right.$ divided by $\left.\mathrm{G}\right)$. Expenditures on food, housing, and transportation exhibit the highest correlations with the rank of total expenditures. A high Gini correlation means that the higher the total expenditures the greater the spending on an individual commodity. Relative measures of inequality are presented in the last two columns of tables 6.3-6.17. The relative expenditure inequality $\left(I_{k} / S_{k}\right)$ measures the inequality for components as a percentage of expenditure shares. Relative expenditure inequalities are calculated as the ratio of proportional contribution to the share of total expenditures. Expenditures for food, housing, entertainment, transportation, and personal care and education contribute greater, proportionally, to the inequality in total expenditures than they contribute to total expenditures in terms of their shares. The last column presents the relative effect of marginal increase in each budget component. The component would exert a negative effect on inequality if the relative marginal effect is negative. For 1980, all components have this negative effect except for expenditures on transportation and personal care and education.

Overall Ginis were also calculated for expenditures based on age and race. The Gini measuring inequality within each age group indicate nearly equal expenditures, implying that incomes are probably relatively uniform within each age group. Also disparity in expenditures within black and white groups is similar to that for the entire sample, but the measures do not reflect the degree of inequality between the two groups.

The material well-being of the population, as defined in terms of expenditures, is evaluated in terms of the inequality across consumer units in the United States in 1980-1994. Results presented in this 
study shed light about the state of our well-being through measuring inequality in expenditures. From these measures one may be able to deduce broader implications, especially in terms of designing the right government policies towards improving the welfare of the lower income class. Slesnick (1994) pointed out that an indicator of well being that is consistent with economic theory should be based on consumption. In spite of this, the preponderance of empirical evidence on inequality in the United States is based on the income distribution (Slesnick,1994). Income might have performed poorly as a proxy for household welfare in measuring inequality.

\subsection{Conclusions and Policy Implications}

This study has addressed two important issues, the impact of demographic attributes on expenditures and inequality in expenditures which are directly related to economic well being. Household's ability to improve its state of well-being is very much affected by its ability to increase its level of consumption through increasing expenditure. The level of expenditure is influenced by the compositions and demographic characteristics of a household. The impacts of demographic characteristics of households on consumption expenditures was fully examined using an econometric model. The results of the analysis reveal that demographic characteristics of households such as age, family size, geographic location of residence, and race have direct effects on the consumption patterns of households. For example, as the age of the head of the household increases the share expenditures allocated for medical services also increases. The implications of this phenomenon is that a relatively high proportion of income of the elderly goes to medical services instead of entertainment or transportation. The allocation of resources for food and beverages depend on the size of the family. As the number of people in the household increases so does the expenditure share. From the interpretations and inspections of the results one can clearly see a well defined patterns in expenditure distributions given 
the demographic characteristics of households. The second main objective of this study is to measure inequality in consumption expenditures using the Gini coefficient method. The results obtained from this analysis show that while there is little change in the overall Gini ratio and fairly low inequality in expenditures when compared to incomes from 1980 to 1994, there is ample evidence that there exist bigger disparity in consumption expenditures for commodities such as apparel, health care, entertainment, transportation, and personal care and education. There is very little differences in inequality within age and race groups, but there might be between groups. Comparisons also are made between expenditure and income inequalities to confirm that the Gini for expenditure is smaller than the Gini for income. While no evidence is available from this study, one reason for the difference is that people may not spend all their earnings on consumption of goods and services. A part of their previous income could have been saved or invested; they use those savings when their incomes decline. In general, the method applied to measure inequality has provided a comprehensive framework for analyzing not only the inequality in expenditures; but the marginal effects of the consumption of each commodity on inequality.

An indicator of well-being that is consistent with economic theory should be based on consumption. In this study we have shown that consumption is affected by demographic characteristics of a household, prices, geographic location of residence, and race which are major factors that should be included in measuring welfare. Without taking these factors into account, putting a household into a certain income groups and making comparisons among households can cause erroneous conclusions. As a result, income inequality overstates consumption-based inequality measures by a substantial amount (Slesnick, 1994). While income inequality measures inequality based on current income, expenditure inequality may not reflect inequality based on the current income. Without some of the expenditures coming from life time savings and future income, expenditure inequality based on current income could 
be larger than what is presented in this study. Future income is not earned income.

Results presented from measuring inequality in consumption expenditures substantiate the importance of evaluating the differential impacts of proposed policies on subgroups of the population and differences in inequality which can result when expenditures for budget components change.

\subsection{Limitations and Future Research}

This study does not answer all the questions related to demographic attributes and expenditure inequality. There are numerous unanswered question towards identifying the core sources of inequality in expenditures and the effects on demographic characteristics. One major limitation of the data set is that price does not vary adequately if a study uses a yearly data. Price is a measure factor affecting household expenditure. This problem could affect the precision of the parameters estimated. Also, price differences between urban and rural areas is not desegregated. Using the average price for both rural and urban consumers may not reflect the real price the consumers face at the market place. Households may not pay the same price for the same quantity and quality of goods consumed. Price data should be obtained from households instead of using the labor statistics aggregated price. Pseudo prices may be considered as a proxy for price which can be calculated from expenditure and quantity of goods and services.

It is important that one not get the impression that income inequality and consumption inequality are the same. In terms of measuring the well-being of households income or expenditure inequality or both can be employed. But income must be comprised of current income, income from assets, benefits gained from existing properties such as old cars, houses and other facilities used by the household free of charge. These benefits must be translated into income to reflect how well off the household is. Basically, it is the same as using the permanent income approach. Current income alone may not reflect 
the well-beingness of a household and inequality measurement based on current income alone is inadequate. Rather, inequality based on expenditures is better than the inequality measured based on current income. Current consumption of goods and services does not solely depend on current income. Besides depending on current income, current consumption of goods and services depends on direct and indirect monetary and non-monetary benefits including future income and current government cash and in-kind assistance. Future studies on inequality and well-beingness must consider these and other sources on incomes and benefits.

This study can be expanded to learn more about economic of well-being by using a better methodology and data set. The impact of demographic characteristics can be analyzed more effectively using true panel data. The main advantage of panel data, compared to a single cross-section or a timeseries, is that it allows one to control for temporally persistent differences among individuals or firms that in many instances may bias estimates obtained from cross-sections. Hsiao (1985, 1986), Klivmarken (1989), and Solon (1989), and Baltagi (1995) list several advantages and benefits from using panel data. The most visible advantages are the following:

1. Controlling for individual heterogeneity. Panel data treats individuals firms, states or countries as heterogenous. Time series and cross-section studies are not adequately capable of controlling for this heterogeneity and run the risk of obtaining biased results (Moulton, 1986, 1987).

2. Panel data give more informative data, more variation, less collinearity among variables, more degrees of freedom and more efficiency compared to time series. Multicollinearity is a common problem in time series studies. Panel data usually give researchers a large number of data points, increasing the degree of freedom and reducing the collinearity among independent variables, hence improving the efficiency of econometric estimates. With this more informative data one 
can produce more reliable parameter estimates.

3. Panel data are more convenient in the study of dynamic adjustments. Cross-sectional distributions that look relatively stable, do not fully reveal a multitude of changes. Spells of unemployment, job turnover, residential and income mobility are better studied with panels. Panel data are also well suited in the study of the duration of economic states like unemployment and poverty, and if these panels cover a long enough time period, they can shed light on the speed of adjustments to economic policy changes (Baltagi, 1995). Panel data are also useful for the estimation of inter-temporal relations, life-cycle and inter-generational models.

4. Panel data are useful in identifying and measuring some effects that are not detectable in crosssectional and time-series data. Based on the example given by Ben-Porath, suppose we have a cross-section of women with a 50\% average yearly labor force participation rate. This may be the results of:

a. Each woman having a 50\% chance of being in the labor force, in any given year, b. $50 \%$ of the women work all the time and $50 \%$ do not.

Case (a) has higher turnover, while case (b) has no turnover. Only panel data could make distinctions between these two cases. Another example is the determination of whether union membership increases or decreases wages. This can be better answered as we observe a worker moving from union to nonunion jobs or vice versa. Holding the individual characteristics constant, we can determine whether union membership affects wages and by how much (Freeman, 1984).

5. Panel data models allow the constructing and testing of more complicated behavioral models than regular cross-sectional and time series data. Also, fewer restrictions need to be imposed on 
a distributed lag model than in a purely time series study (Hsiao, 1986).

Panel data has its own limitations. Some of the limitations include:

1. Problems of Survey Design and Data Collection: These include problems of coverage (incomplete account of the population of interest), non-response (due to lack of cooperation of the respondent or errors in framing the questions to solicit information), recall (respondent not remembering clearly), frequency of interviewing, interview spacing, reference period, the use of bounding and the time-in-sample bias (Bailar, 1989).

2. Distortions of Measurement Errors: Measurement errors may arise as a result of faulty responses due to unclear questions, memory errors, deliberate distortion responses, inappropriate informants, mis-recording of responses and interviewer effects (Kalton, Kasprzyk and McMillen, 1989).

3. Short Time-Series Dimension: Typical panels involve annual data covering a short panel of time for each individual (Baltagi, 1995). This means that asymptotic arguments depend crucially on the number of individuals tending ti infinity. Increasing the time span of the panel is not without cost.

Future research in the area of measuring expenditure inequality must include out-of-pocket expenditures, including expenditures for savings and taxes paid. This approach would provide information more related to permanent income which ultimately would help us to narrow down differences between income and expenditures. 


\section{REFERENCES}

Advisory Commission on Intergovernmental Relations (ACIR). (1990). Significant Features of Fiscal Federalism, Vol. 1, Budget Processes and Tax Systems, M-169.

Ahearn, Mary, J. Johnson, and R. Strickland, (1985), “The Distribution of Income and Wealth of Farm Operator Households", Paper Presented at the AJAE meeting, Ames, Iowa.

Allison, Paul, (1978), “Measures of Inequality”, American Sociological Review 43, 865-880.

Atkinson, A.B., (1970), “ On Measurement of Inequality, “ Journal of Economic Theory 2 (3) September, 244-263.

, (1983). Social Justice and Public Policy, The MIT Press, Cambridge, Massachusetts.

Bailar, B.A., (1973). "Information Needs, Surveys, and Measurement Errors", in D. Kasprzyk, G.J. Ducan, G. Kalton and M.P. Singh, eds., Panel Surveys, John Wiley: New York, 1-24.

Baltagi, B.H, (1995). Econometric Analysis of Panel Data, John-Wiley and Sons

Barten, A.P., (1964), "Family Composition, Prices and Expenditure Patterns", in Colston Papers 16,277293.

Beach, C.M., and R. Davidson, (1983), "Distribution-Free statistical Inference with Lorenz Curves and Income Shares", Review of Economics and Statistics 59, 56-66.

Beach, C.M., (1977), "Cyclical Sensitivity of Aggregate Income Inequality", Review of Economics and Statistics, 59, 56-66.

Bergson, Abram, (1938), "A Reformulation of Certain Aspects of Welfare Economics", Quarterly Journal of Economics, 52(February), 310-34.

Berrebi, M., and J. Silber, (1985), "Income Inequality Indices and depravation: A Generalization", Journal of Economics 99, 807-810.

, (1987, "Regional Differences and the Components of Growth and Inequality Change", Economic Letters 25, 295-298.

Bishop, J.A., K.V. Chiou, and J.P. Formby, (1992), "Truncation Bias and the Ordinal Evaluation of Income Inequality". Working Paper, Department of Economics, University of Alabama.

Bishop, J.A., K.V. Chow, and J.P. Formby, (1991a), “A Stochastic Dominance Analysis of the Effects of Growth and Recessions on the U.S. Income Distribution, 1967-1986, Souther Economic 
Journal 57, 936-946.

-, (1991b), "A large Sample Test for Differences between Lorenz and

Concentration Curves". Working Paper Department of Economics, University of Alabama.

Bishop, J.A. and John Formby, (1994). "A Dominance Evaluation of Distributions of Income and the Benefits of Economic Growth". In The Changing Distribution of Income", ed. Bergstrand, J.H., T.F. Cosimano, J.W. Houck and R.G Sheehan, in Open U.S. Economy, North Holland.

Bishop, J.A., K.V. Chow, J.P. Formby, and C.C. Ho, (1993), Tax Payer Non-compliance and the Distribution of Income and Tax Burdens in the United States: Evidence from Recent TCMP Audits.Report to the KPGM Peat Marwick Foundation and the Division of Research of the Internal Revenue Service. Department of Economics University of Alabama.

Bishop, J.A., J.P. Formby, and R. Sakano, (1992a), "Lorenz stochastic Dominance Comparisons of European Income Distributions", in C. Dagum and A,. Lemmi (eds.), Research on Income Inequality, Vol. 6, Greenwich, CT: JAI press.

Bishop, J.A., J.P. Formby, and W.J. Smith, (1991a), "Lorenz Dominance and Welfare: Changes in the U.S. Distribution of Income", 1967-1986, Review of Economics and Statistics 73, 134-139. , (1991b), "International Comparisons of Income Inequality: Test for Lorenz Dominance Across Nine Countries", Economica, 58, 461-477. (1992), "International Comparisons of Welfare and Poverty",Canadian Journalof Economics, XXVI, No. 3, August, 707-726.

Bishop, J.A., J.P. Formby, and P.D. Thistle, (1991), "Rank Dominance and International Comparisons of Income Distributions", European Economic Review 35, 1399-1410.

Bishop, J.A., J.P. Formby, and P.D. Thistle, (1992a), "The Convergence of South and Non-South Income Distributions, 1969-1979", American Economic Review 82, 262-272. , (1992b), "The Convergence and Divergence of Regional Income Distributions and Welfare". Working Paper, Department of Economics, University of Alabama.

Bishop, J.A., J.P. Formby, and L.P. Zeager, (1992a), "Evaluating a Neglected dimension of Economic Development: Mortality, Risk Aversion and Uncertainty", International Journal of Economics and Finance.

, (1992b), "Nutrition and Non-Participation in the U.S. food Stamp Program", Applied Economics 24, 945-949. 
Blaylock, J. and D. Smallwood, (1982), “Analysis of Income and Food Expenditure Distribution”, Review of Economics and Statistics 64, 104-109.

Blinder, A.S. and H.Y. Esaki, (1978), "Macroeconomic Activity and Income Distribution in the Postwar United States", Review of Economics and Statistics, 61, 604-609.

Blundell, Richard, Martin Browning, Costas Meghir, (1994), "Consumer Demand and Life-Cycle Allocation of Household Expenditures", Review of Economic Studies 61, 57-80.

Braun, Denny, (1988), "Multiple Measurement of U.S. Income Inequality", The Review of Economics and Statistics, Vol. LXX, Number 3, 398-405.

Budd, Edward C., (1970), "Changes in the size of Distribution of Income in the U.S.", American Income Review 60, 247-260.

Case, Bradford and Robert Ebel, 1989, Using State Consumer Tax Credits for Achieving Equity, National Tax Journal 42, 323-337.

Dalton, H., (1920), “ The Measurement of the Inequality of Income, " Economic Journal 30 (119) September, 361-384.

Deaton, A., (1982), "Inequality and Needs: Some Experimental Results for Sri Lanka, in Yoram BenPorath, ed., Income Distribution and The family", A supplement to Population and Development Review 8, 35-49. $109-126$.

Deaton, A. and J. Muellbauer (1980), "An Almost Ideal Demand System", American Economic Review, $70,312-326$.

Dorfman, Robert, (1979), "A Formula for the Gini Coefficient", Review of Economics and Statistics, Vol. LXI, No.1, February, 146-149.

Donaldson, D. and J. Weymark, (1980), "A single Parameter Generalization of the Gini Indices of Inequality", Journal of Economic Theory 22, 67-87.

, (1983), "Ethically Flexible Gini Indices for Income Distribution in the Continuum", Journal of Economic Theory, April, 353-358.

Fei, J., Gustav Ranis, and Shirely Kuo, (1978), "Growth and the Family Distribution of Income by Factor Components", Quarterly Journal of Economics 92, 17-53. 
Fisher, F.M. (1956), “ Income Distribution, Value Judgements, and Welfare, “ Quarterly Journal of Economics, May, 380-424.

Fisher, F.M and K. Shell, (1967). "Taste and Quality Change in the Pure Theory of the Cost of Living", in: J.N. Wolf, ed., Value and Capital: Essays in Honor of Sir John Hicks, Edinburgh.

Foster, J.E. and A.F. Shorrocks, (1988), "Poverty Orderings", Econometrica 56, 173-177.

Freeman, R.B., (1984), "Longitudinal Analysis of the Effects of Trade Unions", Journal of Labor Economics 2, 1-26.

Friedman, M., (1957). A Theory of Consumption Function, National Bureau of Economic Research, Princeton, N.J.: Princeton University Press.

Garner, Thesia, (1993), "Consumer Expenditures and Inequality: An Analysis Based on Decomposition of the Gini Coefficient", The Review of Economics and Statistics, 134-138.

Gastwirth, Joseph, (1972), "The Estimation of the Lorenz Curve and Gini Index", $\underline{\text { Review of Economics }}$ and Statistics 54, Aug.

Graaff, J., (1957), Theoretical Welfare Economics, London: Cambridge University Press.

Gorman, William, (1953), "Community Preference Fields", Econometrica 21, No. 1(January):63-80.

Hammod, Peter, (1976, "Equity, Arrow's Conditions, and Rawl's Difference Principle", Econometrica, Vol.44, No. 4, 793-809.

Herwaarden, Floor and Arie Kapteyn, (1981), "Empirical Comparison of the Shape of Welfare Functions", European Economic Review, 15, 262-286.

Hicks, J.R.., (1939), "The Foundation of Welfare Economics," Economic Journal, 49, No. 196, (December), 696-712.

Hicks, J.R. and R.G.D. Allen, (1934), " A Consideration of the Theory of Value", Economic, 1, 52-75, 196-219.

Houthakker, H.S., (1950) "Revealed Preference and Utility Function", Economic, 17, 159-174.

Hsiao, Chen, 1985, "Benefits and Limitations of Panel Data", Econometric Reviews 4, 121-174. , (1986), Analysis of Panel Data, Cambridge University Press, Cambridge.

Husted, Thomas, 1991, "Changes in State Income Inequality from 1981 to 1987", The Review of 
Regional Studies, Number 3, 248-260.

Iyengar, Sreenivasa, (1960), "On a Method of Computing Engel Elasticities from Concentration Curves", Econometrica, 28(4), 882-891.

Jonish, James F. and James Kau, (1973), "State Differentials in Income Inequality", Review of Social Economy 31, 179-190.

Jorgenson, D.W., L.J. Lau, and T.M. Stocker, (1980), “A Welfare Comparison Under Exact Aggregation”, American Economic Review 70 (2) May, 268-272.

-, (1982), “The Transcendental Logarithmic Model of Aggregate Consumer Behavior", Advances in Econometrics, Vol. 1, Greenwich: JAI Press, 97-238.

, (1981), Aggregate Consumer Behavior and Individual Welfare, In D Currie, R. Nobay, and D. Peel (eds.), Macroeconomic Analysis, London, Croom- Helm, 35-64.

, 1982), "The Transcendental Logarithmic Models of Aggregate Consumer Behavior", in R.L. Basmann and G.F. Rhodes, Jr. (Eds.), Advances in Econometrics, Vol. 1, Greenwich, CT., JAI Press: 97-238.

Jorgenson, D. W. and Daniel T. Slesnick, (1984), “ Aggregate Consumer Behavior and the Measurement of Inequality, " Advances in Econometrics, Vol. 3, Greenwich: JAI Press, 67-130.

Just, Richard E., Darrel L. Hueth, and Andrew Schmitz, (1982), Applied Welfare Economics and Public Policy. Englewood Cliffs, N.J.: Prentice-Hall.

Kakwani, N., (1980), Income Inequality and Poverty methods of Estimation and Policy Applications, New York: Oxford University Press.

, (1978), "A New Method of Estimating Engel Elasticities", Journal of Econometric 8, 103-110.

Kakwani, N. and N. Podder, (1973), "On the Estimation of Lorenz Curves from Grouped Observations", International Economic Reviews, Vol. 14, No. 2, 278-292.

, (1976), "Efficient Estimation of the Lorenz Curve and Associated Inequality Measures from Grouped Observations", Econometrica, 44(January): 138-148.

, (1977), "Application of Lorenz Curve in Economic Analysis", Econometrica 45 (April), 719-727.

Kaldor, Nicholas, (1939), "Welfare Proposition of Economics and Interpersonal Comparisons of 
Utility", The Economic Journal, 49, No. 195(September), 549-52.

Kalton, G., Kasprzyk and D. McMillen, (1989), "Nonsampling Errors in Panel Surveys", in D. Kasprzyk, G.J. Ducan, G. Kalton and M.P. Singh, eds., Panel Surveys, John Wiley: New York, 249-270.

Kapteyn, A., (1977), A Theory of Preference Formation, Leyden University, Unpublished Ph.D. Thesis.

Kirman, A.P., (1987), Pareto as An Economist", in J. Eatwell et al. (eds.), The New York Palgrave: A Dictionary of Economics, London, Macmillan.

Klevmarken, N.A., (1989), "Panel studies: what can we learn from them? Introduction", European Economic Review 33, 523-529.

Knott, J., (1970), "The Index of Income Concentration in the 1970 Census of Population and Housing", Working Paper Available from the Population Division, U.S. Bureau of Census.

Kolm, S.C., (1969), The Optimal Production of Social Justice, In J. Margolis and H. Guitton (eds.), Public Economics, London, Macmillan: 145-200.

Kolm, S.C. (1976a and 1976b), "Unequal Inequalities I and II," Journal of Economic Theory 12 (3) June: 416-442, and 13(1) August, 82-111.

Lau, Lawrence J., (1977a), "Complete Systems of Consumer Demand Functions Through Duality", in eds. Michael Intriligator and David A. Kendrick, Frontiers of Quantitative Economics, vol. 3, 59-86. Amsterdam: North Holland.

, (1977b), "Existence Conditions for Aggregate Demand Functions: The Case of Multiple Indexes". Technical Report No. 248 (October), Stanford, CA.

Lancaster, K. (1966), "A New Approach to Consumer Theory", Journal of Political Economy 84.

Lerman, R.I., and S. Yitzhaki, (1985), "Income Inequality Effects by Income Source: A New Approach and Applications the United States", Review of Economics and Statistics 67 (1), 151-156.

, (1984), "A Note on the Calculation and Interpretation of the Gini Index", Economic Letters $15,363-368$.

Lerner, A.P. 1946. The Economic of Control. New York: Macmillan.

Little, I.M.D., (1957), Critic of Welfare Economics. $2^{\text {nd }}$ ed., Oxford: Clarendon Press.

Lyengar, S., (1960), "On a Method of Computing Engel Elasticities from Concentration Curves", Econometrica 28 (4), 882-891. 
Marshall, Alfred, (1920), Principles of Economics. $8^{\text {th }}$ ed. London: Macmillan \& Co.

Modigliani, Franco, (1986), "Life Cycle, Individual Thrift, and the Wealth of Nations", American Economic Review, June, 76(3): 297-313.

Moon, Marilyn, (1977), "The Economic Welfare of the Aged and Income security programs,"in Improving Measurement of Economic Well-Being, ed. Moon, Marilyn and Eugene Smolensky, New York: Academic Press.

Morgan, James, (1962), "The Anatomy of Income distribution", The Review of Economics and Statistics $44,270-283$.

Moulton, B.R., (1986), "Random Group Effects and the Precision of Regression Estimates, Journal of Econometrics 32. 385-397.

------------, (1987), "Diagnosis for Group Effects and the Precision of Regression Estimates, Journal of Business and Economic Statistics 5, 275-282.

Muellbauer, J., (1974a), "Household Composition, Engel Curves and Welfare Comparisons Between Households: A Duality Approach", European Economic Review 5 (2) August, 103-122.

, (1974b), " Inequality Measures, Prices and Household Composition", Review of Economic Studies 41 (128) October, 493-504.

, (1974c), "Prices and Inequality: The United Kingdom Experience", Econometric Journal 84(333) March, 32-55.

-----------, (1973), "Taste and Quality Change and the True Cost of Living Index: The Implications of Economic Theory of Measurement", Discussion Paper No.2 (Economics Department, Birkbeck College).

----------, (1975), "Aggregation, Income Distribution, and Consumer Demand", $\underline{\text { Review of }}$ Economic Studies 42, No. 132 (October): 525-543.

Nelson, Charles, (1994), "Levels of and Changes in the Distribution of U.S. Income", in The Changing Distribution of Income in Open U.S. Economy, ed. Bergstrand, J.H., T.F. Cosimano, J.W. Houck and R.G. Sheehan, North Holland.

Osberg, Lars, (1984), Economic Inequality in the United States, New York: M.E. Sharpe.

Paglin, M., (1975), "The Measurement of Trends of Inequality: A Basic Revision", American Economic Review 65, 598-609. 
Pareto, V., (1896), Cours D'Economie Politique, 2, Lausanne.

Pigou, A.C., 1946, The Economics of Welfare, London: Macmillan \& Company Ltd.

Pollak, R.A., (1981), "The Social Cost of Living Index", Journal of Public Economics" 15, (3) June,311336.

Pollak, R.A. and T.J. Wales, (1979), "Welfare Comparisons and Equivalent Scales", American Economic Review 69, (2) May, 216-221.

Porter, Philip and Daniel Slottje, (1985), "A comprehensive Analysis of Inequality in the Size Distribution of Income for the United States, 1952-1981," Southern Economic Journal 52(2) October, 412-420.

Pyatt, G., C. Chen, and J. Fei, (1980), "The Distribution of Income by factor Components", Quarterly Journal of Economics 95, 451-473.

Rao, V.N., (1969), "Two Decompositions of Concentration Ratios", Journal of the Royal statistical society, Series A, 132, 418-425.

Reynolds, M. and E. Smalsky, (1977), Public Expenditures, taxes, and the Distribution of Income, New York: Academic Press.

Ricardo, David, 1829, The Principles of Political Economy and taxation, London: Macmillan and Company Ltd..

Roberts, K.W.S ,(1980c), Price Independent Welfare Prescriptions, Journal of Public Economics 13(3) June, 277-298.

Robins, L., (1932), An Essay on the Nature and Significance of Economic Science, London, Macmillan.

Sale, Tom S., (1974), "Interstate Analysis of the size Distribution of Family Income 1950-1970", Southern Economic Journal 40, 434-441.

Samuelson, P.A., 1942, Consistence of Marginal Utility of Income, Studies in mathematical Economics in Memory of Henry Schultz, ed. O. Lange et al. Chicago: University of Chicago Press. $1-29$.

-----------, (1956), "Social Indifference Curves", Quarterly Journal of Economics 70, (1) February, $1-22$.

Saposnik, R., (1981), “Rank Dominance”, Public Choice 6, 147-151. 
, (1983), "On Evaluating Income Distribution: Rank Dominance, the Suppes-Sen Grading Principle of Justice, and Pareto Optimality", Public Choice, 40, 329-336.

Schwarz, J. and c. Winshing, (1979), The Welfare Approach of Measuring Inequalities, in KarlF. Schuessler (ed.), Sociological Methodology 1980, San Francisco: Jossey-Bass.

Scitovsky, T., 1941, “A Note on Welfare Proposition in Economics”, Review of Economic Studies, 9, No. 1(November), 77-88.

Sen, A.K., (1973), On Economic Inequality, Oxford: Claredon Press.

Shalit, H., (1985), "Calculating the Gini Index for Individual Data”, Oxford Bulletin of Economics and Statistics 47, 185-189.

--------------, (1983), "On Evaluating Income Distributions: Rank Dominance, the Suppes-Sen Grading Principle of Justice, and Pareto Optimality", Public choice 40, 329-336.

Shorrocks, A.F., (1983), "Ranking Income Distributions", Economic 50, 3-17. 193-211.

Silber, Jacques, (1989), "Factor Components, Population Subgroups and the Computation of the Gini Index of Inequality", The Review of Economics and Statistics, 71(1): 107-116.

Slesnick, D.T., (1994), "Consumption, Needs and Inequality", International Economic Review, vol. 35, No. 3, 677-703.

Slottje, Daniel J., (1989), The Structure of Earnings and the Measurement of Income Inequality in the U.S., Amsterdam: North Holland.

Solon, G.S., (1989), The Value of Panel Data in Economic Research, in D. Kasprzyk, G.J. Ducan, G. Kalton and M.P. sign, eds., Panel Surveys, John-Wiley, New York, 486-496.

Soltow, Lee, (1971), Pattern of Wealthholding in Wisconsin Since 1850, Madison: Wisconsin University Press.

Stewart, Allen, (1954), "The Correlation Between Variate Values and Ranks in Samples from a Continuous Distribution", British Journal of Statistical Psychology, Vol. VIII, 25-27.

Theil, H., (1967), Economics and Information Theory, Amsterdam: North-Holland Pub. Co.

U.S. Department of Labor (1979-1994), Consumer Expenditure Survey: Interview Survey, Bureau of 
Labor Statistics.

Van Praag, Bernand, (1994), Ordinal and Cardinal Utility: An Integration of Two Dimensions of the Welfare Concept, in the Measurement of Household Welfare, Edited by: Richard Blundell, Ian Preston and Ian Walker, Cambridge University Press. (1971), "The Welfare Function of Income in Belgium: An Empirical Investigation", European Economic Review, 2, 337-369.

Viscusi, Kip, (1979), Welfare of the Elderly: An Economic Analysis and Policy Prescription, John Wiley \& Sons.

Yitzhaki, S., (1983), "On An Extension of the Gini. Index", International Economic Review 24, 617628.

--------, (1990), "On the Progressivity of Commodity Taxation", Working Paper \# 187, Department of Economics, Hebrew University, Jerusalem, Israel.

Yitzhaki, S. and Thrisk, (1990), "Welfare Dominance and the Design of Excise Taxation in the Cote D'Ivoir", Journal of Development Economics 33, 1-18.

Weisbrod, Burton and Lee Hanson, (1977), "An Income Net Worth Approach to Measuring Economic Welfare", in Improving Measurement of Economic Well-Being, ed. Moon, Marilyn and Eugene Smolensky, New York: Academic Press. 
Appendix 


\section{Appendix P-1: Program to Download Data and Create Data Set}

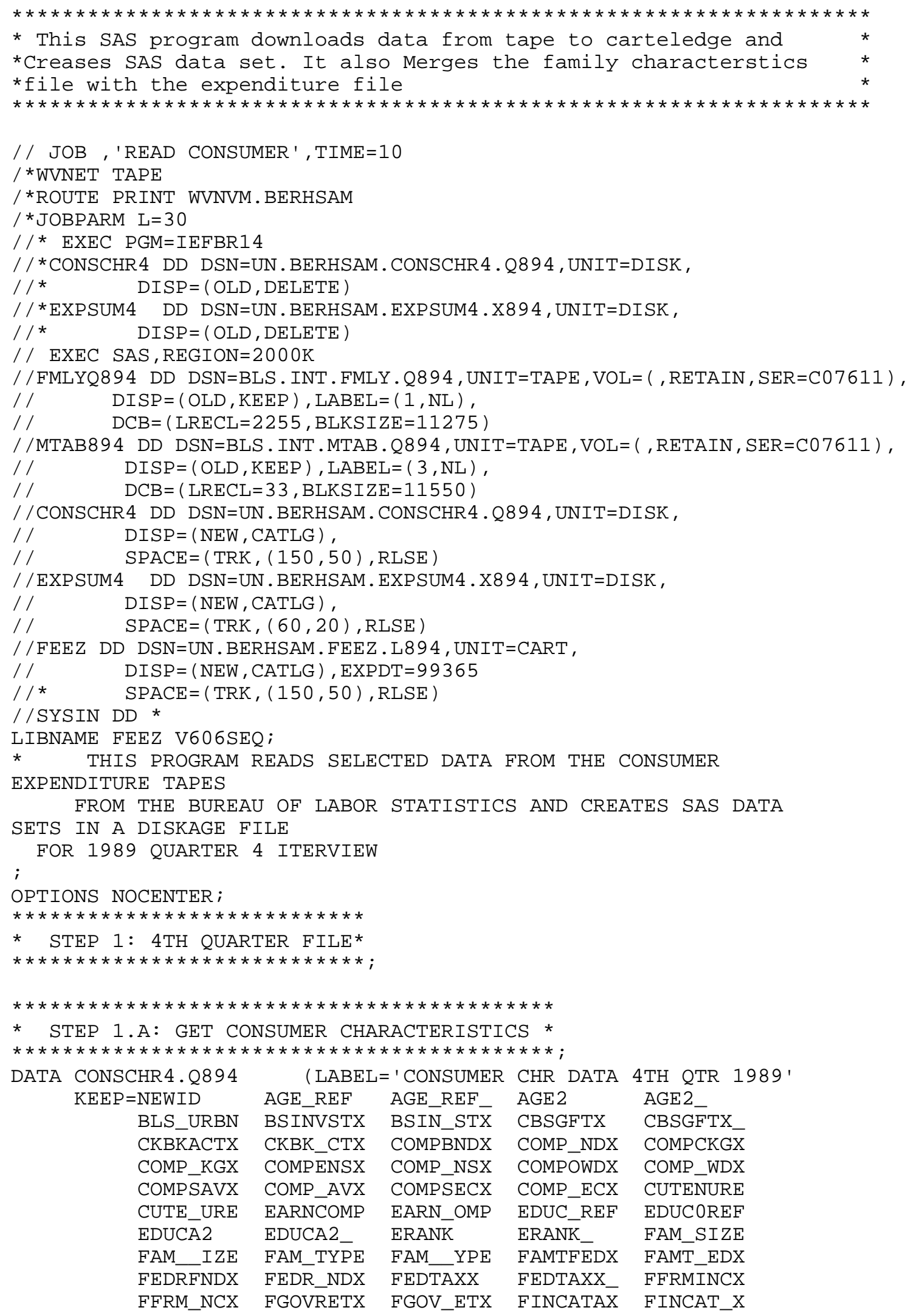




\begin{tabular}{|c|c|c|c|c|c|}
\hline & FINCBTAX & FINCBT_X & FINDRETX & FIND_ETX & FININCX \\
\hline & FININCX_ & FINLWT21 & FJSSDEDX & FJSS_EDX & FNONFRMX \\
\hline & FNON_RMX & FPRIPENX & FPRI_ENX & FRRDEDX & FRRDEDX \\
\hline & FRRETIRX & FRRE_IRX & FSALARYX & FSAL_RYX & FSLTAXX \\
\hline & FSLTAXX_ & FSSIX & FSSIX & GOVTCOST & GOVT_OST \\
\hline & INC_HRS 1 & INC__ RS 1 & INC_HRS 2 & INC__ RS 2 & INC_RANK \\
\hline & INCCONTX & INCC_NTX & INCLASS & INCLOSSA & INCL__SSA \\
\hline & INCLOSSB & INCL_SSB & INCNONW1 & INCN_NW1 & INCNONW2 \\
\hline & INCN_NW2 & INCOMEY1 & INCO_EY1 & INCOMEY2 & INCO_EY2 \\
\hline & INCSTAT1 & INCS_AT1 & INCSTAT2 & INCS_AT2 & INCWEEK1 \\
\hline & INCW_EK1 & INCWEEK2 & INCW_EK2 & INSRFNDX & INSR_NDX \\
\hline & INTEARNX & INTE_RNX & JFDSTMPA & JFDS_MPA & JOTAXNET \\
\hline & JOTA_NET & LUMP SUMX & LUMP_UMX & MARITAL1 & MARI_AL1 \\
\hline & MISCNTRX & MISC_TRX & MONYOWDX & MONY_WDX & NO_EARNR \\
\hline & NO_E_RNR & NO_EĀRNX & NO_E_RNX & NONIÑCMX & NONI_CMX \\
\hline & NUM_AUTO & NUM_UTO & OCCUPPRE1 & OCCU_RE1 & OCCUPRE2 \\
\hline & OCCU_RE2 & ORIGIN1 & ORIGIN1_ & ORIGIN2 & ORIGIN2_- \\
\hline & OTHRFNDX & OTHR_NDX & OTHRINCX & OTHR_NCX & PENSIONX \\
\hline & PENS_ONX & PERSLT1 8 & PERS_T18 & PERSOT 64 & PERS_T64 \\
\hline & POPSIZE & PRINEARN & PRIN_ARN & PTAXRFDX & PTAX_FDX \\
\hline & PURSSECX & PURS_ECX & QINTRVMO & QINTRVYR & $\mathrm{RACE} \overline{2}$ \\
\hline & RACE2_- & REF_RACE & $\mathrm{REF} \quad \mathrm{ACE}$ & REGION & RESPSTAT \\
\hline & RESP_TAT & SALEINCX & SALE_NCX & SAVACCTX & SAVA_CTX \\
\hline & SECESTX & SECESTX_ & SELLSECX & SELL_ECX & SETLINSX \\
\hline & SETL_NSX & SEX_REF & SEX_REF_ & $\mathrm{SEX} 2$ & SEX2_- \\
\hline & SLOCTAXX & SLOC_AXX & SLRFUNDX & SLRF_NDX & SMSASTAT \\
\hline & SSOVERPX & SSOV_RPX & TAXPROPX & TAXP_OPX & TOTTXPDX \\
\hline & TOTT_PDX & UNEMP LX & UNEMP LX_ & USBNDX & USBNDX_ \\
\hline & VEHQ & VEHQ_ & WDBSASTX & WDBS_STX & WDBSGDSX \\
\hline & WDBS_DSX & WELFAREX & WELF_REX & TOTEXPPQ & TOTEXPCQ \\
\hline & FOODPQ & FOODCQ & FDHOMEPQ & FDHOMECQ & FDAWAYPQ \\
\hline & FDAWAYCQ & ALCBEVPQ & ALCBEVCQ & HOUSPQ & HOUSCQ \\
\hline & SHELTPQ & SHELTCQ & OWNDWEPQ & OWNDWECQ & RENDWEPQ \\
\hline & RENDWECQ & OTHLODPQ & OTHLODCQ & UTILPQ & UTILCQ \\
\hline & HOUSOPPQ & HOUSOPCQ & HOUSEQPQ & HOUSEQCQ & APPARPQ \\
\hline & APPARCQ & TRANSPQ & TRANSCQ & VEHICLPQ & VEHICLCQ \\
\hline & GASMOPQ & GASMOCQ & OTHVEHPQ & OTHVEHCQ & PUBTRAPQ \\
\hline & PUBTRACQ & HEALTHPQ & HEALTHCQ & ENTERTPQ & ENTERTCQ \\
\hline & PERSCAPQ & PERSCACQ & READPQ & READCQ & EDUCAPQ \\
\hline & EDUCACQ & TOBACCPQ & TOBACCCQ & MISCPQ & MISCCQ \\
\hline & CASHCOPQ & CASHCOCQ & PERINSPQ & PERINSCQ & LIFINSPQ \\
\hline & LIFINSCQ & RETPENPQ & RETPENCQ) & & \\
\hline ATTRIB & B NEWID & LENGTH= & $\$ 8$ LABEL $=$ & ' CONSUMER & UNIT ID NO.'; \\
\hline ATTRIB & B AGE_REF & LENGTH $=$ & $\mathrm{LABEL}=$ & ' AGE OF RE & FERENCE PERSON'; \\
\hline ATTRIB & B AGE_REF_ & LENGTH $=$ & $\mathrm{LABEL}=$ & 'FLAG - AC & E OF REFERENCE PERSON ' \\
\hline ATTRIB & $\mathrm{B} A \mathrm{AGE} 2$ & LENGTH $=$ & $\mathrm{LABEL}=$ & 'AGE OF SE & OUSE' ; \\
\hline ATTRIB & B AGE2_- & LENGTH $=$ & $\mathrm{LABEL}=$ & 'FLAG - AC & E OF SPOUSE'; \\
\hline ATTRIB & B BLS_URBN & LENGTH= & $\mathrm{LABEL}=$ & ' URBAN ( 1 ) & OR RURAL (0) '; \\
\hline ATTRIB & B BSINVSTX & LENGTH= & $\mathrm{LABEL}=$ & ' INVESTMEI & T-OWN FARM/BUSINESS ' ; \\
\hline ATTRIB & B BSIN_STX & LENGTH= & $\mathrm{LABEL}=$ & 'FLAG - BS & INVSTX'; \\
\hline ATTRIB & B CBSGFTX & LENGTH $=$ & $\mathrm{LABEL}=$ & 'GIFTS IN & CASH, BONDS OR STOCKS'; \\
\hline ATTRIB & B CBSGFTX & LENGTH= & LABEL= & 'FLAG - CF & SGFTX' ; \\
\hline ATTRIB & B CKBKACTX & LENGTH $=$ & $\mathrm{LABEL}=$ & 'AMT IN CH & KG, BROK, OTH ACCTS'; \\
\hline ATTRIB & B CKBK_CTX & LENGTH $=$ & $\mathrm{LABEL}=$ & 'FLAG - CI & $\mathrm{BKACTX}^{\prime} ;$ \\
\hline ATTRIB & B COMPBNDX & LENGTH $=$ & LABEL $=$ & 'CHANGE II & SAVINGS BONDS'; \\
\hline ATTRIB & B COMP_NDX & LENGTH $=$ & $\mathrm{LABEL}=$ & 'FLAG - CC & MPBNDX ' ; \\
\hline ATTRIB & B COMPCKGX & LENGTH $=$ & $\mathrm{LABEL}=$ & ' CHANGE II & CHKG ACCTS'; \\
\hline ATTRIB & B COMP_KGX & LENGTH $=$ & $\mathrm{LABEL}=$ & 'FLAG - CC & MPCKGX' ; \\
\hline ATTRIB & B COMPENSX & $\mathrm{LENGTH}=$ & $\mathrm{LABEL}=$ & 'WORK COMF & /VETS PYMTS'; \\
\hline ATTRIB & B COMP_NSX & LENGTH= & $\mathrm{LABEL}=$ & 'FLAG - CC & MPENSX' ; \\
\hline
\end{tabular}


ATTRIB COMPOWDX LENGTH $=8$ ATTRIB COMP_WDX LENGTH $=\$ 1$ ATTRIB COMPSAVX LENGTH $=8$ ATTRIB COMP_AVX LENGTH $=\$ 1$ ATTRIB COMPSECX LENGTH $=8$ ATTRIB COMP_ECX LENGTH $=\$ 1$ ATTRIB CUTENURE LENGTH $=\$ 1$ ATTRIB CUTE_URE LENGTH $=\$ 1$ ATTRIB EARNCOMP LENGTH= $\$ 1$ ATTRIB EARN_OMP LENGTH $=\$ 1$ ATTRIB EDUC_REF LENGTH= $\$ 1$ ATTRIB EDUCOREF LENGTH $=\$ 1$ ATTRIB EDUCA2 LENGTH $=\$ 1$ ATTRIB EDUCA2 $-\quad$ LENGTH $=\$ 1$ ATTRIB ERANK LENGTH $=8$ ATTRIB ERANK_ LENGTH $=\$ 1$ ATTRIB FAM_SIZE LENGTH= 2 ATTRIB FAM_IZE LENGTH= $\$ 1$ ATTRIB FAM_TYPE LENGTH= \$1 ATTRIB FAM_YPE LENGTH $=\$ 1$ ATTRIB FAMTEEDX LENGTH $=8$ ATTRIB FAMT_EDX LENGTH $=\$ 1$ ATTRIB FEDRFNDX LENGTH $=8$ ATTRIB FEDR_NDX LENGTH $=\$ 1$ ATTRIB FEDTAXX LENGTH $=8$ ATTRIB FEDTAXX_ LENGTH $=\$ 1$ ATTRIB FFRMINCX LENGTH $=8$ ATTRIB FFRM_NCX LENGTH= \$1 ATTRIB FGOVRETX LENGTH $=8$ ATTRIB FGOV_ETX LENGTH $=\$ 1$ ATTRIB FINCATAX LENGTH $=8$ ATTRIB FINCAT_X LENGTH $=\$ 1$ ATTRIB FINCBTAX LENGTH $=8$ ATTRIB FINCBT_X LENGTH $=\$ 1$ ATTRIB FINDRETX LENGTH $=8$ ATTRIB FIND_ETX LENGTH $=\$ 1$ ATTRIB FININCX LENGTH $=8$ ATTRIB FININCX_ LENGTH $=\$ 1$ ATTRIB FINLWT21 LENGTH= 8 ATTRIB FJSSDEDX LENGTH $=8$ ATTRIB FJSS_EDX LENGTH $=\$ 1$ ATTRIB FNONFRMX LENGTH $=8$ ATTRIB FNON_RMX LENGTH $=\$ 1$ ATTRIB FPRIPENX LENGTH $=8$ ATTRIB FPRI_ENX LENGTH $=\$ 1$ ATTRIB FRRDEDX LENGTH $=8$ ATTRIB FRRDEDX_ LENGTH= $\$ 1$ ATTRIB FRRETIRX LENGTH= 8 ATTRIB FRRE_IRX LENGTH= $\$ 1$ ATTRIB FSALARYX LENGTH= 8 ATTRIB FSAL_RYX LENGTH $=\$ 1$ ATTRIB FSLTAXX LENGTH $=8$ ATTRIB FSLTAXX_ LENGTH $=\$ 1$ ATTRIB FSSIX LENGTH $=8$ ATTRIB FSSIX__ LENGTH $=\$ 1$ ATTRIB GOVTCOST LENGTH= $\$ 1$ ATTRIB GOVT_OST LENGTH= $\$ 1$ ATTRIB INC_HRS1 LENGTH= 3 ATTRIB INC_RS1 LENGTH $=\$ 1$ ATTRIB INC_HRS2 LENGTH= 3
LABEL $=$ 'CHANGE IN MONEY OWED CU';

LABEL='FLAG - COMPOWDX';

LABEL='CHANGE IN SVGS ACCT';

LABEL='FLAG - COMPSAVX';

LABEL $=$ 'CHANGE IN STKS, BNDS';

LABEL='FLAG - COMPSECX';

LABEL='HOUSING TENURE: $1-6$ ';

LABEL='FLAG - CUTENURE';

LABEL=' COMPOSITION OF EARNERS 1-8';

LABEL = 'FLAG - EARNCOMP ';

LABEL='EDUCATION OF REF. PERSON 1-7';

LABEL='FLAG - EDUC_REF';

LABEL='EDUCATION OF SPOUSE 0-32';

LABEL='FLAG - EDUCA2';

LABEL='WTD. RANKING BY EXPENDS. (9.7)';

LABEL = 'FLAG - ERANK';

LABEL='NO. OF MEMBRS IN CONS. UNIT';

LABEL='FLAG - FAM_SIZE';

LABEL $=$ ' CONS. UNIT TYPE 1-9';

LABEL='FLAG - FAM_TYPE';

LABEL='FED Y TX WHLD LAST CHK-ANNUAL.';

LABEL='FLAG - FAMTFEDX';

LABEL='REFUND FROM FED INCOME TAX';

LABEL ='FLAG - FEDRFNDX';

LABEL='FEDERAL TAX PAID';

LABEL='FLAG - FEDTAXX' ;

LABEL='INCOME/LOSS FROM OWN FARM';

LABEL='FLAG - FFRMINCX';

LABEL='GOVT RETIREMT DEDUCTED';

LABEL='FLAG - FGOVRETX';

LABEL='CONS. UNIT INCOME AFTER TAXES';

LABEL ='FLAG - FINCATAX';

LABEL $=$ 'CONS. UNIT INCOME BEFORE TAXES';

LABEL='FLAG - FINCBTAX';

LABEL='SELF-EMPLOYED RETIREMENT PLAN';

LABEL ='FLAG - FINCRETX';

LABEL= ' DIVID/ROYALTIES/ESTATES/TRUSTS ' ;

LABEL='FLAG - FININCX';

LABEL ='CONS. UNIT WEIGHT (11.3) ' ;

LABEL='SOC SEC PAYMENT';

LABEL='FLAG - FJSSDEDX';

LABEL='INC. FROM NONFARM BUSINESS';

LABEL ='FLAG - FNON_RMX';

LABEL='PRIV. PENS. DEDUCT. FR LAST PAY';

LABEL='FLAG - FRIPENX' ;

LABEL='RAIL. RETIR. DEDUCT FR LAST PAY';

LABEL='FLAG - FRRDEDX';

LABEL='AMT. FROM RRR AND SS';

LABEL='FLAG - FRRETIRX';

LABEL='WAGE AND SALARY INCOME';

LABEL='FLAG - FSALARYX';

LABEL='ST. AND LOCAL INCOME TAXES';

LABEL='FLAG - FSLTAXX';

LABEL='COMBINES SSI CHECKS';

LABEL ='FLAG - FSSIX';

LABEL='GOVT. PAYS HOUSING 1-2';

LABEL='FLAG - GOVTCOST';

LABEL='HOURS WORKED/WK BY REF. PERSON';

LABEL='FLAG - INC_HRS1';

LABEL='HOURS WORKED/WEEK BY SPOUSE'; 
ATTRIB INC RS2 LENGTH $=\$ 1$ ATTRIB INC RANK LENGTH $=8$ ATTRIB INCCONTX LENGTH $=8$ ATTRIB INCC_NTX LENGTH $=\$ 1$ ATTRIB INCLASS LENGTH $=\$ 1$ ATTRIB INCLOSSA LENGTH $=8$ ATTRIB INCL_SSA LENGTH $=\$ 1$ ATTRIB INCLOSSB LENGTH $=8$ ATTRIB INCL_SSB LENGTH $=\$ 1$ ATTRIB INCNONW1 LENGTH $=\$ 1$ ATTRIB INCN_NW1 LENGTH= $\$ 1$ ATTRIB INCNONW2 LENGTH= \$1 ATTRIB INCN_NW2 LENGTH $=\$ 1$ ATTRIB INCOMEY1 LENGTH $=\$ 1$ ATTRIB INCO_EY1 LENGTH $=\$ 1$ ATTRIB INCOMEY2 LENGTH= $\$ 1$ ATTRIB INCO_EY2 LENGTH= $\$ 1$ ATTRIB INCSTAT1 LENGTH $=\$ 1$ ATTRIB INCS_AT1 LENGTH= \$1 ATTRIB INCSTAT2 LENGTH $=\$ 1$ ATTRIB INCS_AT2 LENGTH $=\$ 1$ ATTRIB INCWEEK1 LENGTH $=2$ ATTRIB INCW_EK1 LENGTH $=\$ 1$ ATTRIB INCWEEK2 LENGTH= 2 ATTRIB INCW_EK2 LENGTH $=\$ 1$ ATTRIB INSRFNDX LENGTH $=8$ ATTRIB INSR_NDX LENGTH $=\$ 1$ ATTRIB INTEARNX LENGTH $=8$ ATTRIB INTE_RNX LENGTH $=\$ 1$ ATTRIB JFDSTMPA LENGTH $=8$ ATTRIB JFDS_MPA LENGTH $=\$ 1$ ATTRIB JOTAXNET LENGTH $=8$ ATTRIB JOTA_NET LENGTH $=\$ 1$ ATTRIB LUMP SUMX LENGTH $=8$ ATTRIB LUMP_UMX LENGTH $=\$ 1$ ATTRIB MARITAL1 LENGTH $=\$ 1$ ATTRIB MARI_AL1 LENGTH $=\$ 1$ ATTRIB MISCNTRX LENGTH $=8$ ATTRIB MISC_TRX LENGTH $=\$ 1$ ATTRIB MONYOWDX LENGTH $=8$ ATTRIB MONY_WDX LENGTH $=\$ 1$ ATTRIB NO_EARNR LENGTH $=2$ ATTRIB NO_E_RNR LENGTH $=\$ 1$ ATTRIB NO_EARNX LENGTH $=8$ ATTRIB NO_E_RNX LENGTH $=\$ 1$ ATTRIB NONINCMX LENGTH $=8$ ATTRIB NONI_CMX LENGTH= $\$ 1$ ATTRIB NUM_AUTO LENGTH= 2 ATTRIB NUM_UTO LENGTH $=\$ 1$ ATTRIB OCCUPRE1 LENGTH= $\$ 2$ ATTRIB OCCU_RE1 LENGTH $=\$ 1$ ATTRIB OCCUPRE2 LENGTH= \$2 ATTRIB OCCU_RE2 LENGTH $=\$ 1$ ATTRIB ORIGIN1 LENGTH $=\$ 1$ ATTRIB ORIGIN1_ LENGTH= $\$ 1$ ATTRIB ORIGIN2 LENGTH $=\$ 1$ ATTRIB ORIGIN2_ LENGTH= $\$ 1$ ATTRIB OTHRFNDX LENGTH $=8$ ATTRIB OTHR_NDX LENGTH $=\$ 1$ ATTRIB OTHRINCX LENGTH $=8$

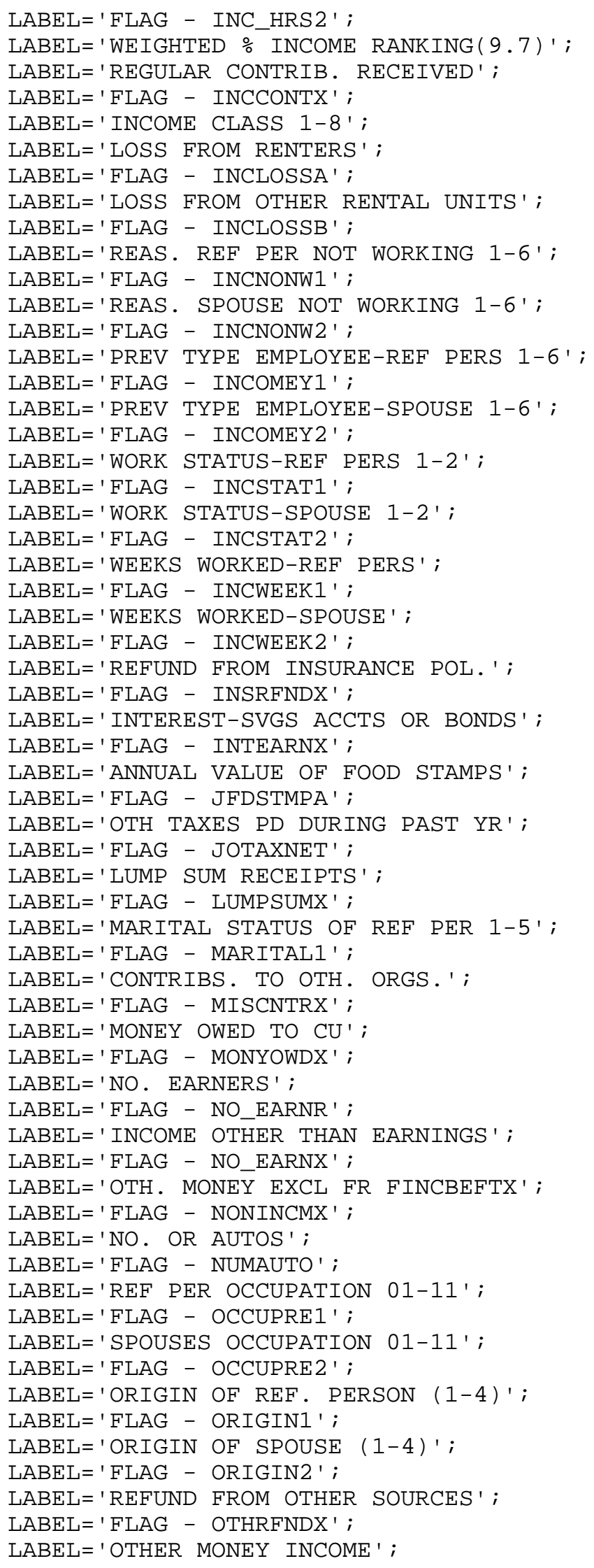


ATTRIB OTHR_NCX LENGTH= \$1 ATTRIB PENSIONX LENGTH $=8$ ATTRIB PENS_ONX LENGTH $=\$ 1$ ATTRIB PERSLT18 LENGTH $=2$ ATTRIB PERS_T18 LENGTH $=\$ 1$ ATTRIB PERSOT64 LENGTH $=2$ ATTRIB PERS_T64 LENGTH $=\$ 1$ ATTRIB POPSIZE LENGTH $=\$ 1$ ATTRIB PRINEARN LENGTH $=\$ 2$ ATTRIB PRIN_ARN LENGTH $=\$ 1$ ATTRIB PTAXRFDX LENGTH $=8$ ATTRIB PTAX_FDX LENGTH= \$1 ATTRIB PURSSECX LENGTH $=8$ ATTRIB PURS_ECX LENGTH $=\$ 1$ ATTRIB QINTRVMO LENGTH $=\$ 2$ ATTRIB QINTRVYR LENGTH= $\$ 2$ ATTRIB RACE2 LENGTH $=\$ 1$ ATTRIB RACE2 _ LENGTH $=\$ 1$ ATTRIB REF_RACE LENGTH= \$1 ATTRIB REF_ACE LENGTH $=\$ 1$ ATTRIB REGION LENGTH $=\$ 1$ ATTRIB RESPSTAT LENGTH $=\$ 1$ ATTRIB RESP_TAT LENGTH $=\$ 1$ ATTRIB SALEINCX LENGTH $=8$ ATTRIB SALE_NCX LENGTH $=\$ 1$ ATTRIB SAVACCTX LENGTH $=8$ ATTRIB SAVA_CTX LENGTH $=\$ 1$ ATTRIB SECESTX LENGTH $=8$ ATTRIB SECESTX_ LENGTH $=\$ 1$ ATTRIB SELLSECX LENGTH= 8 ATTRIB SELL_ECX LENGTH $=\$ 1$ ATTRIB SETLINSX LENGTH $=8$ ATTRIB SETL_NSX LENGTH= \$1 ATTRIB SEX_REF LENGTH $=\$ 1$ ATTRIB SEX_REF_LENGTH $=\$ 1$ ATTRIB SEX2 LENGTH $=\$ 1$ ATTRIB SEX2_ LENGTH $=\$ 1$ ATTRIB SLOCTAXX LENGTH $=8$ ATTRIB SLOC_AXX LENGTH $=\$ 1$ ATTRIB SLRFUNDX LENGTH $=8$ ATTRIB SLRF_NDX LENGTH $=\$ 1$ ATTRIB SMSASTAT LENGTH $=\$ 1$ ATTRIB SSOVERPX LENGTH $=8$ ATTRIB SSOV_RPX LENGTH $=\$ 1$ ATTRIB TAXPROPX LENGTH $=8$ ATTRIB TAXP_OPX LENGTH $=\$ 1$ ATTRIB TOTTXPDX LENGTH $=8$ ATTRIB TOTT_PDX LENGTH $=\$ 1$ ATTRIB UNEMPLX LENGTH $=8$ ATTRIB UNEMPLX_ LENGTH $=\$ 1$ ATTRIB USBNDX LENGTH $=8$ ATTRIB USBNDX_ LENGTH $=\$ 1$ ATTRIB VEHQ LENGTH $=2$ ATTRIB VEHQ_ LENGTH $=\$ 1$ ATTRIB WDBSASTX LENGTH $=8$ ATTRIB WDBS_STX LENGTH $=\$ 1$ ATTRIB WDBSGDSX LENGTH $=8$ ATTRIB WDBS_DSX LENGTH $=\$ 1$ ATTRIB WELFAREX LENGTH $=8$ ATTRIB WELF_REX LENGTH= $\$ 1$
LABEL='FLAG - OTHRINCX';

LABEL='AMT. FROM PENSIONS/ANNUITIES'; LABEL='FLAG - PENSIONX';

LABEL $=$ 'NO. PERSONS LESS THAN 18';

LABEL='FLAG - PERSLT18';

LABEL $=$ 'NO. PERSONS OVER 64';

LABEL='FLAG - PERSOT64';

LABEL=' CODES-URBAN (NO PSUS-W. OR RUR) ' ;

LABEL='MEMBER NO. OF PRINCIPAL EARNER';

LABEL='FLAG - PRINEARN';

LABEL='PROPERTY TAX REFUNDS IN PAST YR';

LABEL='FLAG - PTAXRFDX';

LABEL='PURCHASE PRICE OF STOCKS, BONDS';

LABEL='FLAG - PURSSECX';

LABEL = ' INTERVIEW MONTH';

LABEL = ' INTERVIEW YEAR' ;

LABEL='RACE OF SPOUSE $(1-5)$ ';

LABEL='FLAG - RACE2';

LABEL='RACE OF REF . PERSON (1-5)' ;

LABEL='FLAG - REF_RACE' ;

LABEL $=$ 'CENSUS REGION (URBAN ONLY) (1-4) ';

LABEL=' 1=COMPLETE Y RESP, 2=INCOMPLETE' ;

LABEL='FLAG - RESPSTAT';

LABEL='SALE OF HH FURN \& EQUIP';

LABEL='FLAG - SALEINCX';

LABEL='AMT IN SAVINGS ACCT';

LABEL='FLAG - SAVACCTX';

LABEL='MARKET VALUE OF STOCKS/BONDS' ;

LABEL='FLAG - SECESTX';

LABEL='AMT FROM SALE OF STOCKS/BONDS';

LABEL='FLAG - SELLSECX';

LABEL = ' INSURANCE SETTLEMENTS ' ;

LABEL='FLAG - SETLINSX';

LABEL='SEX-REF PERSON 1=MALE 2=FEMALE' ;

LABEL='FLAG - SEX_REF' ;

LABEL='SEX OF SPOUSE 1=MALE 2=FEMALE';

LABEL='FLAG - SEX_REF' ;

LABEL='ADDITIONAL ST/LOCAL TAXES PAID';

LABEL='FLAG - SLOCTAXX';

LABEL='ST/LOCAL INCOME TAX REFUND';

LABEL='FLAG - SLRFUNDX';

LABEL=' $1=$ =INSIDE MSA 2=OUTSIDE';

LABEL='REFUND OF OVERPAY ON SOC SEC';

LABEL='FLAG - SSOVERPX';

LABEL='PERSONAL PROP TAXES PAID';

LABEL='FLAG - TAXPROPX';

LABEL='TOTAL AMT PERSONAL TAXES';

LABEL='FLAG - TOTTXPDX';

LABEL='AMT FROM UNEMPLOYMENT COMP';

LABEL = 'FLAG - UNEMPLX' ;

LABEL='AMT. OF SAVINGS BONDS';

LABEL = 'FLAG - USBNDX' ;

LABEL='NUMBER OF VEHICLES OWNED';

LABEL='FLAG - VEHQ';

LABEL='ASSETS WITHDRAWN FROM BUSINESS';

LABEL='FLAG - WDBSASTX';

LABEL $=$ 'GOODS WITHDRAWN FROM BUSINESS';

LABEL='FLAG - WDBSGDSX';

LABEL=' INCOME FROM PUBLIC ASSISTANCE';

LABEL='FLAG - WELFAREX'; 
ATTRIB TOTEXPPQ LENGTH= ATTRIB TOTEXPCQ LENGTH= ATTRIB FOODPQ LENGTH= ATTRIB FOODCQ LENGTH= ATTRIB FDHOMEPQ LENGTH= ATTRIB FDHOMECQ LENGTH= ATTRIB FDAWAYPQ LENGTH= ATTRIB FDAWAYCQ LENGTH= ATTRIB ALCBEVPQ LENGTH= ATTRIB ALCBEVCQ LENGTH= ATTRIB HOUSPQ LENGTH= ATTRIB HOUSCQ LENGTH= ATTRIB SHELTPQ LENGTH= ATTRIB SHELTCQ LENGTH= ATTRIB OWNDWEPQ LENGTH= ATTRIB OWNDWECQ LENGTH= ATTRIB RENDWEPQ LENGTH= ATTRIB RENDWECQ LENGTH= ATTRIB OTHLODPQ LENGTH= ATTRIB OTHLODCQ LENGTH= ATTRIB UTILPQ LENGTH= ATTRIB UTILCQ LENGTH= ATTRIB HOUSOPPQ LENGTH= ATTRIB HOUSOPCQ LENGTH= ATTRIB HOUSEQPQ LENGTH= ATTRIB HOUSEQCQ LENGTH= ATTRIB APPARPQ LENGTH= ATTRIB APPARCQ LENGTH= ATTRIB TRANSPQ LENGTH= ATTRIB TRANSCQ LENGTH= ATTRIB VEHICLPQ LENGTH= ATTRIB VEHICLCQ LENGTH= ATTRIB GASMOPQ LENGTH= ATTRIB GASMOCQ LENGTH $=$ ATTRIB OTHVEHPQ LENGTH= ATTRIB OTHVEHCQ LENGTH= ATTRIB PUBTRAPQ LENGTH= ATTRIB PUBTRACQ LENGTH= ATTRIB HEALTHPQ LENGTH= ATTRIB HEALTHCQ LENGTH= ATTRIB ENTERTPQ LENGTH= ATTRIB ENTERTCQ LENGTH= ATTRIB PERSCAPQ LENGTH= ATTRIB PERSCACQ LENGTH= ATTRIB READPQ LENGTH= ATTRIB READCQ LENGTH= ATTRIB EDUCAPQ LENGTH= ATTRIB EDUCACQ LENGTH= ATTRIB TOBACCPQ LENGTH= ATTRIB TOBACCCQ LENGTH= ATTRIB MISCPQ LENGTH= ATTRIB MISCCQ LENGTH= ATTRIB CASHCOPQ LENGTH= ATTRIB CASHCOCQ LENGTH= ATTRIB PERINSPQ LENGTH= ATTRIB PERINSCQ LENGTH= ATTRIB LIFINSPQ LENGTH= ATTRIB LIFINSCQ LENGTH= ATTRIB RETPENPQ LENGTH= ATTRIB RETPENCQ LENGTH=
8 LABEL='TOT EXPENDS LAST QTR';

8 LABEL='TOT EXPENDS THIS QTR';

8 LABEL='TOT FOOD LAST QTR';

8 LABEL='TOT FOOD THIS QTR';

8 LABEL='FOOD AT HOME LAST QTR';

8 LABEL='FOOD AT HOME THIS QTR';

8 LABEL='FOOD AWAY FROM HOME LAST QTR';

8 LABEL='FOOD AWAY FROM HOME THIS QTR';

8 LABEL='ALCOHOLIC BEVS LAST QTR';

8 LABEL='ALCOHOLIC BEVS THIS QTR';

8 LABEL='HOUSING LAST QTR';

8 LABEL='HOUSING THIS QTR';

8 LABEL='SHELTER LAST QTR';

8 LABEL='SHELTER THIS QTR';

8 LABEL='OWNED DWELLINGS LAST QTR';

8 LABEL='OWNED DWELLINGS THIS QTR';

8 LABEL='RENTED DWELLING LAST QTR';

8 LABEL='RENTED DWELLING THIS QTR';

8 LABEL='OTHER LODGING LAST QTR';

8 LABEL='OTHER LODGING THIS QTR';

8 LABEL='UTILS, FUELS, PUB SERVS LAST QTR';

8 LABEL='UTILS, FUELS, PUB SERVS THIS QTR';

8 LABEL='HOUSEHOLD OPERATIONS LAST QTR';

8 LABEL='HOUSEHOLD OPERATIONS THIS QTR';

8 LABEL='HOUSE FURN. \& EQUIP. LAST QTR';

8 LABEL='HOUSE FURN. \& EQUIP. THIS QTR';

8 LABEL='APPAREL/SERVICES LAST QTR';

8 LABEL='APPAREL/SERVICES THIS QTR';

8 LABEL=' TRANSPORTATION LAST QTR';

8 LABEL='TRANSPORTATION THIS QTR';

8 LABEL='VEHICLES LAST QTR';

8 LABEL='VEHICLES THIS QTR';

8 LABEL='GASOLINE/MOTOR OIL LAST QTR';

8 LABEL='GASOLINE/MOTOR OIL THIS QTR';

8 LABEL='OTHER VEH EXPENSES LAST QTR';

8 LABEL='OTHER VEH EXPENSES THIS QTR';

8 LABEL='PUBLIC TRANSPORTATION LAST QTR';

8 LABEL='PUBLIC TRANSPORTATION THIS QTR';

8 LABEL='HEALTH CARE LAST QTR';

8 LABEL='HEALTH CARE THIS QTR';

8 LABEL='ENTERTAINMENT LAST QTR';

8 LABEL='ENTERTAINMENT THIS QTR';

8 LABEL='PERSONAL CARE LAST QTR';

8 LABEL='PERSONAL CARE THIS QTR';

8 LABEL='READING LAST QTR';

8 LABEL='READING THIS QTR';

8 LABEL='EDUCATION LAST QTR';

8 LABEL='EDUCATION THIS QTR';

8 LABEL='TOBACCO LAST QTR';

8 LABEL='TOBACCO THIS QTR';

8 LABEL='MISCELLANEOUS LAST QTR';

8 LABEL='MISCELLANEOUS THIS QTR';

8 LABEL='CASH CONTRIBUTIONS LAST QTR';

8 LABEL='CASH CONTRIBUTIONS THIS QTR';

8 LABEL='PERSONAL INSUR/PENSIONS LAST QTR';

8 LABEL='PERSONAL INSUR/PENSIONS THIS QTR';

8 LABEL='LIFE/OTHER PERS INSUR LAST QTR';

8 LABEL='LIFE/OTHER PERS INSUR THIS QTR';

$8 \mathrm{LABEL}=$ 'RETIRE/PENSIONS/SOC SEC LAST QTR';

$8 \mathrm{LABEL}=$ 'RETIRE/PENSIONS/SOC SEC THIS QTR'; 
INFILE FMLYQ894 RECFM=FB LRECL=2255;

INPUT NEWID \$ 1-8 AGE_REF 11-13 AGE_REF_\$ 14 AGE2 15-17 AGE2_\$ 18 BLS_URBN \$ 70 BSINVSTX 74-83 BSIN_STX \$ 84 CBSGFTX 91-98 CBSGFTX_ \$ $9 \overline{9}$ CKBKACTX 109-118 CKBK_CTX \$ 119 COMPBNDX 174-181 COMP_NDX \$ 182 COMPCKGX 185-192 COMP_KGX \$ 193 COMPENSX 194-201 COMP_NSX \$ 202 COMPOWDX 209-216 COMP_WDX \$ 217 COMPSAVX 220-227 COMP_AVX \$ 228 COMPSECX 231-238 COMP_ECX \$ 239 CUTENURE \$ 267 CUTE_URE \$ 268 EARNCOMP \$ 272 EARN_OMP \$ 273 EDUC_REF \$ 284 EDUCOREF \$ 285 EDUCA2 \$ 286-287 EDUCA2_\$ 288 ERANK 297-305 .7 ERANK_\$ 306 FAM_SIZE 335-336 FAM_IZE \$ 337 FAM_TYPE \$ 338 FAM_YPE \$ 339 FAMTFEDX 340-347 FAMT_EDX \$ 348 FEDRFNDX 349-356 FEDR_NDX \$ 357 FEDTAXX 358-365 FEDTAXX_\$ 366 FFRMINCX 367-375 FFRM_NCX \$ 376 FGOVRETX 377-384 FGOV_ETX \$ 385 FINCATAX 386-394 FINCAT_X \$ 395 FINCBTAX 396-404 FINCBT_X \$ 405 FINDRETX 406-413 FIND_ETX \$ 414 FININCX 415-422 FININCX_\$ 423 FINLWT21 424-434.3 FJSSDEDX 439-446 FJSS_EDX \$ 447 FNONFRMX 448-456 FNON_RMX \$ 457 FPRIPENX 463-470 FPRI_ENX \$ 471 FRRDEDX 472-479 FRRDEDX_\$ 480 FRRETIRX 481-488 FRRE_IRX \$ 489 FSALARYX 490-497 FSAL_RYX \$ 498 FSLTAXX 499-506 FSLTAXX_\$ 507 FSSIX 508-515 FSSIX_\$ 516 GOVTCOST \$ 523 GOVT_OST \$ 524 INC_HRS1 548-550 INC__RS1 \$ 551 INC_HRS2 552-554 INC_RS 2555 INC_RANK 556-564.7 INCCONTX 576-583 INCC_NTX \$ 584 INCLASS \$ 585 INCLOSSA 586-593 INCL_SSA \$ 594 INCLOSSB 595-602 INCL_SSB \$ 603 INCNONW1 \$ 604 INCN_NW1 \$ 605 INCNONW2 \$ 606 INCN_NW2 \$ 607 INCOMEY1 \$ 608 INCO_EY1 \$ 609 INCOMEY2 \$ 610 INCO_EY2 \$ 611 INCSTAT1 \$ 612 INCS_AT1 \$ 613 INCSTAT2 \$ 614 INCS_AT2 \$ 615 INCWEEK1 616-617 INCW_EK1 \$ 618 INCWEEK2 619-620 INCW_EK2 \$ 621 INSRFNDX 622-629 INSR_NDX \$ 630 INTEARNX 631-638 INTE_RNX \$ 639 JFDSTMPA 640-647 JFDS_MPA \$ 648 JOTAXNET 649-656 JOTA_NET \$ 657 LUMPSUMX 664-671 LUMP_UMX \$ 672 MARITAL1 \$ 673 MARI_ALI \$ 674 MISCNTRX 675-682 MISC_TRX \$ 683 MONYOWDX 684-691 MONY_WDX \$ 692 NO_EARNR 693-694 NO_E_RNR \$ 895 NO_EARNX 696-704 NO_E_RNX \$ 705 NONINCMX 712-719 NONI_CMX 720 NUM_AUTO $721-722$ NUM_UTO \$ 723 OCCUPRE1 \$733-734 OCCU_RE1 \$ 735 OCCUPRE2 \$ 736-737 OCCU_RE2 \$ 738 ORIGIN1 \$ 739 ORIGIN1_\$ 740 ORIGIN2 \$ 741 ORIGIN2_\$ 742 OTHRFNDX 749-756 OTHR_NDX \$ 757 OTHRINCX 758-765 OTHR_NCX \$ 766 PENSIONX 775-782 PENS_ONX \$ 783 PERSLT18 784-785 PERS_T18 \$ 786 PERSOT64 787-788 PERS_T64 \$ 789 POPSIZE \$ 792 PRINEARN \$ 793-794 PRIN_ARN \$ 795 PTAXRFDX 796-803 PTAX_FDX \$ 804 PURSSECX 809-816 PURS_ECX \$ 817 QINTRVMO \$ 818-819 QINTRVYR \$ 820 RACE2 \$ 828 RACE2_ \$ 829 REF_RACE \$ 830 REF_ACE \$ 831 REGION \$ 832 RESPSTAT \$ 840 RESP_TAT \$ 841 SALEINCX 852-859 SALE_NCX \$ 860 SAVACCTX 861-870 SAVA_CTX \$ 871 SECESTX 872-881 SECESTX_\$ 882 SELLSECX 883-892 SELL_ECX \$ 893 SETLINSX 894-901 SETL_NSX \$ 902 SEX_REF \$ 903 SEX_REF_\$ 904 SEX2 \$ 905 SEX2_\$ 906 SMSASTAT \$ 934 SLOCTAXX 916-923 SLOC_AXX \$ 924 SLRFUNDX 925-932 SLRF_NDX \$ 933 SSOVERPX 941-948 SSOV_RPX \$ 949 TAXPROPX 960-967 TAXP_OPX 968 TOTTXPDX 973-981 TOTT_PDX \$ 982 UNEMPLX 983-990 UNEMPLX_\$ 991 USBNDX 992-999 USBNDX_\$ 1000 VEHQ 1001-1002 VEHQ_ \$ 1003 WDBSASTX 1011-1020 WDBS_STX \$1021 WDBSGDSX 1022-1029 WDBS_DSX \$ 1030 WELFAREX 1031-1038 WELF_REX \$ 1039 TOTEXPPQ 1527-1538 .4 TOTEXPCQ 1539-1550 .4 FOODPQ 1551-1562 . 4 FOODCQ 1563-1574 . 4 FDHOMEPQ 1575-1586 . 4 FDHOMECQ 1587-1598 . 4 FDAWAYPQ 1599-1610 . 4 FDAWAYCQ 1611-1622 .4 ALCBEVPQ 1623-1634.4 ALCBEVCQ 1635-1646.4 HOUSPQ 1647-1658.4 HOUSCQ 1659-1670 .4 SHELTPQ 1671-1682 .4 SHELTCQ 1683-1694 .4 OWNDWEPQ 1695-1706 .4 OWNDWECQ 1707-1718 .4 RENDWEPQ 1719-1730 .4 RENDWECQ 1731-1742 .4 OTHLODPQ $1743-1754$. 4 OTHLODCQ $1755-1766$.4 UTILPQ 1767-1778.4 UTILCQ 1779-1790.4 HOUSOPPQ 1791-1802 . 4 HOUSOPCQ 1803-1814 .4 HOUSEQPQ $1815-1826.4$ HOUSEQCQ $1827-1838$.4 APPARPQ 1839-1850 . 4 APPARCQ $1851-1862.4 \quad$ TRANSPQ $1863-1874.4$ TRANSCQ 1875-1886 . 4 VEHICLPQ 1887-1898 .4 VEHICLCQ 1899-1910 .4 
GASMOPQ 1911-1922 . 4 GASMOCQ 1923-1934 .4 OTHVEHPQ 1935-1946 .4 OTHVEHCQ 1947-1958 . 4 PUBTRAPQ 1959-1970 .4 PUBTRACQ 1971-1982 .4 HEALTHPQ 1983-1994.4 HEALTHCQ 1995-2006 .4 ENTERTPQ 2007-2018 .4 ENTERTCQ 2019-2030 . 4 PERSCAPQ 2031-2042 .4 PERSCACQ 2043-2054 . 4 READPQ 2055-2066 . 4 READCQ 2067-2078 .4 EDUCAPQ 2079-2090 . 4 EDUCACQ 2091-2102 . 4 TOBACCPQ 2103-2114 .4 TOBACCCQ 2115-2126 .4 MISCPQ 2127-2138.4 MISCCQ 2139-2150 .4 CASHCOPQ 2151-2162 .4 CASHCOCQ 2163-2174 .4 PERINSPQ 2175-2186 .4 PERINSCQ 2187-2198 .4 LIFINSPQ 2199-2210 . 4 LIFINSCQ 2211-2222 .4 RETPENPQ 2223-2234 .4 RETPENCQ 2235-2246 . 4;

NEWID=RIGHT (NEWID);

RUN;

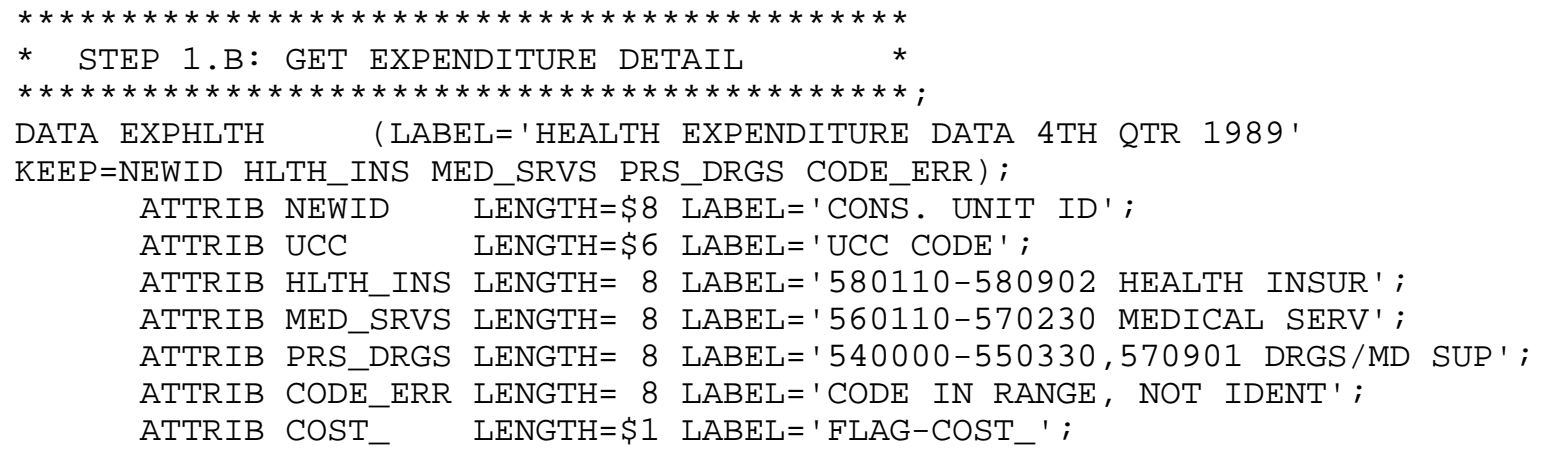














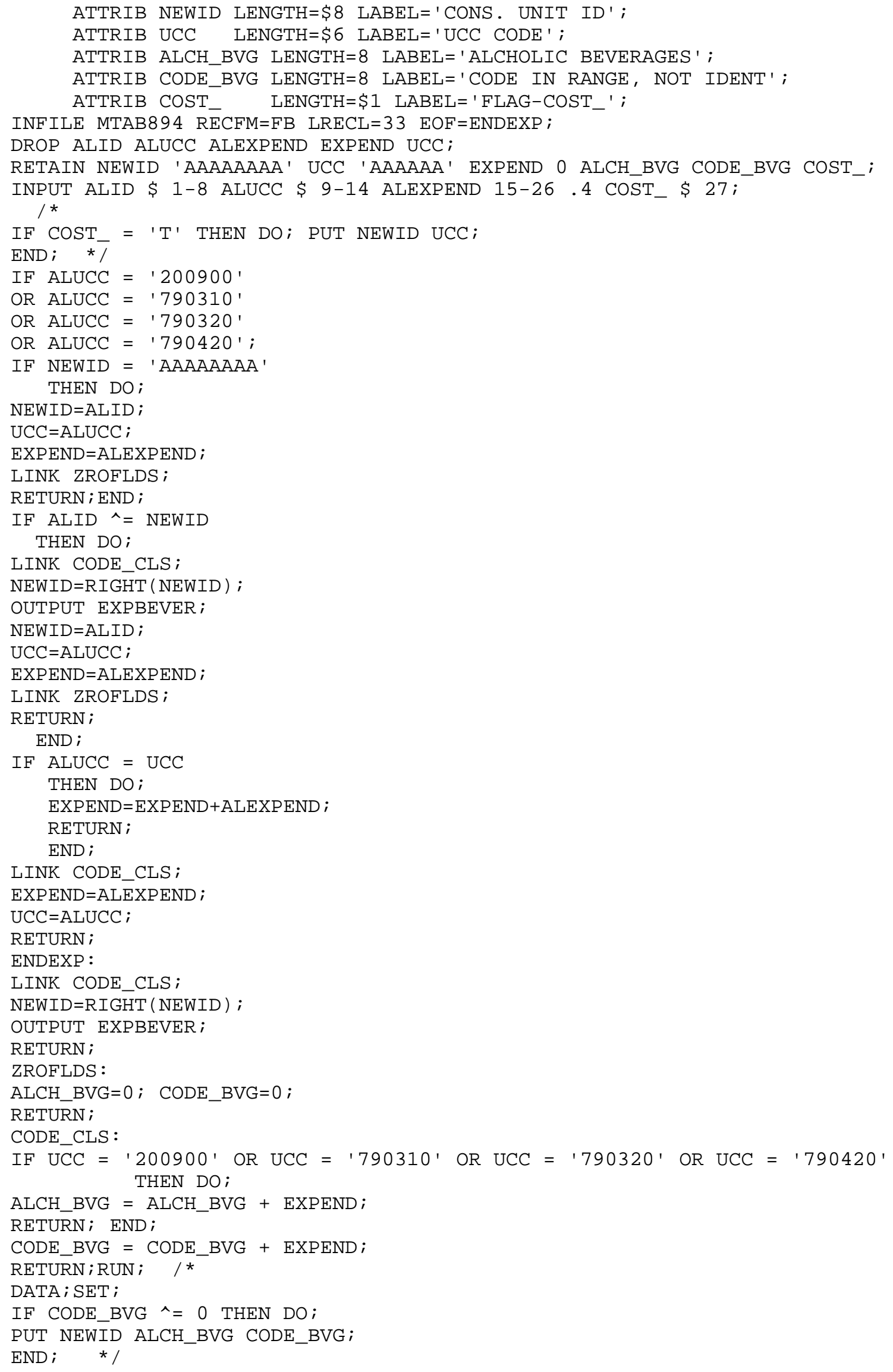




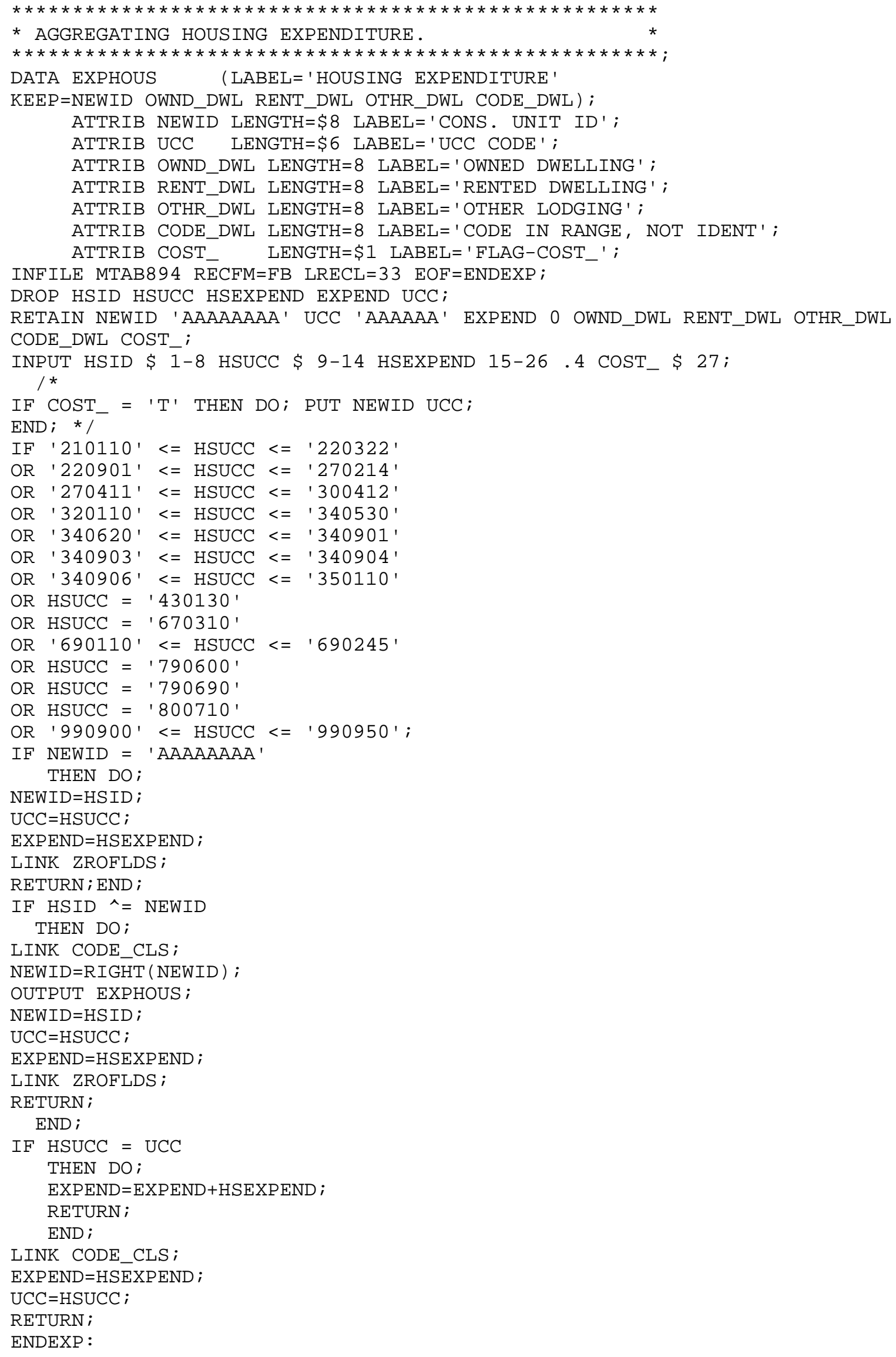














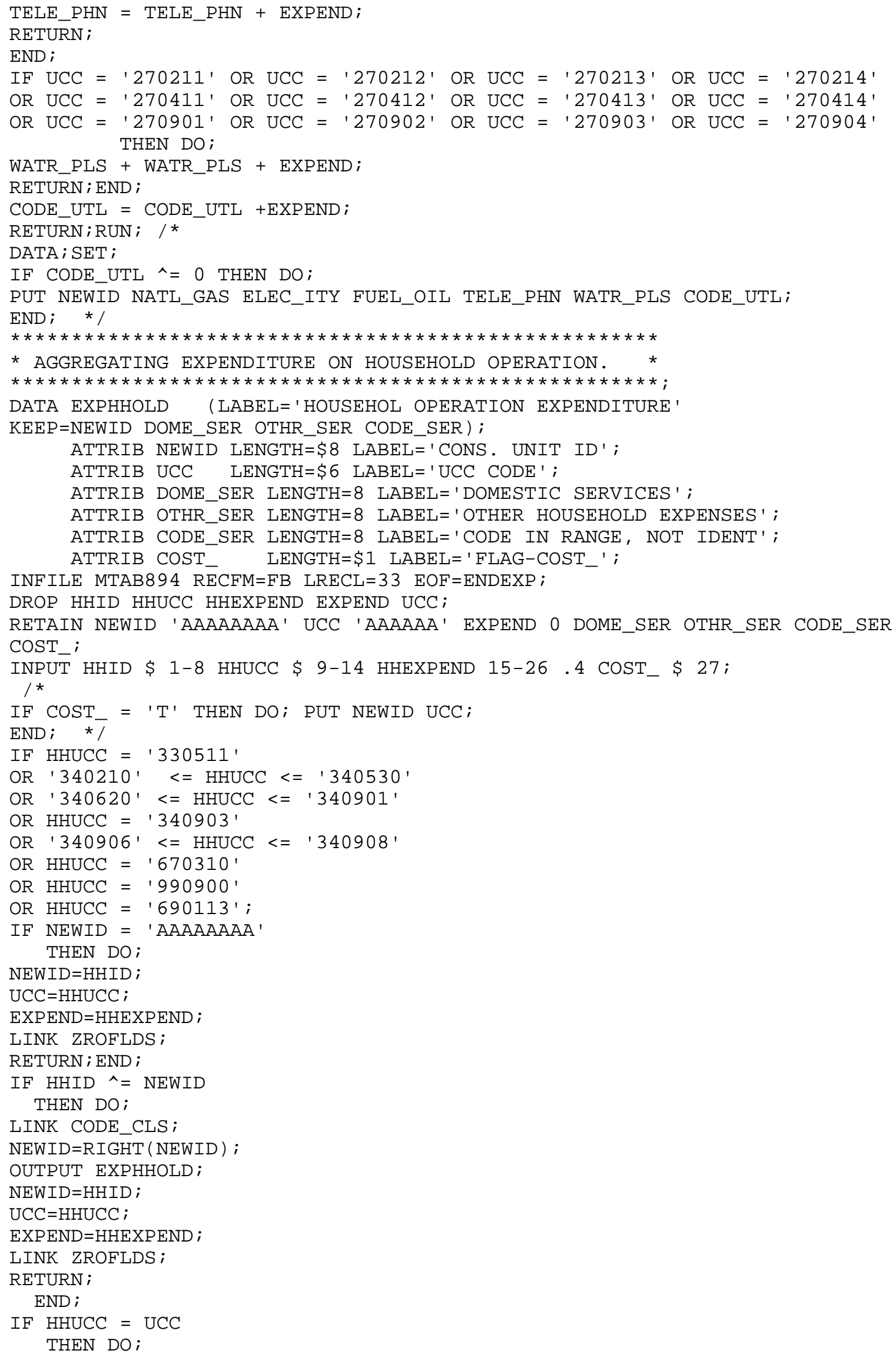









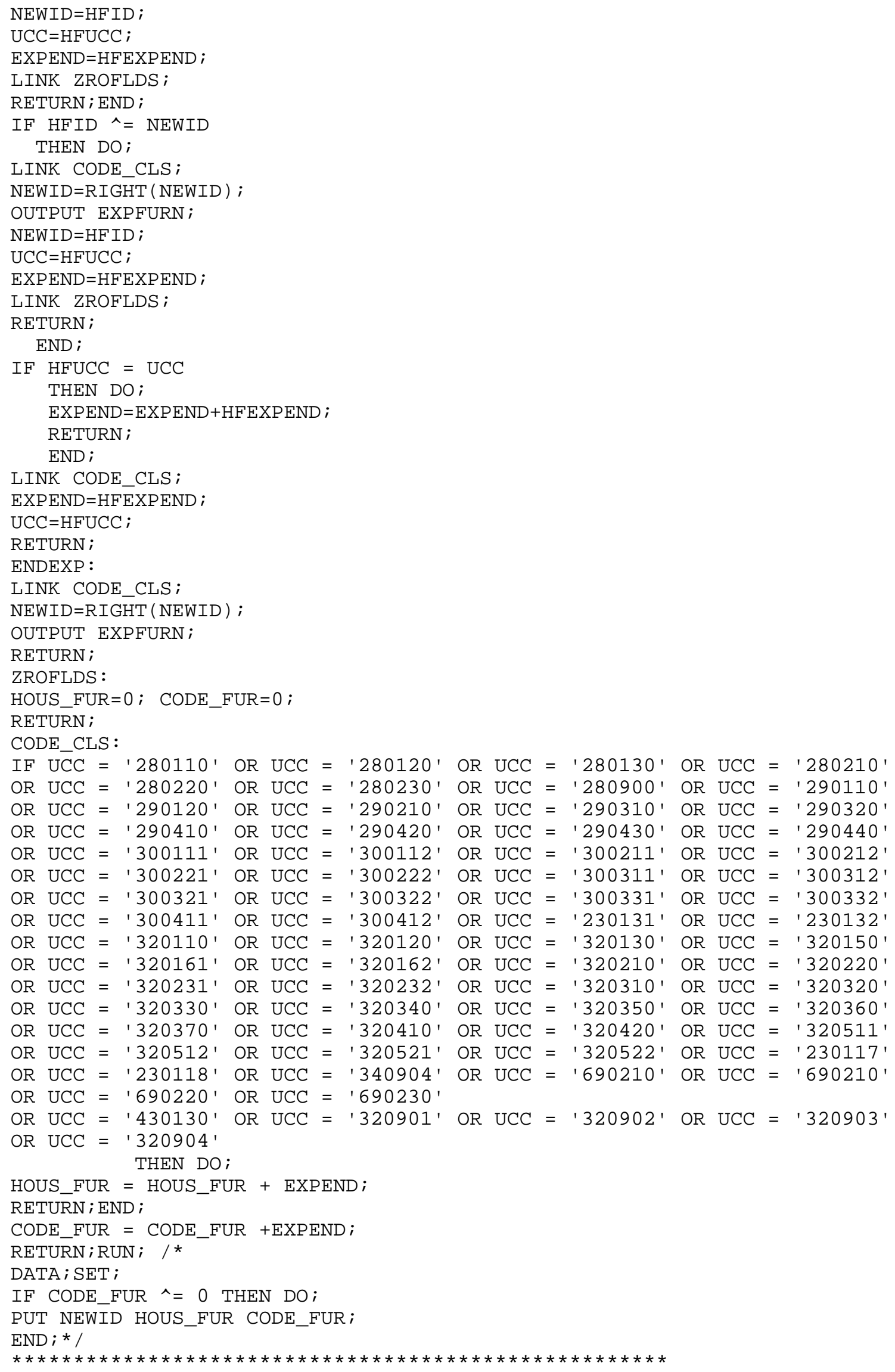




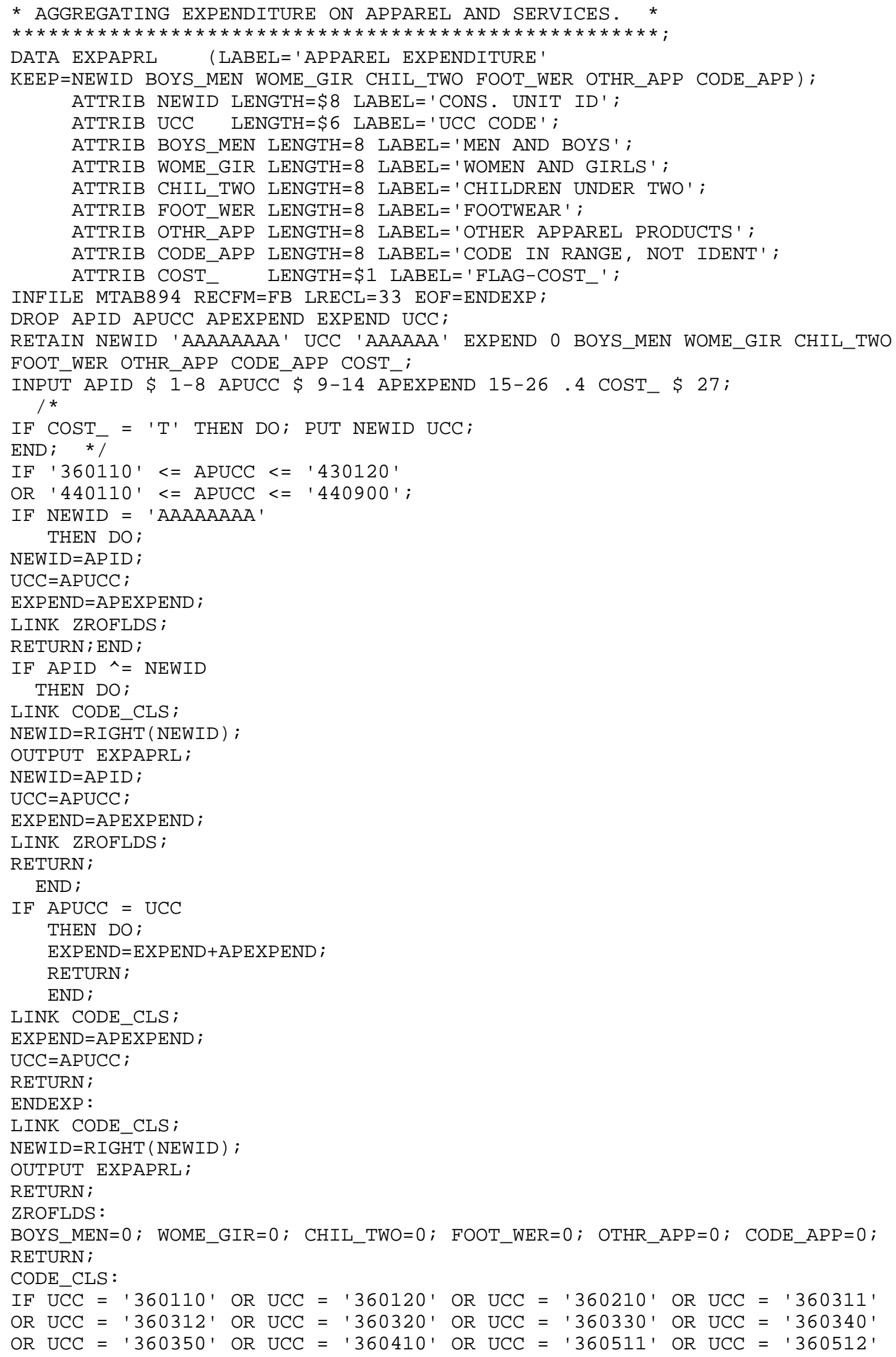




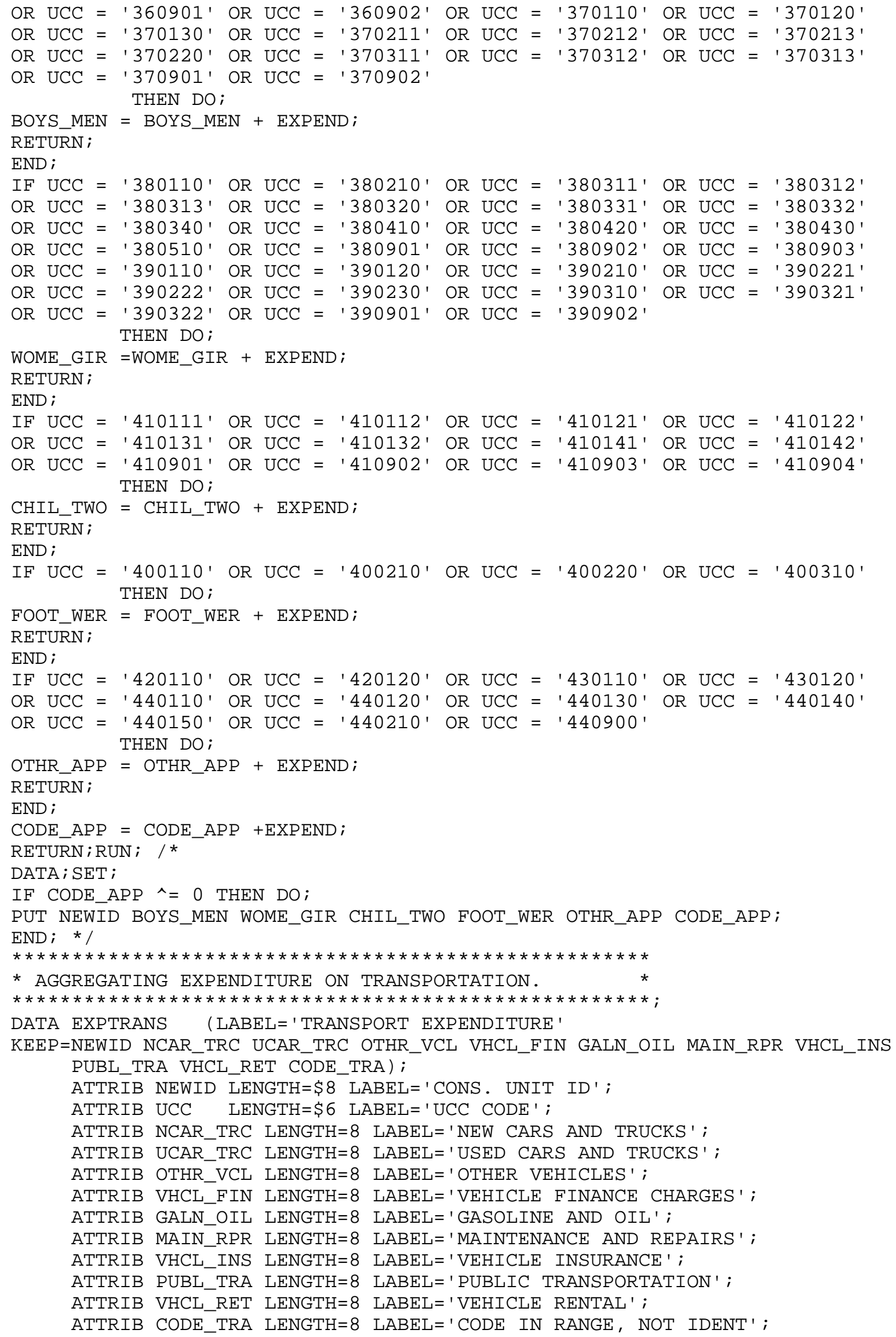


ATTRIB COST_ LENGTH=\$1 LABEL='FLAG-COST_';

INFILE MTAB894 RECFM=FB LRECL=33 EOF=ENDEXP;

DROP TRID TRUCC TREXPEND EXPEND UCC;

RETAIN NEWID 'AAAAAAAA' UCC 'AAAAAA' EXPEND 0 NCAR_TRC UCAR_TRC OTHR_VCL

VHCL_FIN GALN_OIL MAIN_RPR VHCL_INS PUBL_TRA VHCL_RET CODE_TRA COST_;

INPUT TRID \$ $\overline{1-8}$ TRUCC \$ 9-14 TREXPEND $1 \overline{5}-26.4$ COST_ \$ 27;

/*

IF COST $=$ ' $\mathrm{T}$ ' THEN DO; PUT NEWID UCC;

END; */

IF TRUCC $=' 450110^{\prime}$

OR TRUCC $=' 450210^{\prime}$

OR TRUCC $=' 450220^{\prime}$

OR TRUCC $=' 460110^{\prime}$

OR TRUCC $=' 450900^{\prime}$

OR '460901' $<=$ TRUCC $<=$ '460903'

OR ' $470111^{\prime}<=$ TRUCC $<=$ '470212'

OR ' $470220^{\prime}<=$ TRUCC $<=$ '530902'

OR ' $620906^{\prime}<=$ TRUCC $<=$ '620907'

OR TRUCC $=$ ' 850300 '

OR TRUCC $=$ '620902';

IF NEWID = 'AAAAAAAA'

THEN DO;

NEWID=TRID;

$\mathrm{UCC}=\mathrm{TRUCC}$;

EXPEND=TREXPEND;

LINK ZROFLDS;

RETURN; END;

IF $\operatorname{TRID} \wedge=$ NEWID

THEN DO;

LINK CODE_CLS;

NEWID=RIGHT (NEWID);

OUTPUT EXPTRANS;

NEWID $=$ TRID;

$\mathrm{UCC}=\mathrm{TRUCC}$;

EXPEND=TREXPEND;

LINK ZROFLDS;

RETURN;

END;

IF TRUCC $=$ UCC

THEN DO;

EXPEND=EXPEND+TREXPEND;

RETURN;

END;

LINK CODE_CLS;

EXPEND=TREXPEND;

$\mathrm{UCC}=\mathrm{TRUCC}$;

RETURN;

ENDEXP :

LINK CODE_CLS;

NEWID=RIGHT (NEWID);

OUTPUT EXPTRANS;

RETURN;

ZROFLDS :

NCAR_TRC $=0$; UCAR_TRC $=0$; OTHR_VCL=0; VHCL_FIN=0; GALN_OIL=0; MAIN_RPR=0;

$\mathrm{VHCL}$ INS $=0$; $\mathrm{PUBL}$ TRA $=0$; VHCL_RET $=0 ; \mathrm{CODE} \_\mathrm{TRA}=0$;

RETURN;

CODE_CLS :

IF $\mathrm{UCC}=' 450110^{\prime} \mathrm{OR} \mathrm{UCC}=$ ' $^{\prime} 450210^{\prime}$

THEN DO;

NCAR_TRC $=$ NCAR_TRC + EXPEND;

RETURN;

END; 


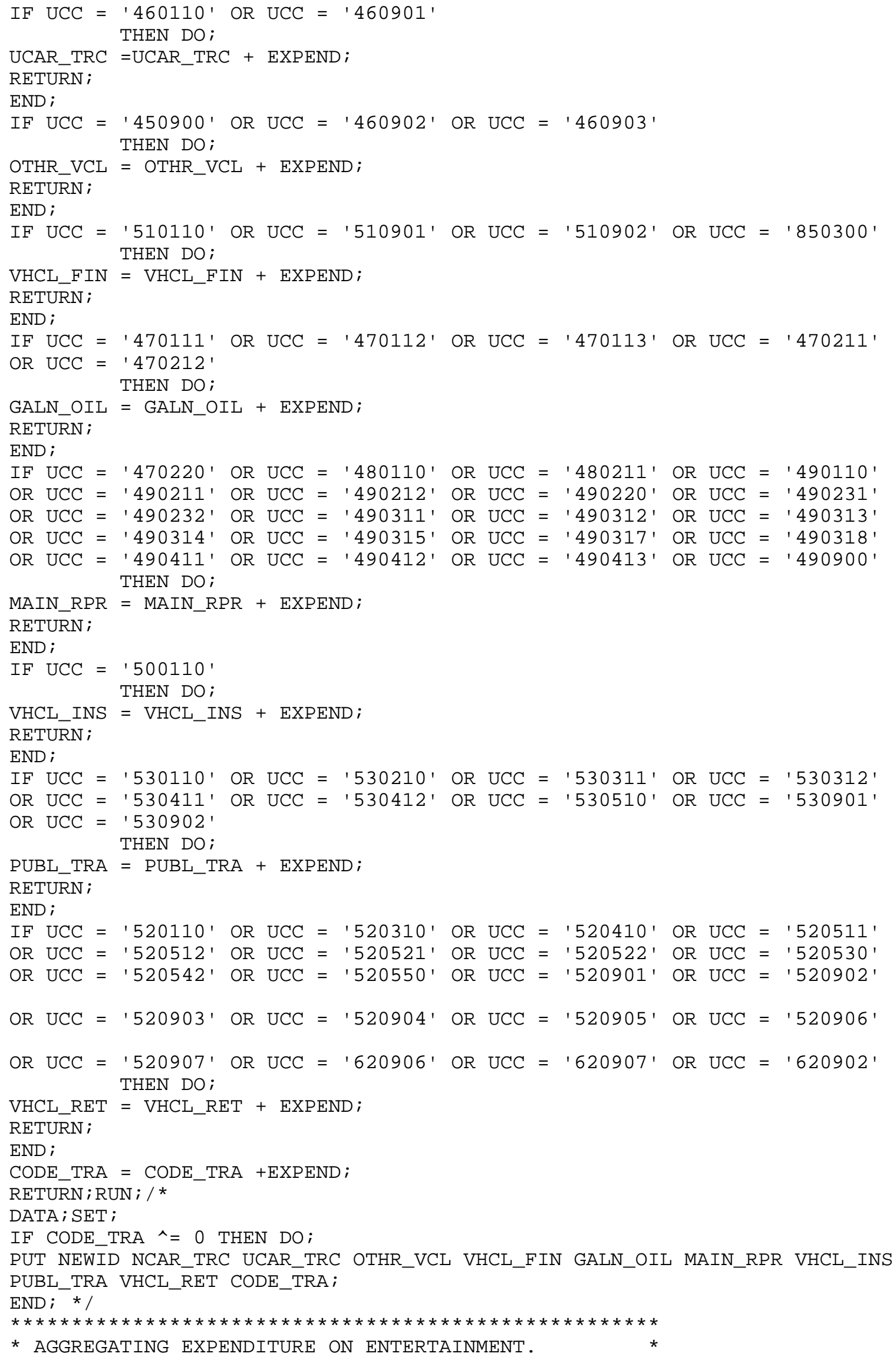




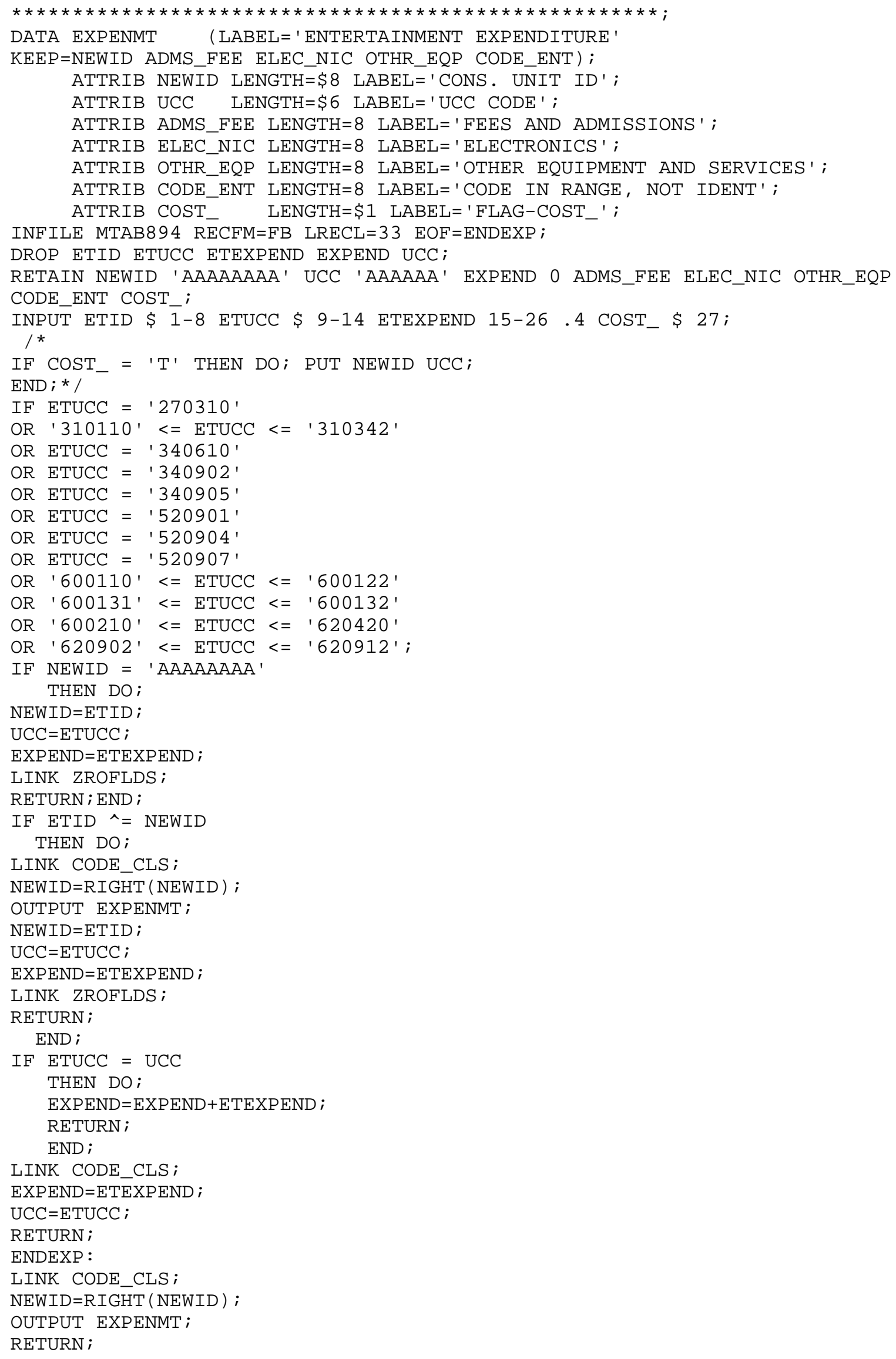




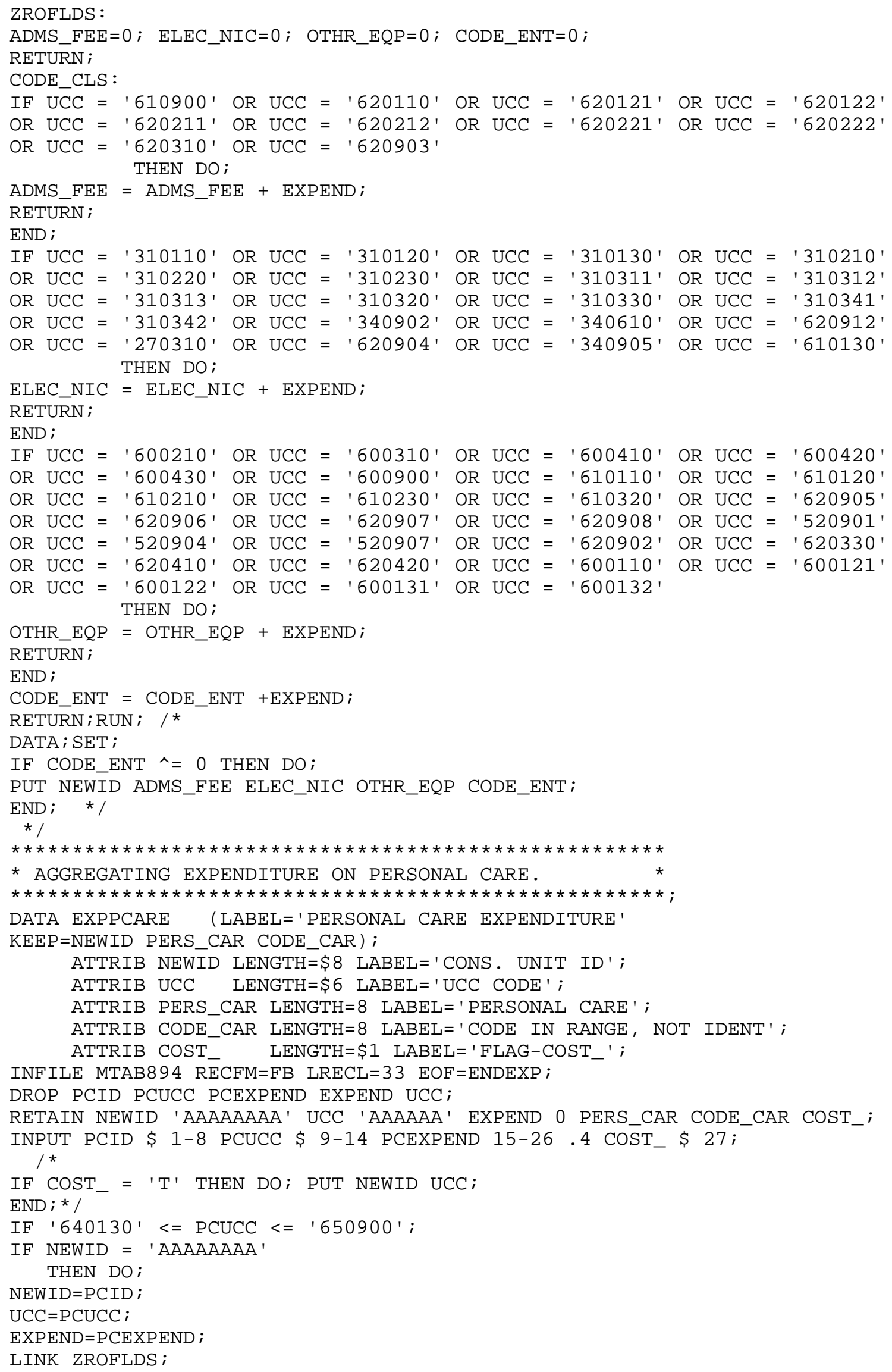




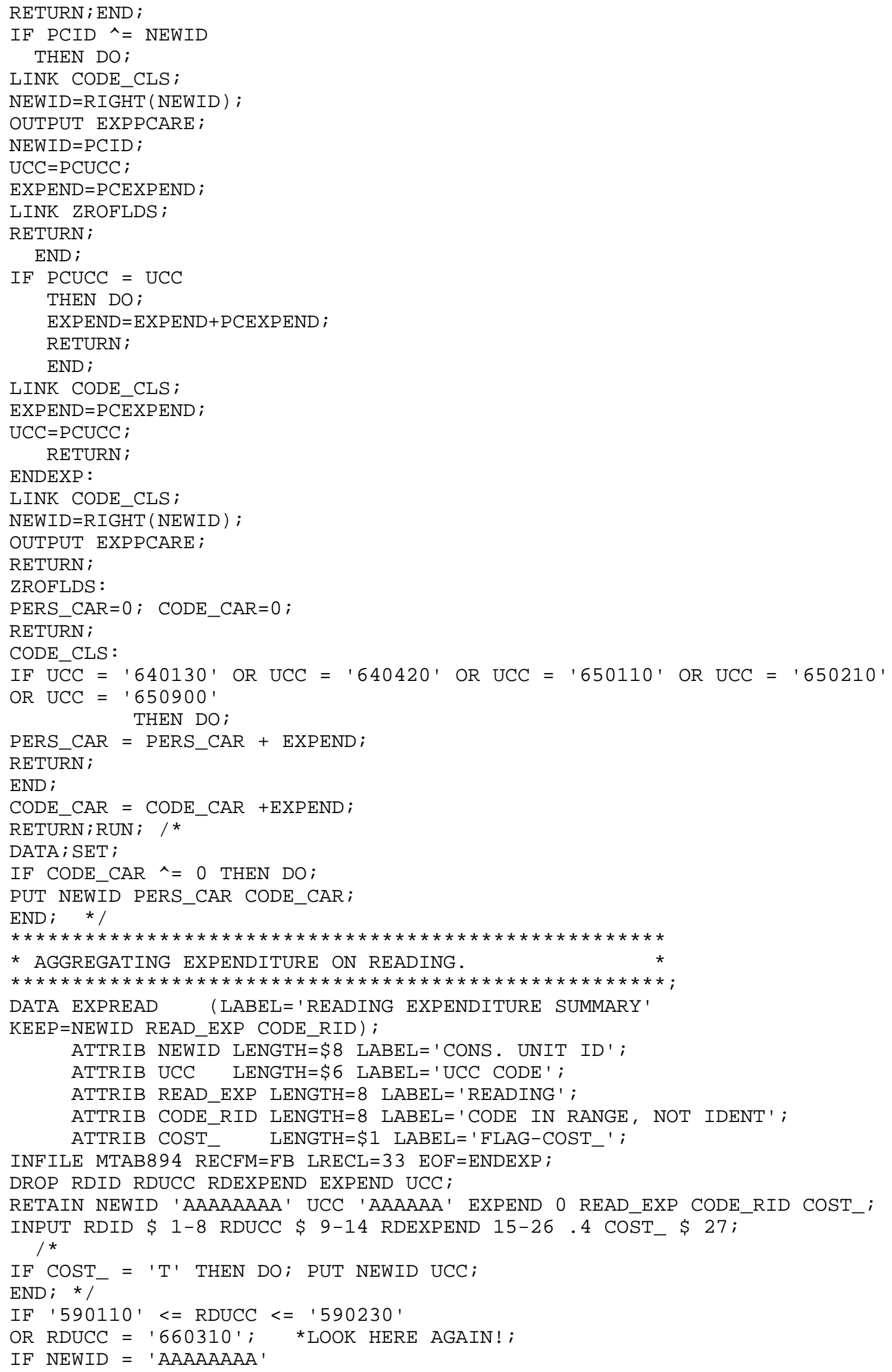


THEN DO;

NEWID $=$ RDID;

$\mathrm{UCC}=\mathrm{RDUCC}$;

EXPEND=RDEXPEND;

LINK ZROFLDS;

RETURN; END;

IF $\operatorname{RDID} \wedge=\mathrm{NEWID}$

THEN DO;

LINK CODE_CLS;

NEWID=RIGHT (NEWID) ;

OUTPUT EXPREAD;

NEWID=RDID;

$\mathrm{UCC}=\mathrm{RDUCC}$;

EXPEND=RDEXPEND;

LINK ZROFLDS;

RETURN;

END;

IF $\mathrm{RDUCC}=\mathrm{UCC}$

THEN DO;

EXPEND=EXPEND+RDEXPEND;

RETURN;

END;

LINK CODE_CLS;

EXPEND=RDEXPEND;

$\mathrm{UCC}=\mathrm{RDUCC}$;

RETURN;

ENDEXP :

LINK CODE_CLS;

NEWID=RIGHT (NEWID) ;

OUTPUT EXPREAD;

RETURN;

ZROFLDS :

READ_EXP $=0$; CODE_RID $=0$;

RETURN;

CODE_CLS :

IF UCC $=$ '590110' OR UCC $=$ '590210' OR UCC $=$ '590220' OR UCC $=$ '590230'

OR UCC $=$ ' $660310^{\prime}$ THEN DO;

READ_EXP = READ_EXP + EXPEND;

RETURN;

END;

CODE_RID $=$ CODE_RID +EXPEND;

RETURN; RUN; /*

$\mathrm{DATA} ; \mathrm{SET}$;

IF CODE_RID $\wedge=0$ THEN DO;

PUT NEWID READ_EXP CODE_RID;

END; $\quad * /$

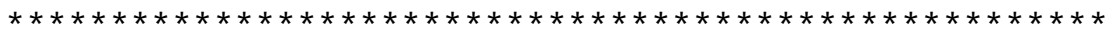

* AGGREGATING EXPENDITURE ON EDUCATION.

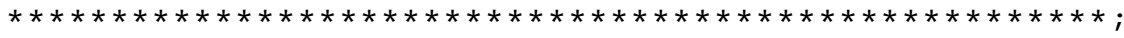

DATA EXPEDUC (LABEL='EDUCATION EXPENDITURE'

$\mathrm{KEEP}=\mathrm{NEWID}$ EDUC_EXP CODE_EDU) ;

ATTRIB NEWID LENGTH=\$8 LABEL='CONS. UNIT ID';

ATTRIB UCC LENGTH=\$6 LABEL='UCC CODE' ;

ATTRIB EDUC_EXP LENGTH=8 LABEL='EDUCATION' ;

ATTRIB CODE_EDU LENGTH=8 LABEL='CODE IN RANGE, NOT IDENT';

ATTRIB COST_ LENGTH $=\$ 1$ LABEL $=$ 'FLAG-COST_' ;

INFILE MTAB894 RECFM=FB LRECL=33 EOF=ENDEXP;

DROP EDID EDUCC EDEXPEND EXPEND UCC;

RETAIN NEWID 'AAAAAAAA' UCC 'AAAAAA' EXPEND 0 EDUC_EXP CODE_EDU COST_;

INPUT EDID \$ 1-8 EDUCC \$ 9-14 EDEXPEND 15-26.4 COST_ \$27;

$/ \star$ 


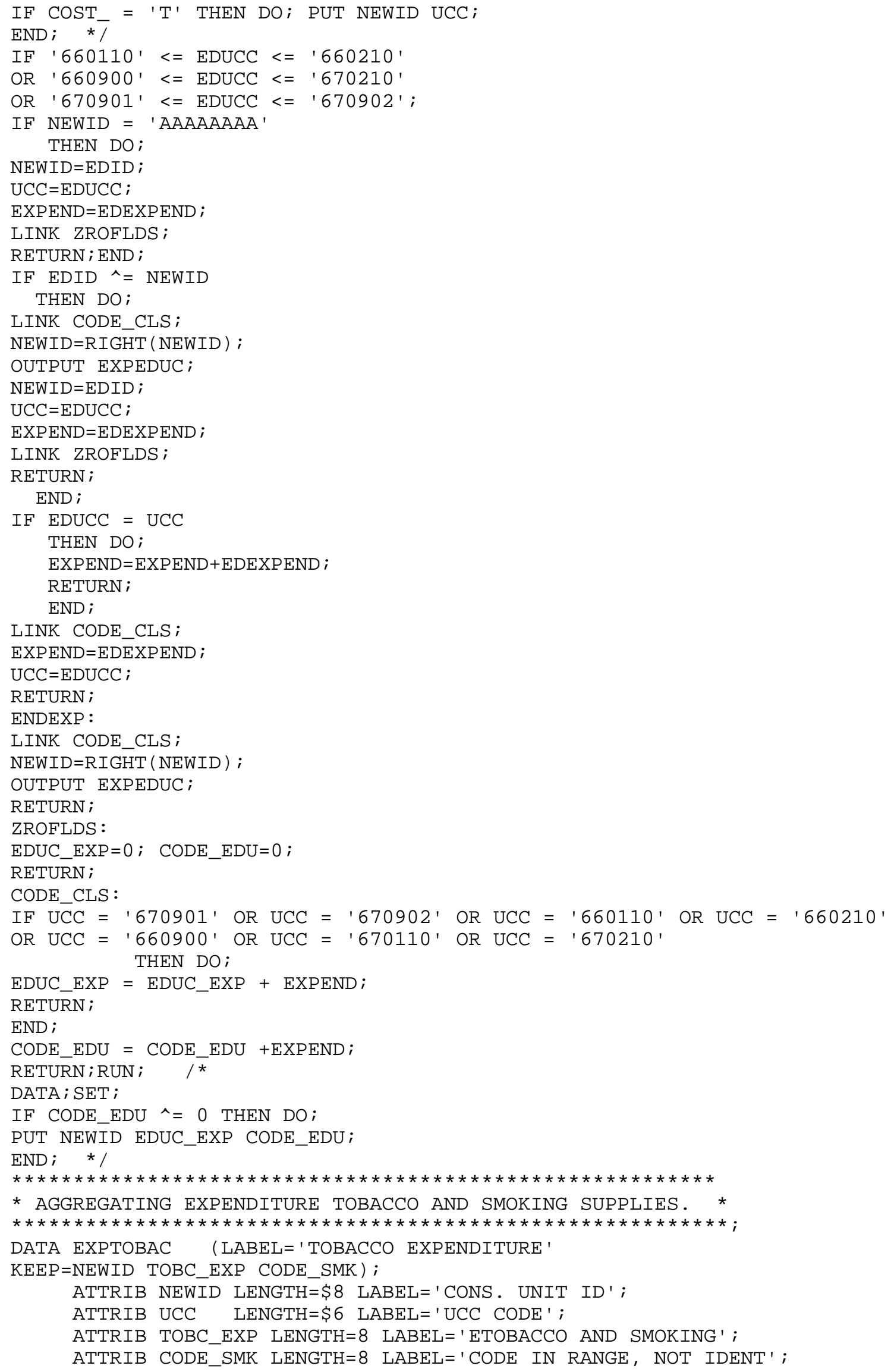


ATTRIB COST_ LENGTH=\$1 LABEL='FLAG-COST_';

INFILE MTAB894 RECFM=FB LRECL=33 EOF=ENDEXP;

DROP TBID TBUCC TBEXPEND EXPEND UCC;

RETAIN NEWID 'AAAAAAAA' UCC 'AAAAAA' EXPEND 0 TOBC_EXP CODE_SMK COST_;

INPUT TBID \$ 1-8 TBUCC \$ 9-14 TBEXPEND 15-26.4 COST_ \$ 27;

/*

IF $\mathrm{COST}_{-}=$' $\mathrm{T}$ ' THEN DO; PUT NEWID UCC;

END; $\quad * /$

IF '630110' $<=$ TBUCC $<=$ '630210';

IF NEWID = 'AAAAAAAA'

THEN DO;

NEWID=TBID;

$\mathrm{UCC}=\mathrm{TBUCC}$;

EXPEND=TBEXPEND;

LINK ZROFLDS;

RETURN; END;

IF $\operatorname{TBID} \wedge=$ NEWID

THEN DO;

LINK CODE_CLS;

NEWID $=$ RIGHT (NEWID) ;

OUTPUT EXPTOBAC;

NEWID $=$ TBID ;

$\mathrm{UCC}=\mathrm{TBUCC}$;

EXPEND=TBEXPEND;

LINK ZROFLDS;

RETURN;

END;

IF TBUCC $=$ UCC

THEN DO;

EXPEND $=$ EXPEND + TBEXPEND;

RETURN;

END;

LINK CODE_CLS;

EXPEND=TBEXPEND;

$\mathrm{UCC}=\mathrm{TBUCC}$;

RETURN;

ENDEXP :

LINK CODE_CLS;

NEWID=RIGHT (NEWID);

OUTPUT EXPTOBAC;

RETURN;

ZROFLDS :

TOBC_EXP $=0$; CODE_SMK $=0$;

RETURN;

CODE_CLS :

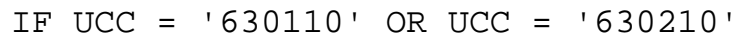

THEN DO;

TOBC_EXP = TOBC_EXP + EXPEND;

RETURN;

END;

CODE_SMK $=$ CODE_SMK +EXPEND;

RETURN; RUN; /*

DATA; SET;

IF CODE_SMK $\wedge=0$ THEN DO;

PUT NEWID TOBC_EXP CODE_SMK;

END; $*$ /



* AGGREGATING EXPENDITURE ON MISCELLANEOUS SPPLIES.

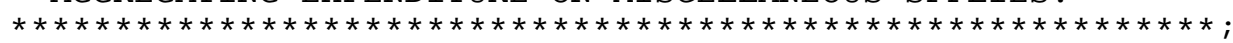

DATA EXPMISC (LABEL='MISCELLANEOUS EXPENDITURE'

KEEP=NEWID MISC_EXP CODE_MSC) ;

ATTRIB NEWID LENGTH $=\$ 8$ LABEL='CONS. UNIT ID'; 


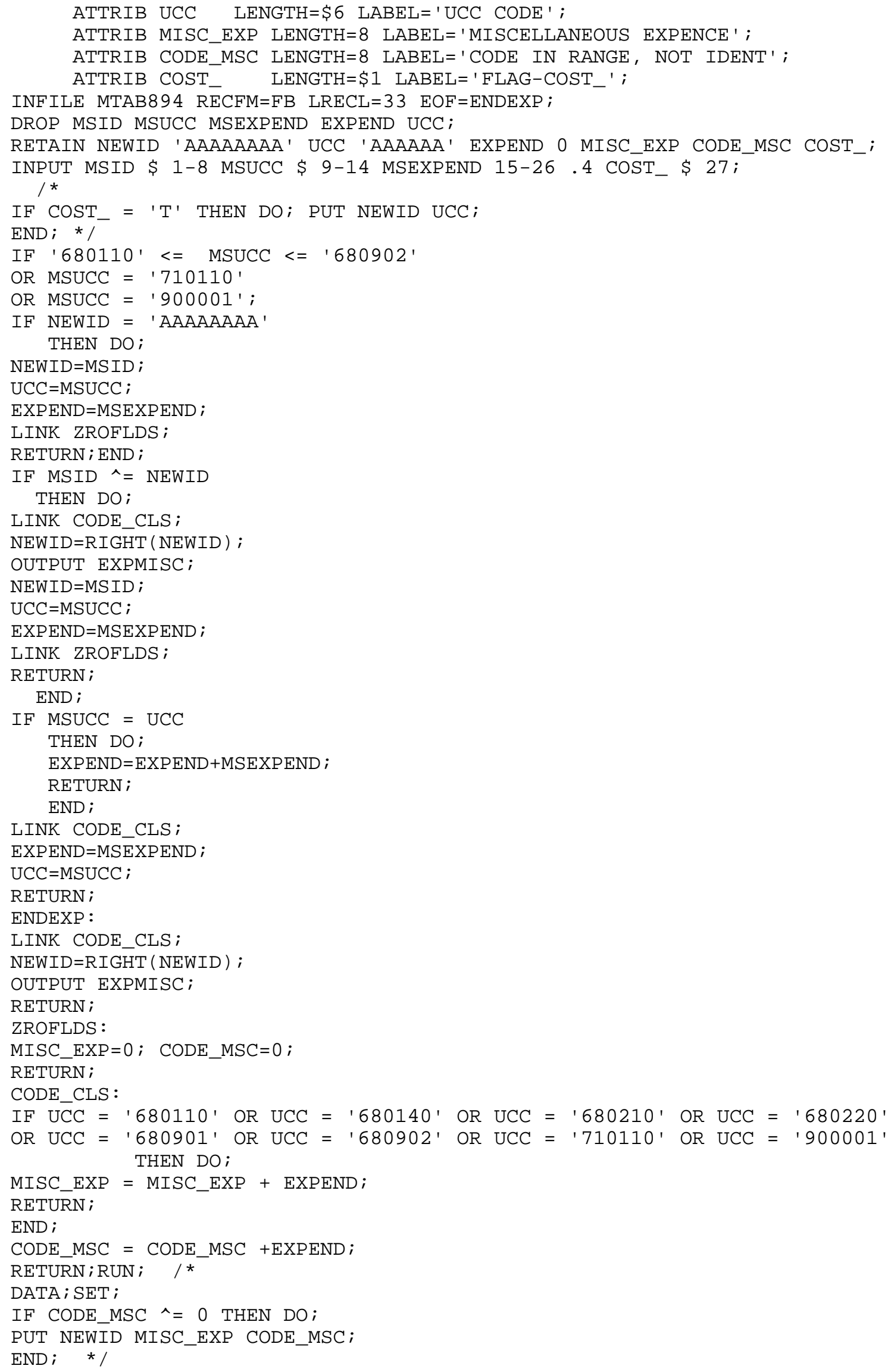




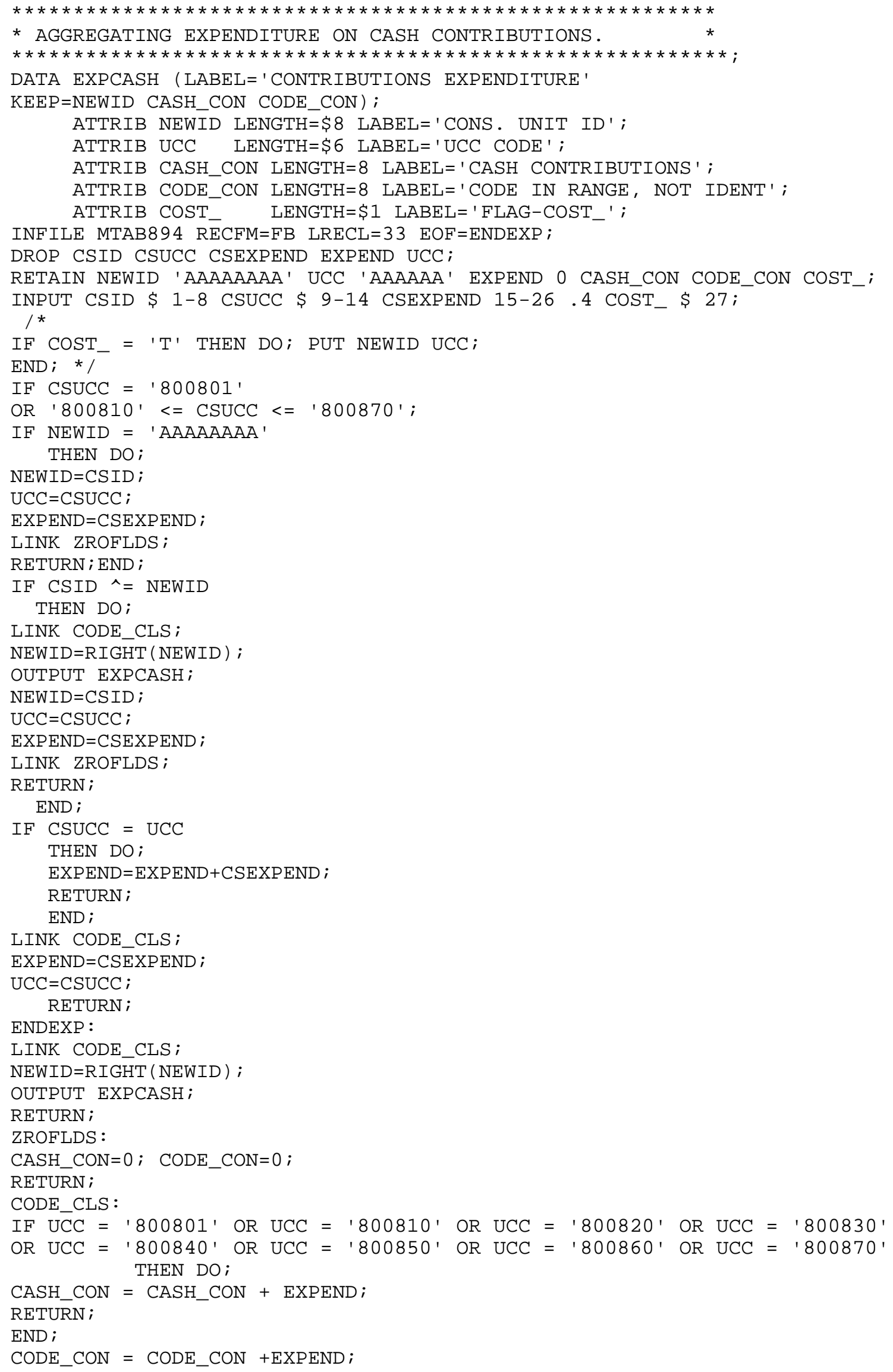












$/ \star$

$/ / *$ EXEC PGM=IEFBR14

$/ / *$ CONSCHR4 DD DSN=UN.BERHSAM. CONSCHR4, UNIT=DISK, $/ / * \quad$ DISP $=$ (OLD, DELETE)

$/ / \star$ EXPSUM4 DD DSN=UN.BERHSAM.EXPSUM4, UNIT=DISK, $/ / * \quad$ DISP $=$ (OLD, DELETE) 
Appendix P-2: Program to Compute Expenditures by Month and Year




ELEC_ITY FUEL_OIL TELE_PHN WATR_PLS

CODE_UTL DOME_SER OTHR_SER CODE_SER

BOYS_MEN WOME_GIR CHIL_TWO FOOT_WER

OTHR_APP CODE_APP NCAR_TRC UCAR_TRC

OTHR_VCL VHCL_FIN GALN_OII MAIN_RPR

VHCL_INS PUBL_TRA VHCL_RET CODE_TRA

ADMS_FEE ELEC_NIC OTHR_EQP CODE_ENT

PERS_CAR CODE_CAR READ_EXP CODE_RID

)$;$

EDUC_EXP CODE_EDU

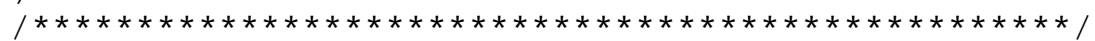

/* Create new variables which will be aggregated */

$1 *$

$1 *$

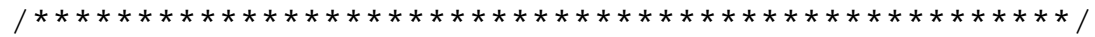

Tothlth = hlth_ins + code_err;

totfood = food_hom + food_awy + code_fud;

totalhl = alch_bvg + code_bvg;

tothous = ownd_dwl + rent_dwl + othr_dwl + code_dwl;

totutil = natl_gas + elec_ity + fuel_oil + tele_phn

+ watr_pls + code_utl;

totdomes $=$ dome_ser + othr_ser + code_ser;

totapp = boys_men + wome_gir + chil_two + foot_wer

+ othr_app + code_app;

tottran = ncar_trc + ucar_trc + othr_vcl + vhcl_fin

+ galn_oil + main_rpr + vhcl_ins

+ publ_tra + vhcl_ret + code_tra;

TOTEXP $=$ TOTHLTH + TOTUTIL + FB + HSNG +

$\mathrm{TPE}+$ TOTTRAN + TOTENT + TOTAPP;

totent $=$ adms_fee + elec_nic + othr_eqp + code_ent;

tpercar = pers_car + code_car;

tread = read_exp + code_edu;

totedu = educ_exp + code_edu;

$\mathrm{fb} \quad=$ totfood + totalhl;

hsing = tothous + totdomes;

tpe $\quad$ tpercar + totedu;

\begin{tabular}{|c|c|}
\hline /* now perform the divisions & */ \\
\hline / * & * / \\
\hline / & $\star /$ \\
\hline
\end{tabular}

nfincatx $=$ fincatax $/ 12$;

nfincbtx = fincbtax / 12;

nfnlwt $21=$ finlwt $21 / 12$;

ntothlth = tothlth / 3;

ntotutil $=$ totutil / 3 ;

$\mathrm{nfb} \quad=\mathrm{fb} / 3$;

nhsng $=$ hsng / 3 ;

ntpe $=$ tpe / 3;

ntottran $=$ tottran $/ 3$;

ntotent $=$ totent $/ 3$;

ntotapp $=$ totapp / 3;

\footnotetext{
*format intdate realdate monyy.;

format intdate realdate date9.;

label

intdate = "Interview Date"

realdate = "Simulated Date"
} 





Appendix P-3: Rearrange the Month with the Year






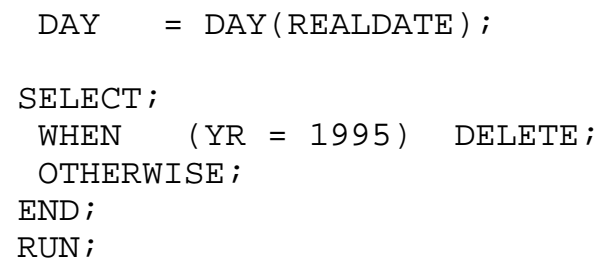




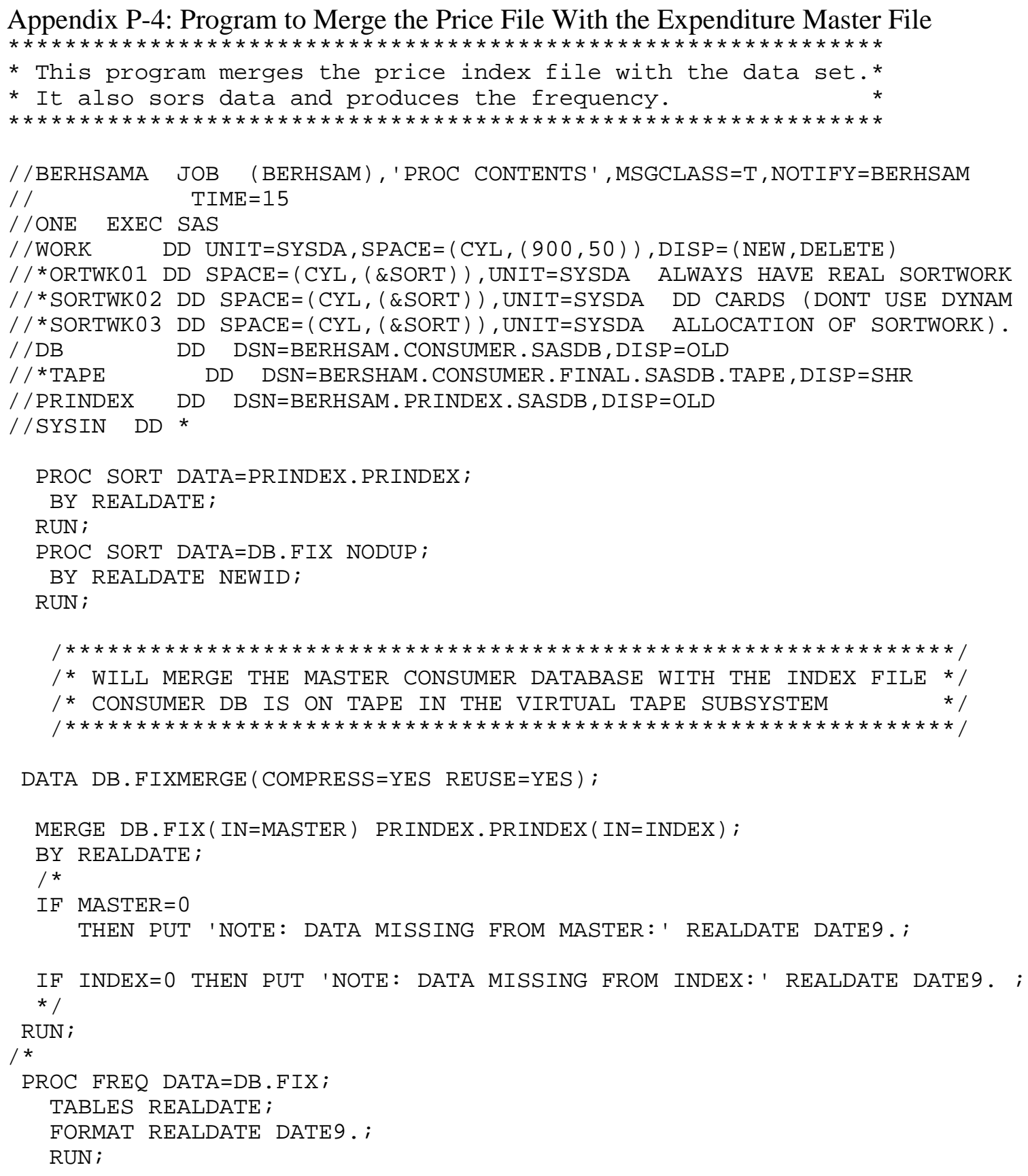


Appendix P-5: Program to Display the Content of the Data Set






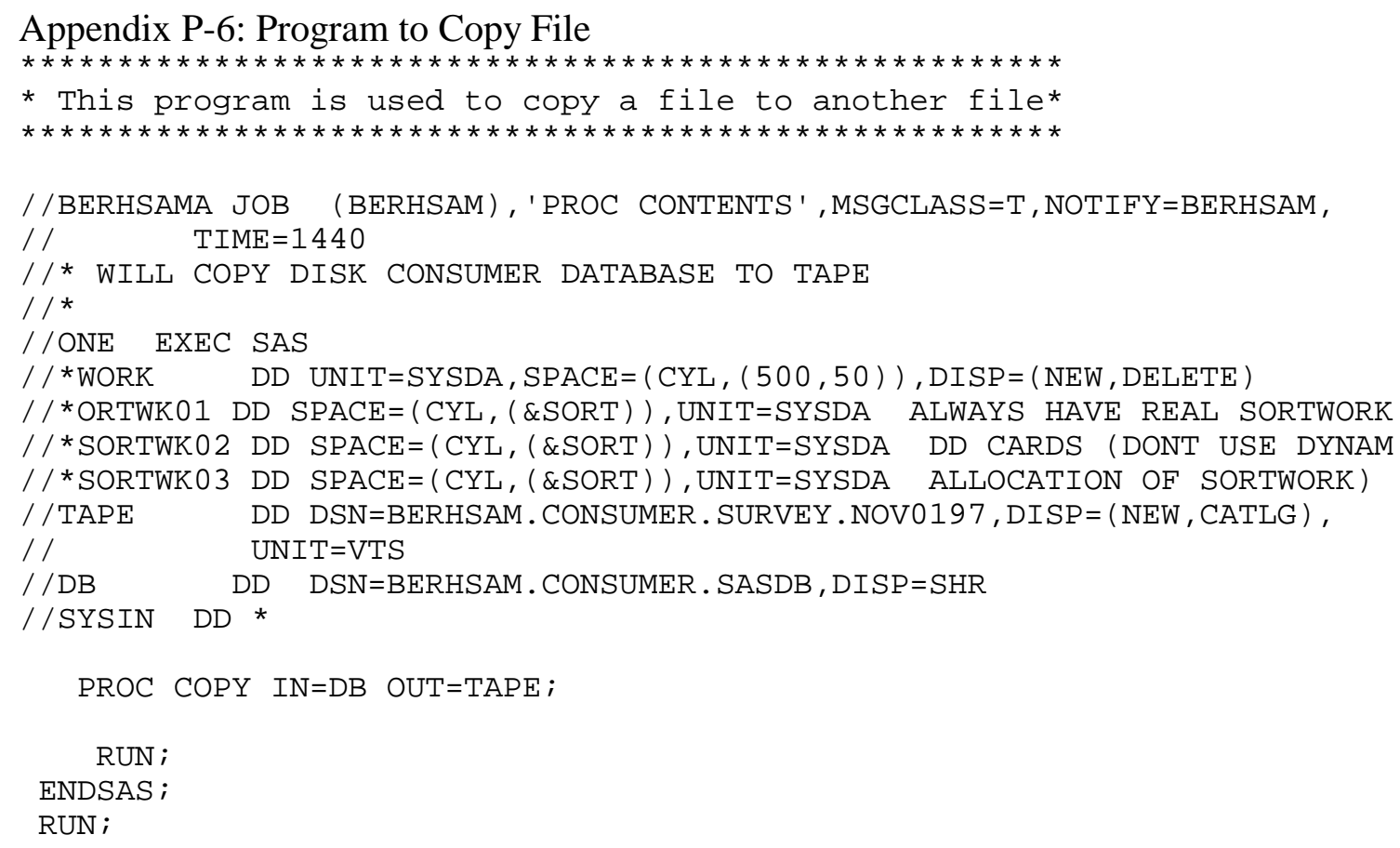




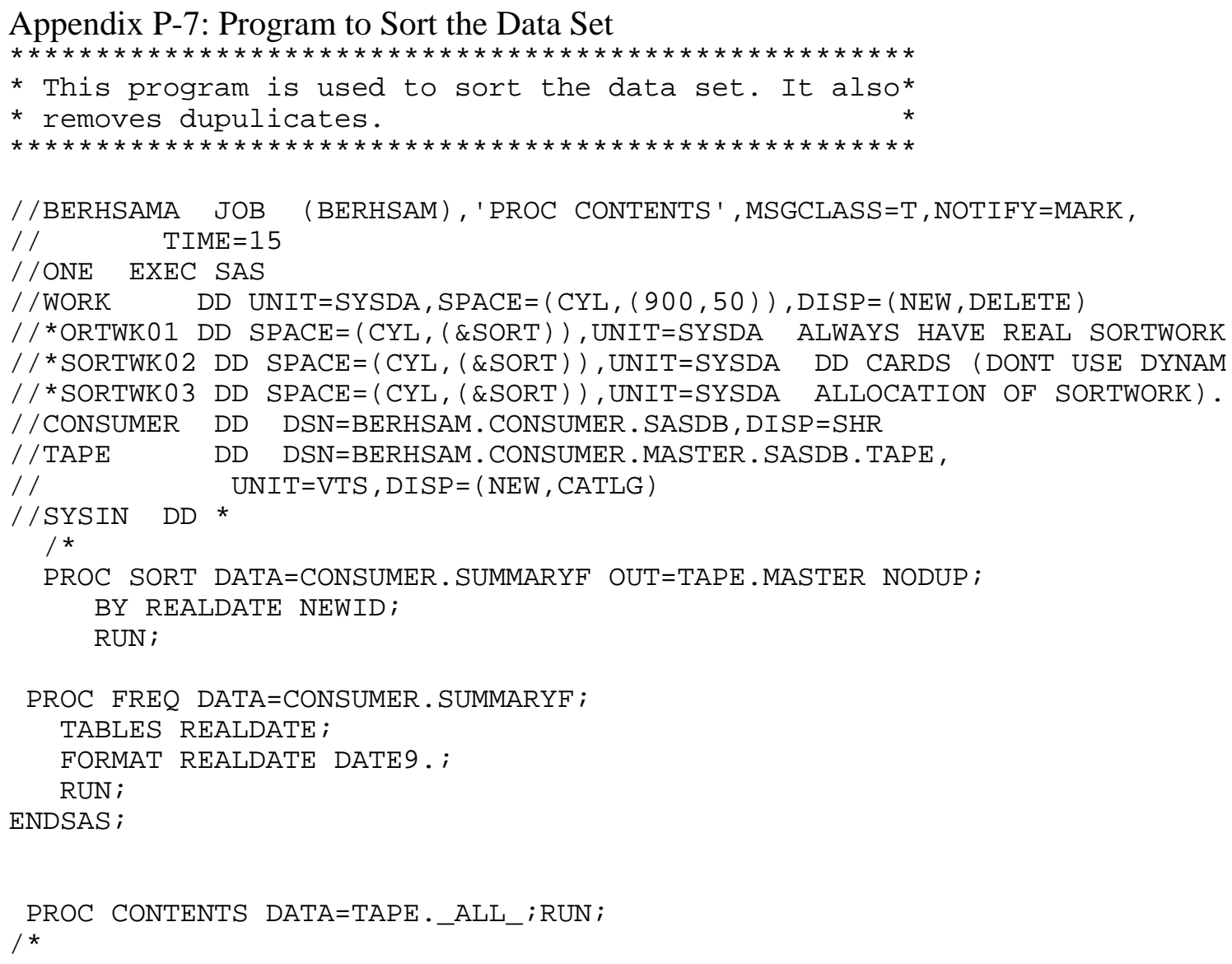




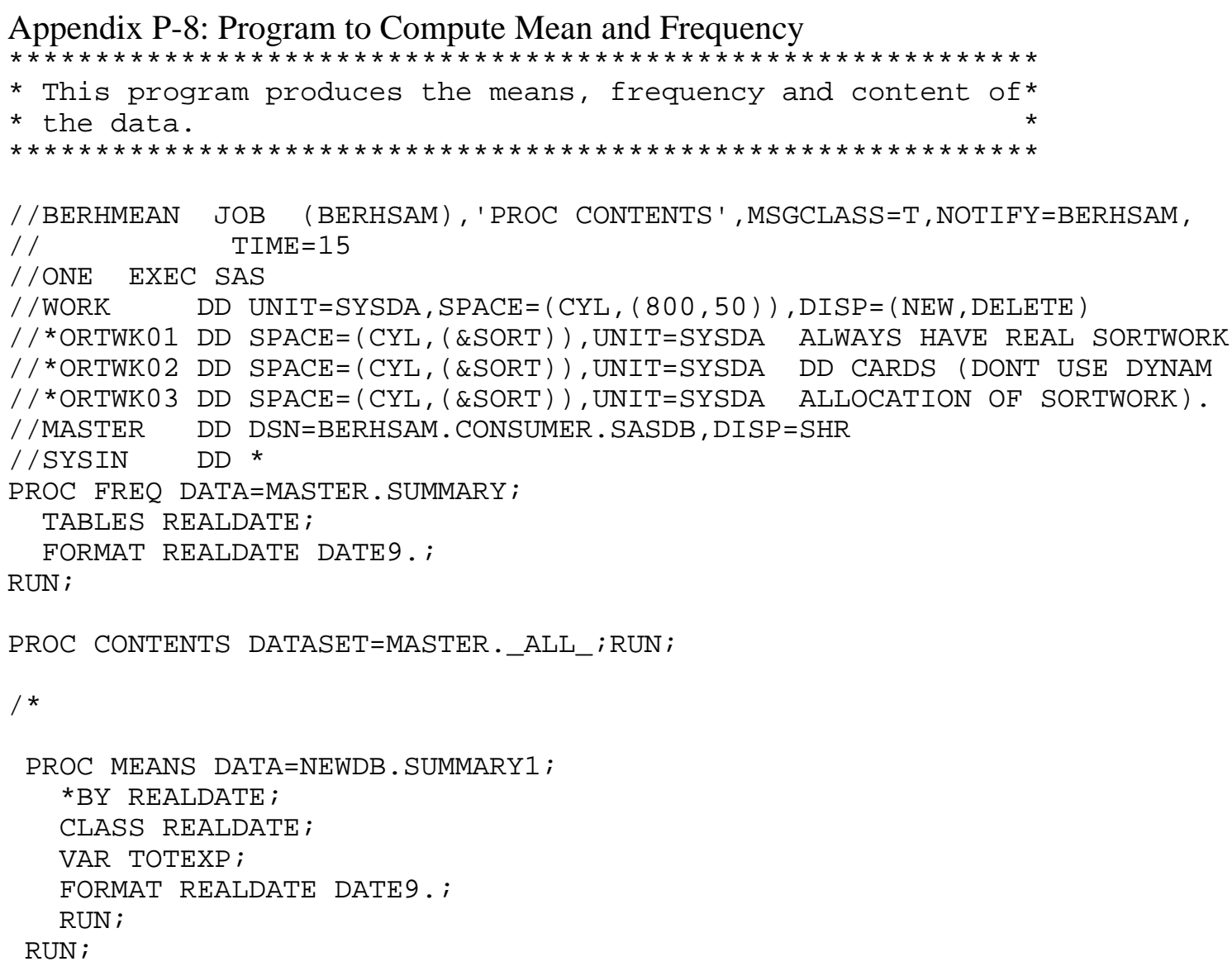


Appendix P-9: Program to Display Frequency Table

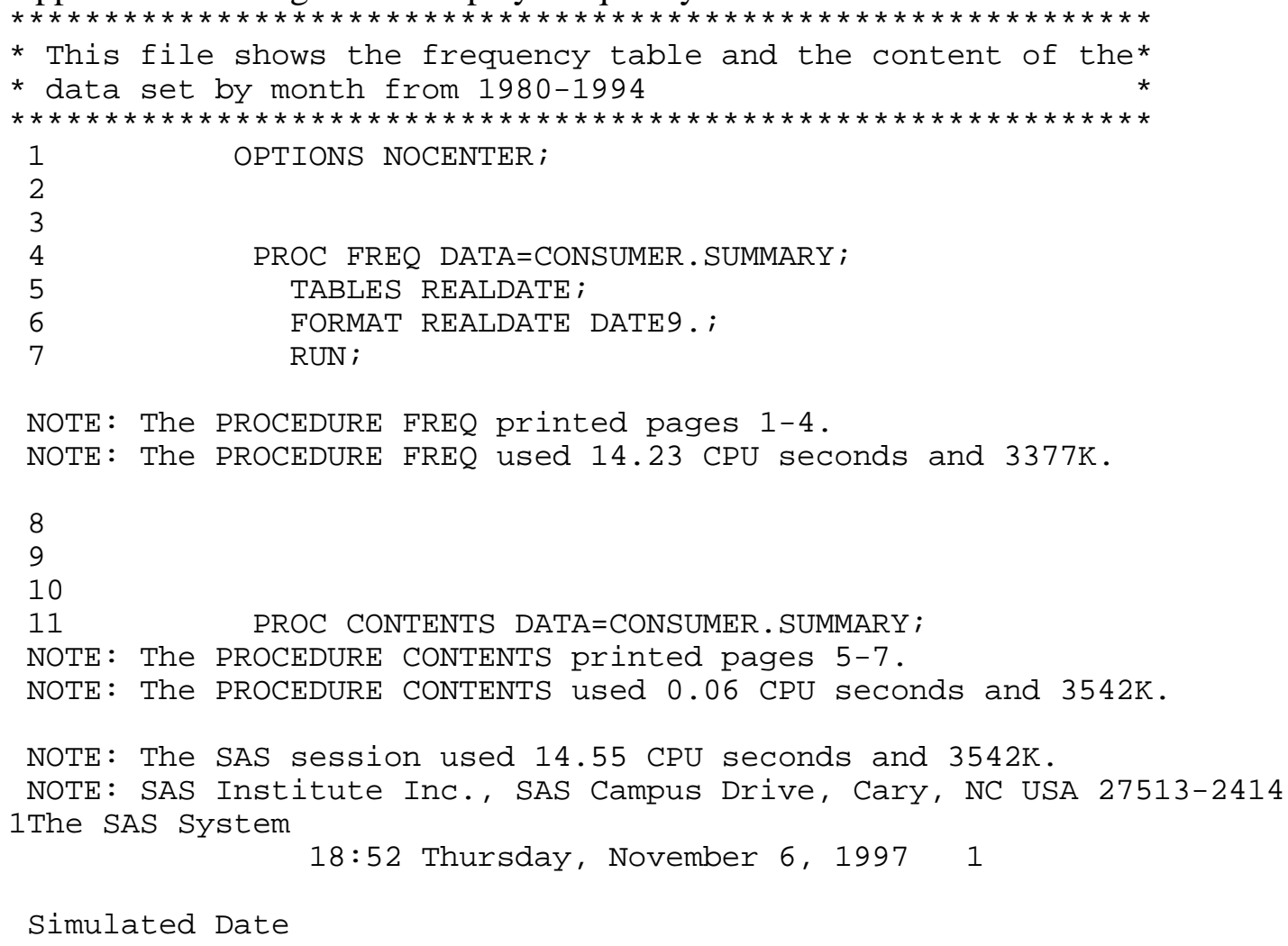

\begin{tabular}{|c|c|c|c|c|}
\hline REALDATE & Frequency & Percent & $\begin{array}{c}\text { Cumulative } \\
\text { Frequency }\end{array}$ & $\begin{array}{c}\text { Cumulative } \\
\text { Percent }\end{array}$ \\
\hline 01 JAN1980 & 1501 & 0.2 & 1501 & 0.2 \\
\hline 01FEB1980 & 3035 & 0.4 & 4536 & 0.5 \\
\hline 01MAR1980 & 4561 & 0.5 & 9097 & 1.1 \\
\hline 01APR1980 & 4569 & 0.5 & 13666 & 1.6 \\
\hline 01MAY1980 & 4611 & 0.5 & 18277 & 2.2 \\
\hline 01 JUN1980 & 4783 & 0.6 & 23060 & 2.7 \\
\hline 01 JUL1980 & 4916 & 0.6 & 27976 & 3.3 \\
\hline 01AUG1980 & 4961 & 0.6 & 32937 & 3.9 \\
\hline 01SEP1980 & 4935 & 0.6 & 37872 & 4.5 \\
\hline 010СТ1980 & 3294 & 0.4 & 41166 & 4.9 \\
\hline 01NOV1980 & 1673 & 0.2 & 42839 & 5.1 \\
\hline 01DEC1980 & 4987 & 0.6 & 47826 & 5.7 \\
\hline 01 JAN1981 & 1631 & 0.2 & 49457 & 5.9 \\
\hline 01FEB1981 & 3280 & 0.4 & 52737 & 6.3 \\
\hline 01MAR1981 & 4907 & 0.6 & 57644 & 6.9 \\
\hline 01APR1981 & 3277 & 0.4 & 60921 & 7.2 \\
\hline 01MAY1981 & 1628 & 0.2 & 62549 & 7.4 \\
\hline 01 JUN1981 & 4784 & 0.6 & 67333 & 8.0 \\
\hline 01 JUL1981 & 1513 & 0.2 & 68846 & 8.2 \\
\hline 01AUG1981 & 2939 & 0.3 & 71785 & 8.5 \\
\hline 01SEP1981 & 4399 & 0.5 & 76184 & 9.1 \\
\hline 010СT1981 & 4342 & 0.5 & 80526 & 9.6 \\
\hline 01NOV1981 & 4372 & 0.5 & 84898 & 10.1 \\
\hline 01DEC1981 & 4439 & 0.5 & 89337 & 10.6 \\
\hline 01 JAN1982 & 4434 & 0.5 & 93771 & 11.2 \\
\hline 01FEB1982 & 4417 & 0.5 & 98188 & 11.7 \\
\hline 01MAR1982 & 4376 & 0.5 & 102564 & 12.2 \\
\hline 01APR1982 & 4312 & 0.5 & 106876 & 12.7 \\
\hline 01MAY1982 & 4267 & 0.5 & 111143 & 13.2 \\
\hline
\end{tabular}




\begin{tabular}{|c|c|c|c|c|}
\hline 01 JUN1982 & 4311 & 0.5 & 115454 & 13.7 \\
\hline 01 JUL1 982 & 4384 & 0.5 & 119838 & 14.3 \\
\hline 01AUG1982 & 4492 & 0.5 & 124330 & 14.8 \\
\hline 01SEP 1982 & 4538 & 0.5 & 128868 & 15.3 \\
\hline 010СТ1982 & 4566 & 0.5 & 133434 & 15.9 \\
\hline 01NOV1982 & 4584 & 0.5 & 138018 & 16.4 \\
\hline 01DEC1982 & 4616 & 0.5 & 142634 & 17.0 \\
\hline 01JAN1983 & 4590 & 0.5 & 147224 & 17.5 \\
\hline 01FEB1983 & 4570 & 0.5 & 151794 & 18.1 \\
\hline 01MAR1983 & 4488 & 0.5 & 156282 & 18.6 \\
\hline 01APR1983 & 4472 & 0.5 & 160754 & 19.1 \\
\hline 01MAY1983 & 4445 & 0.5 & 165199 & 19.6 \\
\hline 01 JUN1983 & 4507 & 0.5 & 169706 & 20.2 \\
\hline 01 JUL1 983 & 4562 & 0.5 & 174268 & 20.7 \\
\hline 01AUG1983 & 4633 & 0.6 & 178901 & 21.3 \\
\hline 01SEP 1983 & 4624 & 0.5 & 183525 & 21.8 \\
\hline 010CT1983 & 3092 & 0.4 & 186617 & 22.2 \\
\hline 01NOV1983 & 1550 & 0.2 & 188167 & 22.4 \\
\hline 01DEC1983 & 5172 & 0.6 & 193339 & 23.0 \\
\hline 01 JAN1 984 & 1734 & 0.2 & 195073 & 23.2 \\
\hline 01FEB1984 & 3428 & 0.4 & 198501 & 23.6 \\
\hline 01MAR1984 & 5121 & 0.6 & 203622 & 24.2 \\
\hline 01APR1984 & 5053 & 0.6 & 208675 & 24.8 \\
\hline 01MAY1984 & 5046 & 0.6 & 213721 & 25.4 \\
\hline 01 JUN1 984 & 5086 & 0.6 & 218807 & 26.0 \\
\hline 01 JUL1 984 & 5193 & 0.6 & 224000 & 26.6 \\
\hline 01AUG1984 & 5236 & 0.6 & 229236 & 27.3 \\
\hline 01SEP 1984 & 5225 & 0.6 & 234461 & 27.9 \\
\hline 010СТ1984 & 5206 & 0.6 & 239667 & 28.5 \\
\hline 01NOV1984 & 5199 & 0.6 & 244866 & 29.1 \\
\hline 01DEC1984 & 5237 & 0.6 & 250103 & 29.7 \\
\hline 01 JAN1 985 & 5241 & 0.6 & 255344 & 30.4 \\
\hline 01FEB1985 & 5247 & 0.6 & 260591 & 31.0 \\
\hline 01MAR1985 & 5182 & 0.6 & 265773 & 31.6 \\
\hline 01APR1985 & 5102 & 0.6 & 270875 & 32.2 \\
\hline 01MAY1985 & 5048 & 0.6 & 275923 & 32.8 \\
\hline 01 JUN1985 & 5070 & 0.6 & 280993 & 33.4 \\
\hline 01 JUL1 985 & 5186 & 0.6 & 286179 & 34.0 \\
\hline 01AUG1985 & 5263 & 0.6 & 291442 & 34.7 \\
\hline 01SEP 1985 & 5320 & 0.6 & 296762 & 35.3 \\
\hline 010СT1985 & 5290 & 0.6 & 302052 & 35.9 \\
\hline 01NOV1985 & 5245 & 0.6 & 307297 & 36.5 \\
\hline 01DEC1985 & 5262 & 0.6 & 312559 & 37.2 \\
\hline 01 JAN1 986 & 1985 & 0.2 & 314544 & 37.4 \\
\hline 01FEB1986 & 3861 & 0.5 & 318405 & 37.9 \\
\hline 01MAR1986 & 5815 & 0.7 & 324220 & 38.6 \\
\hline 01APR1986 & 5749 & 0.7 & 329969 & 39.2 \\
\hline 01MAY1986 & 5728 & 0.7 & 335697 & 39.9 \\
\hline 01 JUN1986 & 5775 & 0.7 & 341472 & 40.6 \\
\hline 01 JUL1986 & 5828 & 0.7 & 347300 & 41.3 \\
\hline 01AUG1986 & 5923 & 0.7 & 353223 & 42.0 \\
\hline 01SEP 1986 & 5870 & 0.7 & 359093 & 42.7 \\
\hline $010 \mathrm{CT} 1986$ & 5906 & 0.7 & 364999 & 43.4 \\
\hline 01NOV1986 & 5926 & 0.7 & 370925 & 44.1 \\
\hline $01 \mathrm{DEC} 1986$ & 5906 & 0.7 & 376831 & 44.8 \\
\hline 01 JAN1 987 & 5923 & 0.7 & 382754 & 45.5 \\
\hline 01FEB1 987 & 5923 & 0.7 & 388677 & 46.2 \\
\hline 01MAR1987 & 5875 & 0.7 & 394552 & 46.9 \\
\hline 01APR1 987 & 5766 & 0.7 & 400318 & 47.6 \\
\hline 01MAY1987 & 5689 & 0.7 & 406007 & 48.3 \\
\hline 01 JUN1 987 & 5767 & 0.7 & 411774 & 49.0 \\
\hline 01 JUL1 987 & 5878 & 0.7 & 417652 & 49.7 \\
\hline
\end{tabular}




\begin{tabular}{|c|c|c|c|c|}
\hline 01AUG1987 & 5954 & 0.7 & 423606 & 50.4 \\
\hline 01SEP1987 & 5999 & 0.7 & 429605 & 51.1 \\
\hline $010 \mathrm{CT} 1987$ & 1785 & 0.2 & 431390 & 51.3 \\
\hline 01NOV1987 & 3552 & 0.4 & 434942 & 51.7 \\
\hline 01DEC1987 & 5286 & 0.6 & 440228 & 52.3 \\
\hline 01 JAN1988 & 1670 & 0.2 & 441898 & 52.5 \\
\hline 01FEB1988 & 3301 & 0.4 & 445199 & 52.9 \\
\hline 01MAR1988 & 4994 & 0.6 & 450193 & 53.5 \\
\hline 01APR1988 & 4958 & 0.6 & 455151 & 54.1 \\
\hline 01MAY1988 & 4975 & 0.6 & 460126 & 54.7 \\
\hline 01 JUN1988 & 5040 & 0.6 & 465166 & 55.3 \\
\hline 01 JUL1988 & 5119 & 0.6 & 470285 & 55.9 \\
\hline 01AUG1988 & 5198 & 0.6 & 475483 & 56.5 \\
\hline 01SEP1988 & 5190 & 0.6 & 480673 & 57.2 \\
\hline 010CT1988 & 3476 & 0.4 & 484149 & 57.6 \\
\hline 01NOV1988 & 1749 & 0.2 & 485898 & 57.8 \\
\hline 01DEC1988 & 5153 & 0.6 & 491051 & 58.4 \\
\hline 01 JAN1989 & 1688 & 0.2 & 492739 & 58.6 \\
\hline 01FEB1989 & 3422 & 0.4 & 496161 & 59.0 \\
\hline 01MAR1989 & 5076 & 0.6 & 501237 & 59.6 \\
\hline 01APR1989 & 5078 & 0.6 & 506315 & 60.2 \\
\hline 01MAY1989 & 4987 & 0.6 & 511302 & 60.8 \\
\hline 01 JUN1989 & 5008 & 0.6 & 516310 & 61.4 \\
\hline 01 JUL1989 & 5028 & 0.6 & 521338 & 62.0 \\
\hline 01AUG1989 & 5100 & 0.6 & 526438 & 62.6 \\
\hline 01SEP1989 & 5104 & 0.6 & 531542 & 63.2 \\
\hline 010СT1989 & 5088 & 0.6 & 536630 & 63.8 \\
\hline 01NOV1989 & 5085 & 0.6 & 541715 & 64.4 \\
\hline 01DEC1989 & 5139 & 0.6 & 546854 & 65.0 \\
\hline 01 JAN1990 & 5201 & 0.6 & 552055 & 65.6 \\
\hline 01FEB1990 & 5206 & 0.6 & 557261 & 66.3 \\
\hline 01MAR1990 & 5169 & 0.6 & 562430 & 66.9 \\
\hline 01APR1990 & 5106 & 0.6 & 567536 & 67.5 \\
\hline 01MAY1990 & 5023 & 0.6 & 572559 & 68.1 \\
\hline 01 JUN1990 & 5045 & 0.6 & 577604 & 68.7 \\
\hline 01JUL1990 & 5120 & 0.6 & 582724 & 69.3 \\
\hline 01AUG1990 & 5184 & 0.6 & 587908 & 69.9 \\
\hline 01SEP1990 & 5168 & 0.6 & 593076 & 70.5 \\
\hline 010СТ1990 & 5190 & 0.6 & 598266 & 71.1 \\
\hline 01NOV1990 & 5161 & 0.6 & 603427 & 71.8 \\
\hline 01DEC1990 & 5188 & 0.6 & 608615 & 72.4 \\
\hline 01 JAN1991 & 3398 & 0.4 & 612013 & 72.8 \\
\hline 01FEB1991 & 1729 & 0.2 & 613742 & 73.0 \\
\hline 01MAR1991 & 5091 & 0.6 & 618833 & 73.6 \\
\hline 01APR1991 & 1678 & 0.2 & 620511 & 73.8 \\
\hline 01MAY1991 & 3299 & 0.4 & 623810 & 74.2 \\
\hline 01JUN1991 & 5066 & 0.6 & 628876 & 74.8 \\
\hline 01 JUL1991 & 5126 & 0.6 & 634002 & 75.4 \\
\hline 01AUG1991 & 5205 & 0.6 & 639207 & 76.0 \\
\hline 01SEP1991 & 5181 & 0.6 & 644388 & 76.6 \\
\hline 010СТ1991 & 5151 & 0.6 & 649539 & 77.2 \\
\hline 01NOV1991 & 5171 & 0.6 & 654710 & 77.9 \\
\hline 01DEC1991 & 5158 & 0.6 & 659868 & 78.5 \\
\hline 01 JAN1 992 & 5203 & 0.6 & 665071 & 79.1 \\
\hline 01FEB1992 & 5232 & 0.6 & 670303 & 79.7 \\
\hline 01MAR1 992 & 5157 & 0.6 & 675460 & 80.3 \\
\hline 01APR1992 & 5152 & 0.6 & 680612 & 80.9 \\
\hline 01MAY1992 & 5094 & 0.6 & 685706 & 81.5 \\
\hline 01 JUN1 992 & 5165 & 0.6 & 690871 & 82.2 \\
\hline 01 JUL1992 & 5197 & 0.6 & 696068 & 82.8 \\
\hline 01AUG1992 & 5234 & 0.6 & 701302 & 83.4 \\
\hline 01SEP1992 & 5223 & 0.6 & 706525 & 84.0 \\
\hline
\end{tabular}




\begin{tabular}{|c|c|c|c|c|c|c|}
\hline \multicolumn{7}{|r|}{ EDUCATION OF REF. } \\
\hline 8 & EDUCA2 & Char & 1 & 18 & & EDUCATION OF SPOUSE $0-32$ \\
\hline 9 & EDUCA2 & Char & 1 & 19 & & FLAG - EDUCA2 \\
\hline 35 & ELEC_ITY & Num & 8 & 154 & & ELECTRICITY \\
\hline 60 & ELEC_NIC & Num & 8 & 354 & & ELECTRONICS \\
\hline 98 & EN_P & Num & 8 & 658 & & Energy Price \\
\hline 104 & $\mathrm{ET}_{-} \mathrm{P}$ & Num & 8 & 706 & & \\
\hline 10 & FAM_SIZE & Num & 2 & 20 & & NO. OF MEMBRS IN CONS. UNIT \\
\hline 81 & FB & Num & 8 & 522 & & \\
\hline 99 & FB_P & Num & 8 & 666 & & \\
\hline 11 & FINCATAX & Num & 8 & 22 & & CONS. UNIT INCOME AFTER \\
\hline \multicolumn{7}{|c|}{ TAXES } \\
\hline 12 & FINCBTAX & Num & 8 & 30 & & CONS. UNIT INCOME BEFORE \\
\hline \multicolumn{7}{|c|}{ TAXES } \\
\hline 13 & FINLWT21 & Num & 8 & 38 & & CONS. UNIT WEIGHT (11.3) \\
\hline 26 & FOOD_AWY & Num & 6 & 84 & & FOOD AWAY FROM HOME \\
\hline 25 & FOOD_HOM & Num & 8 & 76 & & FOOD AT HOME \\
\hline 46 & FOOT_WER & Num & 8 & 242 & & FOOTWEAR \\
\hline 36 & FUEL_OIL & Num & 8 & 162 & & FUEL OIL \\
\hline 53 & GALN_OIL & Num & 8 & 298 & & GASOLINE AND OIL \\
\hline 14 & GOVTCOST & Char & 1 & 46 & & GOVT. PAYS HOUSING $1-2$ \\
\hline 23 & HLTH_INS & Num & 8 & 60 & & 580110-580902 HEALTH INSUR \\
\hline 100 & HS_P $P^{-}$ & Num & 8 & 674 & & \\
\hline 82 & HSNG & Num & 8 & 530 & & \\
\hline 95 & INTDATE & Num & 8 & 634 & DATE9. & Interview Date \\
\hline 54 & MAIN_RPR & Num & 8 & 306 & & MAINTENANCE AND REPAIRS \\
\hline 103 & MD_P & Num & 8 & 698 & & \\
\hline 34 & NATL_LAS & Num & 8 & 146 & & NATURAL GAS \\
\hline 49 & NCAR_TRC & Num & 8 & 266 & & NEW CARS AND TRUCKS \\
\hline 1 & NEWID & Char & 8 & 0 & & CONSUMER UNIT ID NO. \\
\hline 89 & $\mathrm{NFB}$ & Num & 8 & 586 & & \\
\hline 84 & NE INCATX & Num & 8 & 546 & & \\
\hline 85 & NF INCBTX & Num & 8 & 554 & & \\
\hline 86 & NFNLWT21 & Num & 8 & 562 & & \\
\hline 90 & NHSNG & Num & 8 & 594 & & \\
\hline 94 & NTOTAPP & Num & 8 & 626 & & \\
\hline 93 & NTOTENT & Num & 8 & 618 & & \\
\hline 87 & NTOTHLTH & Num & 8 & 570 & & \\
\hline 92 & NTOTTRAN & Num & 8 & 610 & & \\
\hline 88 & NTOTUTIL & Num & 8 & 578 & & \\
\hline 91 & NTPE & Num & 8 & 602 & & \\
\hline 15 & ORIGIN1 & Char & 1 & 47 & & ORIGIN OF REF. PERSON (1-4) \\
\hline 47 & OTHR_APP & Num & 8 & 250 & & OTHER APPAREL PRODUCTS \\
\hline 32 & OTHR_DWL & Num & 8 & 130 & & OTHER LODGING \\
\hline 61 & OTHR_EQP & Num & 8 & 362 & & OTHER EQUIPMENT AND \\
\hline \multicolumn{7}{|c|}{ SERVICES } \\
\hline 41 & OTHR_SER & Num & 8 & 202 & & OTHER HOUSEHOLD EXPENSES \\
\hline 51 & OTHR_VCL & Num & 8 & 282 & & OTHER VEHICLES \\
\hline 30 & OWND_DWL & Num & 8 & 114 & & OWNED DWELLING \\
\hline 105 & PE_P & Num & 8 & 714 & & \\
\hline 63 & PERS_CAR & Num & 8 & 378 & & PERSONAL CARE \\
\hline 16 & PERSLT18 & Num & 2 & 48 & & NO. PERSONS LESS THAN 18 \\
\hline 17 & PERSOT 64 & Num & 2 & 50 & & NO. PERSONS OVER 64 \\
\hline 18 & PRINEARN & Char & 2 & 52 & & MEMBER NO. OF PRINCIPAL \\
\hline \multicolumn{7}{|c|}{ EARNER } \\
\hline 56 & PUBL_TRA & Num & 8 & 322 & & PUBLIC TRANSPORTATION \\
\hline 19 & QINTRVMO & Char & 2 & 54 & & INTERVIEW MONTH \\
\hline 20 & QINTRVYR & Char & 2 & 56 & & INTERVIEW YEAR \\
\hline 65 & READ_EXP & Num & 8 & 394 & & READING \\
\hline 96 & REALDATE & Num & 8 & 642 & DATE9. & Simulated Date \\
\hline 21 & REF_RACE & Char & 1 & 58 & & RACE OF REF. PERSON (1-5) \\
\hline
\end{tabular}




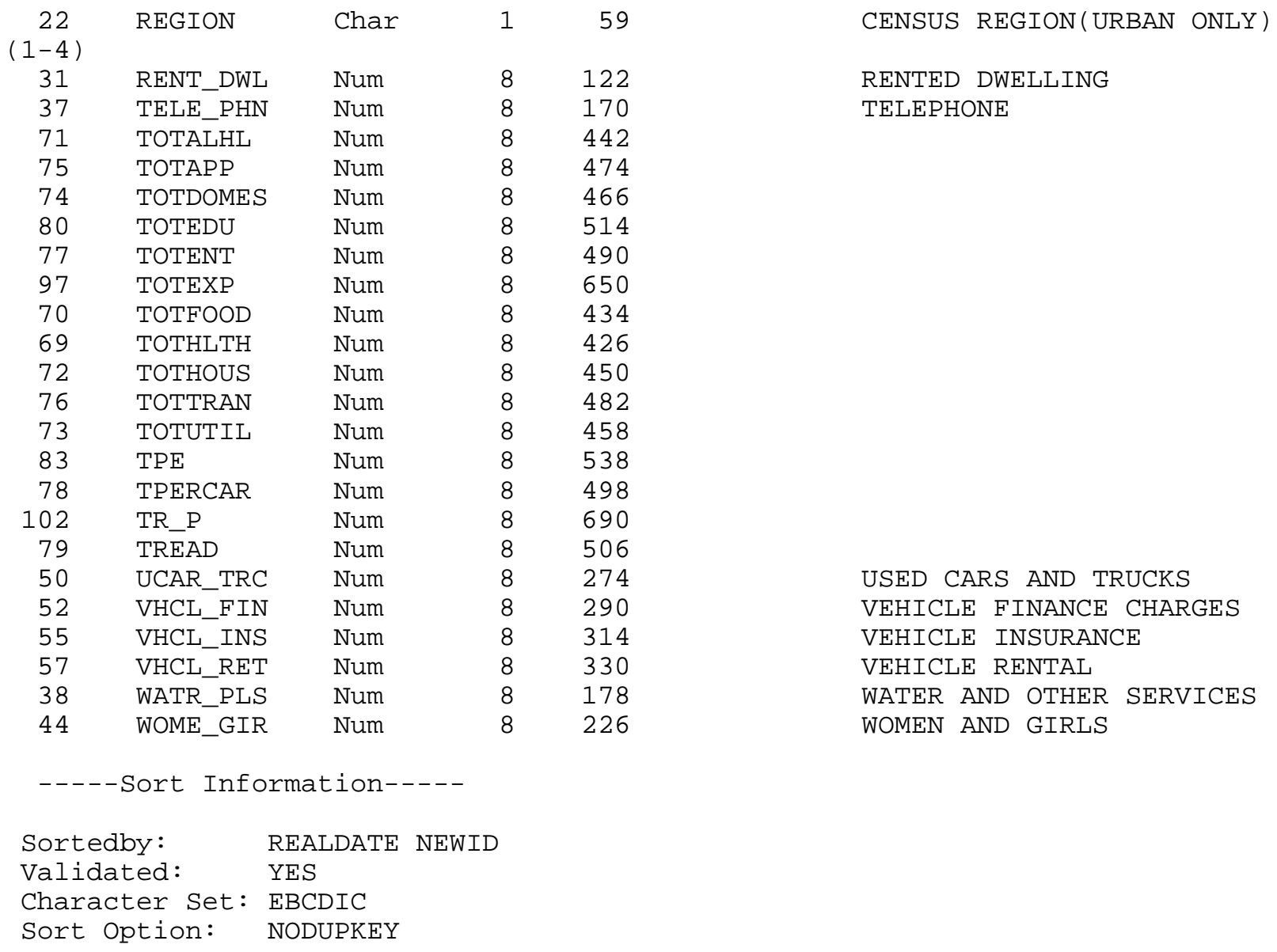

